The Effecis of Disturbance on Desert Soils, Vegetation and Community Procesises with Emphasis on Off Road Vehicles:

\title{
A Critical Review
}
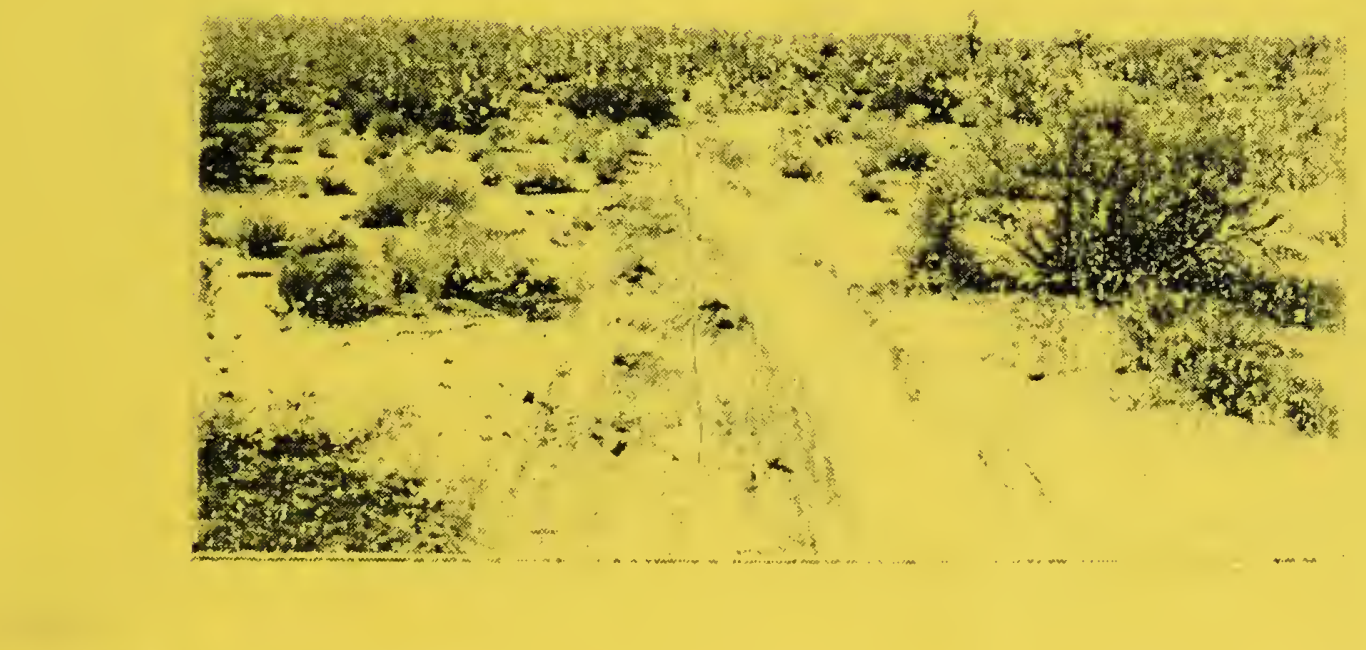

SDl, Bureau of Land Manegememi,

\section{[Desert Plan Starff}




\title{
The Effects of Disturbance on Desert Soils,
} Vegetation and Community Processes with Emphasis on Off Road Vehicles:

\section{A Critical Review}

\author{
Peter G. Rowlands, Editor \\ 1980 \\ with contributions from \\ John A. Adam s \\ Albert S. Endo \\ John A. Hall \\ Hyrum B. Johnson \\ Peter G. Rowlands
}

USDI/Bureau of Land Management,

Desent Plan Staff,

Special Publication 
EFFECTS OF DISTURBANCE ON DESERT SOILS, VEGETATION, AND COMMUNITY PROCESSES WITH EMPHASIS ON OFF-ROAD VEHICLES

\author{
A CRITICAL REVIEW
}

\title{
PETER G. ROWLANDS, BOTANIST, BUREAU OF LAND MANAGEMENT GENERAL EDITOR
}

1980

With contributions from: John A. Adams, Soil Scientist, BLM, Riverside District Office

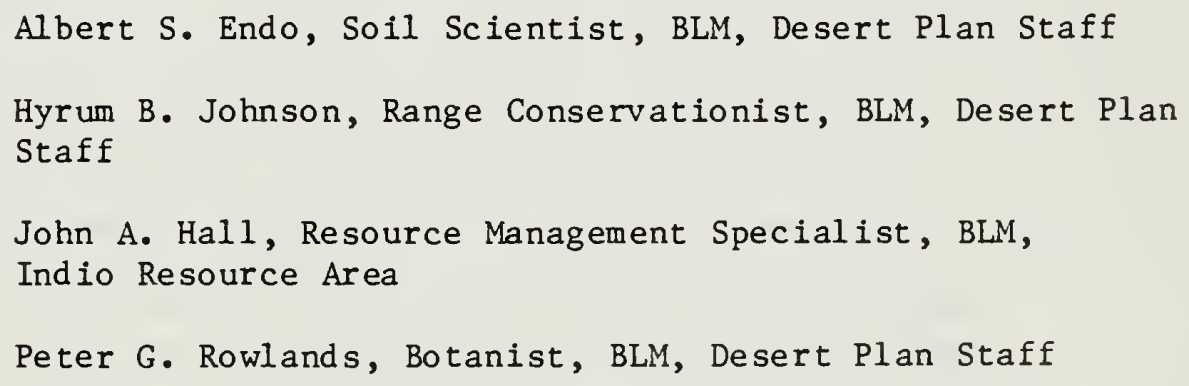




\section{Preface}

Discerning the effects of off-road vehicles on both soils and the soilvegetation system is a difficult problem associated with a very controversial subject; controversial, because opposing factions of society (ORV users and conservationists) disagree on the proper use of public lands and management agencies are forced to make often unpopular risk/benefit decisions involving use with the "meagerest" of data; difficult because the establishment of cause and effect relationships between the agents of disturbance and the response of soils and vegetation is hindered by lack of published information and previous research, confounded by the manner in which the researcher collects, manipulates and interprets his data and often rendered unobjective by the researchers own (possibly subconscious) prejudices. There is a great need to synthesize in a disinterested manner both the published and unpublished data regarding the impact of off-road vehicles on soils, vegetation, and community processes, evaluate it critically and discuss management and environmental implications of the information. This is the purpose of this report.

The material is presented in seven chapters, two of which, chapters 5 and 6 represent original research. Chapter 1 is a general treatise on the effects of disturbance on soils, and soil systems, with special attention given to disturbance induced by off-road vehicles. Chapter 2 deals with soil crusts particularly those associated with micro-organisms. Three contains information regarding the direct effects of off-road vehicles on vegetation and Chapter 4 addresses the problem of the effects which take place after disturbance; that is the community process of succession and revegetation of denuded or disturbed areas; and the possibilities of rehabilitating areas disturbed by off-road vehicles or, for that matter any other kind of disturbance, which results in removal of vegetation. Chapter 7 is an overall summary of our findings which we hope will present our findings in a manner which is more easily accessible to the more casual reader.

The contributions that I would like to extend our most gracious thanks to several people who made the production of this work possible: Tad Taylor, Paul Ernst and Roger Twitchell performed much valuable fieldwork. The draft manuscript was very kindly reviewed by Drs. Ted L. Hanes, Plant Ecologist, California State University at Fullerton, Richard Vogl, Plant Ecologist, California State University at Los Angeles and member of the California Desert Adivisory Committee and Lewis Stolzy, Soil Scientist, University of California, Riverside. Much hard-to-obtain literature was lent to us by Howard Wilshire of the U.S. Geological Survey and Robert Webb of Stanford University. Lastly, Marty Townsend of the BLM California State office in Sacramento was principally responsible for initiating this project and giving us the opportunity to work on it, an opportunity for which we are grateful. 


\section{Table of Contents}

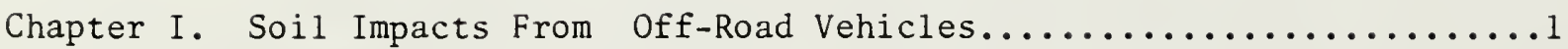

Chapter II. Soil Crusts................................

Chapter III. Direct Impacts of Off-Road Vehicles on Vegetation.........63

Chapter IV. Recovery, Succession and Revegetation in the Mojave Desert......................................

Chapter V. Controlled Experiments on Soil Compaction Produced by Off-Road Vehicles in the Mojave Desert, California...........121

Chapter VI. Experiments on the Effects of Soil Compaction on Establishment, Cover, and Pattern of Winter and Summer

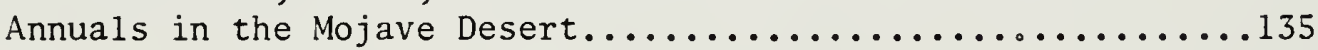

Chapter VII. The Effects of Off-Road Vehicles on Soils, Vegetation, and Community Processes: A Summary...........................65

Cover: Vehicle tracks winding through Creosotebush Scrub vegetation in the western, Mojave Desert, California. 


\section{SOIL IMPACTS FROM OFF-ROAD VEHICLES}

BY

JOHN A. ADAMS, AND ALBERT S. ENDO, SOIL SCIENTISTS, BUREAU OF LAND MANAGEMENT

\section{Table of Contents}

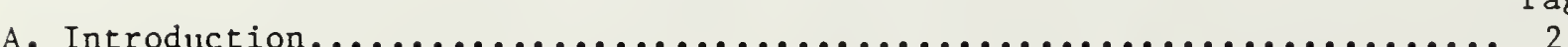

B. Impacts to Soil Physical Properties by off-Road Vehicles............ 2

1. Soil Compaction................................... 2

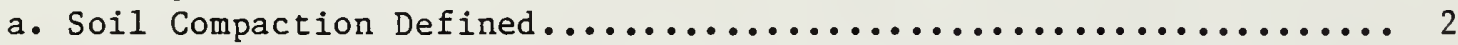

b. Measurement of Soil Compaction in Arid and Semi Arid Lands...... 2

c. Characterictization of Magnitude of Soil Compaction in the

California Desert.............................. 4

2. Soil Moisture and Temperature.......................... 6

C. Infiltration and Water Erosion and Their Relation to Soil Compaction... 11

1. Infiltration Rates and Rainfall Simulation Studies.............11

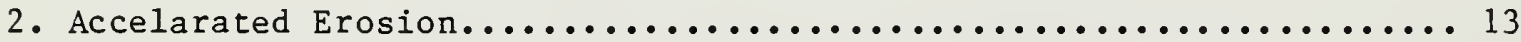

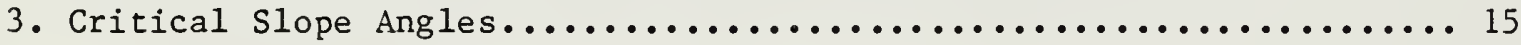

4. Estimating Soil Limitation for ORV Use.................... 16

D. Dust Produced by Vehicle Activity - Direct Effects............... 17

1. Prediction of Dust Emission By ORV Activity................. 17

2. Levels of Fugitive Dust During, and After Desert ORV Events.......18

3. Reduction of Fugitive Dust Produced by ORV's $\ldots \ldots \ldots \ldots \ldots \ldots \ldots \ldots \ldots 23$



1. Increases in Dust Storm Frequency........................ 23

2. Threshold Velocities for Soil Erosion by Wind and Soil Erodibility.. 25

3. Other Factors Effecting Susceptibility of Soils to Wind Erosion..... 29

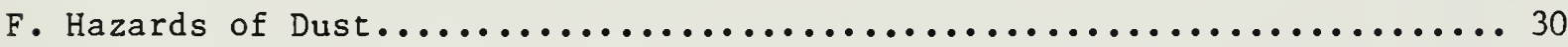

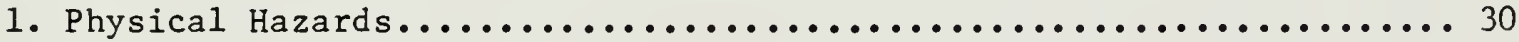

2. Biological Hazards - Valley Fever........................ 30

G. Impacts of Off-Road Vehicles on Soil Chemical Properties............ 32

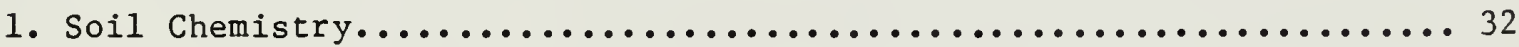

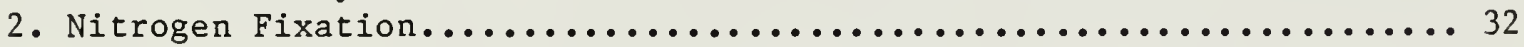

H. Longevity of ORV-Caused Visual Impacts.................... 33

I. Overall Extent of $\mathrm{ORV}$ and Military Activity in the California Desert... 34

1. Areas of Disturbance Associated with Race Courses.............. 34

2. Area Extent of Concentrated ORV and Military-Use Zones...........4 4

J. Summary of Soil Impacts.............................. 42 
A large amount of recent unpublished data about impacts of off-road vehicles (Dune buggies, four-wheel drive trucks, jeeps, etc., ATVs, motorcycles, Baja Bugs) on soils, has been accumulated, much of it by the Bureau of Land Management or by studies sponsored by the Bureau of Land Management. Although a growing, yet still meager literature exists, many of these published studies have taken a rather naive approach to evaluating the cause and effect relationships between impacting agents, the degree and frequency of disturbance and soil response. Pertinent data from the agricultural literature regarding the inducement and nature of soil compaction and its effects on seed germination and plant establishment and growth have not been discussed in these studies, nor have these studies, with possibly a few exceptions (e.g., Vollmer et al 1976), been concerned with conducting and interpreting controlled experiments. There is a need to synthesize these data as they are contained in both published and unpublished reports, in agricultural and non-agricultural sources, and subject it to objective critical evaluation. The purpose of the following discussion on the impacts to soil physical properties by off-road vehicles is not only to do this, but also to discuss management and environmental implications of the information and some possible means of mitigation.

\section{B. Impacts to Soil Physical Properties by off-Road Vehicles}

\section{Soil Compaction}

\section{a. Soil Compaction - Definition}

Soil compaction refers to the increase in density of a soil as a result of applied loads or pressure. The soil has a certain density before the added force is applied; soil compaction is a dynamic soil behavior by which the state of compaction is increased (Gill and Vandenberg, 1967). This increase above the normal density is a function of both the compactive effort and the water content (Baver, et al 1972)

\section{b. Measurement of Soil Compaction in Arid and Semi-Arid Lands}

A number of studies (e.g., Fox, 1973; Davidson and Fox, 1974; Babcock, 1973; and Wilshire and Nakata, 1976) have shown that high intensities of off-road vehicle use result in significant compaction of most desert soils. Snyder et al (1976), Webb et al (1978), and Wilshire et al (1978) showed that significant soil compaction results from heavy $\overline{\mathrm{ORV}} \overline{\mathrm{Use}}$ of non-desert areas in central and northern California. Except for Wilshire and Nakata (1976), these studies used bulk density measurements (dry weight per unit volume of soil) as at least one method of characterizing soil compaction. Bulk density measurements in desert soils of ten involve a number of uncertainties: 1) A small difference in the value of soil dry density can have a large impact on plant response or water infiltration, especially with increasing degrees of compaction, 2) Variation of rock and gravel content in desert soils will cause considerable variation in measured values of bulk density apart from that caused by soil compaction, 3) The loose, sandy nature of many desert soils makes it difficult to use some methods 
for measuring bulk density which involve removal of soil cores of an exact known volume. A study done by the University of California at Irvine (1974) measured bulk density values on desert ORV campsites which were equal to or lower than values measured for adjacent undisturbed locations. In contrast, soil penetrometer measurements indicated that the campsites were more compacted than the undisturbed locations. The authors concluded that the bulk density measurements were in error because of difficulties in making measurements in desert soils, 4) An additional difficulty in interpreting bulk density measurements is the uncertainty in relating the values to plant response. Variation in bulk density with rocks or gravel in desert soils prevents comparison of values to "threshold" bulk density values determined to be limiting to root growth.

Penetrometer measurements are superior to bulk density measurements for interpretations of plant response (Taylor, 1971 and 1974). Some investigators have used penetrometers to characterize compaction of desert soils caused by ORVs. The penetrometers used by Wilshire and Nakata (1976), Wilshire et al (1978), and Webb et al (1978) measured depth of penetration of a tipped cone into soil by application of body weight to the penetrometer. These instruments provide relative comparisons of compaction but do not measure changes in mechanical impedance (resistance to movement of penetrometer through soil) with soil depth in such a way as to allow best correlation with plant response. Also, the above measurements were not made at a defined soil moisture content which adds considerable uncertainty to their interpretation. The ease at which a penetrometer can be inserted into the soil varies greatly with soil water content. The penetrometer used to characterize the Barstow-Las Vegas race course (BLM, 1975) was only a soil surface measurement and could not measure mechanical impedence greater than 4.4 bars (soils can be compacted to much greater values), and was not used at defined moisture contents.

The portable soil recording penetrometer used at defined moisture contents in more recent studies by the BLM gives much more informative results. These measurements are much better for characterizing patterns of soil compaction than the types of measurements used in the above literature. Measurements were generally made near field capacity (about two days after a rain) for purposes of comparison. Field capacity is the water remaining in a sandy soil two or three days after having been saturated and after drainage has practically ceased. It is an approximate concept but has often been used for comparative purposes in agricultural soils. Bulk density measurements, made with a gamma ray technique (using a nuclear densometer), showed much less sensitivity to differences in soil compaction than did the soil strength measurements made with the penetrometer. The mechanical resistance of soil to expanding roots is best characterized by penetrometer strength measurements (Taylor, 1971 and 1974), even though a disadvantage exists in the dissimilar construction of penetrometers. The penetrometer used in the BLM field studies has been used in previous studies to obtain correlations between soil strength and root responses of agricultlural plants (Grimes et al, 1975; Grimes et al, 1978). Taylor and Gardner (1963) concluded that soil strength, which increased with increasing bulk density or lower water content, was the critical impedence 
factor controlling root penetration rather than bulk density. Also, use of the penetrometer in the field shows a high degree of utility by permitting direct comparisons of strength between soils that differ widely in textural class. In contrast, Veihmeyer and Hendrickson (1948) reported that the "threshold bulk density" for sunflower roots were about $1.75 \mathrm{~g} / \mathrm{cm}^{3}$ for sands and varied between $1.46 \mathrm{~g} / \mathrm{cm}^{3}$ abd $1.63 \mathrm{~g} / \mathrm{cm}^{3}$ for clays, indicating that direct comparisons of plant response to bulk density cannot be made between soils with considerably different textures.

Limitations of bulk density measurements reduces one's ability to discriminate between small differences in soil compaction (as would result from relatively light use) and to interpret results in relation to plant response. However, a number of conclusions can be reached from the published data about relative degrees of compaction on different types of desert soil in heavy use areas.

\section{c. Characterization and Magnitude of Soil Compaction in the California Desert}

Dry density of disturbed and undisturbed soils has been observed at Stoddard Valley, Shadow Mountain, Chemehuevi Wash, Dumont Dunes, Baker, Dove Springs, Teagle Wash, Orocopia, Glamis, and the Yuha Desert (Babcock, 1973). Disturbed locations were heavily tracked by off-road vehicles. Cohesionless sands (near Dumont Dunes and Glamis) had the greatest resistance to compaction. The bulk density values for undisturbed soils in the dunes were slightly higher than for disturbed soils, indicating the loosening had occurred rather than compaction. Measurements made in a broad alluvial wash at Dove Springs showed a $3 \%$ increase in bulk density in the disturbed track as compared to an undisturbed area. Bulk density measurements from the seven other test areas, which were located on alluvial fans or on desert flats, were at least $10 \%$ greater in disturbed areas than those in nearly undisturbed soil. Soil profiles were not described and engineering group symbols were used to characterize soils. Babcock concluded that the poorly sorted sands of the dune areas showed the greatest resistance to off-road vehicles. Well-graded sands with contrasting particle size had the least resistance to compaction. This is to be expected because well-graded particles provide a wider range of smaller sized grains to fill the native voids. Furthermore, the rounded particles of blow sand (edges abraded by impacts) in the dunes compact less readily than more angular particles.

Some investigators have reported increased compaction on coastal sand dunes as a result of vehicle traffic (Hosier and Eaton, 1980; Liddle and Grieg-Smith, 1975; and Trew, 1973). Liddle and Grieg-Smith reported that the compaction increased water holding capacity and speculated that this may increase plant-available water. The coastal dunes measured may differ from many desert dunes in such features as particle size gradation (including silt and clay content), organic matter content, particle shape, and presence of extraneous material such as fragments of seashells, so the results may not be totally applicable to desert sand dunes. However, the results do suggest that some compaction of desert sand dunes may take place with sufficient driving. The rate of compaction with increasing numbers of vehicle passages and the maximum possible increase in compaction would be far less than for cohesive desert soils. 
Wilshire and Nakata (1976) characterized soil compaction on a variety of surface types along the Barstow to Las Vegas race course. As in the case of the Babcock report, sand dunes were found to be most resistant to compaction by vehicles. Penetrometer measurements by Wilshire and Nakata showed a loosening of the sand. Compaction was also relatively slight in heavy use zones of dry washes. Much greater compaction was measured in heavy use zones on alluvial fans. Dry playas which are wet only during and immediately after significant rainfall, compacted less than wet playas, which have high water tables and are generally wet on or just below the immediate surface. Motorcycle use on Soda Lake, a moist playa where the ground water level is close to the surface, compacted the lake bed and formed ruts in the underlying damp, soft playa material. Compaction to depths of more than $15 \mathrm{~cm}$ was observed. Greater compaction on the wet playa occurs because wet soils compact to a much greater extent than do dry soils. Tracks made by General Patton's tanks and jeeps on practice maneuvers in the desert north of Vidal Junction, California, in the early $1940^{\prime}$ s remained significantly compacted in relation to adjacent undisturbed areas.

Measurements along the Barstow to Las Vegas race course made by the BLM (1975) showed increased bulk densities in two-thirds of the samples taken after the race. Most of the areas which had decreased bulk density (loosening) after the race occurred on playas or in loose sandy soil in washes. Penetrometer and shear strength measurements were also made. However, the report states that a number of the measurements made after the race were obtained one week after a rain. Since shear strength or penetrometer measurements vary greatly with soil moisture, the comparisons between measurements made under varying moisture conditions involve great uncertainties.

We measured soil compaction during 1977 to 1979 in areas disturbed by ORV use. Pit areas in Dove Springs, McCain Valley, the Plaster City area, and Johnson Valley all had mechanical impedance values near the surface of soils at or near field capacity in excess of 34 bars, indicating very high intensities of compaction. Well-defined trails with highly compacted soils usually radiate from these concentrated use areas. Average values of compaction in trails ranged from 31 to 59 bars in McCain Valley, 27 to 41 bars in the Plaster City area, 21 to 41 bars in the Horse Canyon area, 14 to 31 bars in the Bird Springs area, over 34 bars at Johnson Valley. See Chapter 5 for additional measurements of mechanical impedance in controlled experiments.

Figure 1.1 shows mechanical impedance values on a heavily used hillclimb in Dove Springs. Soils are loosened on the surface with significant compaction at lower depths. Maximum values of mechanical impedance ranged between 21 and 27 bars, whereas an adjacent control (undisturbed) area reached a maximum mechanical impedance value of about nine bars.

Table 1.1 contains estimates of percentages of highly compacted soil in areas with many compacted trails. These areas were calculated from low level colored, aerial photographs (1: 1000 scale). Penetrometer measurements made in the field and the results of the controlled motorcycle compaction study described in Chapter 5 indicate that heavily-compacted sites are those with large numbers of vehicle passes such as pit areas or heavily-used trails. Tracks created by one or a few motorcycle passes 
tend to have little or no compaction. This allows fairly good recognition of areas of heavily-compacted soil in the low-level photos. The greatest uncertainty is in estimating the location of the edge of the severe compaction on the margins of pit areas or trails.

Immediately adjacent to pit areas heavily-compacted trails may cover over $10 \%$ of the surface. Many heavily-used sections of open areas away from the immediate vicinity of the pit area contain from $3-6 \%$ total cover of heavily compacted trails. The frequency of trails decreases with distance from centers of activity.

Table 1.2 summarizes soil impact and compaction studies which have been done in different areas of the CDCA. Those done specifically by BLM are presented in Figure 1.2.

\section{Soil Moisture and Temperature}

Compacted soils may exhibit differences in soil moisture and temperature (Webb et al, 1978 and Wilshire et al, 1978). Most disturbed soils examined at Hollister Hills in central California have decreased moisture content and more extreme maximum and minimum temperatures than nearby undisturbed soils (Webb et al, 1978). In a study of seven sites in the San Francisco Bay area Wilshire et al (1978) reported that soil moisture showed a reduction as a result of vehicle use of the more silty and clayey soils, but generally increased in samples taken from areas with very sandy soils. These relationships might vary with different rainfall-runoff patterns. Compacted sandy soils subjected to intense rains, especially on significant slopes, may contain less water than adjacent, undisturbed sandy soil because of an increased amount of runoff. If water entering soil is not significantly limited, contents may be higher at a given soil water potential in compacted soil than non-compacted soil (Warkentin, 1971).

Diurnal variation of temperatures in compacted soils was more extreme: the disturbed soil was as much as $6^{\circ} \mathrm{C}$. to $10^{\circ} \mathrm{C}$. warmer in the day and $2.5^{\circ} \mathrm{C}$. cooler at night. The increase in temperature extremes is due to removal of vegetation (through alteration of the energy environment) and changes in soil characteristics caused by compaction (Willis and Raney, 1971). Removal of vegetation may change soil water content which will also affect soil temperature.

Studies done by the BLM in Stoddard and Johnson Valleys (discussed in Chapter 5) showed similar amounts of water and wetting depths under tracked areas and undisturbed areas. This occurred because tracks were on gentle slopes and rainfall was not sufficiently intense to cause runnoff from the tracks. Measurements made near the end of the growing season for summer annuals in 1977 gave indications of greater amounts of soil water content in soil under tracks than in undisturbed soil. This probably occurred because fewer plants were growing in the tracks than on the undisturbed soils so less water was lost through evapotranspiration. 

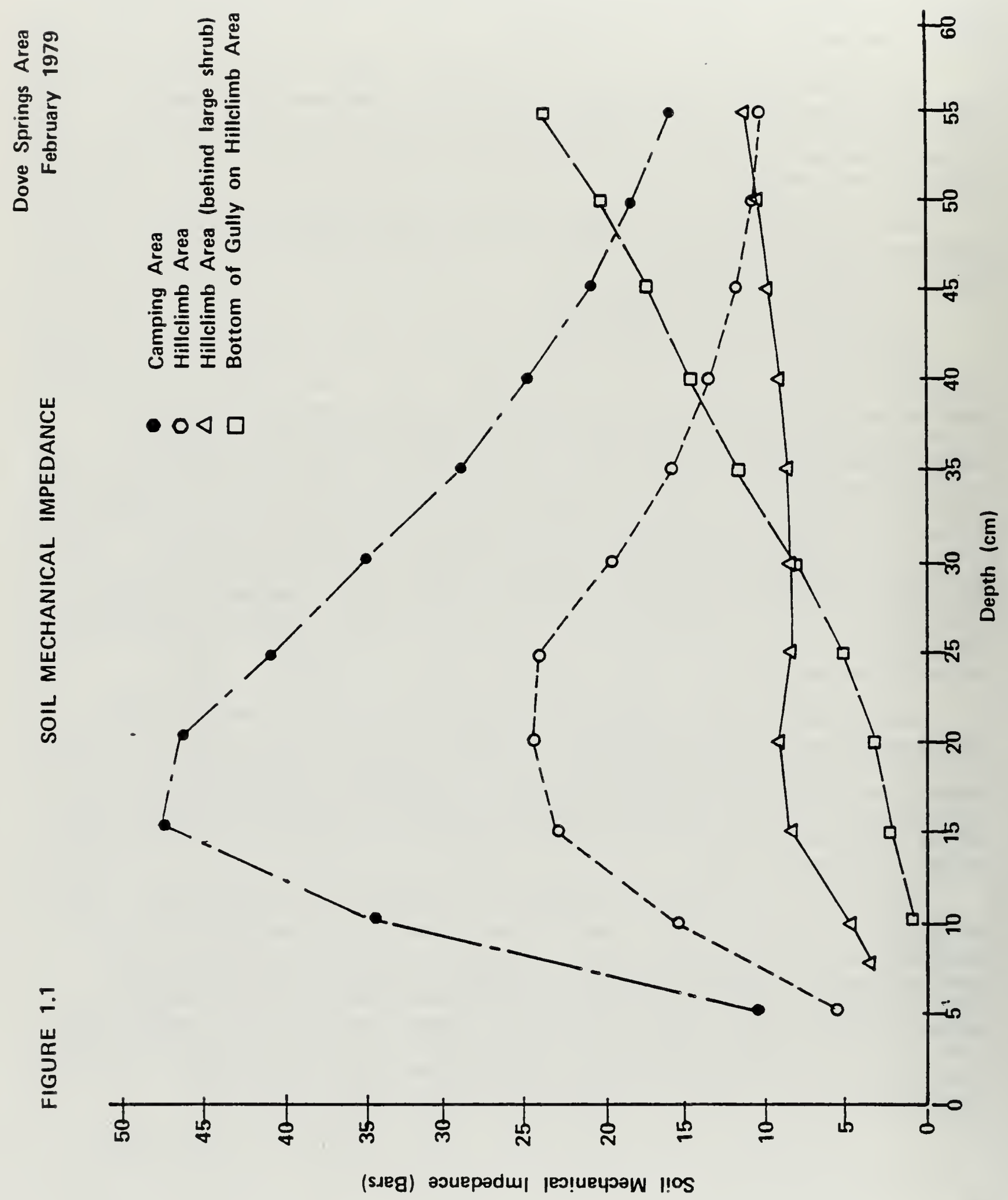
TABLE 1.1

Estimates of percentages of total soil areas which have been highly compacted by off-road vehicles in various free-play areas from low-level aerial photos $(1.1,000$ scale) $(1978-79)$.

Areas adjacent to pit areas - motorcycle trails

\section{Location}

Johnson Valley

Jawbone Canyon

Dove Spring

ORV use areas - motorcycle trails

\section{Location}

Teagle Wash

Stoddard Valley

Dove Spring

Kramer Hills

North of Stoddard Mtn.

Shad ow Mtn.

North of California City

Rand Mtn .

\section{Average Percentage ${ }^{1}$}

$8 \%$

$14 \%$

$13 \%$

Average Percentage

$4 \%$

$4 \%$

$6 \%$

$4 \%$

$4 \%$

$5 \%$

$3 \%$

$5 \%$

1 Note: Total areas crossed by tracks are generally much higher. These are trails which have been driven across a sufficient number of times to produce very severe compaction. 
Table 1.2 Soll - ORV Impacts Measurements Made On-The-Ground in the California Desert (see also Figure 1.2).

\begin{tabular}{|c|c|c|c|c|c|c|c|c|c|c|c|c|c|c|c|c|}
\hline  & $\mid \sum_{-\infty} \underset{\sigma}{N}$ & 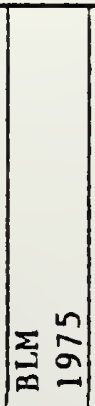 & 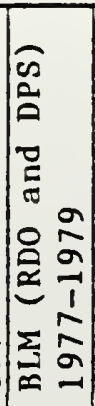 &  & $\begin{array}{cc}1 \\
x \\
0 & 0 \\
0 & 0\end{array}$ & 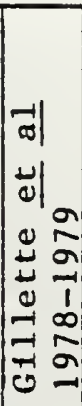 & 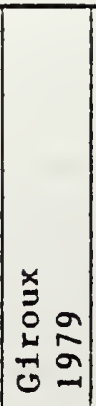 &  & 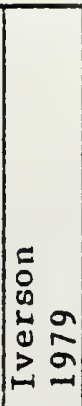 & 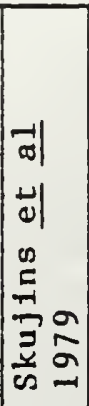 & 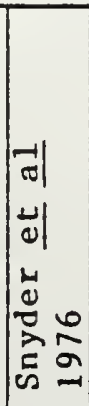 &  & 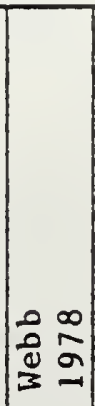 & 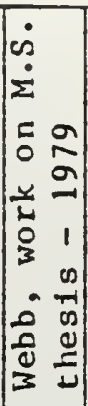 &  & 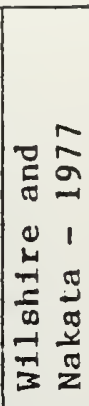 \\
\hline & & & & & & & & $X$ & & & & & & & & \\
\hline $\mathrm{X}$ & & & $\mathrm{x}$ & & & & $x$ & & & & & & & & & \\
\hline \multicolumn{17}{|l|}{$\mathrm{X}$} \\
\hline & & $\mathrm{X}$ & & & & & & & & & & & & & $\mathrm{X}$ & \\
\hline & & & & & $\mathrm{X}$ & & & & & & & & & & & \\
\hline \multicolumn{17}{|l|}{$X$} \\
\hline & & & & & & $\mathrm{X}$ & & & & & & & & & & 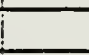 \\
\hline & & & & & & $x$ & & & & & & & & & & 1 \\
\hline & & & & & & $\mathrm{X}$ & & & & & & & & & 1 & $!$ \\
\hline $\bar{X}$ & & $\mathrm{X}$ & & & & & & $\mathrm{X}$ & $\bar{X}$ & & $\mathrm{X}$ & & $\bar{X}$ & & & \\
\hline \multicolumn{17}{|l|}{$\mathrm{X}$} \\
\hline & & & & & & $x$ & $x$ & & & & & & & & 1 & $I$ \\
\hline & & & & & & $X$ & & & & & & & & & 1 & \\
\hline & & & & & & & & & & & & & & $X$ & & \\
\hline & & & & $\mathrm{X}$ & & & & & & & & & & & & \\
\hline & & & & & & $\mathrm{X}$ & & & & & & & & & & \\
\hline & & & $\mathrm{X}$ & & & & & & & & & & & & & \\
\hline & & & & & & $\mathrm{X}$ & & & & & & & & & & \\
\hline & & & & & & & & $X$ & & & & & & & & \\
\hline & & & $\mathrm{X}$ & & & $\bar{X}$ & & $\bar{X}$ & & $\bar{x}$ & & & & & & \\
\hline & & & & & & & & & & & & $x$ & & & & 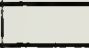 \\
\hline & & & & & & & $\mathrm{X}$ & & & & & & & & & 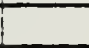 \\
\hline & & & & & & $\bar{X}$ & & & & & & & & & & 1 \\
\hline & & & $\mathrm{X}$ & & & & & & & & & & & & & \\
\hline & & & & & & $\mathrm{X}$ & & & & & & & & & & \\
\hline \multirow[t]{7}{*}{$\mathrm{X}$} & & & & & & & & & & & & & & & & 1 \\
\hline & & & & & & $\mathrm{X}$ & & & & & & & & & & 1 \\
\hline & & & & & & & $\bar{X}$ & $\mathrm{X}$ & & & & & & & & $I$ \\
\hline & & & & & & & & $X$ & & & & & & & & 1 \\
\hline & & & & & & & & & $X$ & & & & & & & 1 \\
\hline & & & & & & & & & & & & & & & & $\mathrm{X}$ \\
\hline & & & & & & $\bar{X}$ & & & & & & & & & & $I$ \\
\hline \multirow[t]{3}{*}{$\bar{X}$} & & & & & & & & & & & & & & & & \\
\hline & & & & & & $\bar{x}$ & & & & & & & & & & \\
\hline & & & & & & $X$ & & & & & & & & & & $I$ \\
\hline \multirow[t]{2}{*}{$X$} & & & $\mathrm{X}$ & & & & & $x$ & 8 & $\mathrm{X}$ & & & $L$ & & & 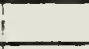 \\
\hline & & & & & & & & $X$ & & & & & 4 & & & \\
\hline \multirow[t]{4}{*}{$\mathrm{X}$} & & & & & & & & $X$ & & & & & $i$ & & & \\
\hline & 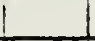 & & & & & $X$ & & & & & & & I & & & I \\
\hline & $i$ & & & & & $X$ & & & & & & & $I$ & & & $!$ \\
\hline & 1 & & & & & & & $X$ & & & & & $I$ & & & 1 \\
\hline $\mathrm{X}$ & $\mathrm{X}$ & & $\mathrm{X}$ & & & & & $x$ & & & & & 1 & & & \\
\hline
\end{tabular}




\section{Infiltration and Water Erosion and their Relation to Soil Compaction}

\section{Infiltration Rates and Rainfall Simulation Studies}

Babcock and Sons (1973) measured equilibrium percolation rate on level or gently sloping soils in ten locations with ORV use in the California Desert. Infiltration rates on compacted soil showed large decreases in comparison to adjacent undisturbed areas except for very sandy soils which occurred primarily in sand dunes and washes. They also measured significant decreases in void ratio (ratio of voids to solids) in all except the very sandy soils. The infiltration rate of a flooded layer of surface water was measured. These measurements showed a larger difference in infiltration rate between disturbed and undisturbed soil than would be expected to occur with most rainstorms. Under most conditions of precipitation the amount of water entering the soil is less than occurs when the same soil is artificially flooded.

Iverson (1979) studied accelerated erosion on desert hillslopes used by off-road vehicles. Data were collected during 50 in situ rainfall simulation experiments at three ORV use areas (Stoddard Valley, Dove Springs, and in the vicinity of Randsburg) in the western Mojave Desert. Comparisons were made between plots in disturbed and undisturbed locations. Sediment yield from $1 \mathrm{~m}^{2}$ desert hillslope plots subjected to 20 -minute rainfall simulation intensities averaging $66 \mathrm{~cm} / \mathrm{hr}$ was typically increased 10 to 20 fold following slope modification by motorized vehicles. Iverson (1979) concluded that increased surface runoff due to reduced infiltration was not sufficient to explain the greatly accelerated erosion. Runoff appeared to be strongly influenced by vehicular effects which loosened transportable particles and altered runoff hydraulics. Smoothing of the hillslope by vehicles reduces resistance to overland flow and vehicle tracks parallel to slopes tend to localize runoff power by channeling flow. Both of the se modifications lead to increased capacity for sediment transport.

Iverson used a rainfall simulator which released water from about 5.2 meters above the ground. This allowed an impact velocity which approached that of a natural rainstorm. This is important because dispersion of fine soil particles by impact of raindrops and subsequent sealing of the surface can result in significant increases in runoff during a rainstorm. The application rate $(45.3 \mathrm{~mm} / \mathrm{hr}$.$) represents a rainfall$ intensity which could be expected only during intense summer thunderstorms (Rowlands, 1980). The differences in sediment production between disturbed and undisturbed soil would be less during less intense winter cyclonic storms. Because most erosion occurs during infrequent, very intense rainstorms, the use of a high application rate for tests is informative. 
Webb (personal communication) placed trails consisting of 1,10 , 100 , and 200 motorcycle passes near Fremont Peak in the California Desert on a fine, mixed, thermic, typic Haplargid with a sandy loam surface soil. Trails were made on wet soil with a high potential for compaction. The 100 and 200 pass trails had a highly significant reduction in infiltration rate in comparison to the control. The control (undisturbed area) had an infiltration rate of $9.8 \mathrm{~cm} / \mathrm{hr}$ and the 200 pass track had an average infiltration rate of $2.6 \mathrm{~cm} / \mathrm{hr}$. On the 100 and 200 pass trails, only one plot out of seventeen did not show runoff when rainfall was applied at a rate of 1.8 centimeters per hour for one hour with a rainfall simulator (Meeuwig, 1971). On the controls, only one plot out of a total of thirteen plots had runoff when a simulated rainfall of $5.8 \mathrm{~cm}$ per hour was applied for one hour.

The rainfall simulation used by Webb was applied to soil on slopes of 4.4 percent. One disadvantage of the rainfall simulator is that drops are released only about two feet above the soil and their impact velocity is lower than that of natural rainfall.

Eckert et al (1977) studied effects of off-road vehicles on infiltration and sedimentation on two sites in Nevada. Soil at one site was a loamy-skeletal, carbonitic, thermic, shallow, typic Paleorthid with a silt loam surface horizon. Soil at the other site was a loamy-skeletal, mixed, shallow, thermic, typic Durorthid with a gravelly loamy sand surface. Single motorcycle and truck passes, 50 passes of the motorcycle, and 20 passes of the truck were made at each site at the beginning of the study. Fifty motorcycle passes and twenty truck passes were also made at the two sites at two later dates.

The single pass tracks had infiltration rates in and sediment production values which were similar to the undisturbed areas. The multiple vehicle passes generally caused a large reduction in infiltration capacity and increased the rate of sediment production. Both runoff and sediment were much greater from disturbed soil between shrubs than from disturbed soil under shrubs. In general, more water ran off from treated areas after the soil had been disturbed, wet, and the soil allowed to dry and the crust to reform. However, runoff after reformation of the crusts contained similar amounts of sediment in comparison to runoff water after the initial treatment. Apparently the reformed crust reduced infiltration, but the new crust was more resistant to particle detachment by raindrop impact. The greatest amount of runoff and sediment came from interspace soil rather than from soil under shrubs after crust reformation.

The rates of artificial rainfall application were either $3.38 \mathrm{~cm} / \mathrm{hr}$ for 30 minutes or $7.50 \mathrm{~cm} / \mathrm{hr}$ for 30 minutes. The higher rate represents a precipitation rate in excess of a 100-year reocurrence interval at both sites. Application of $3.38 \mathrm{~cm} / \mathrm{hr}$ for 30 minutes represents a precipitation rate of about once every 50 years at one site and somewhere between once every 2 years and once every 50 years at the other site. Most natural cyclonic rainstorms would have lower rates of precipitation and would show a smaller difference in runoff and sedimentation between disturbed and undisturbed sites than occurred in the experiments in Nevada. However, the experiments may approach the conditions created by violent summer thunderstorms. 
The sites studied had gentle slopes. Runoff water and sediment from the area around the infiltration plot generally collected in adjacent low parts of the space between shrubs. Therefore, it was concluded that runoff and sediment from large off-road vehicle events on gentle slopes, even at these high rates of rainfall, probably would not move off-site. On steeper slopes, however, much of the sediment produced should be found in the drainage, especially if vehicle tracks run up and down slopes.

In our studies the results of which are presented in chapter 5 natural rainfall on the off-road vehicle tracks showed a similar depth of the wetting front in undisturbed areas and even under the most intensely compacted adjacent tracks. No observable traces of runoff or erosion was seen on the tracks. During the same period of time (about two years), evidence of some water erosion was noted on a nearby dirt road. The normal rainfall intensities (most likely all much less than used in artificial applications in the above literature) and gentle slopes appeared to prevent significant runoff from the tracks in our study. In contrast, the nearby dirt road accumulated sufficient water (intercepting drainages, etc.) for noticeable erosion to occur during the same period of time.

Reicosky et al (1979 abstract) studied unsaturated waterflow through a simulated wheel track. The data indicated that the water flowed toward the wheel track. This phenomena occurred early in the drying cycle and was exaggerated when the wheel track was packed wet as compared to when it was packed dry. Therefore, even if infiltration were reduced under tracks, unsaturated flow toward tracks may tend to equalize soil moisture under tracks in comparison to soil adjacent to tracks.

\section{Accelerated Erosion}

Observations on steep terrain show strong evidence of soil displacement and accelerated erosion by ORVs. High rates of accelerated erosion have been reported at ORV sites on steep slopes in the California desert (Snyder et al, 1976; Wilshire and Nakata, 1976; Wilshire, 1977; Wilshire and Nakata, 1978; and Webb, 1978), in central California (Webb et al, 1978; Knott, 1978), in the Los Padres National Forest (Wilshire, 1978), and in northern California (Wilshire et al, 1978).

Soil loss from a hillside near Red Rock Canyon in the Mojave Desert that had been disturbed by ORV use was estimated by Wilshire and Nakata (1976). The pre-erosion surface was inferred from exposed shrub roots. Displacement of surface material along transects was estimated and volumes and weight of soil loss were calculated. Measurements made across a single heavily used trail with a slope length of $68 \mathrm{~m}$ and slopes between $44 \%$ and $58 \%$ showed loss to an estimated depth of $24 \mathrm{~cm}$. This was equivalent to a loss of 150 metric tons or somewhat more than 0.4 metric tons $/ \mathrm{m}^{2}$. Other transects in less heavily used locations had a mean estimated soil loss to a depth of $15 \mathrm{~cm}$, amounting to more than 0.2 metric tons $/ \mathrm{m}^{2}$. The total loss for the used part of the hill (assuming a mean loss of 0.2 metric tons $/ \mathrm{m}^{2}$ ) was estimated to be nearly 11,000 metric tons. A loss of 0.2 metric tons $/ \mathrm{m}^{2}$ amounts to $809 \mathrm{U} . \mathrm{S}$. tons/acre. Since soil loss tolerances 
(tons/acre/year) estimated by the Soil Conservation Service of the U.S. Department of Agriculture are typically 5 tons/acre/year or less (e.g., estimates for Coachella Valley by Quesenberry, 1978), the estimated losses on the hillside near Red Rock Canyon (even if they occurred over a period of quite a few years) are extremely high in comparison to those considered acceptable for agricultural soils. Wilshire and Nakata reported that a substantial part of the sediments were deposited on adjacent floodplain slopes where signs of plant burial were common.

Soil loss tolerance values were derived in the Midwest by estimating the age of a soil profile, and calculating the depth of soil loss per time which would match the rate of soil formation per time. This involves uncertainty because it is not known if soil formation occurs as a linear function of time. Furthermore, rates of soil formation in other climates may differ widely from those in the Midwest. Rates of soil formation in the deserts would be much lower.

The loss of soil will be most serious on shallow soils underlain by impervious bedrock or pans where roots cannot penetrate. Depths of soil which become very limiting to desert vegetation have not been determined. Deeper soils or soil with parent material which can be penetrated and utilized by root systems will be less sensitive.

Water erosion may also reduce plant growth by removing surface nutrients. This would be most pronounced under shrub canopies where some nutrients may have accumulated to much higher concentrations than in the intershrub spaces as a result of nutrient recycling by the shrubs themselves. Nutrients which are concentrated will be dispersed. Smaller storms may move nutrients into parts of the drainage system where later, heavy storms could transport them for long distances.

Snyder et al (1976) measured changes along erosion transects in Dove Spring Canyon between 1970 and 1975. Two transects on the upper part of the used slope showed large changes. One transect had a loss of 0.15 to $0.23 \mathrm{~m}$ of surface material from the trail areas between 1970 and 1975. Another transect had a soil loss of 0.23 to $0.30 \mathrm{~m}$ between 1973 and 1975. In contrast, one transect had a gain of displaced soil. A level of 0.06 to 0.09 m of soil accumulated on one side of the transect between 1970 and 1975 and a transect which had low to moderate use between 1970 and 1975 showed little change. No control (undisturbed) area could be measured because transects established for this purpose were subsequently disturbed by ORV activity.

The drainage area of Dove Springs Canyon above the Los Angeles Aqueduct is approximately 4,000 hectares. This drainage is tributary to Red Rock Canyon which has a total of approximately 13,000 hectares of drainage above its outflows. Within this drainage an estimated 36 hectares were severely compacted by ORVs, based on 1973 ( $1: 20,000)$ aerial photographs. This represents an estimated $0.9 \%$ of the drainage down to the Los Angeles Aqueduct and $0.3 \%$ of the drainage to the lower end of Red Rock Canyon (about 3 kilometers north of the junction of Highway 14 and Randsburg Red Rock Road). The highly compacted area shown in a 1973 photo 
in Jawbone Canyon represents an even smaller percentage. Even though the runoff and sediment production may have been much greater from the disturbed soil, the smaller fraction of disturbed soil in the large drainage area may have resulted in a relatively small increase in runoff and sediment production from the ephemeral streams flowing from the lower ends of Dove Springs Canyon, Red Rock Canyon, or Jawbone Canyon. Therefore, farmlands or roads below the canyons may not have been significantly impacted by changes in runoff or sediment production resulting from activity of ORVs. However, the total area severely impacted by ORVs has undoubtedly increased since 1973.

No measurements of runoff and sediment yields on comparative basins have been done in the desert. Snyder et al (1976) did such a study on loam soils in the Panoche Hills area of central California. They concluded that runoff in the watershed used by motorcycles produced about eight times as much runoff volume per unit area as the unused watershed. The large difference in runoff was attributed to the reduction in plant cover and infiltration rates in the heavily used area. Sediment yield from the used watershed was $857 \mathrm{~m}^{3} / \mathrm{Km}^{2}$, whereas in the unused watershed the quantity of sediment delivered to the reservoir during the period from 1971 to 1975 was reported to be too small for measurement by survey procedures which were used.

The validity of the study depends to a large extent on the comparability of watersheds. Precalibration measurements during a period of time prior to use would have been useful to prove the hydraulic similarity of the two watersheds, but the study site had already been used by off-road vehicles before the study was initiated. However, the very large difference in runoff and sediment production strongly indicates that ORV activity has had a substantial impact on the hydrology of the area.

Slopes in the used area were reported to be about $65 \%$ whereas hillslopes in the unused area were about $100 \%$, so the greater runoff in the used watershed coincides with lesser slopes which might yield smaller amounts of runoff if the area had not been disturbed. Motorcycle trails in the used area were reported to be completely denuded of plant cover and topsoil and were deeply rilled whereas the unused watershed did not show evidence of such disturbance. During the two years of the Panoche Hills study the rainfall totals between October and April were $208 \mathrm{~mm}$ ( 8.18 in.) and $239 \mathrm{~mm}$ ( 9.39 in.) which are high values compared to the average precipitation of most areas in the California desert. However, in relatively wet years many desert sites could receive rainfall totals and intensities which are as great as those which occurred at Panoche Hills during the study.

\section{Critical Slope Angles}

Wilshire (unpublished data) concluded that coarse sandy soils, which are common in deserts, cannot tolerate slopes greater than about $7 \%$ if Soil Conservation Service tolerances for soil loss are not to be exceeded, whereas trails on clay-rich soils could be tolerated up to $33 \%$ with slope lengths less than about $50 \mathrm{~m}$. Webb et al (1977) made soil erodibility and erosion control recommendations based on studies at Hollister Hills in central California. He reported that personal communications from other 
investigators suggested critical slope angles of $7-11 \%$ for Cieneba, Sheridan, Auberry, and Permanente series (fine to coarse sandy loam surface soil); $9 \%$ for the Comita series (sandy loam surface soil); $11-13 \%$ for the Nacimiento series (sandy loam surface soil); and $20 \%$ for the Diablo series (clay surface soil). Noticeable water erosion has been observed by Endo in long, straight, compacted motorcycle trails running downslope (as gentle as $3 \%$ ) in Johnson Valley. This occurred where water ran off a large, highly compacted pit area and was funnelled down the trails.

\section{Estimating Soil Limitation for ORV Use}

The Soil Conservation Service (1979) has produced new guidelines for rating soil limitations for off-road vehicle trails. The ratings for water erosion are categorized as slight, moderate, and severe. These limits are defined by multiplying the erosion factor ( $K$ from the universal soil loss equation) by the percent of slope. The slight rating is applied to products ( $\mathrm{K}$ times percent slope) less than 2, moderate ratings to products between 2 and 4 , and severe ratings to products greater than 4. Because $K$ values are often between values of 0.15 and 0.4 , ratings of severe restrictions due to water erosion would often occur on slopes within a range from 10 to $27 \%$. Because typical ORV hill climbs (e.g., in Dove Springs or Jawbone Canyon) are on slopes which are often much greater than these values, most hillclimbs would be classified into the severe restriction category. Hillclimbs on dune sand would be an exception, because infiltration will remain extremely high even after disturbance.

Determination of $\mathrm{K}$ values for the slopes involves considerable uncertainty because compaction of the subsurface can cause large decreases in infiltration, increasing runoff and sediment transport, thereby increasing $K$ values. Also, vehicle traffic upslope can cause significant mechanical displacement of soil downslope, in addition to that transported by water erosion. This type of displacement is not considered in the SCS criteria.

It would be very desirable to be able to predict increases in soil water erosion in tons per hectare per year as a result of off-road vehicle activity. The Universal Soil Loss Equation predicts soil loss from sheet and rill erosion but not gully erosion (Wischmeier, 1976). Al so, the equation does not account for soil moved downslope by mechanical displacement by ORVs. These errors will result in an underestimate of soil loss from steep slopes. There is uncertainty in extrapolating slope factor values beyond the maximum slope values for which data have been collected (20\%). Many hillclimbs are on much steeper slopes. The value for the soil erodibility factor cannot necessarily be accurately estimated even in areas where detailed soil surveys are available because ORV activity may greatly alter the soil erodibility value as discussed previously. Cline (1977) pointed out that non-mapped soil inclusions are more than $50 \%$ of many soil mapping units identified as taxa, so on-site investigations of soil erodibility values would probably be necessary for this reason rather than using the order 3 soil surveys required by the Bureau of Land Management. Also, the equation cannot be used for complex watersheds by using overall averages of slope length and gradient with estimated watershed-average values for plant cover and soil erodibility (Wischmeier, 1976), so calculations cannot be readily made in heterogeneous terrain. 


\section{Dust Produced by Vehicle Activity - Direct Effects}

\section{Prediction of Dust Emission by ORV Activity}

Investigators have studied fugitive dust from unpaved roads in Kansas, New Mexico, Iowa, and Washington (Cowherd et al, 1974). Dust emission from unpaved roads depends on (1) average vehicle speed, (2) surface texture, and (3) surface moisture. A formula has been proposed to calculate the amount of dust generated per vehicle-mile of travel:

e $(\operatorname{roads})=0.81 \mathrm{~s}(\mathrm{~s} / 30)$

where: $e=$ emission factor (pounds per vehicle-mile)

$s=$ particles smaller than 75 um in diameter. This is not determined by soil textural analysis but by the percent of dry surface material passing a 200-mesh screen.

$S=$ average vehicle speed (miles per hour).

The equation applies only to days when the soil is dry; emissions were assumed to be negligible on days when rainfall exceeded 0.01 inches. The accuracy of this equation in predicting the results on the emission tests of unpaved roads was $\pm 10 \%$ (Cowherd et al, 1974). All of the test vehicles were passenger cars or small trucks, so the formula may not be applicable to motorcycles. In addition, off-road driving will probably produce dust at a different rate than driving on an unpaved road. Since the formula was based on emissions from four tires, corrections should be made in direct proportion to increasing tire numbers on large trucks. The formula was based only on four road sites in western Kansas: Two gravel roads, a dirt road where the parent soil was a sandy loam, and a dirt road where the parent soil was a silt loam. Furthermore, the formula only applies to speeds between 30 and $50 \mathrm{MPH}$. Accurate predictions on the effects of ORV's on air quality with the above formula may not be possible, but the formula, shows that avoidance of areas with a high percentage of soil particles less than 75 um or reduction of vehicle speeds will diminish fugitive dust production. Driving on moist soils would also result in decreased fugitive dust but would exacerbate soil compaction.

Cowherd et al (1974) claimed that emissions are reduced during periods of rainfall, but quickly return to normal levels. They reported that on the average, dust emissions from unpaved roads were in size ranges as follows: greater than $50 \mathrm{um}(30-45 \%$ by weight), 2 um to 50 um $(30-40 \%)$, and less than 2 um $(50-60 \%)$. Gillette (1977) reported that particles smaller than 20 um predominate in dust carried long distances. The proportions of different sized particles emitted might vary markedly in other situations than the few tested.

Pedco (1973) estimated relative importance of particulate emission on some unpaved roads due to both wind and vehicular traffic. Dust plumes from vehicles $(\bar{x}=32 /$ day $)$ accounted for $58 \%$ of the total and 
wind erosion $42 \%$. The road surface used in the example was composed primarily of loams and sandy clays (70\%), with some sandy loams and clays (30\%). Differences in such variables as number of vehicles passing per day, vehicle speed, and type of soil covering the road will cause changes in the relative percentages of soil loss due to vehicles and wind erosion. However, the results can be used to conclude that amounts of fugitive dust lost from roads as a result of wind erosion are of the same level of magnitude as that which results directly from vehicular traffic.

An attempt was made before the 1974 Barstow-Las Vegas race to predict dust emissions, using a formula for vehicular production of dust (Pedco, 1973). The equation is as follows:

$$
E=(0.27)(1.068)^{x}
$$

Where $E$ = dust emission in 1 bs/veh. mile and $\mathrm{x}=$ vehicle speed in miles per hour.

A prediction value of $195 \mathrm{ug} / \mathrm{m}^{3}$ was calculated for a speed of 40 MPH in Nevada. It was predicted that dust concentrations in California would probably be even higher because of a greater number of vehicles. Actual measured concentrations on the race day were lower. However, the prediction that state and federal standards would be exceeded was correct. Other, smaller, races have had much higher measurements of total suspended particulates than the 1974 race as will be discussed later. The Pedco study does not specify the types of vehicles used to derive the formula but they were most likely vehicles with four wheels rather than motorcycles. Also the formula used has no factor for differences in soil properties as did the formula developed by Cowherd et al (1974). The lack of a variable to compensate for differences in soil properties on the road surface will lead to large errors in comparisons made for different types of road surface.

\section{Levels of Fugitive Dust During and After Desert ORV Events}

Measurements made of total suspended particulates at all ORV races thus far monitored in the California desert have shown values in excess of Federal and California State air quality standards. Suspended particulates were measured at four locations near the 1974 Barstow-Las Vegas motorcycle race (BLM, 1975). Two stations in California had suspended particulate values of $176 \mathrm{ug} / \mathrm{m}^{3}$ and $158 \mathrm{ug} / \mathrm{m}^{3}$ the day of the race and values at these same two stations were, respectively, 180 and $94 \mathrm{ug} / \mathrm{m}^{3}$ the day after the race. The two monitoring locations in Nevada had average values of around $30 \mathrm{ug} / \mathrm{m}^{3}$ two days before the race. During the race, values at the two stations in Nevada were 97 and $161 \mathrm{ug} / \mathrm{m}^{3}$ and the day after the race, values at the same two stations were, respectively, 57 and $16 \mathrm{ug} / \mathrm{m}^{3}$. The California State standard for suspended particulates (determined by high volume sampling) is $100 \mathrm{ug} / \mathrm{m}^{3}$. The primary Federal standard (to protect public health) is $260 \mathrm{ug} / \mathrm{m}^{3}$ and the secondary Federal standard (for any known or adverse impacts) is $150 \mathrm{ug} / \mathrm{m}^{3}$. Therefore, State and Federal air quality standards were exceeded at three of the four monitoring stations on the day of the event. Standards were exceeded at one station the day following the event. The data does not permit separation of normal background concentrations and contributions from the race, but the data gives strong evidence of an increase in particulate levels due to the event. 
Levels of fugitive dust along the Barstow-Vegas race course were analyzed with methods other than high volume dust samplers. It was concluded that dust fall (measured with dust fall jars) averaged $31 \%$ greater than normal background for the period for 30 days during and after the race. Very large differences occurred in dust fall into the nine surviving dust jars at the sampling sites along the course. Only two of the four background sampling sites escaped destruction, making the comparison between experimental and background data somewhat uncertain.

Tape samplers manufactured by the American Iron and Steel Institute were operated before the race, during the race, and after the race. These instruments indicated that the average peak dust concentration was 3 to 5 times greater during the time of the race than after and before the race.

Giroux (1979) measured dust emissions from ORV races and a freeplay area (Table 1.3). These events included the Parker Score 400 race, a race held in the vicinity of the sand dunes in Imperial County, prerace activities and a demolition derby held near the Lenwood offramp of Highway 15 in the Mojave Desert, a race near Lenwood, and free-play activities on El Mirage Lake.

Values collected for the Parker 400 race and the Imperial County race represent calculated values for 24 hours. These were obtained by using the background (upwind) measurements made during the race to estimate the values for the hours after the event which were not measured. Values for the other activities shown in Table 1.1 are only for the hours that samples were collected with the high volume sampler. The measurements were made during the Lenwood race for only 2.5 hours $(5 / 27 / 79)$ because the participants requested that the investigator leave before completion of the event, which continued for several more hours. Measurements were made for 13 hours at Lenwood on $5 / 26 / 79$ and 7 hours at E1 Mirage. The values for all events exceed federal and state standards even without adding the additional dust which would occur during the hours not measured. The values for the Lenwood race $(5 / 27 / 79)$ would have been much higher if measurements had continued for the duration of the event instead of only 2.5 hours.

The Parker race consisted of about 100 motorcycles and 200 fourwheel drive vehicles. Soil samples collected near the start were loamy sand or gravelly loamy sand and samples obtained near the mid-course monitoring station were very gravelly coarse sand. At the time of the event the soil was very wet except for a surface dry layer which was estimated to average about $2 \mathrm{~cm}$ in thickness. Therefore, if the race had been run during drier conditions, more dust would have been produced.

Soil collected from near the start of the race in the vicinity of the sand dunes was coarse sand with about $2.6 \%$ silt. The event consisted of about 50 motorcycles. Despite the small size of the event and the sandy nature of the area, higher values of total suspended particulates were measured than at the Parker 400 race, probably because the soil was 
Dust emissions (TSP - Total Suspended Particulates in ug $/ \mathrm{m}^{3}$ ) from some selected ORV races and free-play areas.

\begin{tabular}{|c|c|c|c|}
\hline & & $\begin{array}{l}\mathrm{TSP} \\
\mathrm{ug} / \mathrm{m}\end{array}$ & Comments \\
\hline Parker $400 *$ & $2 / 10 / 79$ & $\begin{array}{l}104.3 \\
583.1 \\
615.4 \\
858.3\end{array}$ & $\begin{array}{l}\text { Upwind - midpoint } \\
180^{\prime} \text { from starting line } \\
175^{\prime} \text { downwind from midpoint } \\
30^{\prime} \text { from starting line }\end{array}$ \\
\hline Sand Dunes * & $4 / 29 / 79$ & $\begin{array}{r}87.3 \\
166.8 \\
596.3 \\
956.4 \\
1350.0\end{array}$ & $\begin{array}{l}\text { Upwind of raceway } \\
\text { On sand near pit area } \\
\text { Atop motorhome in campground } \\
\text { Along dirt road at checkpoint } \\
-225^{\prime} \text { down road } \\
\text { Along dirt road at checkpoint } \\
-100 \text { ' down road }\end{array}$ \\
\hline $\begin{array}{l}\text { Lenwood } \\
\qquad \begin{array}{l}\text { prerace \& } \\
\text { demolition } \\
\text { derby }\end{array}\end{array}$ & $5 / 26 / 79$ & $\begin{array}{r}422.8 \\
544.2 \\
711.5 \\
795.7 \\
1955.4\end{array}$ & $\begin{array}{l}\text { At starting line } \\
\text { Grandstand bleachers } \\
\text { Midcourse - } 150 \text { ' from raceway } \\
\text { Atop motorhome in parking area } \\
\text { Along race course straight } \\
\text { way }\end{array}$ \\
\hline $\begin{array}{l}\text { Lenwood } \\
\text { race day }\end{array}$ & $5 / 27 / 79$ & $\begin{array}{r}747.8 \\
1046.1 \\
1780.4\end{array}$ & $\begin{array}{l}\text { At starting line } \\
\text { Grandstand bleachers } \\
\text { Atop motorhome in parking area }\end{array}$ \\
\hline E1 Mirage & $5 / 28 / 79$ & $\begin{array}{l}365.2 \\
628.6 \\
811.3\end{array}$ & $\begin{array}{l}175^{\prime} \mathrm{N} \text { of motorhome near } \\
\text { drainage channel. } \\
50^{\prime} \mathrm{E} \text { of motorhome near brush } \\
150^{\prime} \mathrm{W} \text { of motorhome in open } \\
\text { area }\end{array}$ \\
\hline
\end{tabular}

* Samples weighted with: $x$ hours of "clean air" + y hours of "dirty air"/ $(\mathrm{x}+\mathrm{y})$. Lenwood and El Mirage samples not weighted because there was no clean air observed at any monitoring site. 
much drier at the Imperial County area than at the Parker 400. Part of the race was on a dirt road, which probably contained fill material. As a result, more fine material was present on the road than in the dunes. The road surface texture was that of coarse sand. Variables such as location of particulate samplers, wind direction and speed, soil moisture, and activities by spectators can cause measurements to be considerably different than would be expected solely from the type and size of race and soil properties.

Giroux (1979) also measured particulate values in excess of federal and state standards for a race ( 55 four-wheel vehicles) and pre-race activities (about 20 four-wheel drive vehicles and 9 old cars in the demolition derby) near Lenwood. The track had been watered for the race and Giroux reported that little dust was evolved from the wet race track. However, activities by spectators created large amounts of dust. Soil collected near Lenwood was very dry ( $0.31 \%$ moisture) gravelly loamy sand.

Federal and California State standards were also exceeded by activity at El Mirage Dry Lake. About 100 vehicles (motorcycles, three-wheeled vehicles, and four-wheel drive vehicles) passed by the samplers during the 7 hours of measurement. Many more vehicles were being driven further away on the playa. Soil near the edge of the playa where high volume samplers were located was gravelly loamy coarse sand.

Giroux reported that total suspended particulate standards are currently under review for revision. He speculated that a change would probably not occur for several years. When the standards are changed, emphasis will be placed on very fine particles which can cause health problems after entry into lungs. Giroux took samples at each event with a high volume sampler and an Anderson head attachment. These measurements separate suspended particulates into different size ranges. The highest percentage of fine particles occurred in the dust near Lenwood road. A smaller fraction of fine material occurred at El Mirage and the lowest proportions of fine material were measured at the sand dunes and the Parker 400 race. The respirable particulate measurements varied from slightly over $200 \mathrm{ug} / \mathrm{m}^{3}$ to over $950 \mathrm{ug} / \mathrm{m}^{3}$. Giroux reported that the new ambient air standard for respirable particulates is expected to be well below $100 \mathrm{ug} / \mathrm{m}^{3}$ so the respirable fraction may be as much as 10 times or more above levels considered unhealthy for sensitive individuals.

Giroux suggested that total suspended particulate values return to normal within 1-2 days. Total suspended particulate measurements may approach background values in less than 100 meters upwind of the event.

Dale Gillette and Hans Giroux (personal communications) both estimated that dust may travel about 15 kilometers downwind near the surface during stable, early morning meteorological conditions before the temperature inversion begins to break up and ab out 2 kilometers downwind during unstable conditions after the inversion is disrupted. Gillett estimated that sometimes dust could even travel near the surface for 30 to 40 kilometers downwind during stable conditions. The temperature inversion 
may begin to break up by 9:00 a.m. or 10:00 a.m. even under winter conditions and disruption of the inversion will occur earlier during the summer. Because winds are often very light early in the morning, dust may not reach the maximum distance from the track before the inversion begins to break up.

Measurements of total suspended particulates made at the "Mint 400" race in Clark County, Nevada (Clark County District Health Department, Air Pollution Control Division, 1971) are shown in Table 1.4. The values were very high at the track the day of the race $\left(2,158 \mathrm{ug} / \mathrm{m}^{3}\right)$ and the day after the race $\left(859 \mathrm{ug} / \mathrm{m}^{3}\right)$. The report on the race concluded that the "levels measured near the race course are alarmingly high and constitute unacceptable levels of air quality." Values measured 8 kilometers from the track were $170 \mathrm{ug} / \mathrm{m}^{3}$ on the day of the race, exceeding federal and Nevada standards. Measurements made 8 kilometers from the track the day after the race and several days prior were much lower.

The highest value of particulates measured in Parker, Arizona in February 1978 (273 ug $/ \mathrm{m}^{3}$ ) occurred on February 12, the day of the Parker 400 race. February 1978 was a wet month, which could lower dust emission in comparison to drier conditions. Particulate measurements were also made in Parker, Arizona on three days in the second half of September 1978 and six days in October, 1978. The highest value in Parker during this period (232ug/ $/ \mathrm{m}^{3}$ ) occurred the day after a Score 400 race (no measurements were made the day of the race). These measurements suggest that the Parker 400 race may significantly raise the level of air borne particulates in Parker, Arizona.

Another location in the California Desert Conservation Area which may be heavily impacted by fugitive dust from ORV activity is near the Plaster City Open Area. An unpublished study of values, issues, and concerns identified by residents of the California Desert done for the Desert Plan Staff of the BLM (1979) states that a "primary issue is the blow sand (may also refer to increased wind erosion) caused by heavy recreational vehicle use to the west and south." This was reported by residents of Plaster City and Ocotillo to have become more noticeable in recent years, resulting in a very unpleasant living environment for residents. BLM action to rectify this situation was strongly requested by residents of Plaster City. Dust clouds were also noted by some residents of Ocotillo.

It has been reported (BLM, 1974) that tests on off-road vehicle races in Nevada showed particulate matter concentrations for a 24-hour average to range from 28 to $2,400 \mathrm{ug} / \mathrm{m}^{3}$. The reasons for the very large variation in measurements were not quantified, but it was concluded that the variation was due to differences in soil type, topography, and types of vehicles. 


\section{Reduction of Fugitive Dust Produced by ORV's}

Giroux recommended mitigation measures to reduce dust emission from ORV events. Sand dunes or other areas low in fines are much better suited than soils with higher silt and clay contents. Supplemental watering or natural rainfall both reduce dust emission but running events on wet soil may increase compaction. Starting events on small stretches of paved, oiled, or watered roadway will reduce the shower of dust from initial vehicle acceleration.

Precautions should be taken to reduce dust exposure of spectator areas and nearby populated areas. This would include separation by sufficient distance and limiting free play in areas with high dust potential which are near inhabited areas. Wind direction and stability may be estimated, especially for terrain-dominated areas during the cooler months. ORV events should be scheduled and located so that winds carry emissions away from areas of spectator congregation and population during stable conditions which result in rapid settling of dust. Events during the middle of the day should be confined to the cooler months to prevent thermal convection from carrying ORV dust to high altitudes where it can degrade visibility and air quality.

Motorcycles usually create less dust per vehicle than light 4-wheel drives (Bajas, etc.) which create less dust per vehicle than heavier 4wheel drives (such as pickups). Events with heavier types of vehicles may require even closer attention to the types of mitigating measures for dust discussed above.

\section{E. Effects of ORVs on Wind Erosion - Indirect Effects}

\section{Increases in Dust Storm Frequency}

Nakata et al (1976) reported that six dust plumes were photographed during a Santa Ana wind in the Mojave Desert of California on January 1 , 1973 , by the Landsat/ERTS-1 satellite. The plumes ranged in length from 15 to $75 \mathrm{~km}$ and covered an area of $1,735 \mathrm{~km}^{2}$. Points of origin of the plumes were determined and investigations were made on the ground to characterize properties of the source areas. Origin of the dust plumes was attributed to the destabilization of the natural surface through road building, off-road vehicle recreation, agriculture, urbanization, and stream channel modification.

Clements et al (1963) reported an increased frequency of desert dust storms after disturbance by man. He reported that severe sand and dust storms occurred at a rate of less than two per year on the average in undisturbed desert areas of the southwestern United States. Less severe storms average about four per year. 
Table 1.4

Measurements of total suspended particulates (TSP) resulting from the "Mint 400" race, Clark Co., Nevada.

\begin{tabular}{lcc} 
& \multicolumn{2}{c}{ TSP $\left(\mathrm{ug} / \mathrm{m}^{3}\right)$} \\
\cline { 3 - 3 } Date & Near Track & $5 \mathrm{miles}$ from Track \\
\hline $3 / 18-19 / 71$ & 59 & 75 \\
$3 / 22-23 / 71$ (race held $3 / 22)$ & 2158 & 170 \\
$3 / 23-24 / 71$ & 859 & 47 \\
$3 / 24-25 / 71$ & 117 & -- \\
$3 / 25-26 / 71$ & 206 & - \\
\hline
\end{tabular}


In areas where the surface has been highly disturbed by man's activities, the frequency of sand and dust storms shows a large increase. Clements et al (1963) reported that General Patton's training activities in the Desert Center-Parker area resulted in a great deal of disturbance to the surface soil. This caused an incidence of dust storms which was several times greater during this period, and for a few years thereafter, than would have occurred without disturbance. Clements also reported that increased dust occurred in the vicinity of the Yuma Test Station as a result of movement of tanks and other heavy equipment.

Oliver (1945) studied dust storms in the western desert of Egypt with particular reference to their relationship to the war period of 1939-1945. The removal of vegetation and pulverization of surface soil by wartime activities resulted in an increase in the number of dust storms. Before the war years dust storms averaged three or four a year. During 1939, the first year of the war, the number rose to 40 . The peak of war activities in 1941 coincided with a maximum number of 51 dust storms. As activities decreased during the later years of the war, the number of dust storms decreased to 20 in 1942, increased to 26 the next year, and dropped to only four in 1944. Inspection of vegetation, rainfall, and humidity records during these years led to the conclusion that the increase in dust storms and then the return to normal was a direct result of military activities.

\section{Threshold Velocities for Soil Erosion by Wind and Soil Erodibility}

An increase in the frequency of desert dust storms results from a decrease in the threshold velocity for wind erosion of a given desert surface. Lowered threshold velocities will also result in much greater total amounts of wind erosion. Winds in excess of 50 miles per hour are extremely rare in the desert Southwest and probably only occur as gusts. Furthermore, winds in excess of 30 miles per hour can be expected about 1 percent of the time and those over 45 miles per hour only a small fraction of 1 percent of the time. Therefore, lowering of threshold wind erosion velocities of stabilized desert surfaces to threshold wind velocities which occur much more frequently will lead to a large increase in the frequency of dust storms (Clements et al, 1963).

Several experimental studies have been made of idealized soils consisting of loose, monodisperse, and similar particles (Greely et al, 1973; Ishihara and Iwagaki, 1952; Chepil, 1951; and Bagnold, 1941). Very little information exists on threshold wind velocities for undisturbed and disturbed desert soils to determine which surfaces are the largest producers of fugitive dust (i.e., those soils with the lowest threshold velocity). To determine the effects of vehicular traffic on different types of desert soils, a BLM contract was awarded to Dr. Dale A. Gillette of the University of Colorado-CIRES, Boulder, Colorado, to measure soil wind erosion threshold velocities with an open-bottomed portable wind tunnel for soil surfaces in disturbed and undisturbed conditions (Gillette, 1978). 
Soils were disturbed by a $3 / 4$ ton truck on 34 sites representing a large variety of desert soils in the Mojave Desert (Figure 1.1). It was determined that disturbance of the soil profoundly lowers the threshold velocity of most desert soils (Gillette et al, 1979).

Wind speed data were collected at several heights above the surface. The mean velocity vs height data were fitted to the function for aerodynamically rough flow (Priestly, 1959) in the form:

$$
\mathrm{u}=\frac{\mathrm{u} *}{\mathrm{~K}} \ln \frac{\mathrm{Z}}{(\mathrm{Zo})}
$$

Where $u^{*}$ is the friction velocity, Zo is roughness characteristic of the surface height, $\mathrm{Z}$ is the height, and $\mathrm{K}$ is Von Karman's constant using a nonlinear least squares routine. The threshold velocity profile was obtained for that profile at which continuous movement of grains was first visible. Obtaining threshold velocity as friction velocity is useful because wind velocity varies with height and friction velocity gives a characteristic value for soil surfaces independent of height. However, for ease of understanding, friction velocities will subsequently be discussed in terms of their correspondence to wind velocities (in miles per hour) at a height of 6 feet, a more readily comprehensible value.

Increasing threshold values of wind erosion for different types of desert surfaces occurred in the following order (see also Table 3.1):

1. Disturbed soils except in playa centers.

2. Undisturbed sand dunes.

3. Sandy soils with undisturbed surface crusts.

4. Some disturbed playa center soils.

5. Skirts of playas (undisturbed).

6. Undisturbed desert pavements and undisturbed playa centers and some disturbed playa centers.

Sand dunes and sandy washes have low threshold wind erosion velocities whether in a disturbed or undisturbed condition. Therefore, disturbance of these areas will have small effects on frequency of dust storms. Some dry playas (e.g., El Mirage, Emerson, and Soggy Dry Lakes) showed a large reduction in threshold erosion velocities after disturbance but in these cases the layer of loose material was very thin and the total amount of soil eroded from the surface would be small unless a very large area of playa surface was disturbed. In other cases disturbance of playa surfaces produced large fragments which retained very high threshold velocities. Threshold velocities of wet playa surfaces were high with or without disturbance. 
Disturbed areas on East Cronese Lake, California showed different mudcracking patterns than undisturbed areas. Subsequently, and without further vehicle impact, the surface materials in some use zones crumbled to very light weight small clods and dust that are transportable by wind. Unused surfaces, despite having a thin crust, did not crumble (Wilshire and Nakata, 1976).

The areas of most concern are those where there will be a large decrease in threshold erosion velocity after disturbance. This will occur on soils protected by surface crusts (except for some playa soils as discussed previously) or desert pavement. The threshold erosion velocity of the undisturbed soils protected by crusts (and generally surface gravel) increased with increasing hardness of surface crust. For example, soft crusts of sandy soils had threshold erosion velocities which correspond to a wind velocity of 50 miles per hour (very rare winds) at 6 feet, whereas slightly hard crusts of undisturbed silt loams at the margin of playas had threshold velocities greater than 100 miles per hour (essentially unerodible). After disturbance, the soils showed little difference in threshold erosion velocities with values usually around 20 to 30 miles per hour (frequent winds). Therefore disturbance of these soils will increase their potential for erosion from infrequent or never to frequent. The siltier soils (which have the harder crusts) will have a greater relative decrease in threshold velocity after disturbance than sandy soils. The siltier soils will also produce a much greater amount of fine material capable of very high rates of dust emission and long distance transport after disturbance. Areas of silty soil protected by well-developed crusts are often located on the fringes of playas. These soils often contain considerable salt which may also be transported by wind after disturbance.

We11-developed, undisturbed desert pavement has the greatest resistance to wind erosion of any soils. These soils were essentially unerodible except for a few sand grains between the pebbles which blew out at. velocities between 56 and 96 miles per hour in different areas of desert pavement. After disturbance, the wind erosion threshold velocity was around 30 miles per hour. The threshold velocity of disturbed desert pavement soils generally did not drop as low as values of disturbed soils protected from wind erosion only by crusts and surface gravel because the surface fragments of the disturbed desert pavement remained mixed in with surface soil to a considerable extent, affording some additional protection to wind erosion. However, the typically silty soils underlying desert pavement have a greatly increased susceptibility to wind erosion after disturbance.

Gillette determined that soil characteristics other than surface hardness can be related to threshold erosion velocity. The size distribution of loose soil aggregates on the surface has been found to be practically the same as the size distribution of the saltating or winderosion-driving grains (Gillette and Walker, 1977). The Mojave Desert studies done by Dale Gillette and the BLM show that the threshold velocity increases approximately as the 0.41 power of the size of the mode (the most frequent value) of the soil aggregate size distribution. A field measurement of soil aggregate size distribution could be used as a rough predictor of threshold wind erosion velocity. 
Another field measurement to predict effects of ORV activity on wind erosion would be a measurement of the fraction of soil mass in aggregates smaller than $1 \mathrm{~mm}$. The Gillette-BLM studies showed that the threshold velocity decreases with increasing fractions of soil material smaller than $1 \mathrm{~mm}$. Erodibility indices have been constructed using the fraction of soil mass smaller than $1 \mathrm{~mm}$ (Bisal and Ferguson, 1970) or smaller than $0.84 \mathrm{~mm}$ (Chepil and Woodruff, 1963). The effect of aggregation reflects increased soil cohesion, which requires larger wind forces for the onset of wind erosion. The fraction of soil smaller than 0.84 $\mathrm{mm}$ is used in the Wind Erosion Equation (Chepil and Woodruff, 1963) to predict soil losses. Soils with larger proportions of finer material will have greater total wind erosion in addition to lower threshod velocities. The Wind Erosion Equation is not suitable for use in calculating actual ORV-caused soil losses in the desert in its present form (not devised for short distances of disturbed soil or areas of limited vegetation cover such as occur in the desert), but the data relating nonerodible fraction to soil erodibility can be used to determine relative potential of soil for wind erosion. Dale Gillette used $1 \mathrm{~mm}$ as the boundary between erodible and nonerodible size fractions because it has been used by others (Bisal and Ferguson, 1970) and because $1 \mathrm{~mm}$ corresponds to the dividing line between coarse sand and very coarse sand. The distinction between erodible and nonerodible sizes is not exact but is taken to occur at or slightly less than $1 \mathrm{~mm}$ in size so either size can be used as long as it is done consistently.

The fraction of soil samples smaller than $1 \mathrm{~mm}$ (or $0.84 \mathrm{~mm}$ ) can be easily determined by dry sieving. The sample is gently shaken in a circular motion (25 shakes for sands and loamy sands; 30 shakes for sandy loams, fine sandy loams, very fine sandy loams, loams and silt loams; 35 shakes for clay loams, sandy clay loams, sandy clays, silty clays, and clays). After sticks and foreign material are removed the percentage of mass in particles smaller than $1 \mathrm{~mm}$ is determined. The test should be made in the field so that transport will not break soil aggregates. If quantitative data are desired to compare potential of different ORV areas for increased wind erosion, such measurements could be made on disturbed and undisturbed sites.

Gillette derived equations to relate threshold erosion velocities $\left(u_{*_{t}}\right)$ to soil surface properties. A summary formula for undisturbed soils is:

u*t $\longrightarrow \quad 200{\mathrm{~cm}-\mathrm{sec}^{-1}}^{-1}$

for clay content greater than $20 \%$ and

$u_{* t}=390-3.3 \mathrm{~s} ; \mathrm{r}=0.72$

where S is \% sand for clay content less than $20 \%$

A summary formula for disturbed soils is

20

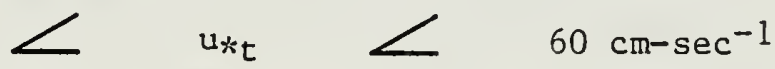

for sand content greater than $90 \%$ and

$u_{* t}=14.5+0.007111+1.59 \mathrm{C} ; r=0.77$ 
for sand content less than $90 \%$ where $M$ is the mode of dry aggregate size distribution and $C$ is the percent colloidal clay (percentage of soil mass in particles less than 0.5 um in dia.). Threshold velocities for undisturbed soils depend on soil textures, fine soils having high threshold velocities and sandy soils have lower threshold velocities. On disturbed soils threshold velocities of finer pulverized soils are lower whereas coarser pulverized soils having higher fine clay content have larger threshold velocities.

\section{Other Factors Affecting Susceptibility of Soils to Wind Erosion}

Wind erosion will not only depend on erodibility of soil but also on a number of other factors such as width of the disturbed area (erosion fetch). The rate of erosion per unit area increases with increasing fetch and finally reaches a maximum value. The maximum value is reached in a much shorter distance on disturbed soil than on undisturbed soil. This occurs because erosion results to a large extent from saltation (bouncing) of sand grains which displace additional soil particles. This motion transfers momentum by collisions of particles originating upstream and thus supplements direct aerodynamic pickup from the soil. Chepil (1951) called the effect of increased sand flux with distance the "avalanche effect."

Because saltating grains are so much more readily dislodged in loose soil, the maximum rate of erosion can be reached in a relatively short distance in contrast to undisturbed soil where maximum erosion rates may not occur except with fetches of hundreds of meters. Wilshire (unpublished data) reported that fetch widths in undisturbed soils of about 5 meters or less are sufficient to bring about significant wind erosion of soil. Gillette (1978) contrasted rate of wind erosion with lengths of fetch ranging from $21.7 \mathrm{~cm}$ down to much shorter distances. The data indicated that the rate of increase in erosion rate was extremely large as fetches were increased to about $5 \mathrm{~cm}$ followed by a relatively slower rate of increase. As fetch was increased from about $11 \mathrm{~cm}$ to $21.7 \mathrm{~cm}$, the amount of airborne soil produced per unit area increased by about $20 \%$. The rate of erosion per unit area was still increasing when erosion fetch was increased to $21.7 \mathrm{~cm}$, so longer fetches would be required to reach equilibrium. Chepil and Milne (1941) ran tests of loose soils in a wind tunnel and the distance required for soil movement to reach an equilibrium was found to be from 8 to 30 feet, depending on the average size and the size distribution of the particles carried. The longer distances were required to reach equilibrium for the soils with particles of larger average sizes.

Many narrow tracks which are separated from other tracks by undisturbed areas will have significantly lower rates of wind erosion at a given wind speed than would occur with longer fetches such as a dirt road or relatively large pit area. However, if tracks remain susceptible to erosion for a considerable length of time (no significant rainfall) most soil particles smaller than about one millimeter in diameter may be removed from the track surface by strong winds. 
Soil particles susceptible to long distance transport are primarily those less than $0.02 \mathrm{~mm}$ in size (Gillette, 1977). Gillette stated that the ratio of fine particle emission to total soil movement is dependent on soil texture, wind speed, mineralogy, and possibly physical weathering. Gillette concluded that, in general, soils having finer textures produced more fine dust for unit soil movement. Soils with high concentrations of clay, which may remain in an aggregated form even after disturbance, would be an exception to this generalization.

Losses of topsoil, plant nutrients, and organic matter, and changes in soil texture by wind erosion have been used to imply lower productivity of soils (Chepil et a1., 1962; Daniel 1936; Daniel and Langham, 1936, Moss, 1935). Typically wind erosion would cause productivity to be decreased more as a result of loss of nutrients than as a result of decreasing the depth of soil. Some nutrients may be concentrated under shrub canopies by recycling whereas concentrations may be much lower in shrub interspaces. Disturbing surface soil and increasing susceptibility to wind erosion in sites with higher concentrations of nutrients may lead to disperal of essential nutrients such as nitrogen or phosphorous and reduce the number of locations which are the most favorable for plant growth.

\section{F. Hazards of Dust}

\section{Physical Hazards}

Fugitive dust may increase hazards to traffic. A study of dust hazards (Arizona State University, 1976) reported a strong association between sparsely vegetated, abandoned farmland and dust-related accidents on I-10. Sixty-eight percent of the accidents occurred in three small clustered areas on highway sites adjacent to abandoned farmland. The dust from abandoned farmland is enhanced by activities which disrupt the soil crust and make sediments available to the wind; off-road vehicles and livestock were reported to be major causes of surface disruption.

\section{Biological Hazards - Valley Fever}

Health effects from biological components of dust may be greater in some locations than from the mineral components. Leathers (1977) reported biological components of desert dust in Arizona. Such analysis of dust has been done at numerous sites in Arizona since 1965. The analysis of dust from Arizona deserts may give some indication of dust components which could be in the California deserts. Pollen from more than 55 species of higher plants was recognized, many of which are known to be important causes of human allergy. Spores of 74 different genera were found, representing more than a hundred species. Several of the fungal spores are known to cause allergies and 15 different species of fungi were found which produce various diseases in man and animals. These include ring worm, athlete's foot, and various respiratory infections including aspergillosis and valley fever (coccidiodomycosis). Valley fever caused more than 20 deaths in Arizona in 1975 and several hundred people were hospitalized for various periods of time. Of 329 dust samples collected at or near the soil surface in Arizona desert areas from 1973 to 1976, 28 were found in California deserts (Lacy, 1971). Dust raising activities have been reported to be an important method of spreading the disease. 
Beginning in September 1977, Chester R. Leathers of Arizona State University at Tempe, has been searching for valley fever in soil samples collected from BLM lands in the California desert (see Figure 1.1). Eleven of the samples were collected on filters in aircraft traveling 100 to 600 feet above the surface of the ground. None of the aircraft samples contained valley fever. Over 500 samples were collected from the entrance to rodent burrows occurring on the north or east side of each bush. Two of the soil samples were positive. These samples were collected in Johnson Valley approximately $\frac{1}{2}$ kilometer north of the pit area. All the mice injected with the suspension of the soil from these samples revealed the diagnostic spherules bearing endospores, confirming the existence of the pathogen in the sample.

Although valley fever fungus has only been identified in Johnson Valley, it cannot be stated emphatically that the fungus does not occur in the other sites sampled because only a small part of each could be sampled. The collection of so many negative samples is worthwhile information because tests for presence and abundance of valley fever fungus have not been done previously in these areas.

The fungus is difficult to locate because it appears to occur in a very limited, spotty distribution. Huppert (1968) pointed out that a major gap in our knowledge of Coccidioides immitis is lack of knowledge as to why the fungus should be so limited in its natural distribution. Plunkett and Swatek (1957) and Swatek et. al. (1967) also reported on the spotty distribution of the fungus in the soil. At one site, an area of approximately $1 \mathrm{~m}$ by $2.5 \mathrm{~m}$ was positive since 1954 at least until the conclusion of an M.S. thesis by Lacy (1971), whereas the surrounding soil had only sporadic positives. Maddy (1965) also found an uneven, but repeatable pattern in his soil isolation work in Arizona. Because of the sporadic nature of the distribution, a very large number of samples may be needed to confirm the presence of the organism in an area.

Leathers has found several fungi in the present study which are indistinguishable or nearly so from Coccidioides when cultured, but which do not produce infections in mice. Some of these fungi produce abundant arthrospores which closely resemble those of the pathogen. Because some investigators have identified valley fever only from cultures, some of the non-pathogenic organisms which closely resemble valley fever may well have contributed to erroneous reports of the presence of valley fever in some locations in the deserts of California and elsewhere. Leathers uses the conversion of arthrospores to spherules and endospores in mice as a reliable test for the positive identification of valley fever.

Leathers (personal communication) reported that a Texas businessman who claimed to have contacted Valley Fever at the International Harvestor Co. proving grounds south of Phoenix has been awarded $\$ 72,000$ in damages in a Federal court suit. This is important because it is the first time that liability has been established relating to Valley Fever. 


\section{G. Impact of off-Road Vehicles on Soil Chemical Properties}

\section{Soil Chemistry}

The amount of investigation of soil chemical impacts has been less than for soil physical impacts. However, a number of studies have compared chemical properties in disturbed and undisturbed soil.

Babcock and sons (1973) compared soil pH, electrical conductivity (salinity), cation exchange capacity, and several extractable cations (calcium, magnesium, sodium, and potassium) in areas disturbed and undisturbed by ORV's. Soil organic matter was also determined. The number of samples was too low for conclusive statistical comparisons between disturbed and undisturbed areas, but the measurements give an indication of the effects of ORV's on the chemical properties determined. The authors concluded that no significant chemical differences were noted between disturbed and undisturbed soils for the chemical properties that were examined.

Webb et al (1978) and Wilshire et al (1978) measured ORV effects on organic matter and some chemical properties in central and northern California, respectively. Although the data were not collected in the desert, the results have applicability to the desert impacts. The data collected by these authors were from areas with much steeper slopes than the data collected by Babcock and sons (1973) and Skujins et al (1979).

Webb et al (1978) reported statistically significant decreases in organic matter, $\mathrm{pH}$, exchangeable calcium, and exchangeable magnesium in some areas where soil had been disturbed by ORV's at Hollister Hills. Wilshire et al (1978) reported that disturbed slopes in the San Francisco Bay Area generally had considerably lower contents of organic carbon than their unused equivalents, although a few samples had no significant difference or opposite results. Soil samples often showed some change, either to more alkaline or acidic values. Many of these soils were on moderately steep to very steep slopes, where considerable displacement of surface soils occurred, exposing deeper horizons which often have different chemical properties. Changes will depend on differences between surface and underlying soil whereas more level areas (such as those characterized by Babcock et al, 1973 and Skujins, 1979) where little or no erosion occurs would be expected to have smaller changes in soil chemical surface properties.

\section{Nitrogen - Fixation}

Skujins et al (1979) reported that pipeline road disturbance in the Kelso Dunes area appeared to reduce total and exchangeable $\mathrm{NH}_{4}^{+}-\mathrm{N}$ and nitrogen fixing capacity of soil organisms. Off-road vehicle disturbances in Johnson Valley and Stoddard Valley appeared to cause no decrease in total and exchangeable $\mathrm{NH}_{4}^{+}-\mathrm{N}$, nitrogen fixing capacity of soil organisms and total nitrogen (measured only in Johnson Valley) in some areas disturbed by ORV's. The data are not completely conclusive, however, because the study was designed to look for trends with "spot checks" rather than with a larger amount of sampling which would give a higher degree of certainty. 
Skujins et al speculated that vehicle impacts may not have negative effects on nitrogen fixation if they are not in areas that are continuously disturbed. They speculated that tire tracks could provide favorable microclimates for algal (some algae fix nitrogen) growth as water may collect in the depressions and retain moisture for growth. A continuously disturbed area (such as the road measured in the Kelso Dune area) may have a much greater impact on nitrogen fixation in desert soils.

\section{H. Longevity of ORV-Caused Visual Impacts}

A BLM memorandum (Badaracco and Branson, 1976) reported on the visual condition of former race routes (ranging from 1972 to 1974) in the Eastern Mojave Desert. Photographs were made to document the effects. Routes were in a variety of terrain types, such as sand dunes, desert playas, creosote-covered flats, alluvial fans, semi-pavement areas, and upland areas.

It was concluded that tracks remained visually obvious after races in all areas except where race routes had crossed dune sand areas or where very heavy rains with heavy runoff and sheet erosion and intense splash erosion had obliterated tracks. It was reported that most of the routes had not undergone any substantial recuperation beyond initial tread smoothing and reformation of crusts. In the sandy flats of the Cadiz Valley, fresh tracks contrasted sharply with the undisturbed soil surface. It appeared that the very high initial degree of contrast rapidly diminished but that additional change was slow. No substantial visual difference in 1976 was noted for 1972, 1973, and 1974 race courses in the same terrain types. It was concluded that the 1972 course was the most visually impacted of the courses. Pre-1972 race courses were also reported to be quite evident.

Closely-spaced sequence of depressions created by bouncing ORV's (whoop-dee-doos) were noted to be especially obvious in low angle (early morning and late afternoon) light. Disturbances in semi-pavement situations (would be worse in well-developed pavement) or sandy flats sprinkled with sparse, black pebbles remained very highly visible after reformation of the crust. It appeared that disturbance in these areas would remain visible for long periods of time.

Table 1.5 contains percentages of desert pavement surface disturbance on some low-level aerial photographs taken in areas with ORV activity. These values indicate that traffic on desert pavement is producing visual impacts which will be very long lasting.

Wilshire and Nakata (1976) noted visual impacts after the 1974 Barstow-Las Vegas race. Compaction on East Cronese and West Cronese lakes strongly modified the mud cracking behavior of the surface. The trends from areas of low to high impact by vehicles are decreasing size, depth, symmetry, and increasing size range of mud cracks. Soda Lake, a playa which remains wet most or all of the time due to a high water table, was reported to have highly visible wheel tracks which were made in the early 1930's (Final BLM EIS for Barstow-Las Vegas Motorcycle Race, 1974). This could also occur on a dry playa if driven on when wet, so that deep, compacted ruts are formed. Wilshire and Nakata (1976) reported that vehicle tracks on Soda Lake are made more visible by salt crystals that have been precipitated from water ponded in the tracks. 
The potential longevity of tracks is suggested by the visibility of prehistoric Indian intaglios, which were constructed by scraping aside a surface layer of darkened pebbles to expose lighter material beneath. 0ld desert wagon trails, unused for 60 years or even 80 years in Death Valley (Hunt and Mabey, 1966, and Hunt et al, 1966) and unused for over 100 years between Needles and San Bernardino Mountains (Davis and Winslow, 1966), remain visible.

Nitrate channel sample grooves little wider than a motorcycle track were reported to have survived since 1912 on ancient lake beds near Shoshone, California (Sharp, 1972). The grooves localized runoff and have become erosional scars. Automobile tracks made on Cadiz Dry Lake were reported by Bassett and Kupfer (1964) to stand above the less compacted surrounding surface, which was lowered by erosion. Tracks made by General Patton's tanks, trucks and jeeps on practice maneuvers in the California desert in the early $1940^{\prime}$ 's remain clearly visible today.

BLM studies in.Stoddard Valley and Johnson Valley (Chapter 5) have shown that whereas a single pass of 4-wheel drive vehicle tracks on three different surface soils composed of dry gravelly sandy loam, loamy sand, and sand may be barely visible after a year, multiple 4-wheel drive passes (five or more) on dry soil or even one motorcycle pass or 4-wheel drive pass on wet soil remain clearly visible after 2 years. Therefore, the permanence of vehicle tracks will depend to a large extent on soil moisture at the time of impact. There is a greater potential for longevity of visual impacts on highly compactable wet soil. In areas with greater slopes, erosion in the track can also greatly increase visibility of the disturbance.

Webb and Wilshire (unpublished abstract, 1979) measured bulk densities in Wahmonie, a Nevada ghost town which was abandoned in 1928. Bulk densities varied from $1.96 \mathrm{~g} / \mathrm{cm}^{3}$ for the active road to $1.71 \mathrm{~g} / \mathrm{cm}^{3}$ for the main avenue (18 years old), $1.66 \mathrm{~g} / \mathrm{cm}^{3}$ for the trampled townsite (51 years old), and $1.50 \mathrm{~g} / \mathrm{cm}^{3}$ for the adjacent undisturbed area. Mean penetration depths and infiltration rates varied from $1.9 \mathrm{~cm}$ and 2.6 $\mathrm{cm} / \mathrm{hr}$ in the active road to $4.3 \mathrm{~cm}$ and $3.4 \mathrm{~cm} / \mathrm{hr}$ in the old main avenue, $8.5 \mathrm{~cm}$ and $12.8 \mathrm{~cm} / \mathrm{hr}$ in the townsite, and $10.7 \mathrm{~cm}$ and $19.6 \mathrm{~cm} / \mathrm{hr}$ in the undisturbed area. They speculated that recovery may require a century.

I. Overall Extent of ORV and Military Activity in the California Desert

\section{Areas of Disturbance Associated With Race Courses}

The area of surface disturbance was calculated after the 1974 Barstow-Las Vegas motorcycle race (BLM, 1975). Estimates were made from 26 Environmental Sampling Photo Plots, vertical $70 \mathrm{~mm}$ color aerial photography before and after the race, and black and white oblique aerial photos at the start, finish, and pit areas on race day. It was estimated that in the impacted area $40 \%$ of the ground was covered by tracks. The area containing disturbances was estimated to have increased by 660 hectares (31\%) over the area of eight previous Barstow-Las Vegas races. 
Table 1.5

Estimates from low-level aerial photographs (1: 1000), of percentages of total areas of desert pavement which have been disturbed by off-road vehicle activity in some free-play areas. None of these areas are necessarily highly compacted.

Location $T$

Adjacent to

Homer Wash

Adjacent to

McCoy Wash

Adjacent to

Milpitas Wash

N. of Orocopia

Mountains
T.

$15 \mathrm{~N}$.

$5 \mathrm{~N}$.

$1 \mathrm{~N}$.

19 E.

$6 \mathrm{s.}$

12 E.

21 E.
Sec.

29

$4 \%$

27

$11 \%$

24

$7 \%$

17 
In sandy locations, tracked areas increased greatly. Motorcycles swerved to retain control in the soft sand, increasing the width of the disturbed area. Deep ruts formed in the soft sand and the sides caved in, causing a greater width of disturbance per track than areas with more aggregated soils. Spreading did not occur along washes because vehicles were concentrated by the confining sides of the drainage. On vegetated flats or alluvial fans, motorcycles concentrated on a few tracks to avoid bushes. On steeper slopes more power was applied and displacement of soil increased. Motorcycles fanned out to the smoothest surfaces on playas for speed and to pass, resulting in a large impacted area. The dirt roads had the smallest increase in adjacent area disturbed by tracks. Motorcycles generally remained on roads where they encountered the least resistance at high speeds. Most of the roads were located past the half-way point of the race where the vehicles were most dispersed along the course, resulting in less passing. The greatest increase in number of tracks occurred at the finish area where many tracks were created by 4 -wheel drive vehicles and campers as well as by motorcycles.

Observations were made along the unauthorized El Cajon motorcycle race course which was driven on December 3, 1972 (BLM, 1975). The race consisted of four laps by about 215 motorcycles over a distance of 33.3 $\mathrm{km}$ per lap. Random measurements of course widths over the entire length produced an average width of disturbance to soil surface and vegetation of 4 meters. Motorcycles dispersed to widths of over 9 meters for short distances after abrupt turns. Following dispersion, tracks generally converged to single course widths which varied from 1.2 m to $5.5 \mathrm{~m}$.

The race course covered some areas which had been previously disturbed (primarily a trail which was increased from an average width of $3 \mathrm{~m}$ to 4 $m$ as a result of the race). Additional area disturbed by the 1972 race was calculated to be 20.5 hectares. Two large funnel shaped areas were disturbed at the start line and at one turn in the race trail where motorcyclists repeatedly cut the corner.

It was concluded that soil compaction over most of the area was not increased appreciably. This was due to dry soil and the lateral spread of motorcycles during the race. There was some indication that significant deflation by wind may have occurred because some tracks which had a loose layer of fine sand and silt up to $10 \mathrm{~cm}$ in depth immediately following the race were reported to have similar loose layers of only $1.3 \mathrm{~cm}$ to $5.1 \mathrm{~cm} 1$ month later.

Much desert pavement along the course was disturbed. In most areas of concentrated use of trails, surface rocks up to $3.8 \mathrm{~cm}$ in size were buried in soil at a depth of up to $7.6 \mathrm{~cm}$ and larger rocks were displaced, producing a sharp contrast in appearance to adjacent, undisturbed desert pavement. Disturbance of the desert pavement produced a flour-like, loose soil which was very vulnerable to movement by wind and water. Nearly all surface pavement was disturbed where trail widths narrowed to around $1.2 \mathrm{~m}$. Where trail widths approached $5.5 \mathrm{~m}$, up to $80 \%$ of the pre-existing rock pavement was displaced. 
Table 1.6

Summary Table Evaluating ORV \& Military Activity ${ }^{1}$ - Desert Wide

\begin{tabular}{lll} 
High Use Areas & ICMP $^{2}-$ Open Areas \\
\cline { 2 - 3 } $\begin{array}{l}\text { camping, pit (Ac.) } \\
\end{array}$ & Areas with many highly & Hill climb \\
& ORV Areas (Ac.)
\end{tabular}

\section{BLM}

Ownership

88

1,652

3,320

294

Mixed

Ownership

868

12,343

20,055

927

Private

Ownership
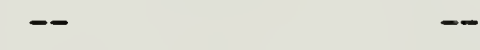

956

13,995

23,375

1,221

Existing Roads \& Trails

$\begin{array}{ll}\text { High Use Areas } & \text { Areas with Many Highly } \\ \text { Camping, Pit (Ac.) } & \text { Compacted Trails (Ac.) } \\ & \text { ORV Military \& ORV }\end{array}$

BLM

Ownership

14

1,190

19,070

115

Mixed

Ownership

244

22,742

23,265

3,664

Private

Ownership

15

2,838

$-$

943

Sub Total

267

26,770

40,765

42,335

65,710

4,722

Hill Climb

Areas (Ac.)

Total

1,229

106,475

5,943

1/ Military Activity includes tank tracks and ORV activity. Areas with many highly compacted trails - range from 13 to 73 highly compacted trails/kilometer.

2/ ICMP - Interim Critical Management Program - 1973 (BLM's Management Program for vehicle use on the California Desert). 
Table 1.7

Evaluation of ORV and Military Use Areas Using Aerial Photographs

\begin{tabular}{llll}
\hline ORV & High Use Areas & Areas with Many Highly \\
Area's & Camping, Pit (Ac.) & Compacted Trails (Ac.) & Hill Climb \\
Area (Ac.)
\end{tabular}

1) Panamint Dunes

2) Panamint Valley

3) Olancha Dunes

4) Dumont Dunes 60

5) Spangler Hills 39

405 36

6) Rand Mtn. Area

88

1,620

328

7) Dove Springs

8) Jawbone Canyon

9) Bristol

21

10) Stoddard Valley

11) El Mirage

12) Johnson Valley

13) Painted Canyon

14) Oricopia

15) Blythe

16) McCoy Valley

17) Arroyo Salada

18) North Algodones

19) Plaster City

20) Yuha

21) South Algodones

22) Shadow Mtn.

23) Ward Valley

9,450

24) Fremont Peak Area 
Table 1.7 Con't.

\begin{tabular}{|c|c|c|c|c|}
\hline & $\begin{array}{l}\text { ORV } \\
\text { Area's }\end{array}$ & $\begin{array}{l}\text { High Use Areas } \\
\text { Camping, Pit (Ac.) }\end{array}$ & $\begin{array}{l}\text { Areas with Many Highly } \\
\text { Compacted Trails (Ac.) }\end{array}$ & $\begin{array}{l}\text { Hill Climb } \\
\text { Areas } \\
\end{array}$ \\
\hline 25) & North of Barstow & 9 & 356 & 17 \\
\hline & West of Soda Lake & 2 & 91 & \\
\hline 27) & $\begin{array}{l}\text { Red Rock Canyons } \\
\text { Sierra Canyon }\end{array}$ & 28 & 1,115 & 235 \\
\hline & Calico Mtn. Area & & 42 & \\
\hline 29) & $\begin{array}{l}\text { West of Hesperia } \\
\text { Hwy. } 395\end{array}$ & 15 & 2,776 & 858 \\
\hline 30) & East of Helendale & & 113 & 18 \\
\hline 31) & Barstow Area & 2 & 178 & 45 \\
\hline 32) & Needles Area & & 35 & \\
\hline 33) & Milpitas Wash & & 1,870 & \\
\hline 34) & Chocolate Mtn. & & 11,080 & \\
\hline 35) & Yuha Area & 12 & 304 & \\
\hline 36) & Rabbit Lake & 3 & 326 & \\
\hline 37) & West of Cuddeback & 1 & & \\
\hline 38) & Turtle Mtn. & & 14,770 & \\
\hline 39) & Iron Mtn. Area & & 4,300 & \\
\hline 40) & Arrowhead Junction & & 995 & \\
\hline 41) & Desert Center Area & & 80 & \\
\hline 42) & Afton Canyon & & 20 & 6 \\
\hline 43) & California City & 13 & 1,674 & 48 \\
\hline 44) & Mesquite Lake & & 120 & \\
\hline 45) & Pahrump Lake & & 90 & \\
\hline 46) & Ivanpah Lake & & 210 & \\
\hline 47) & Soda Lake & & 15 & \\
\hline 48) & Silver Lake & & 37 & \\
\hline 49) & Danby Lake & & 185 & \\
\hline 50) & Coyote Lake & 39 & 190 & \\
\hline
\end{tabular}


Table 1.7 Con't $^{\prime}$

\begin{tabular}{|c|c|c|c|c|}
\hline & $\begin{array}{l}\text { ORV } \\
\text { Area's }\end{array}$ & $\begin{array}{l}\text { High Use Areas } \\
\text { Camping, Pit (Ac.) }\end{array}$ & $\begin{array}{l}\text { Areas with Many Highly } \\
\text { Compacted Trails }\end{array}$ & $\begin{array}{l}\text { Hill Climb } \\
\text { Areas }\end{array}$ \\
\hline 51) & Superior Lake & & & \\
\hline 52) & Cadiz Lake & & & \\
\hline 53) & Silurian Lake & & & \\
\hline 54) & Tehachapi Mtn. & 8 & 4,291 & 760 \\
\hline 55) & Ke1so Valley & 4 & 1,204 & 962 \\
\hline 56) & Walker Pass & & 228 & 115 \\
\hline 57) & Apple Valley Area & & 638 & 326 \\
\hline 58) & Adelanto Area & 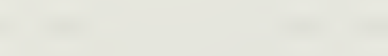 & 62 & 85 \\
\hline 59) & South Johnson Valley & & 26 & 38 \\
\hline 60) & Ocotillo Area & 2 & 34 & 10 \\
\hline 61) & Chemehuevi Valley & & 1,640 & \\
\hline \multicolumn{2}{|c|}{ Total } & 1,229 & 106,475 & 5,943 \\
\hline
\end{tabular}


Rehabilitation was attempted on the disturbed desert-pavement soils with several methods. These included hand raking, hauling and spreading gravel, restoring gravel with a spring tooth harrow and tractor, and protecting the surface with soil sealants. Hand raking restored about $80 \%$ of the buried gravel and rock bank onto the soil surface. The primary disadvantages were that the treatment was very slow and soil was left in a loosened condition.

Hauling and spreading of gravel from a nearby gravel pit produced a cover which duplicated fairly well the natural cover. However, there was some difference in color between the native desert varnished rock and the imported gravel. Also, additional damage was caused by large dump trucks traveling over the soft ground.

Tests with a 12 horsepower tractor and a 4-foot wide harrow with teeth spaced 1 inch apart resulted in a 60-80\% restoration of gravel to the surface. The soil surface remained loose after disturbance but applications of water after harrowing settled the soil to a more natural appearance.

The BLM report stated that soil stabilization was attempted with petrochemical polymers and soil sealants. Results of the tests were not given. It was estimated that 500 to 600 gallons of water per acre would be needed for the treatment.

The BLM report concluded that use of the tractor and harrow appeared to be most promising of all methods considered. It was recommended that hand-hoeing and watering be used to enhance the tractor and harrow treatment.

\section{Aerial Extent of Concentrated ORV and Military Use Zone}

An evaluation of off-road vehicle impacts on soil throughout the CDCA was made from aerial photographs (Tables 1.6, 1.7). Field experience has shown that ORV impacts follow certain patterns. Highly concentrated use areas such as pit areas and camping areas have been shown to have very high soil compaction with virtually no vegetation. Extending from these highly concentrated use areas are many highly compacted trails. With increasing distance from those pit areas or campsites the number of highly compacted trails decreases. Pit areas which are heavily used for starting races usually are surrounded by many compacted trails that extend over long distances.

Two types of aerial photographs were used in this evaluation: natural color photos at a scale of $1: 20,000$ (3.1"/mi.) taken during 1973-1974 and black and white photos at a scale of $1: 30,000(2.11 / \mathrm{mi}$. taken during 1977-1978. Most of the areas were covered by the 1977-1978 photos. Low level, color photos at a scale of $1: 1,000$ were also used to evaluate the highly compacted trails.

Initially the aerial photos $(1: 20,000$ and $1: 30,000)$ of all the ORV open areas were gathered and grouped. After evaluating several high use areas, it was decided that several categories of ORV impact could be determined from these aerial photos. The following areas were determined to be identifiable from the scale of the aerial photos being used. 
1. Very high use areas where camping and racing pit activities occur. These areas have very high soil compaction ( $>6001 \mathrm{~b} / \mathrm{in}^{2}$ for wet soil). Vegetation has been removed by the high use in these areas.

2. Areas with many highly compacted trails are zones radiating from the high use areas. Soils are highly compacted within these trails $(>400$ lb/in. ${ }^{2}$ ). Comparisons of the larger scale aerial photographs with $1: 1000$ aerial photographs made within the same areas showed that trails as narrow as about one foot with high contrast could be recognized in the $1: 30,000$ scale photos. Even though narrower trails couldn't be seen in the high altitude photos the presence of the wider trails in heavy-use areas allowed quantification.

In order to provide relative quantification of frequency of compacted trails within an area, a $1 \mathrm{~cm}$. transect was used on the photo and the number of visible highly compacted trails crossing this transect was recorded. Values from these transects in areas classified as having highly compacted trails showed a range of highly compacted visible trails of 20 to $115 / \mathrm{mi}$. The low level $(1: 1,000)$ aerial photos were used to estimate percent of highly compacted trails within representative areas. Trails created by very large numbers of vehicle passes were easily recognizable on the $1: 1000$ photos. A point grid was used to estimate cover values of trails. Generally a range of 5 to $10 \%$ of the surface was covered. Some areas of many highly compacted trails also contain areas of military activity such as tracks of tanks and trucks.

3. Hillclimb areas with very high use to few trails were identified and delineated.

All three areas were delineated on the aerial photos and measured using acreage grids which ranged in size from 2.5 to 40 acres.

After all the open areas were evaluated, we expanded our evaluation to other areas. Recreation maps were used to determine other areas of use and these were evaluated using the same procedures. Also the recreation personnel or rangers from various area offices were asked to verify the delineations and provide information on any additional areas which are being impacted.

These delineations show the very high impact areas and do not indicate the areas with moderate and light soil compaction which could affect vegetation. The areas with many highly compacted trails may also contain trails with less compaction but with a distinct visual impact especially occurring on well-developed desert pavement areas.

\section{J. Summary of Soil Impacts}

Most desert soils, including many sands, are susceptible to intense compaction if driven across a sufficient number of times. Heavily-used $\mathrm{ORV}$ areas in the desert such as pit areas, trails, and hillclimbs generally are intensely compacted. Some cohesionless sands, such as sand dunes, are very resistant to compaction whether wet or dry. Many playa soils will have considerable resistance to compaction if driven on when dry. 
Compaction produced in most other soils will depend more on vehicle characteristics, amount of vehicle activity, and soil water at the time of impact than on differences between soil properties. Compaction can best be avoided by restricting ORV activity to dry soils.

A single pass on dry soil with either 4-wheel drive vehicles or motorcycles appears to cause small amounts of additional compaction. Experiments have indicated that significant compaction (enough to reduce later annual growth) may result from as few as one vehicle pass by a 4wheel drive vehicle on much more susceptible wet soil. It appears that multiple passes along the same track of a motorcycle (at least a Yamaha 175) on wet soil or a 4-wheel drive vehicle on dry soil are required to produce very significant increases in compaction in comparison to undisturbed areas.

On campsite pit areas, severe soil surface compaction has been measured. Highly compacted trails on adjacent areas generally cover less than $10 \%$ of the surface.

Measurements made of effects of intense ORV use in steep areas (primarily hillclimbs on slopes over $20 \%$ ) show large increases in water erosion as well as mechanical displacement of soil. Increased runoff and sediment production has not been shown from single 4-wheel drive or motorcycle passes but experiments with heavy, simulated rainfall show increases in runoff and sediment movement from tracks made by multiple passes of 4-wheel drive vehicles or motorcycles even on fairly gentle slopes. On gentle slopes, runoff and sediment generally will collect in low parts of the space between shrubs, resulting in little movement offsite. However, where highly compacted trails run for long distances down gentle slopes, significant erosion may occur even on relatively level terrain with slopes as low as $3 \%$.

Severe water erosion, particularly in areas with shallow soil underlain by material impervious to roots, may greatly reduce potential for plant growth. This would most often occur on hill climb areas. Water erosion on deeper soils or soils with parent material which can be penetrated by roots will be less restrictive to growth of plants. Water erosion may also remove surface soil which has high concentrations of elements essential for plant growth. Accelerated water erosion in sites where shrubs are growing or have grown in the past can disperse elements which have been concentrated over a long period of time by recycling. This can reduce the number of desert sites which are very favorable to plant growth.

Dust levels around ORV races are typically well in excess of applicable air quality standards in areas of participants and spectator congregation. Long period (daily) dust exposure levels of participants and spectators of 10 times the standard are not uncommon and short term (hourly) dust levels of 100 times the daily standard may occur under adverse conditions near the activity. Studies have indicated that within 1 to 2 days after the event, total suspended particulate values appear to return to background levels. Dust will probably impact sensitive 
areas from 2 to 15 kilometers downwind of a racecourse, depending on meteorological conditions. Measurements showed that standards are exceeded in the vicinity of the race even for small races and on many sands. On the sand dunes, dust plumes from ORV's generally do not rise above a height of one meter behind the most active vehicle before settling clears the air within seconds. A future ambient air quality standard may be proposed by the EPA for respirable particles. The respirable aerosol mass near races may be as much as 10 times or more over levels considered unhealthy for sensitive individuals in the possible future standard. Dust generation varies greatly with changes in distance from the event, soil conditions including soil moisture, dispersive meteorology, and vehicle participation. Effective measures could be introduced to significantly lower dust from ORV events, including restricting events to soils lacking in fine particles.

Most desert soils are much more susceptible to wind erosion after disturbance than in an undisturbed condition. Exceptions include cohesionless sands (e.g., sand dunes) and some playa soils. Soils with a large fraction of coarse material will lose fewer particles to wind erosion than those with a smaller concentration of coarse fragments. The width of continuous disturbed area (erosion fetch) will have a major effect on erosion rate per unit area of disturbed soil. Longer areas of disturbance will have higher erosion rates per unit area of disturbed soil at a specific wind speed. Erosion rate per unit area of disturbed soil from wind blowing across a single vehicle track will be less than erosion rate per unit area of disturbed soil for a continuously disturbed area the width of a road. Separated tracks with intervening undisturbed soil will be less susceptible to high rates of wind erosion and dust emission than continuous areas of disturbance such as dirt roads or pit areas. Wind erosion and dust emission can be significantly reduced by limiting disturbance to less susceptible soils. These include soils with high existing wind erosion rates in an undisturbed condition which will not have appreciable increases in wind erosion with disturbance (such as unstabilized sand dunes) and soils with low existing wind erosion rates in an undisturbed condition which will retain low wind erosion rates in a disturbed condition (such as some playa center soils). Fine-textured soils tend to emit more fine particles upon unit soil movement unless the structure of the soil aggregates is highly resistant to breakage, so it is best to avoid disturbance of soils with high concentrations of fine particles such as the silty soils often found on playa margins or those underlying desert pavement. Soils with a high percentage of coarse material (over $1 \mathrm{~mm}$ in diameter) are much more resistant to wind erosion than soils lacking such coarse material.

Accelerated wind erosion may decrease soil productivity by removing surface soil which often has higher concentrations of elements essential to plant growth. The greatest effects would probably occur on soil where shrubs are currently growing or have grown in the past. Accelerated erosion on these sites can cause dispersion of high concentrations of essential elements produced by recycling and reduce the number of locations which are very favorable for plant growth. Displacement of such dust could conceivably improve the soil nutrient status of some other plant habitats. 
Valley fever has been located in two soil samples out of over 500 soil samples tested from the California Desert Conservation Area. Both of these samples were collected in the Johnson Valley Open Area. This shows that Valley Fever is not widespread through open areas but it may be present even where not confirmed because the distribution is so spotty that a very large number of samples may be required to show that Valley Fever is present in an area.

Soil chemical properties of surface soils appear to show the greatest changes on hillclimbs where displacement of surface soils exposes subsurface soil which may have markedly different chemical properties. Changes in soil chemical properties from ORV activity are less on more gentle terrain. Because large differences in soil chemical properties frequently exist between soil under shrub canopies (often have more available nitrogen and other essential nutrients) and soil between shrubs (often less of some essential elements), driving over shrubs may result in disturbance and dispersion of areas of soil with chemical properties highly favorable to plant growth.

Areas of soil disturbance may remain visible for very long periods of time. Evidence of soil disturbance readily disappears in sand dunes or washes or where heavy runoff and sheet erosion obliterate tracks. Rill or gully erosion occurring in disturbed areas may greatly increase visual impacts. Desert pavement is particularly susceptible to long lasting visual impacts even with light activity. 
II. SOIL CRUSTS

BY

PETER G. ROWLANDS

TABLE OF CONTENTS

Page

A. Introduction. . . . . . . . . . . . . . . . . . 47

B. Effects of Erosion on Cryptogamic Crusts............ 47



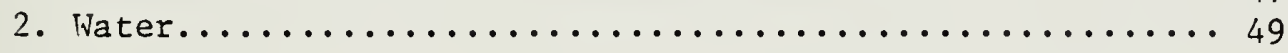

C. Biological Properties of Desert Soils and Soil Crust...... 57

1. Desert Microorganisms.................... 57



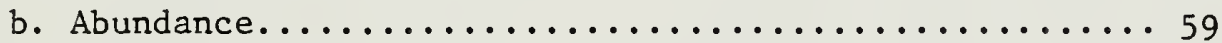

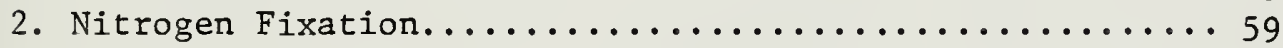





\section{A. Introduction}

The most favorable microhabitats in desert soils occur in cryptogamic (algal and lichen) soil crusts and on the undersurfaces of translucent or transparent materials (Diaphanous substrates) partially embedded in the soil surface (Cameron and Blank 1966). In arid and semiarid regions, algal crusts play important roles in the control of erosion by soil stabilization, control of water infiltration and penetration, modification of soil temperature regimes, as pioneer organisms in the initial stages of both primary and secondary succession, as contributors to the nitrogen economy of arid and semiarid soils (due to the presence of filamentous blue-green algae) and as accumulators of organic matter. (Cameron 1958, 1964a, 1964b, 1966; Moewus 1953; Fletcher and Martin 1948; Drouet 1937, 1943; Durrell 1962; Shields et al 1957; Elwell et al 1938; Llano 1962; Cameron and Blank 1966; Skujins et al 1979; Geolog. Soc. Am. 1977.)

The primary impact of ORV's and other mechanized vehicles is to destroy these surface crusts both by shear and compaction stresses (Geological Soc. Am. 1977; Stebbins 1974; Wilshire et al 1978; Harrison 1976). Once the surface crusts are destroyed or damaged, the possibility of soil loss due to wind erosion is greatly increased (Clements 1963). Conventional wisdom dictates that the biological functions of soil crusts would also be damaged or altered, particularly with regard to nitrogen metabolism; however, according to Skujins et al (1979), the effects of human activities on cryptogamic surface crusts in arid areas is, in general, poorly understood. In a strict botanical sense, the presence of soil crust is not always advantageous and, in fact, may be detrimental to seed germination and seedling emergence; soil crusts reduce water infiltration, increase runoff and water erosion and reduce plant water-use efficiencies (Miller and Gi:ford 1975).

\section{B. Effects of Erosion on Cryptogamic Crusts}

\section{Wind}

Except for heavy clay soils and salt crusts in the middle of playas, disturbance of soil crusts substantially lowers the threshold friction velocity of desert soils (Table 2.1). Threshold velocities for wind erosion are directly proportional to hardness of crust, increasing size of dry aggregates of the soil, soil encrustation and the fraction of soil material greater than $1 \mathrm{~mm}$ in diameter (Gillette et al 1979). Highest threshold values for wind erosion occur in undisturbed desert pavements and the centers of playas whereas the lowest values occur in disturbed soils except in some playa centers (Table 2.1). Through the use of a portable wind tunnel, Gillette (1978) and Gillette et al (1979) were able to show that in all cases where a vehicle was driven over a particular substrate, the result was a substantial lowering of the threshold friction velocity for soil in the track or disturbed area of each site as compared to undisturbed areas (Table 2.1). 
Table 2.1. Threshold Friction Velocities for the Test Sites. NR Means Threshold Velocity Not Reached. Values in $\mathrm{cm} / \mathrm{sec}$.

\begin{tabular}{cccl}
\hline Site & Undisturbed & Disturbed & \multicolumn{1}{c}{$\begin{array}{c}\text { Geomorphological } \\
\text { Setting }\end{array}$} \\
\hline I-1 & NR & NR & Playa (Center) \\
II-1a & 271 & - & Alluvial Stream Deposit \\
II-1b & 278 & 66 & Alluvial Stream Deposit \\
II-2 & 300 (NR) & 59 & Alluvial Fan \\
II-3 & 215 & 42 & Alluvial Fan \\
III-1 & 285 & 182 & Playa (Center) \\
III-2 & 339 & 158 & Playa (Center) \\
III-3 & 155 & 40 & Edge of Playa \\
III-4 & 175 (NR) & 29 & Edge of Playa \\
IV-1 & 191 & 43 & Aeolian Deposit on Fan \\
IV-2 & 147 & 33 & Aeolian Deposit on Fan \\
IV-3 & 146 & 26 & Lower Alluvial Fan \\
\hline
\end{tabular}


One of the long-term effects of ORV's on cryptogamic and other sorts of soil crusts in arid and semiarid areas is increased fugitive dust production due to the destabilization of the desert soils (Gillette et al, 1979; Nakata et al, 1976; Geolog. Soc. Am, 1977). For example, it was predicted that the Barstow-Las Vegas offroad motorcycle race of 1974 released $610,000 \mathrm{Kg}$ ( $\approx 600$ tons) of particulates into the atmosphere presumably both by direct action of the motorcycles themselves and concomitant wind erosion (Wilshire 1977). This amount is, however, quite small when compared to a well developed terrestrial dust storm where from $10^{5}-10^{9}$ tons of material may be removed and carried aloft (Lisitzin, 1972). Dust storm frequencies are increased by any activities which disturb and destabilize the surface crusts of desert soils. Agricultural activities in arid and semiarid areas may be significant in this regard (Clements et al, 1963). Effects of ORV's on dust storm frequencies are probably similar to those produced by fen. George A. Patton's tank maneuvers in the Colorado Desert between Desert Center, California and Parker, Arizona. The incidence of dust storms was several times as great during this period and a few years subsequently; the destruction of protective vegetation, pulverization of surface sediment and the crumbling of the surface crust permit the wind, which under normal circumstances would have little effect, to pick up surface material and cause large dust storms (Clements et al, 1963). In the deserts of western Egypt, Oliver (1945) indicated that the frequency of dust storms rose dramatically from about four per year prior to 1939 to over 50 per year during the height of hostilities during World War II, then dropped off to normal after fighting had ceased.

An increase in the number of desert dust storms is a direct consequence of lowered threshold velocities for wind erosion of a given surface and the consequent erosion by winds of higher velocity. Besides erosional problems, such dust storms pose a health hazard to persons living in desert areas who have allergies, or other lung and respiratory impairments, and may aid the spread of Coccidioidomycosis or "Valley-fever" (Leathers 1979) as reported in the previous section. The portions of the desert most susceptible to sand and dust storms are areas where winds are relatively high and where abundant sediment $<1 \mathrm{~mm}$ in diameter is available for wind transport (Clements et al, 1963).

Dust storms are a significant ingredient of desertification. There is some evidence that dust storm frequencies are currently increasing, both because of drought and increasing human pressures on desert margins (Goudie, 1978; Clements et al, 1963). However, it is possible that during the glacial maximum $(\approx 18,000$ years $B P)$, when aridity was widespread in the low latitudes, dust concentration in the atmosphere may have been greater than at present (Kolla and Biscaye, 1977). Fugitive dust may also inhibit the formation of cumulus clouds because it retards the rising of hot air with the possibility of less rainfall in the area as a consequence.

\section{Water}

Apparently, the erosional properties of soil crusts are related to, among other things, the amount of organic matter present within the soil. Soil crusts are characterized by few large pores, high bulk 
density, platiness, stratification and orientation of different sized materials. The crustal layer is often harder than the rest of the soil because it is drier and such compounds as lime and silica become deposited on the surface as water evaporates. However, infiltration of water is limited because soil crusts have a low saturated hydraulic conductivity, a prime factor causing runoff and erosion. Crusting commonly occurs in soils with small amounts of organic matter, a high silt content and low aggregate stability and is exacerbated by high $\mathrm{Na}^{+}$concentration. Soils with concentrations of organic matter greater than 3 percent are less susceptible to crusting due to the adhesive properties of complex organic molecules which bind soil particles into stable aggregates (Kemper and Miller 1975; Miller and Gifford 1975; Uehara and Jones 1975; Cameron and Blank 1966).

In arid and semiarid regions, soil crusts lose strength upon wetting due to swelling and/or softening of cementing agents. Addition of organic matter does not increase soil-strength, but stabilizes it even under saturated conditions. Although there is no clear agreement, stability is brought about by reduction of the interaction of water with inorganic colloids and/or physically or chemically binding soil particles together (Uehara and Jones 1975). The latter means is of obvious importance with regard to algae and cryptogamic crusts (Skujin et al 1979; Cameron and Blank 1966; Uehara and Jones 1975). A review of the literature by Skujins et al (1979) revealed circumstantial evidence presented by several authors that cryntogamic crusts increase soil stability and infiltration rates and reduce erosion, runoff, and sedimentation. It is therefore highly probable that algal and other types of cryptogamic crusts are less susceptible to water erosion than non-cryptogamic crusts or crusts otherwise lower in organic matter concentration. To further complicate matters, it is well known that certain soils contain mycogenic water-repellent substances (Adams et al, 1969; DeBano and Letey, 1969). In such cases, soils relatively high in organic matter could have extremely low infiltration rates and could contribute to catastrophic runoff or, in low lying areas, pooling of water during torrential desert rainstorms. However, in the process of shedding water, repellent soils remain intact. The relationship between soil crusts and water erosion is, therefore, quite complex.

Soil crusts may be modified, that is, formation can be prevented or encouraged when advantageous to specific land uses (Kemper and Miller 1975; Miller and Gifford 1975). Formation can be prevented or encouraged by the use of chemical agents or by vegetation manipulation; high vegetative cover retards crust formation. As an example, soil crust formation may be beneficial in reducing infiltration (as in water harvesting) on small watersheds to gain additional water on adjacent areas or simply to increase surface water supplies (Miller and Gifford 1975).

In view of the above information, the effects of crustal elimination by ORVs on water erosion in desert soil systems are hard to evaluate. Furthermore, partitioning out the effect of crust removal on water erosion compaction and shear stresses could prove to be very difficult. It can be assumed that whatever effects occur will be dependent upon the nature of the soil crust, the local soil system and geomorphology and, of course, the intensity of impact. It is perhaps not obvious that only very low levels of impact will be important in producing recognizable 
Table 2.2. Some Soil Microfloral Taxa of the Southwest Deserts* $B G=$ blue-green algae, $G=$ green algae, $B=$ brown algae $\mathrm{GA}=$ golden algae

Bacteria and Actinomycetes

Bacteria Actimomycetes

Radiobacter spp., Azotobacter spp., Clostrium spp.

Steptomycetes spp.

Fung i

Ascomycetes

Penicillium spp.

Aspergillus spp.

Algae - General

Chlorococcum spp. G Anacystis spp. BG

Navicula spp. BG Calothrix spp. BG

Nostoc spp. $\quad B G$ Trochiscia spp. BG

Oscillatoria spp. BG $\overline{\text { Protococcus spp. G }}$

Porphyrosiphon spp. BG Phytoconis sp. G

Schizothrix spp. BG Botrydium granulatum B

Scytonema spp. BG Navicula spp. GA

Algae - Cryptogamic Crusts

Nostoc muscorum $\quad B G$

Scytonema hoffmannii BG

Schizothrix calcicola $\quad$ BG

Microcoleus vaginatus $\quad B G$

M. chthonoplastes $\quad B G$

Protococcus grevillei G

Protosiphon cinnamomeus G

Lichens

Acarospoa spp.

Caloplaca spp.

Dermatocarpon spp.

Lecanora spp.

Parmelia spp.

Physica spp.

* Data taken from Cameron and Blank (1966) and Skujins et al (1979). 


\section{Green algae}

Chlorococcum humicola (Naeg.) Rabenhorst

Protococcus viridis Agardh

Rhizoclonium hieroglyphicum (C.A.Ag) Keutzing

Anacystis montana (Lightf.) Dr. and Daily**

\section{Blue-green algae}

Gomphosphaeria aponina Kuetz.

Chamaesiphon incrustans Grunow

Oscillatoria Agardhii Gomont

Phormidium tenue (Menegh) Gomont**

Phormidium angustissimum W. and G. S. West

Phormidium foveolarum (Mont) Gomont

Phormidium subcapitatum Boye P.**

Phormidium retzii **

Phormidium ambiguum Gomont

Phormidium dimorpha Lemm

Lyngbya thermalis Roth

Microcoleus vaginatus (Vauch.) Gomont**

Anabaena variabilis Kuetz.

Nostoc commune Vauch.

Nostoc muscorum Agardh**

Tolypothrix distorta Kuetz.**

Calothrix castelli Fremy

Coccochloris stagnale Sprengel

* Data from Hunt and Durrell (1966)

** Algae associated with translucent stones, mostly found under quartz and quartzite and, to a certain extent, white limestone and calcite (i.e. diaphanous substrates) 
Table 2.4 List of fungi found in Death Valley*

\begin{tabular}{|c|c|c|c|c|c|}
\hline \multirow[b]{2}{*}{ Species } & \multicolumn{5}{|c|}{$\begin{array}{l}\text { Samples Containing } \\
\text { Listed Species }\end{array}$} \\
\hline & \multicolumn{5}{|c|}{\begin{tabular}{|} 
| Percent| Dark \\
Number| of total|species
\end{tabular}} \\
\hline & $T$ & 1 & & $\mathrm{~T}$ & \\
\hline Rhizopus nigricans Ehrenberg & 20 & i & 24 & 1 & \\
\hline Actinomucor repens Schostakowitsch & 3 & $\frac{1}{1}$ & & $\frac{1}{1}$ & \\
\hline Mucor varians Povak & 2 & 1 & & 1 & \\
\hline racemosus Fresenius & 1 & 1 & & 1 & \\
\hline spinescens Lendner & 2 & 1 & & 1 & \\
\hline Thamnidium sp. & 2 & I & & 1 & \\
\hline Pythium echinulatum Mathews & 1 & 1 & & 1 & \\
\hline Chaetomium elatum Kunze and Schmidt & 2 & i & & 1 & $\mathrm{X}$ \\
\hline cochlioides Pallister & 2 & I & & 1 & $\mathrm{X}$ \\
\hline Montemartina myriadea Curzi & 1 & 1 & & 1 & \\
\hline Fimetaria sylvatica (Daszewska) Griff and & $\frac{1}{1}$ & $\frac{1}{1}$ & & $\frac{1}{1}$ & \\
\hline Seaver & 2 & 1 & & 1 & $\mathrm{x}$ \\
\hline Trichosphaeria pilosa (Persoon) Fuckel & 1 & 1 & & 1 & \\
\hline Phoma sp. & 5 & $\frac{1}{1}$ & & $\frac{1}{1}$ & $\mathrm{X}$ \\
\hline Sphaeronaema sp. & 46 & 1 & 55 & I & $\mathrm{X}$ \\
\hline Naemosphaera sp. & 4 & 1 & & 1 & $\mathrm{X}$ \\
\hline Ceratopycnis sp. & 3 & 1 & & 1 & $\bar{X}$ \\
\hline Cephalosporium sp. & 3 & 1 & & 1 & \\
\hline Aspergillus sulfureum (Fres) Thom and Church & 1 & 1 & & 1 & \\
\hline Aspergillus micro-virido-citrinus Costantin & 1 & 1 & & 1 & \\
\hline niveus Beochwits & 5 & 1 & & 1 & \\
\hline niger Van Tiegem & 3 & 1 & & 1 & \\
\hline Wentii Wehmer & 25 & 1 & 30 & 1 & $\mathrm{X}$ \\
\hline ustus (Bainier) Thom and Church & 1 & $\frac{1}{1}$ & & $\frac{1}{1}$ & \\
\hline fumigatus Fres & 4 & 1 & & 1 & \\
\hline nidulans (Eidam) Wint & 1 & 1 & & 1 & \\
\hline fiebus oryzae Link & 2 & I & & 1 & \\
\hline terreus Thom & 1 & 1 & & 1 & \\
\hline Penicillium oxalicum Thom & 33 & 1 & 40 & I & \\
\hline Scopulcroipsis brevicaulis Bainier & 2 & 1 & & 1 & \\
\hline Gliocladium pencilloides Corda & 1 & 1 & & 1 & \\
\hline Botrytis carnea Schum & 7 & 1 & & 1 & \\
\hline Beauveria densa (Link) Picard & 1 & i & & 1 & \\
\hline Mycogone nigra (Morgan) Jensen & 4 & 1 & & 1 & $\mathrm{X}$ \\
\hline Pullularia pullans (deBary) Berkhout & 2 & 1 & & 1 & $\mathrm{X}$ \\
\hline Stachybotrys atra Corda & 5 & 1 & & 1 & $\mathrm{X}$ \\
\hline Nigrospora sphaerica (Sacc) Mason & 1 & 1 & & 1 & $\mathrm{X}$ \\
\hline Humicola brevis (Gilman and Abbott) Gilman & 1 & 1 & & 1 & $\mathrm{X}$ \\
\hline Cladosporium herbarum (Persoon) Link & 7 & 1 & & 1 & $\mathrm{X}$ \\
\hline Curvularia tetramera (McKinney) Boedijn & 7 & 1 & & 1 & $\bar{X}$ \\
\hline geniculata (Tracy and Earl) Boedijn & 1 & 1 & & 1 & $\mathrm{X}$ \\
\hline Stemphylium ilicis Teng & 48 & 1 & 65 & 1 & $\mathrm{X}$ \\
\hline sarciniforme (Cav) Wiltshire & 2 & 1 & & 1 & $\mathrm{X}$ \\
\hline ilicis (Tetracoccosporium type) & 4 & i & & 1 & $\mathrm{X}$ \\
\hline
\end{tabular}

* Data from Hunt and Durrell (1966) 


\begin{tabular}{|c|c|c|c|c|c|c|}
\hline \multirow[b]{3}{*}{ Species } & 1 & \multicolumn{5}{|c|}{$\begin{array}{l}\text { Samples Containing } \\
\text { Listed Species }\end{array}$} \\
\hline & I & & & erce & & ark \\
\hline & 1 & Numbe & rlof & tot & & pecies \\
\hline & I & & 1 & & 1 & \\
\hline Alternaria tenuis Nees & i & 13 & i & 15 & i & $\mathrm{X}$ \\
\hline Fusarium sp. & 1 & 29 & 1 & 35 & 1 & \\
\hline roseum (Link) Snyder and Hansen & T & 1 & $\frac{1}{1}$ & & 1 & \\
\hline Cylindrocarpon heteronemum (Berk and Broome) & 1 & & 1 & & 1 & \\
\hline Wo11 & 1 & 2 & 1 & & 1 & \\
\hline Myrothecium convexum Berk and Curtis & 1 & 2 & 1 & & 1 & \\
\hline Sclerotia & T & 27 & 1 & 32 & 1 & $\bar{X}$ \\
\hline Streptomyces sp. & 1 & 5 & 1 & & 1 & \\
\hline
\end{tabular}

* Data from Hunt and Durre11 (1966) 
Table 2.5 Zonation of fungi in response to a salinity gradient in Death Valley*

\begin{tabular}{|c|c|c|c|c|c|c|c|c|}
\hline \multirow[b]{5}{*}{ Genus } & \multicolumn{8}{|c|}{ Frequency of occurrence in-- } \\
\hline & \multirow{4}{*}{\multicolumn{2}{|c|}{$\begin{array}{l}29 \text { samples } \\
\text { Xerophyte } \\
\text { zone }\end{array}$}} & \multirow{4}{*}{\multicolumn{2}{|c|}{$\begin{array}{l}\text { 130 samples } \\
\text { I phreato- } \\
\text { I phyte zone } \\
\text { I }\end{array}$}} & \multirow{4}{*}{\multicolumn{2}{|c|}{$\begin{array}{l}16 \text { samples } \\
\text { I } \text { Beyond } 6 \\
\text { percent } \\
\text { brine line }\end{array}$}} & \multirow{4}{*}{\multicolumn{2}{|c|}{$\begin{array}{l}\text { I All } 75 \\
\text { I samples } \\
\end{array}$}} \\
\hline & & & & & & & & \\
\hline & & & & & & & & \\
\hline & & & & & & & & \\
\hline & 1 & & 1 & & 1 & & 1 & \\
\hline \multirow{2}{*}{ Stemphylium } & I & 25 & I & 21 & I & 3 & I & 49 \\
\hline & I & & I & & 1 & & 1 & \\
\hline \multirow[t]{2}{*}{ Sphaeronaema } & I & 28 & I & 15 & I & 0 & 1 & 43 \\
\hline & I & & I & & I & & I & \\
\hline \multirow[t]{2}{*}{ Penicillium } & 1 & 20 & । & 7 & I & 5 & I & 32 \\
\hline & I & & I & & I & & 1 & \\
\hline \multirow[t]{2}{*}{ Fusarium } & I & 16 & । & 10 & I & 1 & I & 27 \\
\hline & I & & I & & I & & 1 & \\
\hline \multirow[t]{2}{*}{ Aspergillus Wentii } & i & 13 & । & 8 & I & 3 & I & 24 \\
\hline & 1 & & I & & 1 & & 1 & \\
\hline \multirow[t]{2}{*}{ Rhizopus } & i & 13 & i & 4 & i & 0 & i & 17 \\
\hline & 1 & & I & & 1 & & 1 & \\
\hline \multirow[t]{31}{*}{ Al ternaria } & i & 4 & 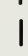 & 5 & i & 3 & I & 12 \\
\hline & I & & I & & I & & I & \\
\hline & I & & I & & I & & 1 & \\
\hline & i & & I & & I & & I & \\
\hline & 1 & & I & & I & & I & \\
\hline & I & & I & & 1 & & I & \\
\hline & 1 & & I & & I & & I & \\
\hline & I & & I & & I & & I & \\
\hline & 1 & & I & & 1 & & I & \\
\hline & I & & I & & I & & i & \\
\hline & I & & I & & i & & i & \\
\hline & I & & I & & I & & i & \\
\hline & I & & I & & I & & i & \\
\hline & i & & I & & i & & i & \\
\hline & 1 & & 1 & & 1 & & 1 & \\
\hline & 1 & & I & & I & & 1 & \\
\hline & 1 & & 1 & & 1 & & 1 & \\
\hline & 1 & & 1 & & 1 & & 1 & \\
\hline & 1 & & I & & 1 & & 1 & \\
\hline & 1 & & 1 & & 1 & & 1 & \\
\hline & I & & I & & I & & I & \\
\hline & 1 & & I & & I & & I & \\
\hline & I & & I & & I & & I & \\
\hline & 1 & & I & & I & & I & \\
\hline & 1 & & I & & I & & 1 & \\
\hline & I & & I & & I & & I & \\
\hline & I & & I & & I & & I & \\
\hline & I & & I & & I & & I & \\
\hline & i & & i & & I & & I & \\
\hline & i & & i & & I & & i & \\
\hline & 1 & & | & & I & & 1 & \\
\hline
\end{tabular}

* Data from Hunt and Durrell (1966) 
Table 2.5. Number of Microorganisms in Soils of Southwestern Deserts. $\mathrm{NR}=$ No Record

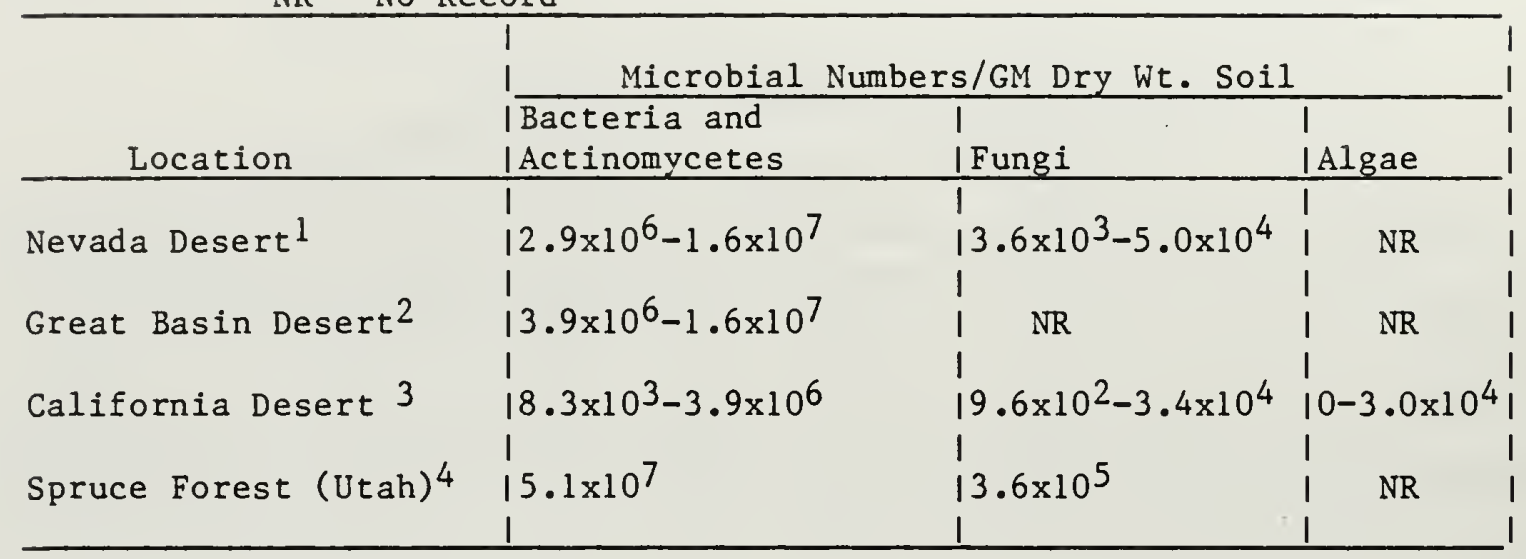

1 Volmer et al (1976)

2 Lynn and Vogelsburg (1974)

3 Cameron and Blank (1966)

4 Skujins (1979 
changes in erosional patterns which can be attributed to soil crustal disturbance. At high levels of ORV use, effects of crustal destruction on water erosion would be overshadowed by the effects of more catastrophic changes in the soil surface structure brought about by shear and compaction (see section on soils).

\section{Biological Properties of Desert Soils and Soil Crusts}

\section{Desert Microorganisms}

\section{a. Composition}

The microflora of desert soils belong to various physiological and morphological taxa including bacteria (chemoautotrophic, autotrophic, aerobic, anaerobic, and microaerophilic), streptomycetes (mostly actmomycetales), fungi (mostly ascomycetales), algae, myxomycetes and lichens (Table 2.2). Viruses probably occur in desert soils but have not been adequately studied (Cameron and Blank, 1966).

An extensive study of desert cryptogams and cryptogam habitats was made in Death Valley by Hunt and Durrell (1966) who found significant differences in the microflora in the environments sampled. In Death Valley, few bacteria were found beyond the $15 \%$ brine line. The authors believed that the microflora in Death Valley has contributed to the precipitation of some of the mineral species there (e.g., calcite crystal). Most of the fungi (Table 2.4) found in Death Valley were striking in their predominantly dark color (e.g., Stemphylium). These dark-spored fungi are resistant to extremes of radiant energy. Germination after 60 minutes exposure to 2500-2600 A ultraviolet light was $90 \%$. The melanin pigment in these dark spored fungi probably acts as a light shield, and to some extent as a protection against dessication. The fungi population and the number of spores decreased as salinity increased from the playa to the pan. They were most abundant in the xerophytic zone, less so in the phreatophyte (Mesquite) zone at the edge of the salt pan and are least abundant on the salt pan (Table 2.5).

In general, algae (Table 2.3) were obtained beyond the limit of flowering plants ( $6 \%$ brine line) out to the $8 \%$ brine line. Algae did not show a zonation due to the salinity gradient comparable to the fungi. Several species of algae were important constituents of the microflora associated with diaphanous substrates, the so called "windowplants" or fensterpflanzen (Table 2.3). On the gravel fans, algae occur regularly under translucent stones (Quartz, Quartzite, White Limestone, Calcite) where there is protection from evaporation and ample light can be transmitted through the translucent rocks. These stone have been referred to as microgreenhouses (Durrell, 1956; Hunt and Durre11, 1966).

Evidently, the soil microflora around the Death Valley salt pan responds to availability and salinity of moisture very much as do the flowering plants (Hunt and Durrell, 1966). Therefore, it seems reasonable to infer from these data that impacts of vehicles or other sources on soil microflora will be of greatest magnitude in those areas of the desert which are not extremely saline. Also areas with a paucity of vascular plants, the bottoms of dry lakes with salinities exceeding 
Table 2.6. Abundance of Algal Crusts and Lichens in the Deserts of the USA

Algal Crusts
Biomass
Cover

Lichens $^{2}$

Biomass

Cover

\author{
(Great Basin Desert) \\ $48-239 \mathrm{~kg} / \mathrm{ha}$ \\ $41-82 \%$
}

1 Lynn and Vogelsburg (1974)

2 Nash et al (1974) 
$8 \%$ will have little microflora to disturb. However, on playa edges and uplands disturbance and destruction of soil microflora and diaphanous substrates could be extensive. How this could affect the entire community metabolism in terms of organic matter incorporation, Nitrogen-fixation and utilization is discussed in the following section.

\section{b. Abundance}

Algae and chemoautotrophic bacteria are among the most abundant groups of soil microflora found in desert areas (Tables 2.2 and 2.5). In fact, the abundance of bacteria and fungi in desert areas may approach the magnitude found within the soil of a spruce forest (Table 2.5). Both bacterial and fungal numbers varied seasonally in the Nevada desert, probably as a function of soil moisture levels, and were lower in the shrub interspaces (Vollmer et al 1976).

Biomass estimates of algal crust range from around $50-240 \mathrm{Kg} / \mathrm{ha}$ with cover values of about 40-80 percent (Table 2.6). Algal abundance in desert soils may be due to the absence of higher plants because the soil, as a result, retains more moisture for cell growth (Schwabe, 1963). This hypothesis fits the relationship between plant cover, soil crusts, and infiltration rates (Kemper and Miller, 1975; Miller and Gifford, 1975) discussed earlier. Lichen biomass and cover estimates are shown in Table 2.6. Nash et al (1974) claimed that variations in biomass and cover of lichens are due to substrate, elevation, precipitation, and slope. Realistically, land use should be added to this list of variables.

We know of no known research relating ORV impacts on desert soils to effects on soil microflora abundance, species composition, or species diversity. This is an area for greater study. For example, would soil microflora flourish in wheel ruts on level sites due to the pooling of water? Does runoff from compacted soils destroy microhabitats for algal, bacterial, and fungal growth? Is there a microflora indicative of disturbed desert soils?

\section{Nitrogen Fixation}

According to Skujins (1979) the nitrogen-fixing ability of desert cryptogams, mostly blue-green algae, either free-living or associated with fungi, forming lichen crusts, has been documented and extensively discussed, but their importance to the nitrogen budget in arid regions is still not well defined. A variety of associated, nitrogen-fixing, microflora are also found in desert soils as moisture conditions become more favorable. These include actinomcycetes and nitrogen fixing bacteria such as Radiobacter, Azotobacter and Clostridium (Cameron and Blank, 1966; Skujins et al, 1979). However, the latter two genera have only been subcultured from the organic matter around translucent stones (diaphanous substrates) and have not been found in soil algae and lichen crusts (Cameron and Blank, 1966). 
The amount of nitrogen fixed over broad areas varies both spatially and temporally and is largely a function of population densities of nitrogen fixers, water availability, soil temperature, nature of soil characteristics, and incident radiation (Skujins et al, 1979; Skujins, 1975; Sorensen and Porcella, 1974). Probably this variability in nitrogen fixation rates (Table 2.7 ) reflects the extreme heterogeneity within areas and variability in the ground cover of cryptogams between areas (Skujins et al, 1979). Soil surfaces which contain clay have a higher concentration of cryptogams than sandy surfaces (Skujins and West, 1974), but the principal factor limiting nitrogen-fixation in desert soil crusts by blue-green algal-lichens is water (Hendrickson, and Simu, 1971; Hitch and Stewart, 1973; Rychert and Skujins, 1974; Eskew and Ting, 1978).

Both input of nitrogen into desert soils and denitrification differ in different desert areas. In the Great Basin Desert fixed nitrogen is quickly lost through denitrification and little nitrogen is added to the soil unless higher plants can use it within a short period of time (Skujins and West, 1974). In the Mojave desert soil system, nitrogen input is low, probably due to low cryptogamic crust cover (Table 2.7), but the nature of the nitrogen cycle in this area suggests that there is a relatively large pool of soil organic nitrogen in equilibrium with a pool of soluble mineral nitrogen and is more than adequate to meet the needs of seasonal plant productivity in years of high rainfall. In addition, small amounts of fixed nitrogen are gained from semisymbiotic organisms in shrub rhizospheres and cryptogams; no one biotic source is major; all contribute. Even though fixation rates by cryptogams in the Mojave Desert is low, they may contribute substantially to the nitrogen cycle (Wallace et al, 1978; Skujins et al, 1979). Eskew and Ting (1978) working in the Colorado Desert doubt the reports of Mayland et al (1966) and McGregor and Johnson (1971) who believe that algal-lichen crusts could supply all of the nitrogen needed in the Sonoran Desert. These conclusions were based on laboratory experiments where water was not limiting. Eskew and Ting in comparing green house and in situ nitrogen fixation concluded that the procedures in previous studies probably overestimated actual rates of nitrogen fixation and that it seemed unlikely that the blue-green algal-lichen crusts would be capable of fixing a very large amount of nitrogen under Colorado Desert conditions.

Although some leguminous shrubs, such as Dalea spp. and bluegreen algal-lichen crusts showed definite evidence of nitrogen fixation under field conditions, together they did not appear to be capable of supporting enough nitrogen to support the Colorado Desert ecosystem. The residual requirement would have to come from either rainfall, or non-legume and associative sysmbioses. Resolution of this point is possible only when a valid estimation of the quantity of nitrogen needed to support a year's plant growth is available (Eskew and Ting, 1978). 
Table 2.7. Nitrogen Fixation Rates in Three American Desert Areas

Sonoran Desert

Great Basin Desert ${ }^{2}$

Northern Mojave Desert ${ }^{3}$
$1 \mathrm{~kg} / \mathrm{ha} / \mathrm{yr}$

$7-18 \mathrm{~kg} / \mathrm{ha} / \mathrm{yr}$

$7-100 \mathrm{~kg} / \mathrm{ha} / \mathrm{yr}$

$40-80 \% 4$

$0.1 \%^{5}$

1 Rychert et al (1978)

2 Rychert et al (1978)

3 Wallace et al (1978)

4 Lynn and Cameron (1973)

5 Hunter et al (1976) 
In the only known study of ORV effects on the nitrogen cycle, Skujins et al (1979) in a report to the Bureau of Land Management Desert Plan Staff reported that in comparing the analytical data of ORV tracked soils with non-tracked soils on Soggy Dry Lake (Station A) it appeared that ORVs had little influence on most of the parameters at this site. Total $\mathrm{NH}_{4}+-\mathrm{N}$, however, seemed to increase in tracked areas. Although exchangeable $\mathrm{NH}_{4}+-\mathrm{N}$, acetylene reduction, cation exchange capacity, organic carbon, and total nitrogen may also have increased in the tracked areas the information was too variable to draw valid conclusions. The result from Station $B$ through $D$ suggested that exchangeable $\mathrm{NH}_{4}+-\mathrm{N}$ increased in the disturbed areas. However, no other disturbancerelated trends were obvious.

At another site impacted by ORV in Stoddard Valley, Skujins et al concluded that vehicle impact appeared to have had no consistent effect on total $\mathrm{NH}_{4}+-\mathrm{N} \quad \mathrm{C}_{2} \mathrm{H}_{4}$ produced or chlorophyll a concentration. There was no suggestion of a correlation between number of vehicle passes and to these values, nor did there appear to be any differences between disturbed and undisturbed areas. In areas which are not continously disturbed such as Stoddard Valley, the tire tracks may provide favorable microclimates for plants and algae as water may collect in such depressions and retain moisture for growth (Skujins et al, 1979).

The overall results of the study as summarized by Skujins et al (1979) were that: ..."certain perturbations may in some areas adversely affect the biological properties of the soil. Reduced exchangeable $\mathrm{NH}_{4}+-\mathrm{N}$ and acetylene reduction (potential $\mathrm{N}_{2}$-fixation) as a result of these perturbations should be viewed with some concern since it has been pointed out by Wallace et al (1978) that nitrogen input into the lojave desert is very low and any disturbance of the soil biological properties may have drastic effects in this ecosystem." However, the scope of the study was limited and according to the authors:..."it would be unreasonable to expect... decisive conclusions based on a study of this nature."

At any rate, implications linking the effects of ORVs to possible declines of soil microflora and by inference nitrogen fixation (Stebbins, 1974, 1980) though plausible are premature, unsubtantiated and highly speculative. On an area wide based (excluding perhaps concentration zones such as pit areas) the number of favorable microclimates, for algae and fungal growth, created by ORV impacts might equal or even exceed those destroyed if the preliminary results of Skujins et al (1979) from Soggy Dry Lake and Stoddard Valley are any indication. Any sigificant impacts over large areas will surely manifest themselves in changes in the patterns of occurrencs of soil nitrogen-fixing microflora and not necessarily in changes in the magnitude and rate of nitrogenfixation and related processes. 
III. DIRECT IMPACTS OF OFF-ROAD VEHICLES ON VEGETATION

BY

JOHN A. HALL

Table of Contents

$\underline{\text { Page }}$

A. Introduction.................................. 64

B. Types of Impacts and Effects on Vegetation............... 64



2. Changes in Plant Cover...........................66 66

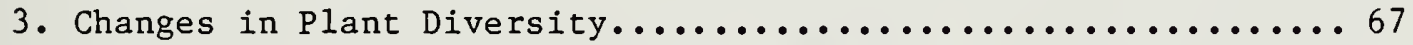

4. Changes in Populations of Annual Species................68

C. Intensity of Impacts............................. 69

D. Positive Changes............................... 70

E. Ecosystem Implications of Vegetation Changes From ORV

Activity and Conclusions......................... 71 
The most obvious of off-road vehicles on vegetation are the direct ones, that is the physical breakage and removal of whole plants and plant parts. This section focuses on the types of surface impacts created by ORVs and the vegetational changes in plant density, cover and diversity caused by direct impacts of ORV activity in the deserts of California. Finally a simplistic model of the effects of off-road vehicles on soils and vegetation will be presented.

In analyzing the various reports for this section two underlying weaknesses were evident in many of the studies: (1) the control plots selected were very heterogeneous and therefore comparisons between control and experimental (ORV impacted) plots were difficult to assess; (2) statistics were often used improperly; in particular misapplication of the student's t-test and analysis of variance to data which were neither normally distributed nor could be transformed to a normal distribution. In many cases data could not meet the necessary condition of homogeneity of variances. These problems might have been overcome by a larger sample size, which would have reflected the heterogeneity of the vegetation and allowed for the grouping of similar sites. A clearer evaluation could have been made by the use of nonparametric statistical methods such as those discussed in Hollander and Wolfe (1973); there was often speculation and "extrapolation" without scientific justification based upon well-organized controlled experimentation.

All of the quantitative studies were site specific and often "worse case" areas were selected. No attempt was made to analyze impacts on a regional or desert-wide scale. However, these problems do not prevent the discernment of general trends. In addition, all of the "worse case" study locations contained areas of varying use intensity. This allowed comparisons between areas of different disturbance levels. Most of the studies were concerned with effects of motorcycle activity, and a few addressed 4-wheel drive impacts. The measurable, direct effects from $O R V^{\prime}$ s are quite similar and plant response is nevertheless similar regardless of what runs over them. The main differences lie in intensity of use and site characteristics.

From this information, a reasonable, probable outcome of direct ORV impacts can be projected to most places in the desert.

\section{B. Types of Impacts and Effects on Vegetation}

There are two types of surface impacts occurring where ORV's traverse: (1) surface shearing and (2) surface compression or compaction (Wilshire et al, 1978; Hovland and Mitchell, 1972). The later type was covered previously in this report by Adams. Surface shearing disturbances (uprooting and disruption of root systems) and crushing effects (crushing of foliage, root systems and seedlings) are the direct impacts on vegetation from ORV's (Wilshire et al, 1978; Wood and Robertson, 1976; Klock, 1976; Luckenbach, 1975; Stebbins, 1974). These types of direct impacts on plants can cause changes in patterns and composition of the vegetation and are reflected in: (1) changes in plant density, (2) changes in plant cover, and (3) changes in diversity (Duck, 1978; Luckenbach, 1975; Stebbins, 1974). These changes can be very subtle or extremely obvious depending on the intensity of use, rate of use and an assortment of environmental factors (intensity and pattern of rainfall, topography, soil type, etc.). 


\section{PERCENT COVER OF ANNUALS}

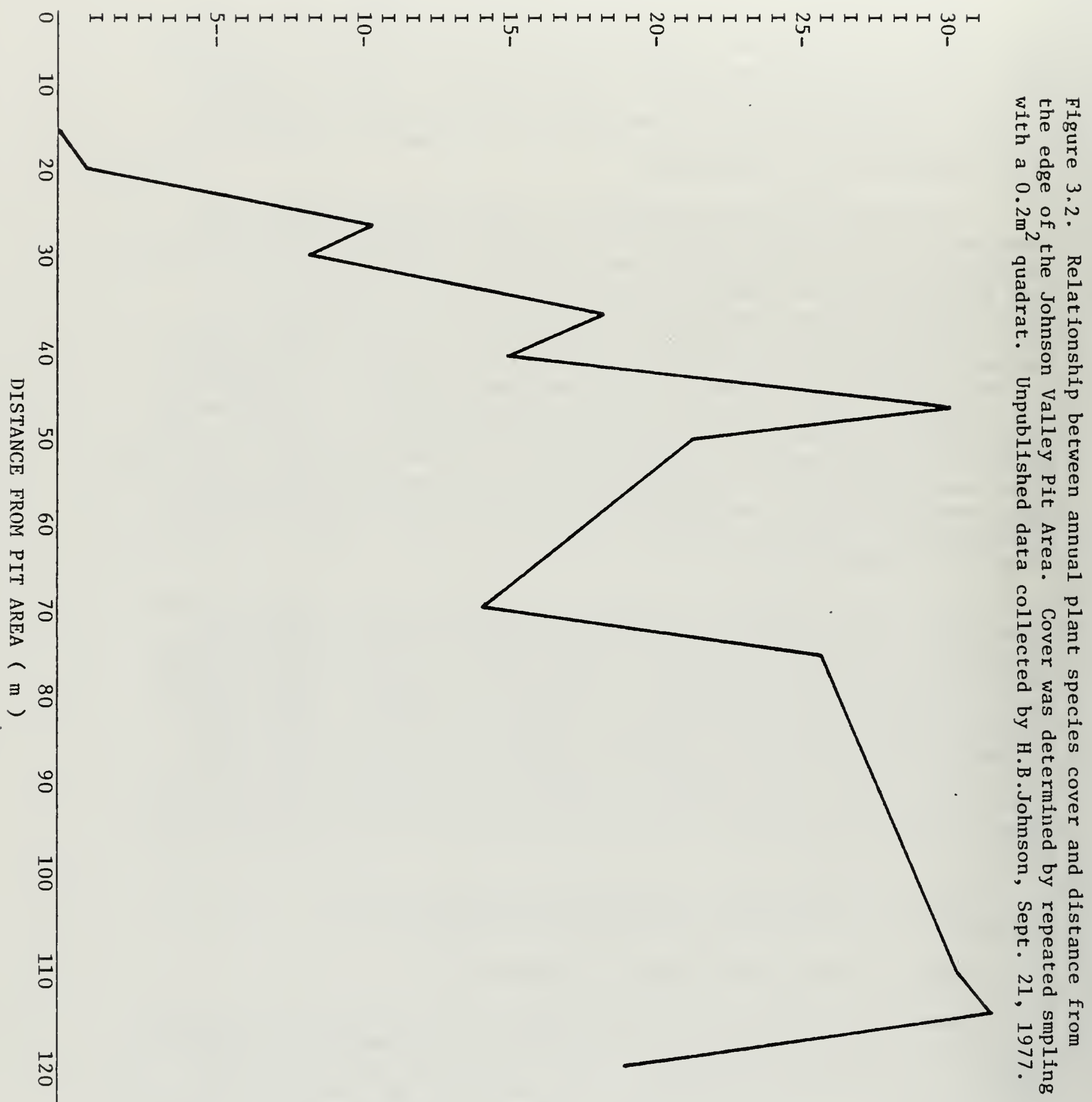




\section{Changes in Plant Density}

Density is a measure of the number of plants per unit area and is a useful indicator of community change (Muller-Dombois and Ellenberg, 1974). All studies that measured plant density reported decreases in density in areas of $\mathrm{ORV}$ use. These decreases varied in degree depending on the intensity of use, and to some extent by the researchers' ability to measure the changes. Keefe and Beery (1973) reported changes in density in areas of three different intensities of use at Dove Springs, Mojave Desert California. Areas of use around Dove Springs were classified as barren, disturbed, and relatively undisturbed. Comparisons among the three types showed the relatively undisturbed areas having 155.6 shrubs/150 $\mathrm{m}^{2}$, disturbed areas average 20.9 shrubs $/ 150 \mathrm{~m}^{2}$ ( $86.5 \%$ change in density) and no shrubs were found in the barren areas ( $100 \%$ change). Davidson and Fox (1974) concluded their poor statistical evaluations of the results reflected subtle site differences rather than motorcycle disturbances; but, with few exceptions their data showed an overall trend towards fewer plants in ORV use areas. On 16 plots of two hectares each (Bury et al, 1977), the average number of creosote bushes (Larrea divaricata) per hectare was 240 on the undisturbed controls, 236 with moderate ORV use (about half of these plants were broken or damaged), 145 with heavy ORV use, and only 84 creosote bushes per hectare in the pit area. Lathrop (1978) used aerial photographs taken in 1952 and 1973 of Dove Springs for a same site comparison. The average plant density on four hillsides decreased $37.5 \%$ from 1952 to 1973 , and a $59.0 \%$ decrease was noted in three pit areas. Ground density measurements of the same area indicated that the aerial photo analysis was conservative because decreases in plant density were found to be larger. Other studies have shown similar decreases in plant densities with ORV use (U.C.I., 1974; Vollmer et al, 1976; Brodhead and Godfrey, 1977; Sparrow et al, 1978) and that the severity of damage is correlated with intensity of use (U.C.I., 1974; BLM, 1975; Vollmer et al, 1976; Johnson, unpublished; Lathrop, 1978).

\section{Changes in Plant Cover}

Cover has been defined as the proportion of the ground occupied by various plant species using a perpendicular projection from the plant canopy (Greig-Smith, 1964). It is actually an estimation of the area covered by a given species and is expressed as a percentage (Kershaw, 1973). Cover as a measure of plant distribution has been emphasized as being of greater ecological significance than density (Rice, 1967; Daubermire, 1968). This idea is based on the observation that cover gives a better measure of plant biomass and influence than does the number of individuals, and biomass is the net primary production of a plant accumulated over time (Smith, 1974). From this, inferences can be drawn on the relative amount of energy in a system. A decrease in cover would reduce the amount of energy available to all the organisms in that system. 
All the studies that measured plant cover in ORV impacted areas showed varying degrees of cover reduction. Lathrop (1978) showed a $90 \%$ decrease in perennial plant cover in Jawbone Canyon when compared with control areas. Hillside trails in Jawbone Canyon were classified according to intensity of use (sparse, dense and very dense tracks) and comparisons with the unused control showed a $35 \%, 52 \%$, and $73 \%$ decrease in plant cover respectively. Lathrop conducted similar studies at Dove Springs, Stoddard Valley, Afton Canyon and along selected areas of the Barstow to Las Vegas race course. Total cover of annual plant species increased from $0.0 \%$ in the Johnson Valley "Pit" to $30 \% 45$ meters away, then appeared to fluctuate possibly because the transect crossed trails adjacent to the pit areas, around 25\% cover (Figure 3.1; Johnson, Unpublished Data). All showed similar findings. A general loss of plant cover is associated with ORV activity. Other authors reported similar results when comparisons were made between ORV use areas and relatively unused areas. Kuhn (1974) showed an $84.8 \%$ decrease in perennial plant coverage in selected areas of the Kelso Dunes. Snyder et al (1976) reported similar loss of plant cover in the Panoche Hills and around Dove Springs. Other authors have reported similar findings (Davidson and Fox, 1974; U.C.I., 1974; BLM, 1975; Wood and Robertson, 1976; Duck, 1978).

\section{Changes in Plant Diversity}

Diversity measures two characteristics: richness or the number of different species within a plant community, and how similar in number those species are in the plant community (Lloyd and Ghelardi, 1964; Pielou, 1966; Watt, 1972; Whittaker, 1975). The importance of species.diversity has many ramifications and is supported by several specific arguments. Most of these arguments fall into one of three categories: (1) diversity promotes stability, (2) diversity provides a greater survival potential for a community, and ( 3 ) the more diverse communities tend to utilize radiant energy more efficiently over the long term (Odum, 1963; Daubermire, 1968; Preston, 1969; Lewontin, 1969; Watt, 1972; Whittaker, 1975; Stebbins, 1974; Vog 1,1976$)$.

Authors who measured plant diversity in ORV use areas reported decreases when compared with controlled areas. Kuhn (1974) reported a $23.6 \%$ decrease in plant diversity along a foredune area of the Kelso Dunes. Keefe and Berry (1973) noted a $26.5 \%$ decrease in diversity, average over five belt transects in disturbed habitat at Dove Springs. Lathrop (1978) reported a decrease of $82 \%$ at the pit area in Jawbone Canyon compared with a control, and noted diversity decreases along impacted hillsides varying from 42 to $58 \%$ depending on the intensity of vehicle tracking. Lathrop reported similar findings at Dove Springs. Possibly changes in diversity occurred because smaller plants tend to receive the greatest degree of physical damage because ORV drivers tend to circumvent the larger shrubs (Keefe and Berry, 1973; Kuhn, 1974; BLM, 1972; Johnson, unpublished).

Some of the larger (older) shrubs, like creosote bush, live for several hundreds of years (Vasek et al, 1975), whereas some of the smaller plants may live only 25 to 50 years or less. Thus the extent of 
damage the older plants receive determines the ultimate recovery time and stability (see recovery section) for the community (Johnson, unpublished). The exact time of recovery is variable and may take between 10 and 100+ years. Some areas may never return to the original vegetation; however failure to do so would not necessarily mean that an ares had not recovered (see section 4 of plant succession).

\section{Changes in Populations of Annual Species}

Annual plants play a very important role in desert ecosystems. They are short lived and highly dependent on climatic factors, particularly precipitation. During favorable seasons they may contribute more to the total biomass production of the community than perennials (Johnson, unpublished; Beatley, 1969; Mooney et al, 1976). Their general strategy, however, is to maximize reproductive effort at the expense of vegetative development (Grime, 1979).

Annuals can respond dramatically to climatic and micro-site conditions. This creates unpredictable models for annual plant density, cover and diversity. Because of this inherent problem, few articles have addressed quantitative changes in annual populations as a result of ORV activity. Johnson (unpublished) measured perennial and annual plants radiating out from a pit area in Johnson Valley. At the pit site no annuals were found growing; 400 meters ( $1 / 4$ mile) from the pit, 2 species were present but the densities were so low as to register 0 ; and 800 meters ( $1 / 2$ mile) from the pit, 12 species were observed with a density of $9 \mathrm{plants} / \mathrm{m}^{2}$. When measurements were made on similar but less disturbed sites, the density was $30 \mathrm{plants} / \mathrm{m}^{2}$ and a total of 17 species was present. Vollmer et al (1976) reported a reduction in annual plant density from $39 / \mathrm{m}^{2}$ to $\frac{1}{24} / \mathrm{m}^{2}$ depending on intensity of use as compared to $46 / \mathrm{m}^{2}$ in a control plot. These differences might have been the result of site differences and not from ORV use. However, when differences were compared between track ruts and humps and other parts of the test area, the differences were judged to be a product of experimental error. In another study conducted by the University of California, Irvine (U.C.I., 1974), an investigation on the effects of ORV and campsite use on the germination success of summer annuals was done near Joshua Tree, California. Enclosed plots in disturbed and undisturbed areas were subjected to artificial rainfall, and indices of density and diversity were derived. Results showed an $83.2 \%$ decrease in density in the motorcycle use enclosure compared to the control, and a $90.0 \%$ decrease in density when the campsite area was compared with the unused control. These differences were attributed to soil compaction which decreases infiltration rates. Soil leaching from infiltration is often very necessary for annual plant germination (Went and Westergaard, 1949). However, some species tend to show a increase from ORV use. Species diversity in the motorcycle plot was considerably higher than in the control plot, whereas species diversity in the campsite plot was lower than the control (U.C.I., 1974). The positive effects were believed to be related to an increase in microsites formed by ridges in the soil surface. This effect was considered to be unimportant due to the relatively small number of individuals that germinated. 
Other studies (see Section 5) conducted by BLM show a decrease in summer annual production in vehicle tracks made after heavy summer rains.

\section{Intensity of Impacts}

There is a paucity of quantitative data about the intensity of ORV use and the degree of vegetation change. Most authors report the greater the ORV use the greater the changes in plant cover and density (Keefe and Berry, 1973; Davidson and Fox, 1974; Bury et al, 1977; Wood and Robertson, 1976; Duck, 1978). Studies are of ten designed by locating areas of various degrees of disturbance and measuring effects on plants in each area. Few studies have taken the approach of measuring vegetation before and after disturbances in the same area. If the disturbances can be controlled, i.e., number of passes over a given point, then a quantification of intensity could be made (Mispagel and Zembal, 1978). The BLM study discussed in Section 5 is one of two studies that took this approach and provides some insight on this topic. Other authors have taken other approaches and have reached similar conclusions. Johnson (unpublished) reports a decrease in plant damage from ORV use as distance increases from a pit area in Johnson Valley. Within the pit area there were no plants $(100 \%$ soil disturbance). Eight hundred meters away $74 \%$ of the small plants (less than $0.5 \mathrm{~m}$ high and $51 \%$ of the larger plants $(1.0+\mathrm{m} \mathrm{high})$ received between 10 and $50 \%$ damage with $99 \%$ of the soil surface disturbed. At 3,200 meters from the pit area $34 \%$ of the small plants and $15 \%$ of the larger plants received between 10 and $50 \%$ damage with $70 \%$ of the soil surface disturbed. A disturbance gradient can be visualized, radiating out from an area of high disturbance to low. A similar study was conducted by the University of California, Irvine (U.C.I., 1974). Studies on creosote bush densities reported that damage appeared to increase exponentially as the distance increased toward the interior of the motorvehicle campsite. In a special study for BLM (Lathrop, 1978) on plant responses to ORV activity, several types of measurements were made to record changes in plant density. An approach similar to Johnson (unpublished) was used to record changes in shrub density radiating out from a pit area in Johnson Valley. Distances were at 100 meter intervals for 600 meters, at six different compass bearings from the center of the pit area. Comparisons were made of 1952 and 1977 aerial photos. When averages of percent change were made for each of the 100 meter intervals, a decrease in plants was observed at all intervals $(45 \%, 52 \%, 69 \%$, $55 \%, 28 \%$ and $40 \%$, respectively). However, no clear intensity gradient was observed probably because additional samples further from the pit were not made and the ORV activity may not be the only factor influencing the decrease in plant density. These data indicate a relationship between degree of vegetation change and intensity of impacts.

A study completed in Rock Valley, Nevada (Vollmer et al, 1976) reported the results of driving 4-wheel vehicles over a fixed and random course for a set period of days. Estimates were made of damage 
to 487 shrubs from random driving and 147 shrubs damaged in a regularly driven track. Shrubs exposed to repeated driving (regular track) were severely damaged, averaging $76 \%$ estimated damage, whereas the random driving averaged $38 \%$ estimated damage. There was a significant correlation between the regularity (intensity) of driving and the degree of damage to a shrub.

In a study at Cape Code National Seashore, Massachusetts, the effects of controlled impacts on plant biomass were measured on coastal habitats (Brodhead and Godfrey, 1977). Plots were established and treatment consisted of 0 (control), 270 (medium) and 650 (heavy) passes of a 4 -wheel drive Jeep. The mean biomass $/ \mathrm{m}^{2}$ for each plot was reduced to a percentage to correct for initial differences between plots, and was seasonally corrected by comparison with the appropriate control. Beach grass biomass measurements on the heavy impact plots showed the foredune biomass had declined to $25 \%$ and the dune biomass to $15 \%$ of the initial biomass. A similar pattern was noted under a medium intensity of impact with a biomass reduction of $42 \%$ ( $58 \%$ of the control) in the foredune and $34 \%$ ( $66 \%$ of the control) in the dune. These figures were calculated from tracks 3 meters wide and apply only to areas impacted by the Jeep. From this study, an increase in the number of passes decreased the amount of available photosynthic tissue of the plants and, hence, the general health of the plants. The authors concluded that upon cessation of impact a period of vegetative regrowth can be expected in three years or less.

\section{Positive Changes}

Some authors have indicated that man-caused disruption to vegetation may not always have negative effects. Johnson et al. (1975) compared vegetation along road edges with nearby undisturbed areas in the desert. The vegetation along the road edge showed significant increases when compared with undisturbed areas. Density increased by $65.8 \%$, percent cover increased by $81.6 \%$ and above ground biomass increased by $85.0 \%$. The authors concluded that roads can act as water harvesting systems (compacted soil can reduce infiltration and increase runoff) and runoff from the roads is collected along the edges. This increase in water supply creates greater plant growth. This same sort of phenomenon may sometimes take place with ORV tracks and trails. Transect data from the Lathrop report (1978) showed a $22 \%$ increase in annual cover in-tracks as compared with out of tracks at one pit area. This may have been due to water accumulations even though the vegetation cover in other areas (see Section 5) declined. Studies by the University of California, Irvine (U.C.I., 1974) showed an increase in annual plant diversity (based on Shannon-Wiener Index) in motorcycle tracks as compared with controls. This may have been the result of creation of new microsites in and along the track edge. This would create a higher diversity of species but the authors noted there was still a decrease in the number of individuals per species and any minor positive benefits would be offset by the decrease in individuals. 


\section{E. Ecosystem Implications of Vegetation Changes From ORV Activity and \\ Conclusions}

There are three possible outcomes from an ORV running over a plant. Each outcome is tempered by the intensity and season of impact. A plant may be uprooted, desiccate and die, or have the foliage broken down and crushed to a condition where no photosynthetic material is left to produce energy (Klock, 1976; Davidson, 1973). In this situation, resprouting may take place (Beatley, 1974) but this is dependent on the plant species, the amount of root energy reserve available and the intensity of ORV use. A second type of impact can reduce plant foliage through breakage and partial crushing of branches. This decreases the photosynthetic surface and above ground biomass, which reduces plant productivity (Vollmer et al, 1976). Losses in above ground biomass reduce the carbohydrate reserve available to the root system and could starve the plant (Vollmer et al, 1976). The plant may be able to resprout but may require a 10 to 20 year period for recovery (Beatley, 1974; Vollmer et al, 1976). A third type of impact involves a partial crushing of plants and damage to root systems. This decreases the ability of the plant to absorb water, thereby reducing photosynthesis and carbohydrate production and the plant could starve. These seemingly simple scenarios are in reality far more complicated and may result in subtle and far reaching effects on the plant community.

From the research gathered and analyzed, generalizations as to the effects of ORV use on vegetation can be predicted: (1) ORV use will reduce perennial plant cover and above ground biomass. The degree of loss is dependent on the intensity of use (Lathrop, 1978; Kuhn, 1974; Snyder et al, 1976; Davidson and Fox, 1974; Davidson, 1973; U.C.I., 1974; Johnson, unpublished; BLM, unpublished; Wood and Robertson, 1976; Duck, 1978). (2) A reduction is perennial plant density often occurs in ORV use areas, especially in areas of moderate to heavy use (Keefe and Berry, 1973; Bury et a1, 1977; Lathrop, 1978; U.C.I., 1974; Vollmer et al, 1976; Broadhead and Godfrey, 1977; BLM, 1975; Sparrow et al, 1978). The terms "moderate" and "heavy" have not been quantitatively defined, but are relative terms and may vary somewhat from site to site. (3) In areas of ORV use (primarily open competitive or extensively used areas), the smaller shrubs are often the first to be damaged and eliminated from a use area. This tends to reduce the plant diversity of the impacted area as indicated by Keefe and Berry (1973), Lathrop (1978), Hall (personal observation), BLM (1972), and Johnson (unpublished). (4) Annual species are affected in similar ways to the perennials (Johnson, unpublished; Vollmer et al, 1976; U.C.I., 1974; Lathrop, 1978); however, slight disturbances may cause no measurable differences with regard to either annual or perennial plants or show some positive response by increasing cover or diversity (Lathrop, 1978; U.C.I., 1974). (5) Changes in the plant community induced by off-road vehicles is directly related to the intensity of use and environmental factors (Johnson, unpublished; U.C.I., 1974; Vollmer et al, 1976; Lathrop, 1978; Broadhead and Godfrey, 1977). (6) Some perennial plants can recover from some ORV impacts. 
If the plant crown has not been completely killed and if sufficient time is given between impacts, some species will resprout (Vollmer et al, 1976; Hall, personal observation; BLM, unpublished; Lathrop, 1978). Best estimates on resprouting perennial plant recovery appear to be around 10-20 years (Beatley, 1974; Vollmer et al, 1976) but soil recovery may be much longer (see Sections 1 and 5). These types of impacts can have large scale implications on the whole ecosystem depending on the size and/or extent of the disturbance and the frequency and intensity of impacts.

Conclusions of the various authors on ORV impacts and effects on vegetation can be expanded as to the effects on the entire plant community. These effects would, in turn, affect other life forms that are dependent on the vegetation. Projecting the long-term effects is very difficult because the biological, environmental and impact processes are not fully understood. Therefore, predictive computer modeling would not be feasible at this time (see Figure 3.2 ).

As plant cover and density is reduced, so is the amount of photosynthetic material for energy production. This reduces plant vitality and available energy to the ecosystem and reduces community stability. As plant diversity is reduced, so is plant productivity and community stability. Other impacts affect soil characteristics which affect vegetation (see soil-plant relationships). All of these impacts affect the animal populations dependent on vegetation. These sequences would occur if large areas were highly disturbed or if a series of smaller areas of close proximity were highly disturbed. A few authors have projected estimates on rate and extent of ORV impacts.

Keefe and Berry (1973) estimated that 960 acres of Dove Spring Canyon has been intensively damaged by ORV use. Of this about 240 acres have been denuded of plant cover. Of the remaining 4,060 acres of the open area, another 303 acres have been denuded by trails. Through extrapolation they estimated that 1,086 acres would be lost in 10 years and 1,629 acres in 20 years. The 1,629 acres constitute about $32 \%$ of the total Dove Springs open area. These estimates seem rather high in light of measurements made by Adams and Endo (Table 1.7, this report) using 1973 aerial photographs of Dove Springs. They found that 176 acres were totally denuded of vegetation (hill climbs, pit areas and campsites) and 110 acres were covered by highly compacted trails. Even allowing for a $300 \%$ increase in 10 years such areas would only constitute about $8 \%$ of the total open area. Bury et al (1977) estimated that a square kilometer of creosote shrub habitat (Johnson Valley, Anderson Valley, Stoddard Wells area) would contain about 6,650 terrestrial vertebrates weighing about 285 kilograms. According to their study, heavy ORV use over $1 \mathrm{~km}^{2}$ would destroy about 3,000 individuals weighing $220 \mathrm{~kg}$. In moderately used areas, about 830 individuals would be lost or about $185 \mathrm{~kg} / \mathrm{km}^{2}$. These types of extrapolations by Keefe and Berry (1973), and Bury et al (1977) though interesting, are very simplistic and highly speculative. The numbers are probably not true reflections but the inferred trends illustrate the essentially negative outcome of moderate to heavy ORV use on the local biota. 


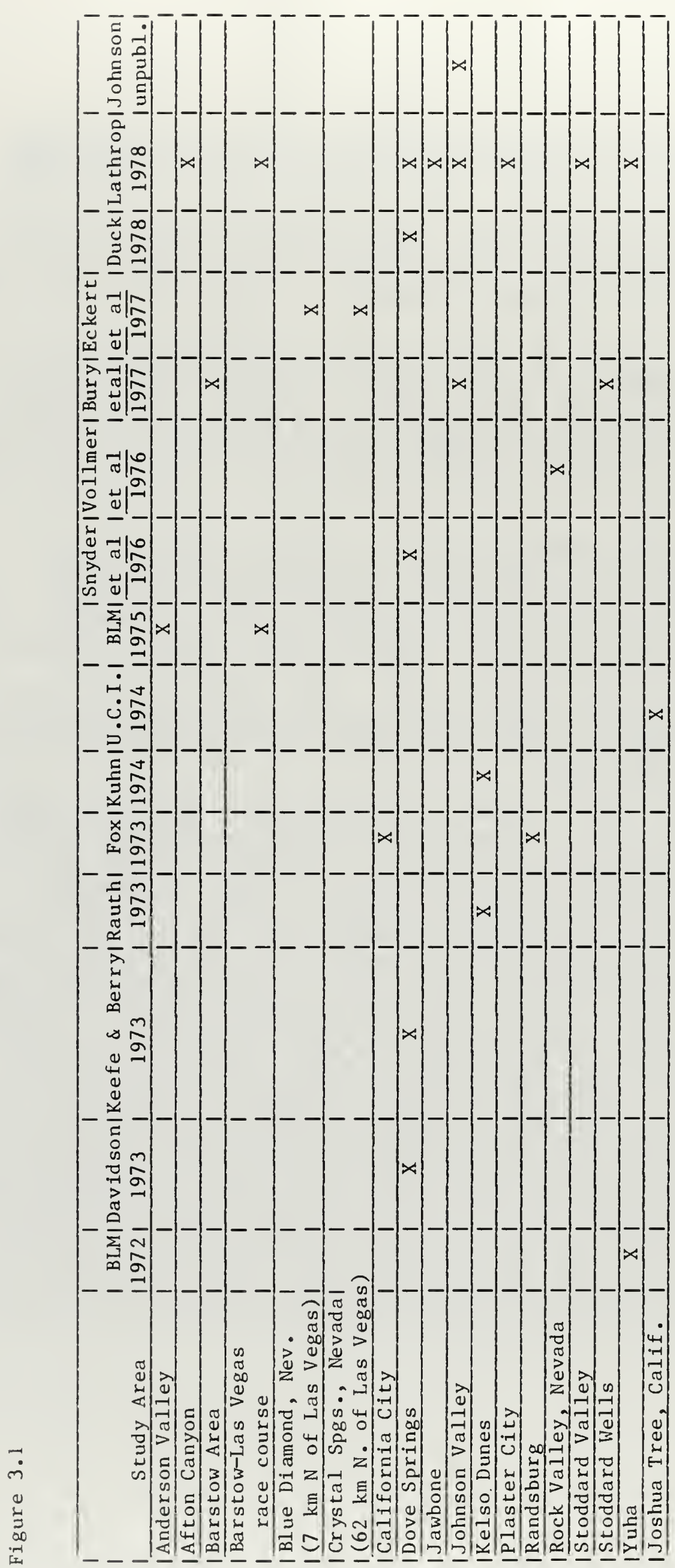








IV. RECOVERY, SUCCESSION, AND REVEGETATION IN THE MOJAVE DESERT

BY

PETER G. ROWLANDS

TABLE OF CONTENTS

A. Definitions ................... $\frac{\text { Page }}{76}$

1. Recovery. ................... 76

2. Succession. .............. 76

3. Revegetation. . . . . . . . ...... 76

4. Climax................ . . 77

B. Succession in Deserts . . . . . . . . . . . . 77

C. Site Specific Studies of Desert Succession. . . . . . . . 79

1. Succession Within Creosote Bush Scrub of the Mojave

Desert.................... 79

a. Energy Corridors ............. 79

b. Abandaned Mine Sites............ 82

c. Patton's Tank Tracks........... 87

2. Succession Recovery of Vegetation in a Nevada Ghost Town. 88 a. The Studies of Wells (1961). . . . . . . 88

b. the Studies of Webb and Wilshire (1979). . . . 90

3. Succession Within an Eastern Mojave Cholla Stand. . . . 99

4. Primary Succession of Halophytes in Rabbit Dry Lake . . 102

5. Conclusions and Comments. . . . . . . . 104

D. Revegetation and Rehabilitation After Impact. . . . . . 106

1. Site Specific Studies . . . . . . . . . 106

a. Panoche Hills................ 106

b. Rehabilitation of a Disturbed Area in the Mojave Desert

- The Los Angeles Aqueduct . . . . . . . . 108

2. Conclusions and Comments. . . . . . . . 118 



\section{A. Definitions}

\section{Recovery}

The return of any specific area, after disturbance, to a condition comparable to that which existed before can be termed recovery. The precise methods of evaluation depend partly upon the investigator and partly on the nature of the information previously known about the area in question. In general, recovery of vegetation is measured by some absolute quantitative vegetational variable such as density, cover, or biomass together with relative indices of species composition such as the Importance Value or I.V. (Curtis, 1959). Recovery may be managed or natural, or a combination of both. Managed recovery could involve artificial revegetation, or various prescribed management and rehabilitation techniques. Natural recovery involves only the natural processes involved in either succession or cyclical change.

\section{Succession}

Succession is the result of processes or a process of community development; an ecocline in time and space; physical and biotic changes within a biogeocoenosis brought about by a back-and-forth interplay between organisms and the environment, each modifying and remodifying the other through an array of negative feedback loops; a gradient of changing environment and a gradient of changing species populations and community characteristics which parallel one another. Causes of succession may be both external or internal to the community or both kinds of causes together with reciprocal influences (Whittaker, 1975; Weaver and Clements, 1938; Clements, 1916; Margalef, 1968). Successions may be autotrophic or heterotrophic (Odum, 1971), retrogressive or progressive (Mueller-Dombois and Ellenburg, 1974). Primary succession takes place on areas where no soil has been developed, secondary on areas which have been in some way denuded of plant growth, but upon which the original soil or a remnant thereof remains (Odum, 1971; Whittaker, 1975; IluellerDombois and Ellenburg, 1974). During successional change there is a progressive alteration in the structure and species composition of the vegetation. In cyclical change, similar vegetation types recur in the same place at various intervals of time. Secondary succession is a feature of the process of recolonization of a disturbed habitat (Grime, 1979).

\section{Revegetation}

Revegetation may be natural or a management prescribed practice. That is, a concerted attempt to stabilize denuded, disturbed areas by the artificial planting or dissemination of native or non-native plants Revegetation is not necessarily synonymous with succession. The former indicates only that an area has "recovered" to the extent that vegetation cover (or biomass) is returning or has returned to a level which existed prior to the disturbance. In reality, because of the wide spread, though sporadic, nature of ORV damage most areas recover their vegetational cover naturally. 
Revegetation differs from rehabilitation which suggests returning the disturbed area to the level of productivity that existed prior to the disturbance; reclamation which implies returning the disturbed site to a level that will support the original (or similar) organisms found in the area; and habitat restoration which requires complete reconditioning and total recovery of the the disturbed area so as to precisely replicate the conditions and species composition that existed prior to the disturbance.

\section{Climax}

A steady-state undisturbed biotic community, the characteristics of which are determined by the characteristics of its own habitat with no evidence of directional change and relatively stable compared with the stages that lead to it (Whittaker, 1975). Within a region, there may be many such biotic "climax" communities which intergrade as ecoclines. Such climax communities should not be interpreted as a mosaic, but as a pattern of intergrading communities corresponding to a pattern of regional environmental gradients. Within this pattern one can usually recognize a central or most extensive steady-state community type which, in some cases, may reflect the regional climate and could be referred to as the climatic or prevailing climax (Whittaker, 1975). According to some authors, the post-glacial vegetation of temperate regions is never stable or therefore "climax." Since primary succession is never terminated, the word climax is meaningless (Miles, 1979; Egler, 1979).

\section{B. Succession in Deserts}

There appears to be a dearth of literature dealing with succession in desert areas. A perusal of Deserts of the World (McGinnies et al, 1977) revealed the absence of the word "succession" from the subject index with not a single portion of the book devoted to succession or related subjects. Work done in North American desert areas has tended to deny the existence or importance of succession in desert areas (Muller, 1940; Pianka, 1974; Shreve, 1942) due to observations of only short-term shifts in species composition indicating a sort of dynamic homeostasis (Vasek, 1979a) or as Odum (1971), Pianka (1974), Shreve (1942) and Beatley (1976) have asserted, that desert vegetation upon destruction, replaces itself directly by new seedlings of the same species. This situation seems similar to the concept of "auto succession" as described by Hanes (1971) in the California chaparral and applied by Beatley (1976) to the desert vegetation of the Nevada Test Site. Shreve (1942) explained the absence of succession in desert areas as being the result of a total lack of reaction of desert plants upon the habitat. Thus, absence of progressive, directional developments of soil, microclimate and other factors preclude sequential and directional changes in species populations. Obviously, the above authors are interpreting true succession as constituting more than one sere or recognizable stage. According to Grime (1979), where the productivity of the habitat is low, the role of ruderal plants and competitors in secondary succession is much contracted and stresstolerant herbs and shrubs become relatively important at an earlier stage. Under severe stress, ruderal and competitive species may be totally excluded and succession may involve simple colonization or recolonization. 
Pickett (1976) believes that ecosystems undergo five general trends through succession.

1. A shift from producing to maintaining

2. An increase in structural complexity and diversity

3. An increase in complementarity and selection for competitive ability

4. A tightening and slowing of nutrient cycling

5. An increase in self-regulation of the system

This is basically a reworking of ideas already stated by Margalef (1968) and Whittaker (1975) among others. Vasek (1979a) further adopts the ideas of Pickett (1976) and Whittaker (1975) and provides a modified list of trends accompanying plant succession, especially in desert areas:

1. Early stages of succession are characterized by communities of pioneer plants with relatively uniform, low stature and rather short life spans. (These would be equivalent to the "ruderal" species of Grime (1979).)

2. The community increases in height, structural complexity, stratification, and biomass as the early successional species are replaced by later successional species and by elements of the mature community (Grime's "stress tolerant" species).

3. Productivity and species diversity increase, as does niche complementarity, as the community increasingly affects the microclimate and soil development.

4. A shift from producing to maintaining, i.e., a decrease in productivity, occurs as late successional species are replaced by longer-lived climax species.

5. As very long-lived species accumulate biomass, productivity stabilizes at maintenance levels, intermediate long-lived species gradually decrease in population size and extreme stability prevails as selection for competitive ability results in dominance by one or a very few long-lived species (Points 2-5 are of course quite speculative).

Vasek (1979a) goes on to state that: "The successional pattern in the Mojave Desert differs from that in more mesic ecosystems in two major factors: the time span may involve several millenia rather than a few centuries; and the very old, mature community of few shrubs includes extensive and long persistent populations of annual plants." Furthermore, he redefines the role of annuals in desert successions. Typically, annuals are viewed as the first pioneers following disturbance (Odum, 1971 ; Whittaker, 1975; Muller-Dombois and Ellenburg, 1974; Pianka, 1974). However, in deserts this role is usurped by perennial herbs and short-1ived shrubs (Wells, 1961; Vasek, 1979a). Annuals or at least 
some constellations of annual species may be members of stable old communities and therefore probably have evolved highly integrated systems adapted to extended persistence in stable desertic conditions. An example would be the extensive populations of annuals occupying the intershrub spaces in ancient (12,700 BP) Larrea communities (Vasek et al, 1975a, 1975b; Vasek, 1979a, 1979b: Sternberg, 1976; Johnson et $\underline{\text { al }}$, 1975.

Grime (1979) classifies arid and semi arid areas as areas which are unproductive or of low productivity. The dominant plants which make up desert vegetation are "ruderal" and "stress tolerant" species. The early invaders are ruderal species and include desert annuals and shortlived perennials. These species generally have high rates of dry matter production to facilitate rapid completion of the life cycle and maximize seed production at the expense of vegetative development, especially during periods of stress. Ruderals are most prevalent in areas with nonsaline, relatively fertile soils which are exposed to a wet season allowing a relatively short period of rapid growth. Otherwise, the predominant vegetation in arid climates is composed of stress-tolerant perennials. These are comparatively long-lived and exhibit a syndrome of similar adaptations for endurance of conditions of low or limited productivity including: slow rates of growth, the evergreen habit, long-lived organs, sequestration, slow turnover of carbon, mineral nutrients, and water, infrequent flowering, and mechanisms which allow intake (and storage) of resources during unfavorable conditions.

In unproductive habitats (i.e., true deserts), the plant biomass remains low without increasing substantially and the path of succession in most cases moves directly from the ruderal to the stress tolerant phase. In contrast, succession in highly productive habitats is characterized by a middle phase of intense competition in which, at first, competitive herbs, then competitive, shade-intolerant species dominate. In terminal phases, stress tolerance becomes progressively more important as shading and nutrient stress coincide with the development of a large plant biomass dominated by large, long-lived trees. Within areas of intermediate productivity, the appearance of highly competitive species is prevented by early onset of resource depletion. The stress tolerant phase is associated with dominance by smaller, slower growing trees and shrubs in various vegetation types (Grime, 1979).

Grime's successional model, therefore, disagrees with Vasek's to the extent that a large monotonic increase in plant biomass would not necessarily occur during succession in desert regions. Otherwise the models are quite compatible.

\section{Site Specific Studies of Desert Succession}

\section{Succession of Creosote Bush Scrub of the Mojave Desert}

\section{a. Energy Corridors}

In their study of vegetation recovery along energy corridors, Vasek et al (1975a, 1975b) defined four functional categories of plants (Table 4.1). Following severe disturbance, pioneer shrubs such as Hymenoclea salsola, and perennial herbs such as Euphorbia invade the disturbed soil 
Table 4.1. Perennial Species Grouped in Four Functional Categories and Listed in Order of Abundance (Data From Vasek et al 1975)

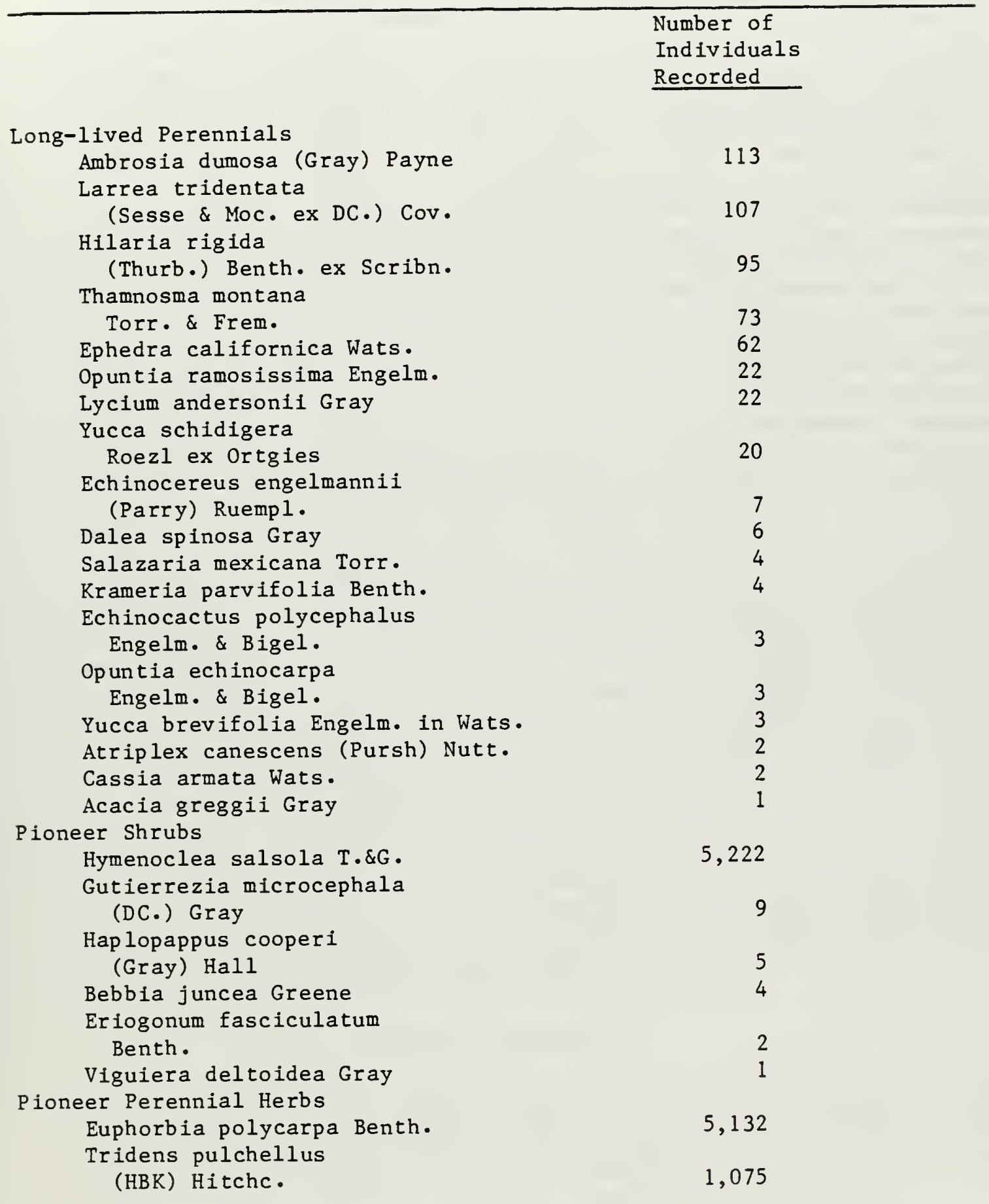


Table 4.1. (Continued)

Number of

Individuals

Recorded

Other Perennials

Sphaeralcea ambigua Gray

103

Eriogonum inflatum

Torr. \& Frem.

24

Dyssodia cooperi Gray

16

Muhlenbergia porteri Scribn. 13

Mirabilis bigelovii Gray 3

Allionia incarnata L. 3

Stephanomeria pauciflora

(Torr.) Nutt.

Sarcostemma hirtellum

(Gray) R. Holm.

1

Nicotiana trigonophylla

Dunal in A. DC. 
and represent an early stage in succession. These pioneers or ruderal species (sensu Grime, 1979) are short-lived species which normally occur within the creosote bush scrub community in "naturally" disturbed situations such as washes and form a small but significant fraction of the mature creosote bush community. They thrive where the Larrea and Ambrosia ("stress-tolerators") are removed. However, Larrea and Ambrosia are not completely eliminated from disturbed areas indicating that members of the mature community also have some capacity to serve either as pioneers or persistent "holdovers," an idea compatible with Grime's (1979) model of succession in unproductive habitats.

Thus, it is characteristic of the Creosote Bush plant community that its members are adapted in varying degrees to slight, continuing disturbance. Within this sparse vegetation type there is always some open ground due to soil shifting, wind, and water erosion, and other slight disturbances. Stands of Creosote Scrub occur as a mosaic composed of various successional stages, and plants such as Hymenoclea and Euphorbia always have suitable sites in which to persist, at least in low numbers (Vasek et al, 1975a, 1975b; Vasek and Barbour, 1977). Eventually, after a period of time measured in terms of centuries, the long-lived perennials gain ascendancy over the short-lived species which are henceforth restricted to their slightly disturbed habitats within the mature Creosote Bush Scrub Community. Exactly how long does this take? Within certain parts of the Mojave Desert (Upper Johnson Valley, for example), where the substrate is relatively stable as suggested by low erosion rates and gentle terrain, creosote bushes clone by progressive crown splitting, manifesting in an outwardly expanding ring of clonal individuals. As mentioned previously, these clones, or more properly, the clonal genome may be as much as 12,700 year old. Diameters of such clonal rings may exceed 6 meters and grow outward at rates estimated between 0.026 and $0.143 \mathrm{~cm} /$ year for rocky and sandy substrates respectively with an average increase in diameter of $0.84 \mathrm{~cm} /$ year (Sternberg, 1976). Associated with these areas of clonal Larrea rings is a floristically rich and dense annual vegetation. The correlation of this annual flora with a stable uniform shrub community of low species diversity and cover, but extreme antiquity suggests that these ruderal (sensu Grime, 1979) desert annuals comprise an integrated and adapted component of very old communities. These age considerations suggest that old, stable Larrea populations may include clonal creosote rings of considerable antiquity. Complete vegetational recovery from catastrophic disturbance would not be expected for several millenia if at all (Vasek et al, 1975).

\section{b. Abandoned Mine Sites}

Sulenski (1972) studied the natural revegetation on some abandoned sand and gravel operations in the Nevada Desert near Las Vegas. All the sites were located in a Creosote Scrub Vegetation type (Table 4.2), and had been abandoned from 2 to over 10 years. The four sites described in Table 4.2 were at least 9 years old. According to Sulenski:

1. No cacti or yuccas succeeded in reestablishing themselves on any of the disturbed areas.

2. Those species that did reinvade tended to be ones which had wind-dispersed seeds. 
Table 4.2. Comparison of the Vegetation at Four Sand and Gravel Operations near Las Vegas, Abandoned in the Early 1960's (Data from Sulenski, 1972).

\begin{tabular}{|c|c|c|c|c|c|c|c|c|}
\hline & \multicolumn{4}{|c|}{ Undisturbed Areas } & \multicolumn{4}{|c|}{ Disturbed Areas } \\
\hline & $\begin{array}{c}\text { Site } \\
1 \\
\end{array}$ & $\begin{array}{c}\text { Site } \\
2 \\
\end{array}$ & $\begin{array}{c}\text { Site } \\
4\end{array}$ & $\begin{array}{c}\text { Site } \\
5 \\
\end{array}$ & $\begin{array}{c}\text { Site } \\
1 \\
\end{array}$ & $\begin{array}{c}\text { Site } \\
2 \\
\end{array}$ & $\begin{array}{c}\text { Site } \\
4\end{array}$ & $\begin{array}{c}\text { Site } \\
5 \\
\end{array}$ \\
\hline Acacia greggii & + & + & & & & & & \\
\hline Ambrosia dumosa & + & + & & & + & + & & \\
\hline A. eriocentra & & + & & & & & & \\
\hline A. confertifolia & & & + & + & & & & \\
\hline Baileya sp. & & & + & + & & & & \\
\hline Coryphantha vivipara & & & & + & & & & \\
\hline Dalea fremontii & & & + & + & & & + & + \\
\hline Echinocereus engelmannii & & & & + & & & & \\
\hline Echinocactus polycephalus & & & + & + & & & & \\
\hline Ephedra nevadensis & + & + & & + & + & + & + & $\begin{array}{l}+ \\
+\end{array}$ \\
\hline Eriogonum inflatum & & & & + & & & & + \\
\hline Hymenoiidea salsola & & & + & + & & & + & + \\
\hline Krameria parvifolia & & + & & & & & & \\
\hline Larrea tridentata & + & + & + & + & + & + & + & \\
\hline Lepidiam fremontii & + & + & & & + & + & & \\
\hline Lygodesmis sp. & & + & & & & + & & \\
\hline Opuntia acanthocarpa & & & + & + & & & & \\
\hline 0. basilaris & & & + & + & & & & \\
\hline 0. ramosissima & + & & & & & & & \\
\hline Salvia carnosa & + & & & & & & & \\
\hline Yucca schidigera & + & & + & + & & & & \\
\hline Year Mining Ceased & & & & & 1962 & 1962 & 1963 & 1962 \\
\hline Elevation (M) & & & & & 707 & 707 & 853 & 1036 \\
\hline
\end{tabular}


Table 4.3. Growth Rates and Estimated No. Yrs. to Maturity of Some Common Plant Species of the Nevada Desert (Data From Sulenski 1972)

Plant Years to Maturity Growth Rates (cm-yr ${ }^{1}$ )

Larrea tridentata

Yucca schidigera

Yucca brevifolia

Echinocereus engelmannii

Echinocactus polycephalus

Ferocactus acanthodes

Opuntia basilaris

Agave utahensis

Fouquieria splendens
$13-18$

$10^{1}$

35

90

$$
12-15
$$

25

25

$$
\text { 2-10 }
$$

$6-30$

$16-18$
$5-25$

$2-11$

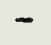

$-$

$-$



1 Rice (1971) gives values of around $5 \mathrm{~cm} / \mathrm{yr}$ for the first 8 growing seasons in the western Mojave Desert of California on disturbed site 
Table 4.4. Absolute Cover of Perennial Vegetation at Gen. Geo. A. Patton's WWII Camp - Needles, Ca. ( $C=$ cover, $\mathrm{N}=$ number of plants $)$

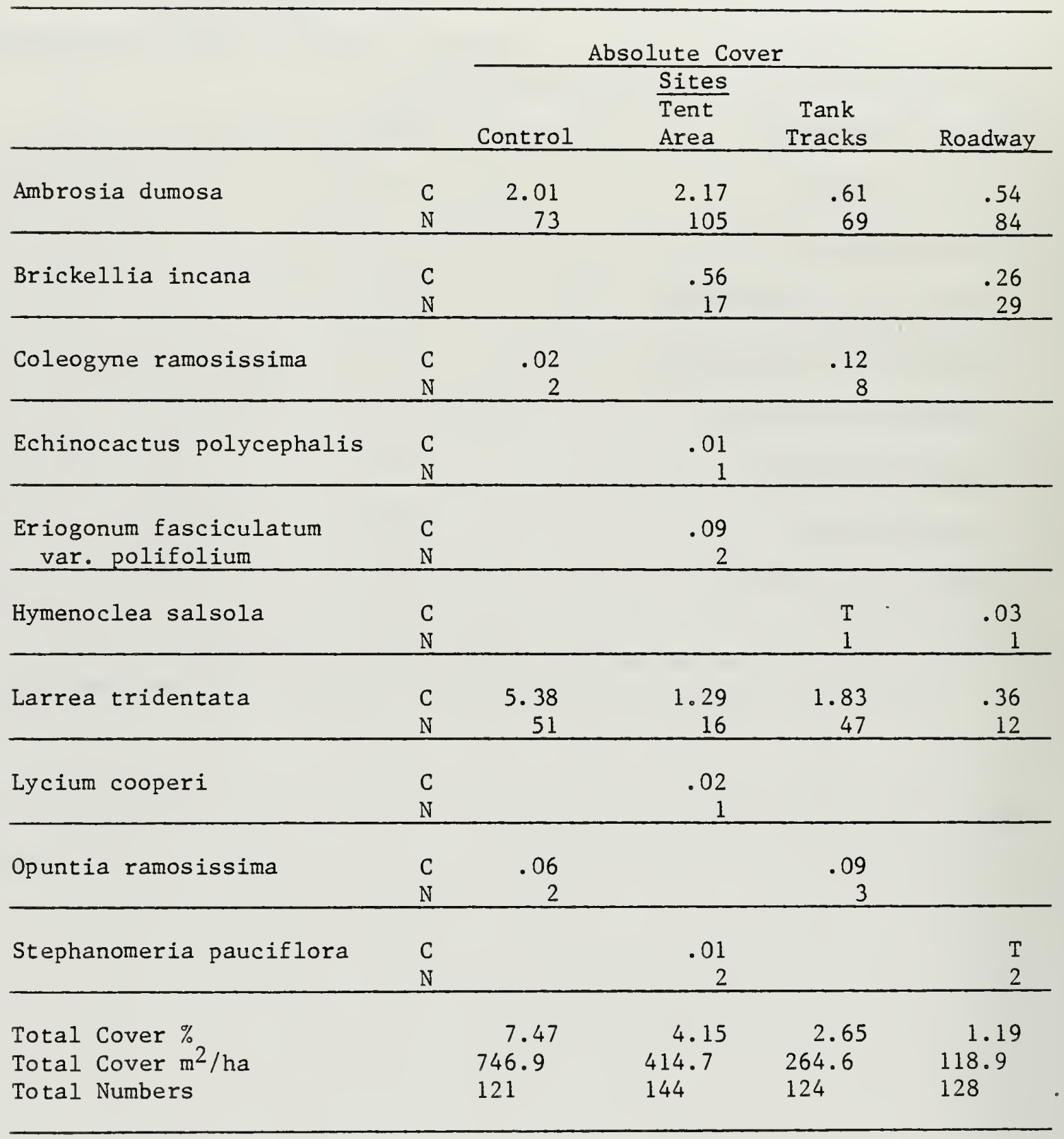


Table 4.5. Absolute Cover of Perennial Vegetation at Gen. Geo. A. Patton's WWII Camp - Essex, Ca. $(\mathrm{C}=$ cover, $\mathrm{N}=$ number of plants $)$

\begin{tabular}{|c|c|c|c|c|c|}
\hline & & \multicolumn{4}{|c|}{ Absolute Cover $\%$} \\
\hline & & Control & $\begin{array}{l}\text { Tent } \\
\text { Area } \\
\end{array}$ & $\begin{array}{c}\text { Tank } \\
\text { Tracks } \\
\end{array}$ & Roadway \\
\hline Ambrosia dumosa & $\begin{array}{l}\mathrm{C} \\
\mathrm{N} \\
\end{array}$ & $\begin{array}{r}3.68 \\
95 \\
\end{array}$ & $\begin{array}{r}1.93 \\
86 \\
\end{array}$ & $\begin{array}{r}.36 \\
19 \\
\end{array}$ & $\begin{array}{r}.91 \\
74 \\
\end{array}$ \\
\hline Coleogyne ramosissima & $\begin{array}{l}\mathrm{C} \\
\mathrm{N} \\
\end{array}$ & & & $\begin{array}{r}.01 \\
2 \\
\end{array}$ & \\
\hline Larrea tridentata & $\begin{array}{l}\mathrm{C} \\
\mathrm{N} \\
\end{array}$ & $\begin{array}{r}4.89 \\
32 \\
\end{array}$ & $\begin{array}{r}2.55 \\
49 \\
\end{array}$ & $\begin{array}{r}2.67 \\
94 \\
\end{array}$ & $\begin{array}{r}.79 \\
22 \\
\end{array}$ \\
\hline Opuntia basilaris & $\begin{array}{l}\mathrm{C} \\
\mathrm{N} \\
\end{array}$ & & & $\begin{array}{r}.01 \\
2 \\
\end{array}$ & \\
\hline Opuntia ramosissima & $\begin{array}{l}\mathrm{C} \\
\mathrm{N} \\
\end{array}$ & & & $\begin{array}{r}.03 \\
3 \\
\end{array}$ & \\
\hline Stephanomeria pauciflora & $\begin{array}{l}\mathrm{C} \\
\mathrm{N} \\
\end{array}$ & $\begin{array}{r}.36 \\
1 \\
\end{array}$ & $\begin{array}{r}.01 \\
1 \\
\end{array}$ & & \\
\hline $\begin{array}{l}\text { Total Cover }(5) \\
\text { Total Cover (m } 2 / \text { ha) } \\
\text { Total Numbers }\end{array}$ & & $\begin{array}{l}8.93 \\
892.6 \\
128\end{array}$ & $\begin{array}{l}\quad 4.49 \\
449.4 \\
126\end{array}$ & $\begin{array}{l}3.07 \\
307.4 \\
120\end{array}$ & $\begin{array}{l}1.70 \\
170.3 \\
96\end{array}$ \\
\hline
\end{tabular}


3. Annual grasses and forbs were common on disturbed areas.

4. Creosote Bush reestablished itself readily and reached maximum heights of about $.9-1.0 \mathrm{~m}$ within 10 years on the disturbed areas, indicating a growth rate of perhaps $.10 \mathrm{~m} /$ year (Table 4.3 ), assuming reestablishment took place immediately after disturbance ceased.

5. Near complete recovery on disturbed areas may take several decades judging from the number of years necessary for most species to reach maturity (Table 4.3). Reestablishment was largely endogenous (Table 4.2). That is, the invaders which established themselves in the disturbed plots could all be found growing in the undisturbed areas of the mine site.

Ephedra and Larrea were present in four and three out of the four disturbed areas of the four sites respectively. "Pioneer perennials" such as Hymenoclea and Lepidium were present in disturbed areas but, in each case, had representatives present in undisturbed portions of the sand and gravel mining sites. When they were not present in undisturbed areas (Table 4.2), they were not found in the disturbed areas either.

\section{c. Patton's Tank Tracks}

Several authors (among them, Lathrop, 1979 and Clements, 1963) have alluded to the "off-road" activities of General George A. Patton and his Tank Corps in the Mojave and Colorado Deserts during World War II. In 1941-42 the U.S. Army conducted training maneuvers in tank and desert warfare in the area between Desert Center, California and Parker, Arizona with extensive activity centered around Essex and Needles, California. We have already mentioned their effect on ambient dust levels, but what about vegetation? A glance at aerial photographs of the region as well as ground inspection shows the continued existence of tracks and tenting/ bivouac areas over 30 years later (Lathrop, 1979). These disturbed areas are easily distinguished from adjacent areas by differences in both the cover and composition of the vegetation. The only extensive study of the vegetational characteristics of these tank tracks and tenting areas was done by Lathrop (1979) who examined the vegetation cover on tracks, tent areas and control areas near Essex and Needles (Tables 4.4 and 4.5). Ground cover of shrubs in tank tracks at both areas was approximately one-third of the control whereas in tent areas ground cover was one-half the control. Assuming that total destruction of plants occurred in the tank tracks (and this is by no means certain), then 36 years has resulted in about a 33 percent recovery. Providing recovery in the Creosote Vegetation type is a linear relationship over time (probably it is a sigmoidal relationship as Vasek (1975a) has pointed out), then complete recovery would take at least 108 years.

Interestingly, total numbers of plants are of the same degree of magnitude in all the sites at both areas and at Needles exceed that of the control. Probably in the disturbed sites most of the these represent small plants and seedlings which have become established subsequent to 
the impact. In light of Vasek's (1979a) ideas, the fact that the dominant species in the control are also the same in the disturbed sites (Larrea and Ambrosia) is not surprising; however, there does not seem to be any great influx of pioneer short-lived perennials. Stephanomeria, Hymenoclea, and Brickellia are present, but not in large numbers. Only Stephanomeria occurs in a control (Table 4.5). The other genera do not. Both Brickellia incana and Hymenoclea salsola are often present in washes, as is Stephanomeria pauciflora. Their low numbers could reflect that there is not much of this habitat type in the vicinity, therefore resulting in only a small pool of individuals able to produce potential invaders by means of disseminules. It is evident that a stage of succession made up of short-lived perennials which precedes the return to a Larrea-Ambrosia vegetation type after disturbance is neither a consistent phenomenon nor a necessary sequence of vegetation recovery in the California desert.

\section{Succession and Recovery of Vegetation in a Nevada Ghost Town}

\section{a. The Study by Wells (1961)}

The obscure Nevada Ghost Town of Wahmonie (el. 4,300 feet), located on a bajada south of Look Out Peak, Nye County, has been the subject of a successional study by Wells (1961) and more recently by Hebb and Wilshire (1979). Abandoned in 1928 after the silver ore ran out, Wells (1961) noted pronounced changes in the physiognomy and floristic composition, both quantitatively and qualitatively, of the vegetation in Wahmonie to the extent that an open stand of bunch grass (Stipa speciosa) had partially replaced the desert shrub (Grayia - Lycium) community (Table 4.6). Shrub invasion was proceeding very slowly, with only the vigorous, root sprouting Ephedra and Lycium occurring in both disturbed and nondisturbed areas. He also thought it significant (as has Vasek, 1979a) that Thamnosma, Hymenoclea, and Salazaria, which are characteristic shrubs of naturally disturbed desert habitats, should appear in large numbers on a man-disturbed site. These shrubs of dry washes can become established on the more xeric upland portions of an alluvial fan when the competition of the dominant upland shrubs is largely removed (Wells, 1961). Webb and Wilshire (1980) add that the percent composition (by density) of Stipa varies from 90 percent in a powerline corridor (18 years old) to 68 percent in the streets and 43 percent in the undisturbed areas.

Is succession taking place here? According to Wells (1961) Thamnosma, Hymenoclea and Salazaria are pioneer shrubs, but except for Hymenoclea, they were not recognized as such by Vasek (1979a; Table 4.1). Wells also claims that these plants appeared in large numbers. Yet, a glance at Table 4.6 shows that they account for only 15.6 percent of the total species density in the ghost town streets whereas the three dominant species, Stipa, Ephedra, and Lycium, account for 79 percent of the total species density. Furthermore, these three species plus Thamnosma also occur, albeit in a different compositional makeup, in the undisturbed plot and all together contribute 86 percent of the total species density in the streets. In the long run, the longer-lived species, such as Grayia, will gain ascendancy in the disturbed areas as they recover. 
Table 4.6. Comparison of Desert Vegetation on an Abandoned Street System 33 Years 0ld With That of an Adjacent, Less Disturbed Site.

Density is Given as Plants Per Acre and Frequency as Percentage.*

\begin{tabular}{|c|c|c|c|c|c|}
\hline Streets of Ghost Town & ensity & $\begin{array}{c}\text { Fre- } \\
\text { quency }\end{array}$ & Adjacent Site & Density & $\begin{array}{l}\text { Fre- } \\
\text { quency }\end{array}$ \\
\hline$\frac{\text { Stipa }}{\text { Rupr. }}$ speciosa Trin. $\&$ & 1050 & 96 & $\frac{\text { Grayia }}{\text { (Hook) Moq. }}$ & 1082 & 100 \\
\hline Ephedra nevadensis Wats. & 378 & 86 & $\frac{\text { Lycium }}{\text { Gray }} \frac{\text { Andersonii }}{}$ & 565 & 96 \\
\hline Lycium Andersonii Gray & 351 & 74 & $\frac{\text { Larrea }}{\text { Cav. }}$ divaricata & 344 & 80 \\
\hline$\frac{\text { Thamnosma montana }}{\text { Frem. }}$ Torr. \& & 153 & 48 & $\frac{\text { Ephedra }}{\text { Wats. }}$ nevadensis & 264 & 70 \\
\hline Hymenoclea Salsola T.\&G. & 108 & 32 & $\frac{\text { Coleogyne }}{\text { sissima }} \frac{\text { ramo- }}{\text { Torr. }}$ & 201 & 42 \\
\hline Salazaria mexicana Torr. & 81 & 20 & $\frac{\text { Stipa speciosa }}{\text { Trin. \& Rupr. }}$ & 138 & 44 \\
\hline Grayia spinosa (Hook.) Moq. & . 45 & 20 & $\frac{\text { Thamnosma }}{\text { Torr. \& }} \frac{\text { montana }}{\text { Frem. }}$ & 21 & 8 \\
\hline$\frac{\text { Acamptopappus }}{\text { Gray }}$ & 32 & 8 & $\frac{\text { Acamptopappus Shock- }}{\text { leyi Gray }}$ & $\underline{-}$ & 2 \\
\hline Larrea divaricata Cav. & 18 & 6 & $\frac{\text { Eurotia }}{\text { (Pursh) Moq. }}$ & 5 & 2 \\
\hline Coleogyne ramosissima Torr. & - 14 & 6 & $\frac{\text { Krameria }}{\text { Benth. }}$ & $\underline{a}$ & 2 \\
\hline Dalea Fremontii Torr. & 4 & 2 & $\frac{\text { Opuntia }}{\text { Engelm. acanthocarpa }}$ & pa & 2 \\
\hline Eurotia lanata (Pursh) Moq. & & 2 & $\frac{\text { Yucca }}{\text { Engelm. }} \frac{\text { brevifolia }}{1 \mathrm{~m}}$ & 5 & 2 \\
\hline$\frac{\text { Haplopappus }}{\text { Hall }}$ cooperi (Gray) & & 2 & & & \\
\hline Krameria parvifolia Benth. & 4 & 2 & & & \\
\hline Lepidium fremontii & 4 & 2 & & & \\
\hline TOTAL & 2250 & & & 2650 & \\
\hline
\end{tabular}

* Data from Wells (1961) 
There is no conflict here with the successional concepts of Shreve (1942) and Muller (1940). It should also be noted that Wells (1961) used density as a vegetational importance value. This can be misleading. looking only at the density values in Tables 4.4 and 4.5 (Lathrop, 1979), one would be hard pressed to discern a great deal of difference between disturbed and undisturbed portions of the sites on Patton's tank training areas. Cover or especially biomass would be a better analytic criterion. Furthermore, Wells used a modified point quarter method (Cottam and Curtis, 1956)--a method designed for determining the density of easily discernible individual trees located randomly in Wisconsin upland forests. Since many species such as Larrea, Yucca schidigera, Yucca brevifolia, Salazaria, Ephedra nevadenis, Lycium spp. and a host of other desert plants form clones (individual clone members therefore form aggregates), there is great difficulty in distinguishing not only individuals but also parts of one clone of individuals of a species, from another (Sternberg, 1976). If individuals are aggregated, the point quarter method is known to underestimate density Ludwig et al (1979). In the case of a simulated plant distribution with a poisson-poisson aggregation, the underestimation was over 60 percent of the actual density (Rowlands, unpublished).

\section{b. The Study by Webb and Wilshire (1979)}

Webb and Wilshire (1980) who studied the recovery rates of both vegetation and compacted soil offered a sowewhat different interpretation of the successional phenomena occurring on the Wahmonie site. They concluded that 1) soil in the townsite has not completely recovered in the 51 years subsequent to abandonment; 2) recovery trends indicate a recovery time on the order of a century; 3 ) the composition of vegetation in the townsite consists of short-lived perennials, whereas the surrounding undisturbed vegetation consists mainly of long-lived perennials; 4) soil compaction is a major limiting factor on the revegetation of (anthropogenically?) ${ }^{1}$ disturbed desert areas; 5 ) the recovery rate of vegetation in the compacted soils was too low to predict a full-recovery time.

Unfortunately their analysis of soils suffers from at least two very tenuous assumptions: 1) the authors assume that although the townsite, old main road, and active road were compacted with cyclical loading of different applied pressures, the total load applied at each site probably compacted the soil to a similar high, if not maximum (bulk) 1 density; 2) it is possible to compare the physical properties of soil compacted to a similar high level at three different times and to study the response of the invading vegetation to compaction. Both these assumptions are dependent upon the existence of similar soil composition across the site; the authors admit that, in fact, the soils were coarser in the southwestern part of the townsite and that the vegetation composition of the undisturbed areas shifted eastward from a Larrea-Grayia association to a Larrea-Grayia-Coleogyne association. Bulk density measurements are effected substantially by differences in soil composition among different samples (see Chapter 1). In order for comparable bulk density measurements to be made in the various study sites chosen by Webb and Wilshire (1980) in Wahmonie, the soils would have to have been very similar in composition and bulk density measurements would have to be measured accurately.

1 Parenthetical inserts are Rowlands' 
As far as assessing the relationships between soil compaction and revegetation, which involves plant germination, establishment and growth, are concerned, soil strength is undoubtedly more important a factor than bulk density (Taylor, 1971, 1974). Although the authors made numerous soil strength measurements with a recording penetrometer, these are not used to any degree except to report that the resistence to penetration of the townsite soil is significantly higher to a depth of $20 \mathrm{~cm}$ than that of the nearby undisturbed soil.

Two methods of analysis were used to predict recovery time for compacted soils: a least-squares linear regression and an exponential decay curve to which the data were "force-fit." In the latter instance, presumably since the bulk density of the control or "undisturbed state" is approached asymmptotically, the time required for $90 \%$ complete recovery is predicted. The value for bulk density attained theoretically after this period is equal to the sum of bulk density for the control ( 1.50 $\mathrm{g} / \mathrm{cm}^{3}$ ) plus $10 \%$ of the difference between the bulk density of the soil of an active road $\left(1.96 \mathrm{~g} / \mathrm{km}^{8}\right)$. Two other variables, infiltration rates and pentration depth were also used as predictors of recovery time using the same models (Table 4.7). Only one of 6 combinations of variables and models gives results which exceed 1 century. This is the exponential decay model using bulk density as the predictor. Webb and Wilshire claim that this "represents a slower yet probably more realistic trend." Why? All the other situations presented by the authors predicted recovery periods of between 70 and 100 years regardless of the model used. Furthermore, the above mentioned problems with the use of bulk density are doubtless known to the authors. They complete their analysis by pointing out that: "These results should be considered only as order of magnitude estimates since both recovery models are derived from only 4 time dependent data points (in fact, for the linear regression model, there are only 3). The authors have apparently used only their mean value points (Table 4.8) in deriving their models, no attempt has been made to analyze the variation in their samples. Certainly an analysis of variance with a posteriori tests are called for. With regard to penetration depths for example, simple conversion of the standard deviations into variances and subsequent application of the $F$ max-test (Sokal and Rohlf 1969) yields an $F \max / F$ min ratio of $3.24 / 0.25=12.96$. Thus, the 4 soils sampled are extremely and significantly heterogeneous with regard to their penetration depths. It can be hypothesized as a result, that the variability of penetration increases as soil compaction is ameliorated. This indicates a "patchiness" quality which could be associated with soils recovering from compaction and which the authors have failed to account for. This patchiness could be expected since the micro and macro-faunal distribution within the soil may itself be patchy. These burrowing animals both small and large, but especially ants, are probably very effective in loosening soils which are compacted. In fact, William P. Mackay, of the Univeristy of California, Riverside, an acknowledged expert on the ants of southern California, has observed that Pogonomyrmex californicus nests were much more frequent within ORVcompacted areas and trails near Phelan, California, than outside of such areas (Mackay, personal communication). Any prediction of recovery time must take into account the possibility of faunal patchiness and that different areas of compacted soil within the same general location, even though compacted at the same time may not recover uniformly. On the whole, the approach to this very complex problem seems rather naive, 
simplistic and written from a point of view which the authors seem to have convinced themselves is correct in spite of data which they clearly present. For example, in the case of a second control and a sample taken from the town's streets and avenues, the mean bulk density in the control is slightly higher than in the "compacted" streets ( 1.61 vs 1.58) after 51 year abandonment little subsequent mention is made of this phenomenon; neither is it used as part of their major analyses nor is it treated at further length in the discussion. It can not be asserted that the mean value for the bulk density of a "control area" constitutes some sort of absolute "undisturbed state" toward which recovery proceeds and cannot exceed. In our opinion the use of the exponential decay curve model as presented by Webb and Wilshire is an inappropriate, basically unstable model.

Webb and Wilshire (1980) measured perennial vegetation on the Wahmonie Site using three methods. Cover was measured by $600 \mathrm{~m}$ of line intercepts in both a northeast control and a southwest control, $400 \mathrm{~m}$ in the townsite and $200 \mathrm{~m}$ of intercept in the old main road of the town. Density and compostion were measured by $2 \mathrm{~m}$ belt transects $800 \mathrm{~m}$ long in the streets, $400 \mathrm{~m}$ long in the townsite and $200 \mathrm{~m}$ in the old main road. Point quarter measurements were taken for 600 individuals in the townsite and northeast control and for 100 individuals in the old main road. The basic finding was that long-lived perennial plants such as Larrea predominated in the surrounding vegetation but short-lived perennial shrubs and bunch grasses dominated the townsite and streets and avenues of Wahmonie.

The authors placed two of their transects in the same area as had Wells (1961) and attempted to compare their results with his reporting that:

"Wells' data consistently show higher densities and compositions for the long-lived perennials in both the streets and undisturbed area than our data. The 1961 densities for Larrea and Grayia are twice as large as we measured and the 1961 densities of Stipa are low when compared to our results. This would indicate that the revegetation in 1979 is much less than the revegetation reported for 1961, but no on-site evidence was found to support this conclusion and the work of Shreve and Hinckley (1937) suggests that long-lived perennial densities change little over decades in arid regions. Assuming that a major decrease in perennials has not occurred, the inconsistencies could have been caused by the difference between measurement techniques (point quarter versus belt transect methods), measurement error in both studies, and/or -differences in the actual sites measured in 1961 and 1979. Regardless of the cause, the inconsistencies prevent any meaningful quantitative comparison of the revegetation after 33 years (Wells, 1961) with the revegetation after 51 years (present study)."

However, a simple comparative analysis of Wells' (1961) and Webb and Wilshire's (1980) data by the construction of a stand similarity/dissimilarity matrix (Table 4.9) using the Sorenson coefficient (Mueller-Dombios and Ellenberg, 1974) and a subsequent polar ordination (Figure 4.1) in one dimension (Bray and Curtis, 1957, Beals, 1960, Mueller-Dombois and Ellenberg 1974, Cox 1976) suggests another alternative. The two stands with the greatest ecological distance (ED) between them after ordination in one dimension are the Wells (1961) control (WC) and the Webb and Wilshire (1979) disturbed streets and avenues (WWD) which are .812 ED units apart. Well's (1961) disturbed streets and avenues (WD) are 
Table 4.7

Recovery periods derived from data on differentially compacted soils in and around the Wahmonie Ghost Town, Nevada Test Site. Data from Webb and Wilshire (1980). L.S.R. = Least square linear regression, Ex.D. = "Forced fit Exponential Decary Curve.

\section{Variable}

Bulk Density

Penetration Depth

Infiltration Rate $\underline{\operatorname{tr} *(\text { L.S.R. }) \quad 90 \% \operatorname{tr}(\operatorname{Ex} . \mathrm{D})}$

$75\left(r^{2} * *=.72\right)$

$70\left(r^{2}=1.00\right)$

$100\left(r^{2}=.92\right)$
680

70

80

*tr=time required for complete recovery from compaction.

$* * \mathrm{r}^{2}=$ coefficient of determination for the regression time used to extrapolate the value for $t r$.

Table 4.8 Comparison of soil physical properties in disturbed vs undisturbed areas of the Wahmonie Townsite (Data from Webb and Wilshire, 1980).

Sample Area

$\begin{array}{lcc} & & \text { Mean } \\ \text { Northeast Central } & & 1 . \\ \text { Townsite } & 51 & 1.66 \\ \text { Old Main Road } & 18 & 1 . \\ \text { Active Road } & 0 & 1.96 \\ \text { Southwest Control } & - & 1.6 \\ \text { Streets and Avenues } & 51 & 1 . \\ & & \\ a_{t}=\text { time since abandonment } \\ b_{S} \text { D. }=\text { Standard deviation } \\ c_{n}=\text { number of replicates }\end{array}$

Penetration Depth $\mathrm{cm}$

Bulk Density

Mean S.D. ${ }^{b}{ }^{c}$

Mean S.D.

10.71 .8

$8.3 \quad 1.9$

326

$\begin{array}{ll}4.7 & 0.7\end{array}$

184

1.90 .5

61

$.61 \quad .06 \quad 10$

$1.58 \quad .08 \quad 10$
Infiltration

Rate $(\mathrm{cm} / \mathrm{nr})$

Mean S.D. N

$22.74 .8 \quad 4$

$12.9 \quad 4.4 \quad 3$

$3.4 \quad 2.0 \quad 3$

$2.6 \quad 1.2 \quad 4$

$\begin{array}{lll}16.6 & 2.6 \quad 4\end{array}$

19.96 .24 
fairly similar to Webb and Wilshire's being only about .18 ED units apart and $.65 \mathrm{ED}$ units from Well's control. Webb and Wilshire's control (WWC) however, is vegetationally more similar to both Well's and their disturbed stands (.16 and .32 ED units respectively) than to Wells' control (.49 units). One logical conclusion is that Webb and Wilshires' control area may be disturbed itself, a possibility which seems to have escaped these authors.

The rest of Webb and Wilshires' vegetational data can be treated similarly using a Sorenson coefficent matrix, and polar ordination (Table 4.10, Figure 4.2) based on absolute percent cover as reported for the 0ld Main Road, townsite, Northeast Control, SouthwestControl and the Streets and Avenues of Wahmonie in Webb and Wilshire (1979).

Both controls are vegetationally similarly $(E D=0.17)$ being both dominated by Larrea which constituted $9.5 \%$ cover in the NE control and 9.1\% in the SW control. The major difference between the two is the greater abundance of Grayia and somewhat lower species diversity in the $\mathrm{SW}$ control. The stand most distant from the two controls on this 2dimensional ordination is the Townsite (ED $=.85$ from SW; .87 from NE) which was abandoned 51 years ago. The stand closest to any control is the Streets and Avenues $(E D=0.48$ ) which were also abandoned 51 years. The old main road abandoned only 18 years ago although not too distant from the NE control (ED $=0.53$ ) seems to be quite distant and therefore vegetationally distinct from the other stands (Figure 4.2). Webb and Wilshire mention that this distinctness was due to the unusually high density and cover of Orysopsis on the old main road which resembles its NE control largely because of their similarly high cover of Ephedra nevadensis (2.3 and $1.8 \%$ respectively). Both Wells (1961) and Webb and Wilshire (1979) call attention to the ability of both Ephedra and Lycium to resprout from root crowns. (Which brings up the question of how either Wells or Webb and Wilshire defined individual plants in collecting their density values.) Webb and Wilshire create some confusion when they state that: "surprisingly Ephedra is abundant in the old main road indicating that it was an early invader" then later assert that its presence in the streets and avenues could be due to root crown sprouting and that the high cover of Ephedra in the old main road is: "strikingly incongruous with its low cover in the townsite and unexpected in light of its purported longevity."

If Ephedra does depend on root crown sprouting for a large part of this reproduction and germination of seedlings is rare or erratic, its abundance in the old main road is also likely due to root crown sprouting and its scarcity in the townsite could very well be due to the fact that it was never abundant there in the first place.

Other differences which Webb and Wilshire reported among the sites were total cover and the percentage of the composition contributed by long-lived perennial species (Table 4.11). Although the townsite has a relatively high vegetational cover, the percent of the species composition contributed by long-lived perennials is low as is overall species diversity. Webb and Wilshire state, and properly so, that the townsite has not recovered to the extent that species composition has approached that of 
Indices of dissimilarity (upper triangular matrix) and similarity (lower triangular matrix) derived from vegetational data reported by Webb and Wilshire (1980) and calculated using the Sorenson coefficient (Mueller-Doubois and Ellenberg 1974. S\&A = Streets and Avenues; SWC - Southwest Control; OMR - Old Main Road; TS = Townsite; NEC = Northeast Control.

\begin{tabular}{lccccc}
\hline & S\&A & SWS & OMR & TS & NEC \\
\hline S\&A & -- & .541 & .671 & .671 & .662 \\
SWC & .459 & --- & .772 & .855 & .296 \\
OMR & .329 & .228 & --- & .805 & .719 \\
TS & .384 & .145 & .195 & --- & .855 \\
NEC & .338 & .704 & .281 & .145 & $-1-$ \\
\hline
\end{tabular}

Table 4.10 Indices of dissimilarity (upper triangular matrix and similarity (lower triangular matrix) derived from density data presented in Webb and Wilshire (1980) and Wells (1961) and calculated using the Sorenson coefficient.

\begin{tabular}{|c|c|c|c|c|}
\hline & $\begin{array}{l}\text { S\&A } \\
(1961)\end{array}$ & $\begin{array}{c}\text { S\&A } \\
(1979)\end{array}$ & $\begin{array}{l}\text { Control } \\
\text { (1961) }\end{array}$ & $\begin{array}{l}\text { Control } \\
\text { (1979) }\end{array}$ \\
\hline $\begin{array}{l}\text { S\&A (We11s, } \\
1961 \text { ) }\end{array}$ & -- & .269 & .647 & .257 \\
\hline $\begin{array}{l}\text { S\&A (Webb } \\
\& \text { Wilshire } \\
1979)\end{array}$ & .731 & --- & .812 & .284 \\
\hline $\begin{array}{l}\text { Contro1 } \\
\text { (Wells, 1961) }\end{array}$ & .353 & .188 & -- & .462 \\
\hline $\begin{array}{l}\text { Control (Webb } \\
\text { \& Wilshire, } \\
\text { 1979) }\end{array}$ & .743 & .716 & .538 & --- \\
\hline
\end{tabular}


Table 4.11 Vegetation Summary of the Wahmonie Ghost Town Study Sites (from Webb and Wilshire, 1980).

Site

Total Cover

Total Density

Long-Lived

Years

Perennials

since

Abandonment

\begin{tabular}{lrrrr}
\hline Southwest Control & 25.9 & 8700 & $88 \%$ & -- \\
Streets \& Avenues & 15.9 & 6140 & $40 \%$ & 51 \\
Northwest Control & 19.0 & 7800 & $87 \%$ & --- \\
Townsite & 21.1 & 19500 & $3 \%$ & 51 \\
Old Main Road & 6.6 & 6630 & $35 \%$ & 18
\end{tabular}

the control although revegetation has exceeded that of the northeast control. Probably, the townsite has a higher overall yearly productivity than either control; however this variable was not estimated. In contrast, the streets and avenues, abandoned for the same length of time ( 51 years) as the townsite had lower plant cover but a relatively higher percentage of long-lived perennials (40\% vs $3 \%$ ) and a much lower absolute cover of Hymenoclea salsola ( $1.5 \%$ vs $6.7 \%$ ), a species acknowledged as a short-lived "poineer Species" by several authors (Wells 1961, Vasek et al. 1975, Lathrop 1979). The old main road has been abandoned 18 years and shows revegetation only to the extent of $6.6 \%$ but compositionally is closer to either control than is the townsite. This reflects in a shorter ecological distance on the polar ordination (Figure 4.2). Interestingly the absolute cover of Hymenoclea solsola was only . $1 \%$. Relative cover of Hymenoclea ranged from around 5 to about $8 \%$ in the controls, $9.4 \%$ in the streets and avenues, $15 \%$ in the old main road and $32 \%$ in the townsite. There is clearly no general trend relating to vegetational response of Hymenoclea to differential degrees of disturbance and time since abandonment of the different sites other than the fact that there is a higher relative cover in disturbed areas than in the undisturbed (?) controls.

The old main road was vegetationally quite different from the other disturbed areas (Figure 4.2) a fact acknowledged by Webb and Wilshire and due primarily to the large amounts of Oryzopsis hymeniodes and Stipa speciosa. The infiltration rate and pentetration depth of the old main road are much less than any other disturbed site except the active road and the bulk density is higher. Results shown in part 5 of this report indicate that monocots with diffuse fibrous root systems such as grasses may be able to overcome soil compaction better than other types of plants. This may explain the vegetational differences seen by Webb and Wilshire on the old main road. Obviously disturbance in Wahmonie has created situations for plant response and vegetation that differ both with the site and the type and degree of disturbance which has taken place. 


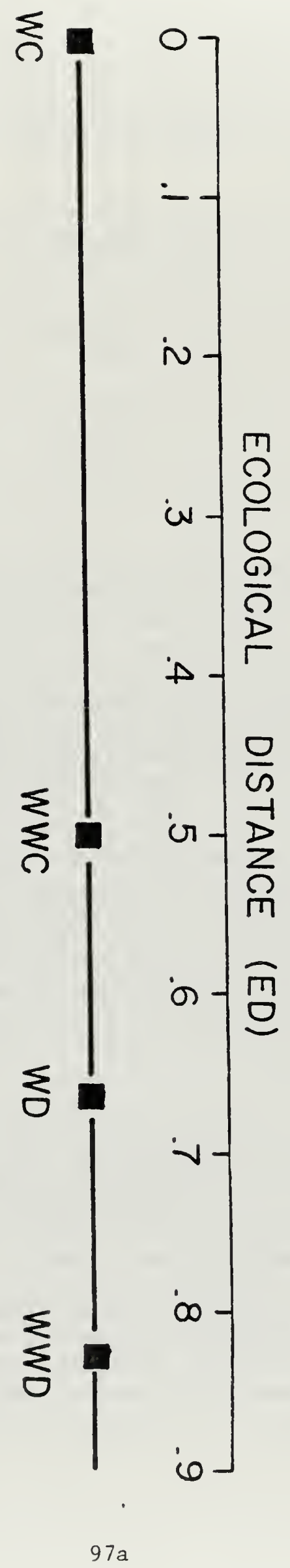

品呂

品

$\pi$ 空

苛菏 is 品 要 कृ के 足

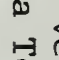
我 tr c 家宫

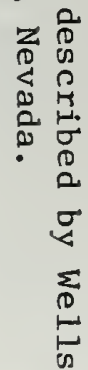




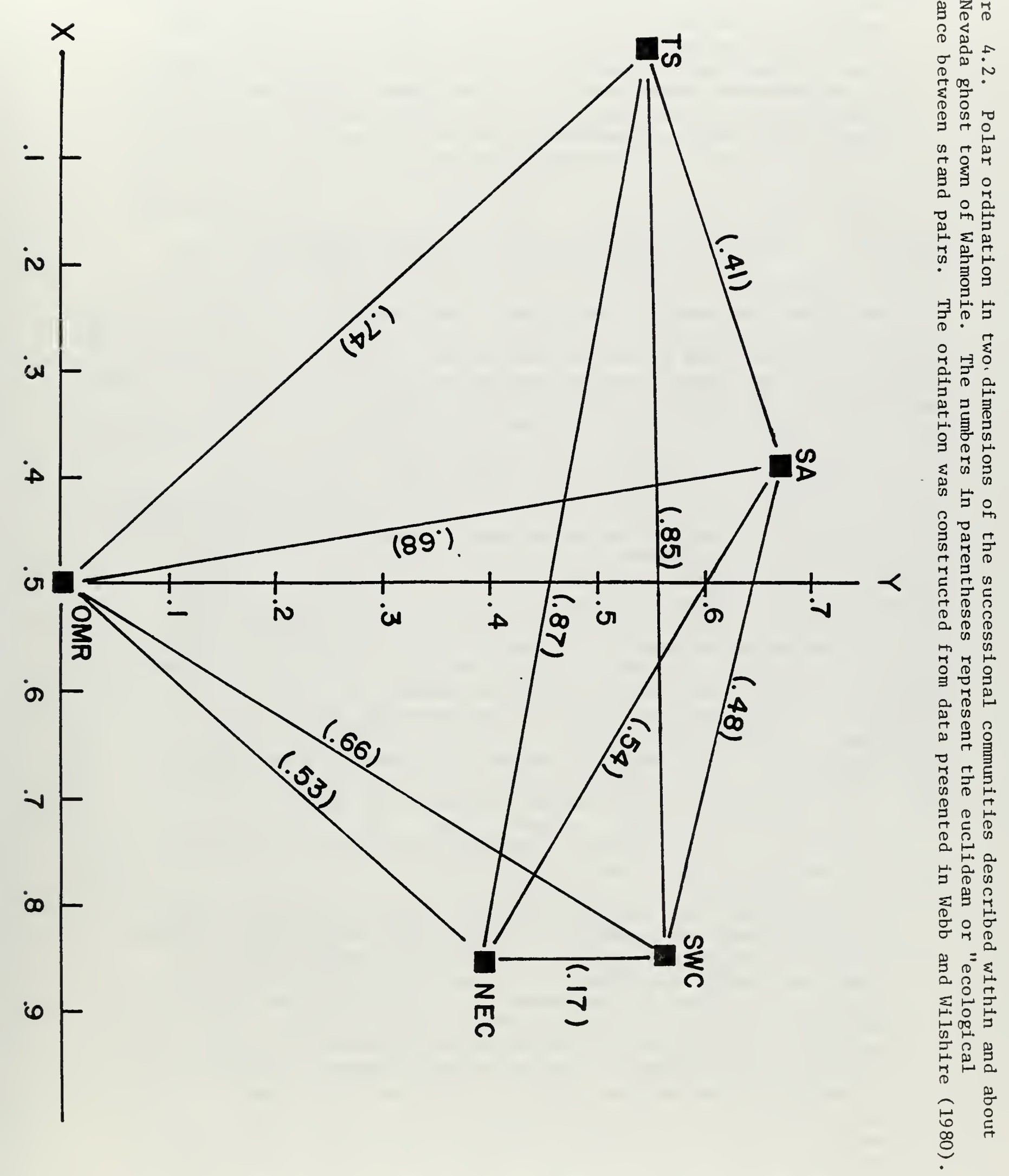


Webb and Wilshire conclude their paper by stating:

\begin{abstract}
"Ecological considerations indicate that further recovery of the vegetation at Wahmonie will be extremely slow. If the percentages of long-lived perennials can be considered as a recovery index linearly dependent on time, then total recovery will require about 100 years for the street and 1-2 thousand years for the townsite. However, recovery cannot be expected to follow a linear trend (Vasek et al. 1975) so these estimates and the Vasek et al. (1975) estimate of centuries are probably optimistic."
\end{abstract}

This statement is misleading. First, Vasek et al. (1975) state and later Vasek (1979a) implied tht the recovery of vegetation was not linear but "sigmoidal," as was also implied by data presented by Chew and Chew (1965). If the relationship is sigmoidal recovery rates could be much faster in the "log phase" - approaching linearity - than in the lag phase, just subsequent to disturbance. Secondly, the term total recovery implies a situation which can never be realized. For example, although a maximum value of 1.00 is theoretically possible, replicate samples for a single homogeneous community ususally show Sorenson similarity coefficients of only about 0.85 (Cox. 1976), usually they are lower. Can one then assume that "total recovery" occurs when the coefficient of similarity between a recovering area and a "control," assuming a control can be defined, is at least 0.85 ? Certainly. The recovery periods cited both by Webb and Wilshire (1980) and Vasek et al. (1975) are neither optimistic nor pessimistic, they are simply estimates based upon a certain set of assumptions which are highly dependent upon the definition of the term "recovery." Webb and Wilshire define recovery as a fullrestoration assuming that soils and vegetation can recover with time to predisturbance conditions. By this definition the townsite of Wahmonie will never recover. The best one can hope for in "total recovery" is the attainment of a new position or state of dynamic vegetational equilibrium which may be identical but would generally be different from the original undisturbed state. The time required for attainment of this state is dependent upon, but not limited to: 1) the nature and extent of the disturbance; 2) the regional climate; 3) the soil factor including parent material; 4) the biological factor; the plants themselves; what kinds are available for revegetation; the soil micro and macro flora and fauna; 5) topography or relief; and will differ among areas.

Probably the best evaluation of disturbed vegetation on the Nevada Test Site has been given by Beatley (1976).

"The region abounds in large and smaller areas where the original vegetation cover has been wholly or partially removed and the soils have been grossly modified. In the Mojave and transition desert areas, recovery of vegetation is an exceedingly slow process, to be considered in terms of centuries of time. At the higher elevations and higher rainfalls of the Great Basin Desert, recovery is a matter of at least several decades. Here increases in rainfall and decreases in temperature are reflected by increased organic matter accumulations, and the whole complex of variables contributes to increased rates of the soil-forming processes at the higher elevations. Removal of the tree and shrub vegetation and physical disturbance of the soils present a greately modified environment in which seedlings must become established. However, even here, although the species 
representation may differ mardekly from that of the original community, it is usually species of the original community that become reestablished and survive in the modified environment.

Characteristic of the whole region is the continuing occupancy of disturbed sites by species of the original vegetation of the area, with population expansions in some species and disappearance or reduced populations in other species. But essentially nowhere in there intercalation of floristically discrete assemblages --seral stages between pioneer and climax communities --- which occurs in orderly and predictable sequence in humid regions (plant succession)."

\section{Succession within an Eastern Mojave Cholla Stand}

Vasek (1979a) observed the reinvasion of plants into a borrow pit located in the eastern Mojave Desert. The pit was constructed in 1970 adjacent to Interstate Freeway 40 at South Pass, California and presented a discordant scar within the otherwise pristine cholla and creosote bush stand. The pit covered $.14 \mathrm{ha}$. and was 1-2 m deep. Vegetation on the pit bottom consisted of Encelia frutescens, Ambrosia dumosa, Stephanomeria pauciflora and other short-lived perennials and was described as having a low degree of structural heterogeneity (Table 4.7). Undisturbed vegetation was dominated by Larrea divaricata, Opuntia bigelovii, with Ambrosia dumosa, Krameria paucifolia, and low growing stem-succulents (Echinocereus engelmanni) as associated species giving this stand a relatively high degree of structural heterogeneity (Table 4.12). Plant density was greater within the pit than without, whereas cover was lower within and greater without. According to Vasek, a very substantial shift in species composition and vegetation structure was observed which demonstrated the occurrence of sencondary succession. Nevertheless, one must be careful in making too quick a judgment. First, according to Vasek, there are soil differences between the borrow pit bottom and the undisturbed. The former is a fine grained, gray soil mixed with rock rubble whereas the latter is a stable intermittent desert pavement of flat rocks darkened with desert varnish on a small bajada. Second, water tends to accumulate on the pit bottom much more than it does on the undisturbed area. Thus, it is entirely possible that a new habitat has been created and that "successional trends" would be far different if the situation involved the simple removal of plants from the bajada without the production of a pit. However, it seems there may be some evidence here for invasions by pioneer perennials to form a temporary assemblage which will. be eventually displaced by more long-lived species. Interestingly, the recruitment of Opuntia bigelovii, whose primary mode of reproduction is vegetative by means of stem joints has been rather fast. Biomass of $\underline{0}$. bigelovii on the undisturbed tract was about 1,700 $\mathrm{kg} / \mathrm{ha}$. as opposed to about $260 \mathrm{~kg} / \mathrm{ha}$. in the borrow pit (Table 4.13). Although this represents only about one-sixth of the control, it can be inferred that the recovery of the cholla has been about 15 percent over the 5-year period since the pit was excavated. At this rate, almost complete recovery of cactus biomass, assuming a linear increase, could be expected in about 35 years, a comparatively short period of time. 
Table 4.12. Vegetational Characteristics in a Mojave Desert Cholla Patch. Samples $\left(D=\right.$ density $/ 100 \mathrm{~m}^{2} ; F=$ frequency (occurrence $/ 100$ sample plots); $C=$ cover $(\%) ; *=$ residual plant; $* *=$ both residual and new plants) (Data from Vasek, 1979a).

\begin{tabular}{|c|c|c|c|c|c|c|}
\hline & Undistu & rbed 1 & Pit Ec & $\operatorname{lge}^{2}$ & Pit Bo & $\operatorname{tom}^{3}$ \\
\hline & Density & Cover & Density & Cover & Density & Cover \\
\hline Long-lived Shrubs & & & & & & \\
\hline$\overline{\text { Larrea tridentata }}$ & 12.33 & 10.19 & $0.54 *$ & 1.53 & 0.88 & 0.01 \\
\hline Krameria parvifolia & 1.00 & 0.19 & & & & \\
\hline Cassia armata & 0.33 & 0.26 & & & & \\
\hline Yucca schidigera & 0.33 & 0.21 & & & & \\
\hline Echinocereus engelmannii & 0.33 & 0.02 & & & & \\
\hline Dalea fremontii & & & $0.54 *$ & 0.71 & & \\
\hline Long-lived Opportunistic Shrubs & & & & & & \\
\hline Opuntia bigelovii & 25.33 & 3.34 & $5.94 * *$ & 1.26 & 5.43 & 0.51 \\
\hline Ambrosia dumosa & 0.33 & 0.02 & 27.57 & 3.23 & 8.86 & 1.06 \\
\hline Pioneer Perennials & & & & & & \\
\hline$\overline{\text { Hymenoclea salsola }}$ & & & 0.54 & 0.45 & & \\
\hline Suaeda torreyana & & & 0.54 & 0.08 & & \\
\hline Erioneuron pulchellum & & & 0.54 & $\mathrm{~T}$ & 1.14 & 0.01 \\
\hline Euphorbia polycarpa & & & 12.43 & 0.01 & 18.00 & .02 \\
\hline Baccharis brachyphylla & & & & & 0.29 & 0.14 \\
\hline Porophyllum gracile & & & & & 3.71 &. .16 \\
\hline Eriogonum inflatum & & & 1.08 & 0.03 & 8.57 & 0.07 \\
\hline Stephanomeria pauciflora & & & 6.49 & 0.42 & 13.71 & 1.04 \\
\hline Encelia frutescens & & & 15.14 & 2.01 & 28.00 & 5.59 \\
\hline Others & & & & & & \\
\hline Dyssodia prophylloides & 0.67 & 0.01 & & & 0.57 & 0.03 \\
\hline Acamptopappas sphaerocephalas & 0.67 & 0.07 & 0.54 & 0.05 & 0.29 & 0.03 \\
\hline Total & 41.32 & 14.31 & 71.89 & 9.78 & 89.45 & 8.67 \\
\hline
\end{tabular}

$1,2,3$ Samples based on $300 \mathrm{~m}^{2}, 185 \mathrm{~m}^{2}$, and $350 \mathrm{~m}^{2}$ respectively 
Table 4.13. Differences in Height, Cover and Biomass of $\underline{0}$. bigelovii Inside and Outside of a Borrow Pit (Data From Vasek,1979a).

\begin{tabular}{lcc}
\hline & \multicolumn{2}{c}{ Area } \\
\cline { 2 - 3 } Pit Bottom & Undisturbed \\
\hline Cover & 49.5 & 96.1 \\
Biomass Estimate $(\mathrm{kg} / \mathrm{ha})^{1}$ & $0.51 \%$ & $3.34 \%$ \\
Year & 260.1 & 1686.4 \\
\hline
\end{tabular}

1 Determined from Volume - Biomass Conversion Data Collected by Bureau of Land Management Desert Plan Staff (1979) 
Interestingly, biomass estimates derived from BLM data (BLM, Desert Plan Staff, 1979) for Encelia frutescens, the dominant plant in terms of cover, in the pit bottom gave a value of $105 \mathrm{~kg} / \mathrm{m}$, about one-half that of Opuntia bigelovii (Table 4.13). Certainly, the interpretation of results depends in large part on what kind of measurements are taken and how the data is manipulated (Major, 1977) but, in this case, we do not think, considering the nature and extent of the disturbance, that a good case for desert "succession," as distinct from that described by Shreve (1942) has been made.

\section{Primary Succession of Halophytes in Rabbit Dry Lake}

The last example of "succession" in deserts is possibly the best documented example of true succession yet found in the southwestern deserts. The case in point was a study of primary succession on the edge of Rabbit Dry Lake, near Lucerne Valley, California (Vasek, 1979a). Vasek observed that, away from the center of the playa, intermittent patches of halophytes may occur on soil mounds which increase in size towards the edge of the dry lake. Both size and vegetation composition of these mounds changed in traveling from the playa to upland regions at the edge of the dry lake. Five zones distinguished by differences in vegetation and mound size (Table 4.14), but which are more or less confluent due to the continuous nature of the processes under study, were observed by Vasek (1979a).

\section{Kochia - Suaeda Zone}

Seedlings of Kochia californica and Suaeda torreyana occasionally become established on the open playa, accumulating sand, silt and organic debris as they grow, forming small mounds in the process. Kochia appeared to establish itself more readily, but Suaeda seems to have the greater mound forming capacity. The largest mounds have both Suaeda and Kochia (Table 4.15).

2. Atriplex torreya Zone

Atriplex torreyi occurs on larger mounds, occasionally with some Suaeda torreyana. Atriplex torreyi apparently establishes itself on the small mounds accumulated by Kochia and Suaeda and then accrues even more material up to a height of $1.3 \mathrm{~m}$ above the playa level. Atriplex torreyi was not observed on the playa or on very small mounds.

\section{Atriplex - Haplopappus or Confluent Mound Zone}

As mounds grow in height, they also grow horizontally becoming confluent with other mounds and increasing dramatically in area (Table 4.14). Areas range from $150-825 \mathrm{~m}^{2}$. Heights are greatest toward the playa and decrease to about $.7 \mathrm{~m}$ away from the playa. Atriplex torreyi is dominant on the higher mounds near Zone 2. Atriplex confertifolia, Haplopappus acradenius and Stanleya pinnata increase in relative biomass on the lower portions of confluent mounds away from Zone 2. Mortality in Atriplex torreyi may open areas in mound vegetation to erosion, 
Table 4.14. Mound Height and Area in Four Vegetation Zones From Rabbit Dry Lake Playa Toward the Lake Edge and Relative Density of The Species Which Grow Above the Lake Shoreline (Zone 5)

(Data From Vasek,1979a)

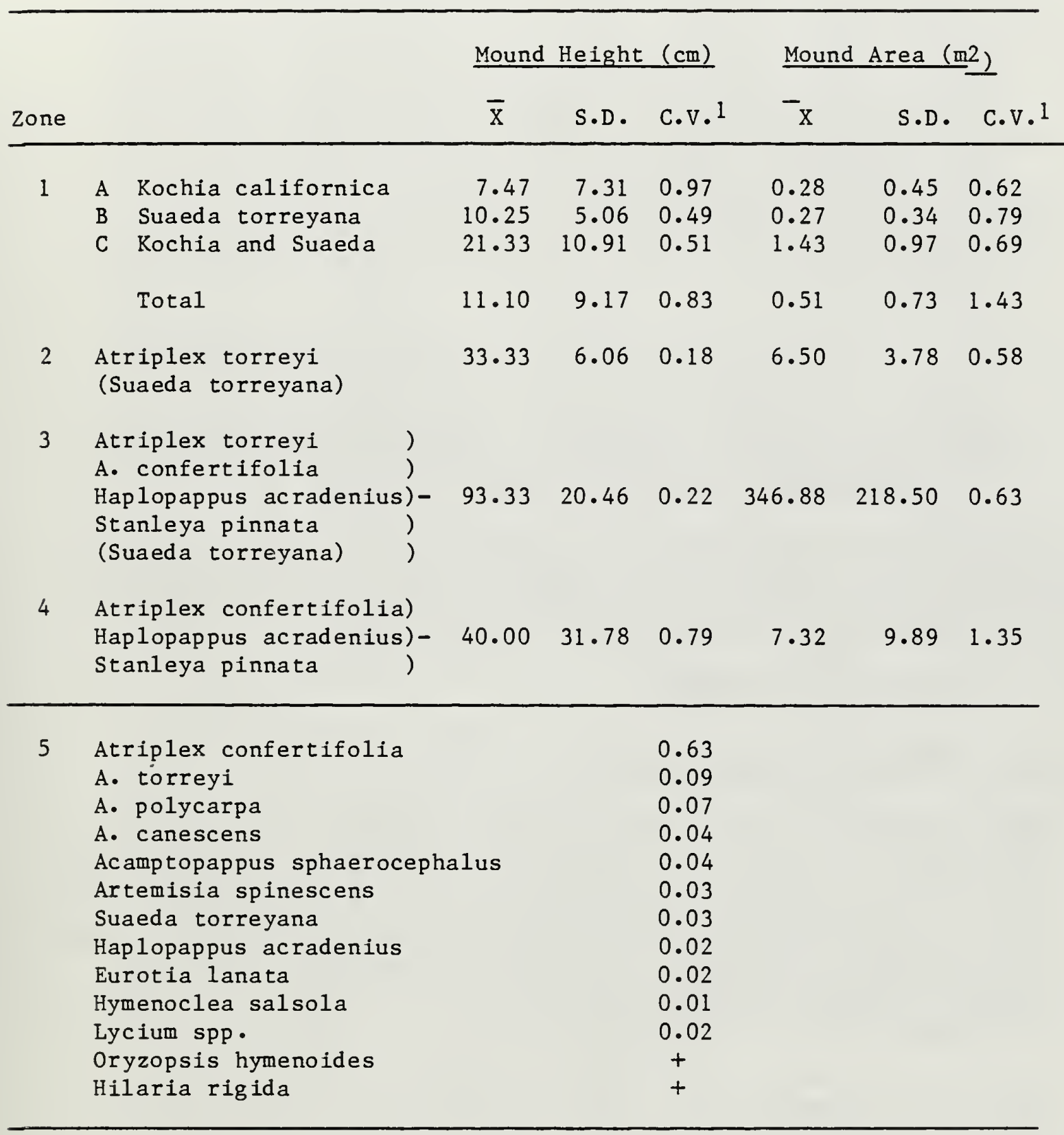

1 Coefficients of Variation (C.V.) calculated by the authors from original data presented by Vasek (1979) 
explaining this decrease in mound height. There is an obvious increase in species richness and in the structural complexity of the vegetation in going from Zone 2 to Zone 3 .

4. Atriplex confertifolia - Haplopappus or Deflation Zone

A heterogeneous mixture of mounds of various sizes in Zone 4 resembles the tops or remnants of the long confluent mounds of Zone 3 (note the large increase in the coefficient of variation for both mound height and area in Zone 4 over Zone 3 as presented in Table 4.14). Erosion of large mounds produces a variety of smaller mounds and partly buries mound remnants in their own debris. This results is an overall decrease in height above the playa level and proceeds to a more or less level plain toward the lake edge. The absence of Atriplex torreyi from most of Zone 4 is the most noticeable vegetational feature.

5. This zone is not strictly a part of the dry lake succession; however, the vegetation of Zone 4 grades into Zone 5 above the shoreline. Continued succession is a reasonable assumption. Vegetation in Zone 5 is dominated by Atriplex confertifolia and also includes $A$. polycarpa, A. torreyi (near the shoreline), A. canescens, and about ten other species (Table 4.14).

The plant species involved in this succession clearly play a role in soil development. Changes in soil properties reflect a "plant reaction" upon the environment permitting a sequential pattern of at least three plant associations in a primary succession (Vasek, 1979a).

\section{Conclusions and Comments}

Some general comments are in order with regard to the concept of succession in arid and semiarid regions:

1. Many authors fail to distinguish between a true succession, as defined by Whittaker (1975) or Odum (1971), and simple re-establishment. often there is a failure to substantiate what Shreve (1942) has called a reaction upon the environment of specific plant species within the successional scheme. In some cases, there may be differences in interpretation depending upon what measurements (i.e., cover, density, biomass) or synthetic indices (e.g. importance value) are used and manipulated in analyzing the data.

2. One should be careful to distinguish between true succession and the effects of spatial zonation due to environmental gradients, and vegetation cycling due to recurrent changes in the environment.

3. Since the effect of plants on soil profile development in deserts is minimal, succession, as defined and studied in mesic ecosystems, may have little relevance in desert areas with respect to soilplant interactions. 
4. Since water is a limiting factor in true desert, and is always very scarce, the biological factors which would be otherwise operating to form soils (e.g., soil microflora) do so at a very slow rate. Probably erosion by wind, water, and other physical and biotic agents exceeds the rate of soil formation, particularly on steep slopes. The dominant species within the desert flora are rigorously adapted to such environmental stresses such as drought, high levels of salinity and alkalinity, and low soil nutrient content. In mesic ecosystems, denudation results in drastic changes in both soil water balance and nutrient balance, creating after disturbance, a situation to which the climax vegetation is poorly adapted. In the deserts, the "climax" vegetation, or more properly the species constituents of the local stable zonal vegetation are adapted to an already very arid and otherwise stressful environment which denudation disrupts proportionally less. As a result, reestablishment of the original vegetation by reseeding, or in some cases vegetative reproduction as with certain shrubs, rhizomatous grasses, and succulents commences upon alleviation of the disturbance and the onset of favorable climatic conditions.

With respect to succession occurring after abatement of a chronic disturbance, favorable climatic conditions may involve the kind of "catastrophic climatic events" described by Holmgren and Hutchings (1972) whose comments on vegetational change after suspension of grazing might well apply to disturbances in general. Elimination of disturbances which have produced compositional changes in vegetation may not alone terminate or reverse changes induced by such disturbances. It may only be under the most favorable of conditions that seedlings of the former species can become established in competition with those species which have developed under the conditions of disturbance. In other words, the system often needs a push.

5. Because longer-lived perennials have a slow rate of growth, a "stage" of vegetational development with "pioneer" perennials may predominate over the young representatives of the former vegetation. (However, this "stage" is clearly not a necessary component of the recovery process, and may be absent in many cases). The latter with time will eventually regain their ascendancy. The former may be present to a greater or lesser degree depending upon local conditions since many are plants which are normally found in washes and other naturally disturbed situations (most have seeds which are wind disseminated). They thrive in disturbed situations probably because of release from competition with the long-lived dominant perennial species shortly after denudation.

6. Because of the extremely long periods of time necessary to develop certain scrub communities, that is, creosote bush scrub with clone formation, the factor of evolutionary changes in plant species within the sequence of vegetational change cannot be ignored.

7. A climax community sensu Odum (1971) cannot be distinguished in deserts; however, successional patterns in unproductive environments, as envisioned by Grime (1979) are observable. 
8. Vegetational change, both cyclic and successional, does take place in arid and semiarid ecosystems. Occasionally, a true succession may be identified such as on dry lake margins (Vasek, 1979a). In general, most vegetational changes are a successional or fall somewhere between the interpretations of Beatley, 1976), Shreve (1942) and Muller (1940), and those of Wells (1961), Webb and Wilshire (1980) and Vasek (1979). Such sequences of vegetational development in arid areas might be termed: PARASUCCESSION.

9. As in other ecosystems of the world, the time required for complete recovery after denudation of arid and semiarid vegetation is on the order of centuries or even millenia.

10. Until long-term studies are made in a variety of sites, discussions of plant succession on deserts will have to be labelled largely theoretical.

\section{Revegetation and Rehabilitation After Impact}

Revegetation may be either natural, as discussed in the previous section, or artificial, as a management practice. In this section we will restrict the discussion to the latter concentrating, for the most part, on reseeding the replanting of native vegetation on mine and energy corridor construction scars. We realize that some revegetation has been attempted in semiarid areas which have received ORV impact (vis-a-vis Panoche Hills; Bureau of Land Management, 1979); however, such rehabilitation has not been attempted on ORV recreational sites in the California desert. In general, rehabilitation of ORV use areas has been minimal on public lands. Where it has occurred, it has mainly consisted of regrading trails after competitive events without any replanting of vegetation (Bureau of Land Management, 1979). Construction and mine site data, therefore, give the most readily available insights into the feasibility and practicability of site-specific rehabilitation of natural areas after disturbance. Rehabilitation of areas after ORV damage may not be feasible because of the extent of the damage and the large size of many of the ORV "open" areas.

\section{Site Specific Studies}

\section{a. Panoche Hills}

The use of the Panoche Hills by ORVs began in 1968 and ended in 1970 when further use was prohibited. The area itself is located southeast of San Francisco in the Inner Coast Ranges and supports a semiarid scrub vegetation of Erodium, Chrysothamnus, Atriplex polycarpa, Festuca and Bromus spp. Vegetation cover was entirely removed in some areas of use and overall plant cover was reduced from an estimated 69 percent in the unused area to 45 percent in the used area (Snyder et al, 1976; Wilshire, 1977).

Accelerated erosion has taken place in the used area resulting in runoff eight times greater and a sediment yield substantially higher $\left(857 \mathrm{~m}^{3} / \mathrm{km}^{2}\right.$ measured over 2 years, versus quantities too small to be measured) than that occurring in the comparison area (Wilshire, 1977). 
In reply to criticism leveled by Sheridan (1979): "The history of BLM and Forest Service management of ORV use is one of failure", the Bureau of Land Management (1979) replied in a position paper stating that:

One area where a general rehabilitation program was conducted with demonstrated success was the Panoche Hills in the California Coast Range. Within the 1100 acres impacted by vehicles, all damaged areas under $30 \%$ slope were contour furrowed and seeded to saltbrush (Atriplex polycarpa) and a variety of perennial grasses to control erosion. Although the perennial grasses did poorly, the saltbrush did very well and today it, and annual grasses common to the area, completely cover the sites leaving no sign of the motorcycle trails. On slopes over $30 \%$, a ball and chain was pulled over the area by a caterpillar tractor to scarify the soil which was then seeded to perennial grasses. Results were disappointing due to non-establishment of perennial grasses. Today, however, annual grasses have come back in these test areas and only signs of the major trails exist where erosion is still occurring. In these areas the erosion has been used to advantage by the California Department of Fish and Game. Under cooperative agreement with the Bureau, they have constructed silt catchment basins below the trails which fill up with soil and are then planted to saltbrush. The brush provides nesting and escape cover for upland game birds and other wildlife. Game bird populations have done well since the closure to ORVs and the hills have become a popular hunting area.

This response prompted Howard Wilshire (personal communication), an expert on the effects of ORVs on soils and erosion, to make the following comments in a letter written to Mr. Charles Warren of the Council of Environmental Quality, dated June 26, 1979:

1. Out of the 1,100 acres, the entire area under 30 percent slope that was rehabilitated was 60 acres, less than 6 percent of the total area impacted and did not include the principal impacted areas but only camping areas and valley bottoms between adjacent slopes.

2. The "rehabilitated" areas are highly conspicuous zones of parallel rows of Atriplex polycarpa and contour-furrowed slopes whose annual plant cover does not mask the plow marks even 7 years after rehabilitation. While erosion control has been achieved, the area is not natural.

3. Although the position paper refers to recovery and "success," recovery rates have not been documented quantitatively.

4. Throughout the Position Paper statement, no reference is made, because there are no data, to the amount of soil that was present in the use area and the amount now remaining. We need to know how much of the still-eroding land has any soil at all on it; how much of it has any hope of reestablishing biological productivity at a level comparable to that which it had before ORV use; and what the present biological productivity of the used land is compared to that not used by ORVs. 
In view of these statements by Wilshire, the "success" of the Panoche Hills program is questionable. In addition, the authors of the Position paper admit that, "the same techniques and revegetation procedures used there (Panoche Hills) may not be applicable to desert or forested areas."

\section{b. Rehabilitation of Disturbed Areas in the Mojave Desert The Los Angeles Aqueduct}

Actually, there are two Los Angeles aqueducts; one, the oldest, was built in 1907 and was opened in 1913, the second was built over a period of 3 years between 1968 and 1971 and runs between Haiwee and Fairmont Reservoirs. Sixty-eight miles by 200 feet $(109.44 \mathrm{~km} \mathrm{x} 60.96 \mathrm{~m}$, or 667.12 ha) are located on public land and a void of perennial vegetation was created along its entire length by construction. Natural revegetation might take as long as 70 years (Rice and Walgren, 1972; Rice, 1970). Unfortunately, the extent of recovery along the old aqueduct may not be a good predictor of the vegetational future of the new aqueduct. According to Rice (1970), the old aqueduct is only a few inches below the soil surface (as opposed to several feet in the case of the new one) and it would be impossible for vegetation to establish on most of its soil cover. The old aqueduct spoil piles show that $12-18^{\prime \prime}$ or about .3 to .4 $m$ of soil has been eroded away since about 1907 and vegetation establishment atop these piles has been sparse (Rice, 1971).

Mean annual precipitation along the aqueduct ranges between $127 \mathrm{~mm}$ at Mojave (el. $833.6 \mathrm{~m}$ ) to $151 \mathrm{~mm}$ at Haiwee Reservoir (e1. $1165.9 \mathrm{~m}$ ). Some precipitation, a negligible amount, falls as snow (U.S. Dept. of Commerce, Weather Bureau). Rainfall tends to be unpredictable in this area, but most falls in the winter with rare thunderstorm activity during the summer, which increases slightly in frequency toward the northern end of the aqueduct. Extremes of temperature at Haiwee may range from $-16^{\circ}$ to $42^{\circ} \mathrm{C}$. The aqueduct area is subject to frequent, often violent, desiccating winds which may both modify the establishment and growth form of plants (Rice, 1971). Soils are derived from decomposing granite, are excessively drained and easily erodible. The A horizon is very low in organic matter, root depth is limited by moisture, and the soils, as a whole, are relatively salt free (Rice, 1971).

In the reestablishment of vegetation on a disturbed area, there is a need to quantify what kind of vegetation and quantity is required to restore the natural aspect (Rice, 1971). The perennial vegetation along the aqueduct is listed in Table 4.15. Although only density values are given, it is obvious that Larrea and Ambrosia are the dominant species. Some important species not sampled included Atriplex hymeneytra, Chrysothamnus nauseosus, Chrysothamnus viscidiflorus, Coleogyne ramosissima, Dalea fremontii, Isomeris arborea, Lepidium fremontii, Opuntia basilaris, o. bigelovii, Oryzopsis hymenoides, Poa scabrella, Salazaria mexicana, and Yucca brevifolia. Many different kinds of annuals are present with Erodium cicutarium being the most common (Rice, 1970).

The objective of the rehabilitation measures along the aqueduct has been to substantially decrease the time for revegetation from $70+$ years 
Table 4.15. Density (No Plants/100m ${ }^{2}$ ) of Perennial Plants and Annual Plant Frequency at Five Undisturbed Locations Along the L.A. Aqueduct (Data From Rice $(1970,1971$ )) Area 1 = Mojave (T. 32 S., R.36 E., S. 7); Area 2 = Freeman Plains (T. 27 S., R. 37 E., S. 26); Area $3=$ Freeman Jct (T. 27 S., R. 38 E., S. $8 \& 7$ ); Area 4 = Nine-Mile Cyn. (T. 24 S., R. 38 E., S. 29); Area $5=$ Red Hill (T. 22 S., R. 37 E., S. 25\&26) Data from Rice (1971).

\section{Perennials}

Eriogonum fasciculatum

Larrea divaricata

Atriplex polycarpa

A. spinifera

Stipa spp.

Haplopappus linearifolius

Ambrosia dumosa

Lepidospartum squamatum

Eurotia lanata

Grayia spinosa

Hymenoclea salsola

Poa spp.

Ephedra spp.

Sphaeralcea ambigua

Haplopappus gracilis

Sitanion hystrix

Lycium spp.

\begin{tabular}{rrrrr}
\hline \multicolumn{5}{c}{ Area } \\
\hline 1 & 2 & 3 & 4 & 5 \\
\hline 13.5 & & & & 37.7 \\
24.2 & 2.7 & 13.5 & 10.8 & \\
& & 2.7 & & \\
& & & 2.7 & \\
2.7 & & 2.7 & & 18.8 \\
2.7 & 35.0 & 37.7 & 2.7 & 21.5 \\
24.2 & 78.0 & 86.1 & 69.9 & 53.8
\end{tabular}

5.4

2.7

2.7

5.4

5.4

5.4

2.7

13.5

5.4

2.7

8.1

Annuals

Erodium cicutarium

Bromus rubens

Schismus spp.

Amsinckia tesselata

Brassica tournefortii

Eriogonum spp.

other (native) annuals

$\begin{array}{lllll}1.00 & .69 & .81 & .75 & .94 \\ .62 & .19 & .19 & .63 & .25 \\ .12 & & .06 & .94 & \\ .19 & .88 & .44 & .13 & .32 \\ & .38 & .25 & .56 & .33 \\ & .25 & .13 & .13 & .12 \\ .44 & .81 & .94 & .56 & .56\end{array}$

I Although listed by Rice, this species is not otherwise known to occur in this area and may be a misidentification. 
to 5-10 (Rice and Walgren, 1972). However, in this area, the degree of success in such a program depends upon several factors (Rice, 1971):

1. Successful germination and establishment of vegetation on the disturbed area.

2. Prevention of $\mathrm{ORV}$ use which could retard establishment and growth.

3. Maximizing moisture intake and retention for rapid growth of perennial plants.

4. Prevention of livestock use to allow vegetation establishment and maximum growth.

5. Choosing the native species most likely to be successful (depending, of course, upon seed availability). In the area of the aqueduct, these would be:

\begin{tabular}{l}
$\frac{\text { Larrea }}{\text { Ambrosia }}$ divaricata \\
\hline Atriplex $\frac{\text { duma }}{\text { polycarpa }}$ \\
A. canescens \\
Eriogonum spp. (1ocal varieties) \\
Chrysothamnus nauseosus
\end{tabular}

6. Solving erosional and other maintenance problems.

Initial attempts at rehabilitation involving artificial seeding by a rangeland drill failed due to an extraordinarily dry spring (Rice and Walgren, 1972); however, subsequent studies have been made by Graves (1976, 1978), Graves et. al., (1978) and Kay $(1974,1975,1976)$. The following is a summary of their results:

Effects of seed storage conditions on germination are summarized in Table 4.16 with viability characteristics in Table 418 (Graves et. al., 1974; Kay, 1976; Williams et al, 1974). These authors found that seeds of Hymenoclea, Larrea, and Ephedra has the highest viability and (except for Larrea) had the highest germination after 7 days (Table 4.17). Larrea seed coats were excised. This action may have reduced germination by damaging the embryo. No evidence of any inhibitory substances on the seed coats was found. In addition, four species (A. canescens, E. nevadensis, Hymenoclea, and Larrea) emerged well from $2 \mathrm{~cm}$ planting depth. A few individuals of $\mathrm{A}$. canescens emerged from $4 \mathrm{~cm}$, and no plants emerged from $8 \mathrm{~cm}$ depths indicating that control of depth of seeding will be essential in rehabilitation projects.

Germination rates could be increased in some species by a variety of chemical and physical treatments (Tables 4.18 and 4.19). According to Graves et. al. (1974, 1978) activated carbon was the most consistent in improving 7 -day germination. Of the six species treated, germination was speeded significantly in four. This treatment need not precede seeding. Activated carbon could be mixed with the seed in normal seeding. Next most effective in improving 7-day germination were treatments with $3 \%$ thiourea, and stratification. Dehulled creosote bush seeds germinated earlier than unhulled seeds. An inhibitor was suspected since a 15 hour 


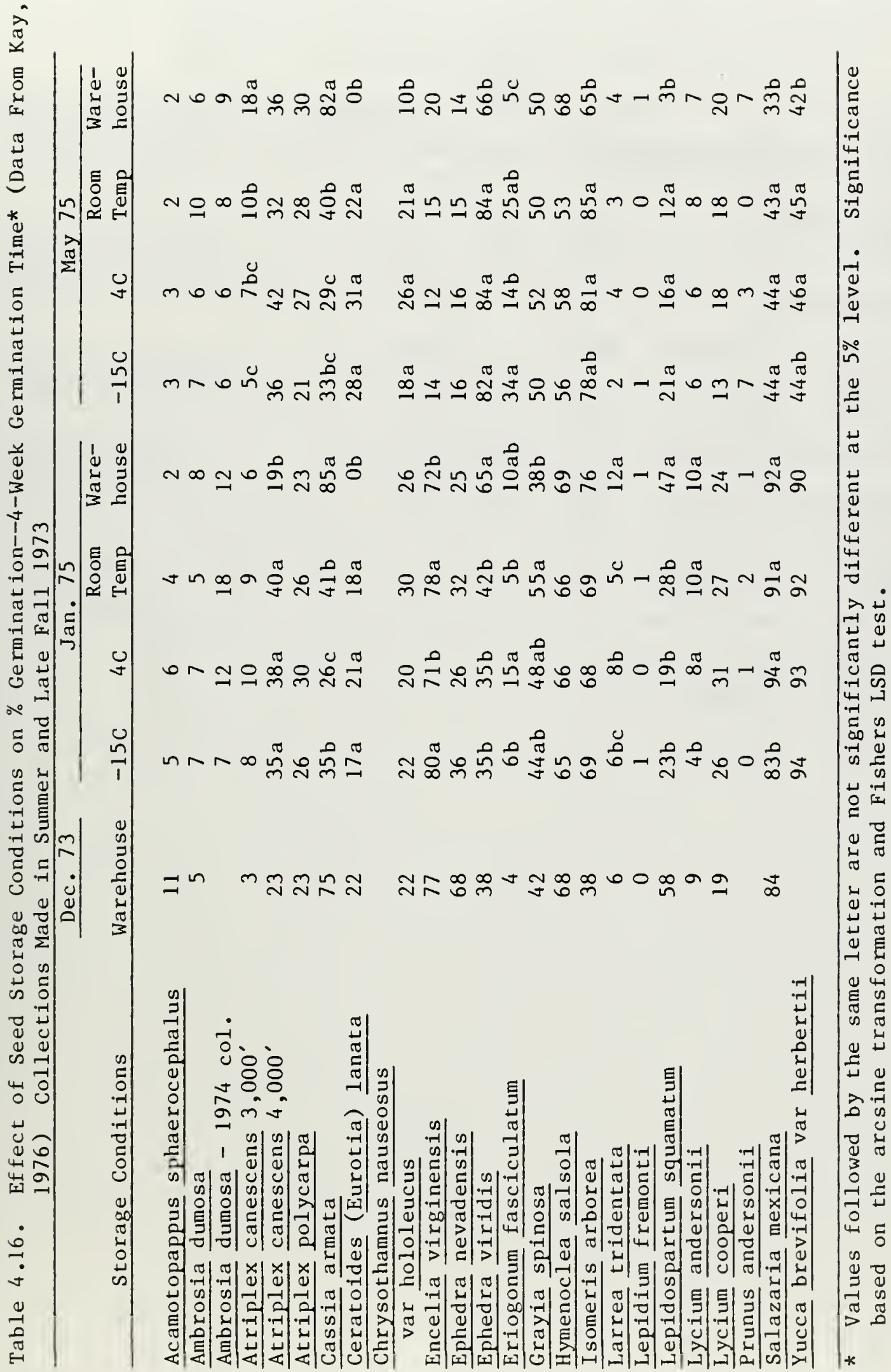


Table 4.17. Viability Characterization for Seed of Seven Desert Shrubs*

\begin{tabular}{|c|c|c|c|c|c|c|c|}
\hline & & Filled & $\begin{array}{l}\text { Tetra- } \\
\text { zolium } \\
\text { test } \\
\text { live }\end{array}$ & Germir & nation & Median Ge & rm. Time \\
\hline Species & No. Seeds & Seed & Lembryo & Untreated & Treated & Untreated & Treated \\
\hline & per 1b & $\%$ & $\%$ & $\%$ & $\%$ & days & days \\
\hline \multicolumn{8}{|l|}{ Atriplex canescens } \\
\hline (dewinged) & 32,000 & 62 & 23 & 26 & 44 & 7.0 & 2.5 \\
\hline Atriplex polycarpa & 546,000 & 68 & 38 & 13 & 24 & 8.5 & 5.0 \\
\hline Ephedra viridis & 18,000 & 90 & 60 & 56 & | & 5.0 & i \\
\hline Franseria dumosa & 138,000 & 27 & 26 & 20 & | & 6.0 &  \\
\hline & & & 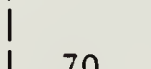 & 57 & 1 & i & 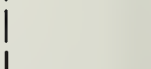 \\
\hline Hymenoclea salsola & 56,000 & 67 & 70 & 57 & | & 5.0 & | \\
\hline Larrea divaricata & 82,000 & 74 & 60 & 24 & 10 & 9.0 & 7.0 \\
\hline \multicolumn{8}{|l|}{ Lepidospartum } \\
\hline squamatum & 488,000 & 35 & -- & 36 & 1 & 3.0 & 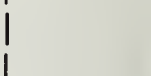 \\
\hline
\end{tabular}

* Data from Williams et al., 1974 
Table 4.18. Germination Rates of Some Mojave Desert Perennial Plant Species Under Various Treatments. Data From Graves et al 1978. The Treatment Indicated is That Which, Aside rrom the Control, Produced the Highest Germination Success.

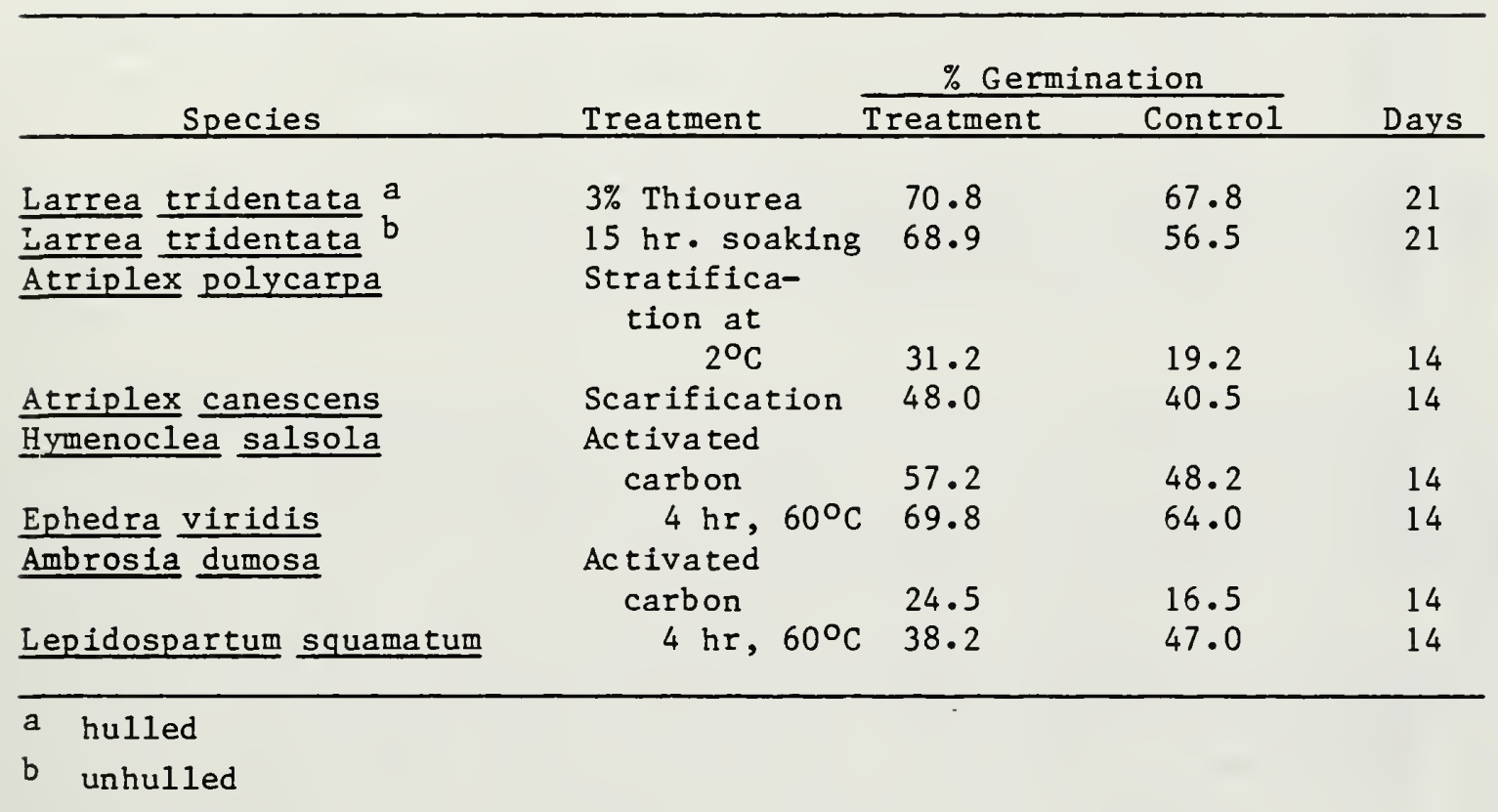




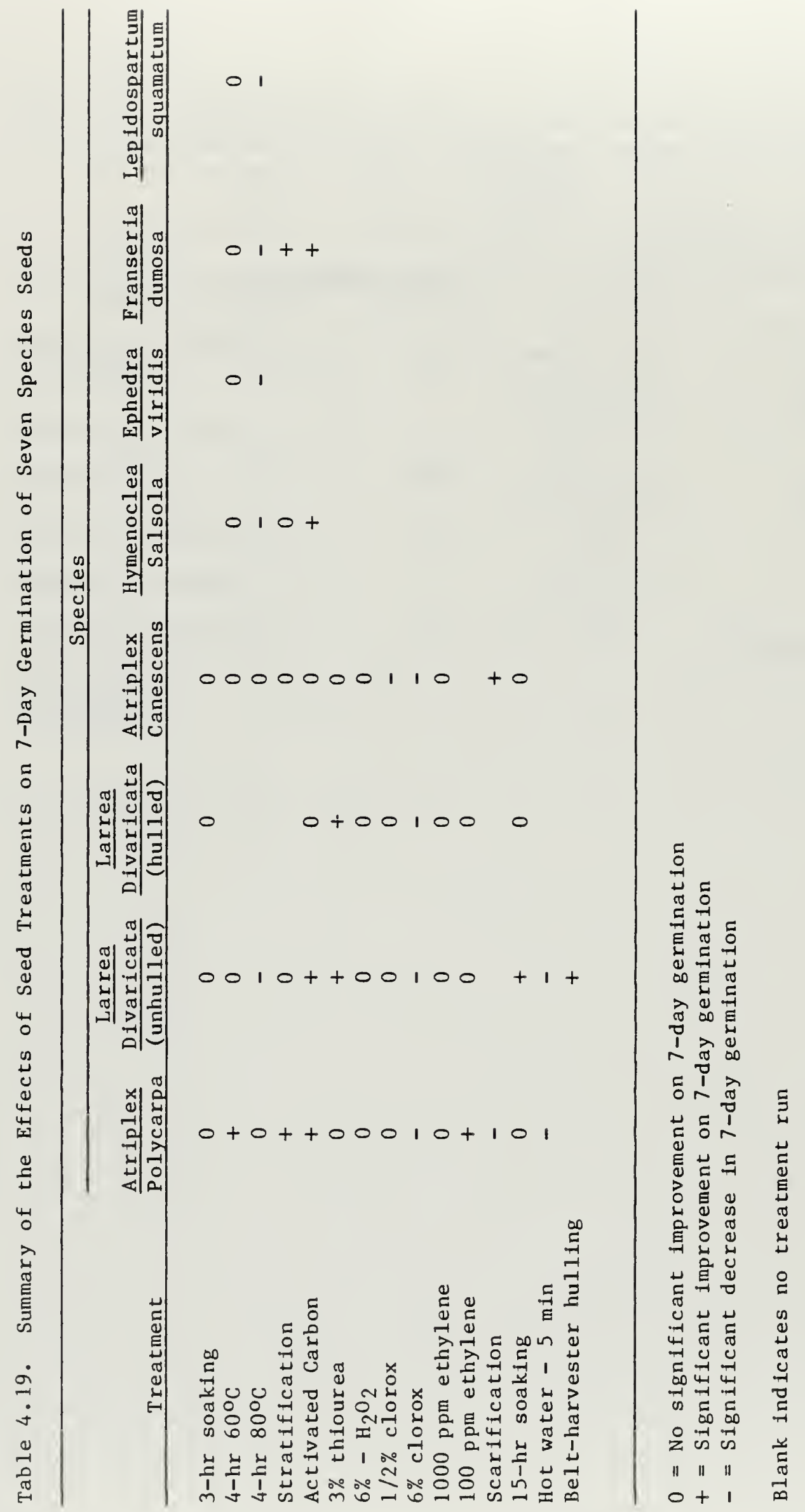


soaking treatment was effective on the carpels of Larrea tridentata. Boiling water, $6 \%$ sodium hypochlorine and $80^{\circ} \mathrm{C}$ heat consistently reduced early germination and germination rates.

Graves (1976, 1978) initiated field tests of germination and seedling and transplant survival in late 1972 on the right-of-way along the new Los Angeles aqueduct. Two sites were chosen designated Mojave and South Freeman, respectively $9.6 \mathrm{~km}$ and $59.2 \mathrm{~km}$ northeast of Mojave, California. The results are summarized in Tables 4.20 and 4.21 .

Revegetation treatments were designed to test the effect of supplemental irrigation on establishment of Ambrosia dumosa, Atriplex canescens, A. polycarpa, Larrea tridentata and Lepidospartum squamatum. Comparisons were also made between success of transplanting nursery stock with direct seeding.

Atriplex canescens was successfully seeded and transplanted at both sites. Both Ambrosia dumosa and Atriplex polycarpa were successfully established from nursery grown seedlings (i.e., transplants) but established themselves poorly from seed. Larrea tridentata and Lepidospartum squamatum exhibited little success at establishing themselves both from seed and transplants (Table 4.15). An initial irrigation treatment did not improve either spot seeding or transplant establishment of any species at either site and nursery "hardening" procedures and weather conditions at the time of transplanting proved to be more critical for transplant survival than drought during establishment. Therefore, if seeding or transplanting is timed to precede the season of the major part of precipitation, stand establishment without irrigation can be as successful as with a supplemental one-time irrigation at planting. Chemicals, such as sarsaponin, applied through irrigation even though they demonstrate protection against soil moisture stress or improvement in germination, may have limited usefulness since supplementary irrigation may not be necessary to ensure stand establishment for this type of site rehabilitation.

While it may be desirable to consider revegetation of disturbed sites in this or any other region with the "dominant" species that make up the adjacent vegetation, one may have to design seed mixes with species that are compatible with artificial methods of reestablishment and that provide maximum assurance of stand survival. Other native shrub species should be screened for revegetation potentials in this region (Graves, 1976; Graves et. al., 1978).

Four years after the revegetation study began, Kay (1979) reported that: "Most of the aqueduct is still a highly visible scar and will remain so for many more years. Results from seeding in this area of low and erratic rainfall can be expected to be equally poor and erratic, even if the best techniques are used." Furthermore, he noted that the most successful species establishing itself on the aqueduct corridor was rubber rabbitbrush (Chrysothamnus nauseosus) a volunteer; one whose seeds or seedlings were never used in the revegetation project. 





Table 4.21. Seedling and Transplant Survival of Native Plants in an Experiment on Revegetation Along the Los Angeles Aqueduct (Data From Graves et al, 1978).

\begin{tabular}{|c|c|c|c|c|c|c|c|c|c|}
\hline \multirow[b]{4}{*}{ Species } & \multirow{4}{*}{$\begin{array}{c}\text { Observation } \\
\text { DateI }\end{array}$} & \multicolumn{8}{|c|}{ Location } \\
\hline & & \multicolumn{4}{|c|}{$10 \mathrm{Km} . \mathrm{N}$. Mojave } & \multicolumn{2}{|c|}{$\frac{59 \mathrm{Km}}{\mathrm{sngt}}$} & N.E. M & jave \\
\hline & & \multicolumn{2}{|c|}{$\begin{array}{l}\text { Spot } \\
\text { Seeding } 2\end{array}$} & \multicolumn{2}{|c|}{ Transplant ${ }^{3}$} & \multicolumn{2}{|c|}{$\begin{array}{l}\text { Spot } \\
\text { Seeding }\end{array}$} & \multicolumn{2}{|c|}{ Transplant } \\
\hline & & $\bar{I}$ & $\mathrm{C}$ & I & $\mathrm{C}$ & I & $\mathrm{C}$ & $\mathrm{I}$ & $\mathrm{C}$ \\
\hline \multirow[t]{2}{*}{ Ambrosia dumosa } & $4 / 17 / 73$ & 0 & 4 & 75 & 69 & 0 & 4 & 58 & 58 \\
\hline & $3 / 25 / 75$ & 0 & 4 & 44 & 44 & 0 & 0 & 42 & 54 \\
\hline \multirow[t]{2}{*}{ Atripiex canescens } & $4 / 17 / 73$ & 50 & 75 & 71 & 19 & 81 & 62 & 19 & 12 \\
\hline & $3 / 25 / 75$ & 31 & 56 & 28 & 19 & 62 & 44 & 12 & 0 \\
\hline \multirow{2}{*}{ A. polycarpa } & $4 / 17 / 73$ & 12 & 12 & 31 & 25 & 0 & 12 & 12 & 0 \\
\hline & $3 / 25 / 75$ & 12 & 6 & 31 & 25 & 0 & 6 & 0 & 0 \\
\hline \multirow[t]{2}{*}{ Lepidospartum squamatum } & $4 / 17 / 73$ & 50 & 38 & 0 & 17 & 8 & 12 & - & - \\
\hline & $3 / 25 / 75$ & 0 & 8 & 0 & 8 & 0 & 0 & - & - \\
\hline \multirow[t]{2}{*}{ Larrea tridentata } & $4 / 17 / 73$ & 0 & 0 & 17 & 21 & 4 & 0 & 0 & 6 \\
\hline & $3 / 25 / 75$ & 0 & 0 & 12 & 12 & 0 & 0 & 0 & 0 \\
\hline
\end{tabular}

1 Date planted was February 1972.

2 Treatments were replicated 4-8 times and randomized, planting distance was $2 \times 2.5$ m. (See Table 4.15) 
According to Brum (1979) writing in the Coolwater - Kramer $220 \mathrm{kV}$ transmission line preliminary revegetation study, revegetation of disturbed sites in the deserts by proportionate seeding will not necessarily be any more rapid than natural recovery, not because of increased germination but of seedling survival, particularly during summer months. However, mortality would still be high. In corroboration with Graves (1976), Brum found that rates of germination and establishment of dominant plant species were very low and that seed pretreatments result in higher in-field germination rates. Both germination and seedling survival were enhanced by herbivore exclosures.

\section{Conclusions and Comments}

In closing this section, after weighing the implications of the data, knowing that much of the information is incomplete, we would nevertheless like to make a few concluding comments about attempts at artificial revegetation in disturbed areas of the desert:

1. No study or attempt at artificial rehabilitation and revegetation of desert disturbance has been an unqualified or even a qualified success, although a potential exists.

2. It is questionable as to whether, without large inputs of time and effort put into breaking soil compaction and establishing a permanent irrigation network, that seeding or introduction of nursery grown transplants will substantially decrease the recovery time of a disturbed area.

3. Timing and extent of irrigation, herbivore exclusion, the climatic conditions at and after replanting and erosion control and monitoring are doubtless extremely important to seedling or transplant survival and cannot be ignored in any rehabilitation program.

4. The dominant plants in most desert areas (i.e., Larrea and Ambrosia) are not the most conducive to establishment of a reseeding or transplanting program because of their low success at establishing themselves from artificially sown seed. It may be necessary to forego aesthetics and seek other more usable species for revegetation programs including, in some cases, exotics.

5. There is certainly no guarantee of success in any attempt to artificially rehabilitate desert revegetation in disturbed areas. Most efforts, even when backed by a large investment of funds and time, will be doomed to failure (if success is gauged as substantially lowering recovery time); those which are well funded will not be without their problems. As a result, a program of rest, recovery, and reuse, particularly with regard to areas of intensive off-road vehicle use is wasteful and futile. Even if severely used areas are subjected to intensive rehabilitation, recovery time would still be on the order of decades. Furthermore, reuse would return these areas to their previous condition in a matter of a few months. The rest recovery and reuse strategy might be operable in areas impacted by dispersed off-road vehicle use, for example, occasional races. However, it must be ensured that these areas be 
irrevocably closed after the event and monitored, until recovery is deemed to be complete. This is an absolute necessity and is based upon basic principles of vegetation processes as they relate to plant strategies in arid lands with low productivity and high environmental stress (Table 4.22).

If all the plant habitats of the earth are considered, it is evident that intensities of both stress and disturbance vary significantly among them. When all the combinations of stress and disturbance levels are considered, only three are viable as plant habitats. In habitats which are characterized by high levels of environmental stress (e.g., deserts), the effect of continuous and severe disturbance is to prevent a sufficiently rapid recovery or reestablishment of the vegetation (Grime, 1979). 
Table 4.22. Basic strategies of plant as they relate to intensity of stress abd disturbance within the environment (Grime, 1979)

Intensity of

Disturbance

Low

High

Ruderals

Intensity of Stress

Low $\mathrm{High}$

Competitors

Stress-Tolerators

No Viable Stretegies 


\section{Controlled Experiments on Soil Compaction Produced by off-Road Vehicles in the Mojave Desert, California}

\section{By}

John A. Adams and Albert S. Endo

Table of Contents

Page

A. Abstract . . . . . . . . . . . . . . . 122

B. Introduction . . . . . . . . . . . . . . 122

C. Methods and Materials

1. The Study Sites . . . . . . . . . . . . 123

2. Rainfall Measurements . . . . . . . . . . 123

3. Methods of Compacting the Soil. . . . . . . . . 123

4. Measurement of Soil Strength. . . . . . . . . . 125

5. Measurement of Annual Plant Response. . . . . . . . 125

D. Results

1. Increases in Soil Strength in Relation to Numbers of Vehicle

Transits. . . . . . . . . . . . . . . 125

2. Increases in Soil Strength Compared to Soil Depth . . . . . 130

3. Relationships Between Compaction and Soil Drying. . . . . 131

E. Discussion . . . . . . . . . . . . . 132 



\section{A. Abstract}

Intensive recreational off-road vehicle activity in the California deserts is producing soil compaction. Vehicle tracks consisting of different numbers of motorcycle and four-wheel drive transits were made in the Mojave Desert of California on a Typic Haplargid and a Typic Torripsamment soil in an attempt to estimate minimum amounts of soil compaction which may produce significant reductions in growth of desert annual plants. Motorcycle transits produced much smaller increases in soil strength than the same numbers of 4-WD transits. Soil strength of drying compacted soil increased at a much greater rate than soil strength of drying uncompacted soil. Significant reductions in annual cover occurred more than a year after tracks had been created by as few as 1 4-WD pass on wet soil, 5 motorcycle passes on wet soil, or 20 4-WD passes on dry soil. Plant response to compaction varied greatly with species or with rainfall characteristics during a growing season. The greater increase of soil strength in drying compacted soil than uncompacted soil may be the reason for the observed reduction in annual desert plant growth on areas with a relatively small amount of compaction.

\section{B. Introduction}

Off-road motorcycle riding has increased greatly since the early 1960 's. At the beginning of the decade there were less than 400,000 registered motorcycles in the United States (Sheridan 1979). By 1976, 8.3 million motorcyles were reported to be in use in the United States, with 5.4 million, or $66 \%$ in use off-road at some time (Motorcycle Industry Council, Inc., 1977). Numbers of other types of off-road vehicles were less certain but Sheridan (1979) estimated that over 3 million 4-WD vehicles were in operation in the United States with perhaps half used regularly for off-road driving. Because much of the activity occurs on public land, concern has been expressed about damage. Presidential Executive Orders 11644 and 11989 require agencies responsible for management of the public lands to adopt policies which protect public resources, including soil. Damage to the soil caused by ORV's is in part the result of soil compaction. off-road vehicle activity has been shown to greatly increase soil compaction in areas of intense traffic (e.g., Davidson and Fox 1974; Wilshire and Nakata 1976; Wilshire et al., 1978; and Webb et al., 1978). Endo (see Chapter 1), used aerial photographs to estimate total areas in the California deserts which have had the largest amounts of intense soil compaction due to off-road vehicles such as motorcycles and 4-WDs. Out of a total of around 10,100,000 hectares of desert land, approximately 495 hectares $(.0049 \%)$ were estimated to be highly compacted campsites or pit areas virtually devoid of vegetation; 2,406 hectares $(0.024 \%)$ were estimated to contain compacted trails on hill climbs; and 16,391 hectares $(0.16 \%)$ were estimated to have a relatively high frequency of highly compacted motorcycle and 4-WD trails on more level terrain. Cover of highly compacted trails in the last category generally ranged from 5 to 10\%. Even though a very low percentage of the desert has received substantial amounts of intense soil compaction, localized effects in some areas are considerable. This results in scars on the landscape (especially on hill climbs) which are highly visible. These scars are for the most part denuded of vegetation. Regrowth and revegetation are particularly slow on the compacted soil. 
The purpose of our research was to investigate the minimum amounts of off-road motorcycle or 4-WD vehicle driving which could cause significant reduction in the establishment and growth of desert annuals in subsequent years. Soil strengths under tracks created by single or increasing numbers of vehicle passages were measured and related to later responses of annuals. Increases in soil strength with drying were also characterized in tracked and untracked soil. The relationships between soil water and soil strength need further study to better understand the implications of increased resistance to root growth of desert annuals during periods of soil drying.

\section{Methods and Materials}

\section{The Study Sites}

Field studies were initiated in 1977 in the Mojave Desert of Southern California and continued through 1979. Soil compaction was produced by driving over both wet and dry desert soil with different types of off-road vehicles at five sites. Illustrative data from the two sites with the most homogeneous values of soil strength in untracked soil are presented in this paper. Site 1 in Stoddard Valley (NW1/4 of SE1/4, Sec. 15, T. 7 N., R. 1 W., Ord Mountains 15' Quadrangle) has coarse loamy, mixed, thermic Typic Haplargid soil with surface textures of loamy coarse sand. The top of the argillic horizon is at a depth of about $60 \mathrm{~cm}$. In the top $60 \mathrm{~cm}$, the soil averages $5 \%$ clay $(<0.002 \mathrm{~mm}), 19 \%$ silt $(0.002-$ $0.05 \mathrm{~mm})$, and $76 \%$ sand $(>0.05 \mathrm{~mm})$. The average $\mathrm{pH}$ was 7.6 ; average electrical conductivity of the saturation extract was $0.4 \mathrm{mmhos} / \mathrm{cm}$, average organic matter content was $0.2 \%$, and average content of $\mathrm{CaCO}_{3}$ was $0.9 \%$.

Site 2 in Johnson Valley (SEl/4 of NWl/4, Section $12, T .3$ N., R. 3 E., Emerson Lake 15' Quadrangle) has mixed, thermic, Typic Torripsamment soil with surface textures of coarse sand. Little profile development is apparent and the top $60 \mathrm{~cm}$ of soil has average values of $1 \%$ clay, $8 \%$ silt, and $91 \%$ sand; the average $\mathrm{pH}$ was 8.3 , average electrical conductivity was $0.2 \mathrm{mmhos} / \mathrm{cm}$, average organic matter content was $0.3 \%$, and average content of $\mathrm{CaCO}_{3}$ was $1.5 \%$.

\section{Rainfall Measurements}

A rain gauge was maintained about $10 \mathrm{~km}$ north of site 1 by the San Bernardino County Flood Control Agency during the period of the study. Seasonal totals for October 1976 to September 1977, October 1977 to September 1978, and October 1978 to September 1979 were $8.28 \mathrm{~cm}, 22.12 \mathrm{~cm}$, and $12.85 \mathrm{~cm}$ respectively.

\section{Methods of Compacting the Soil}

A 4-WD 1975 Ford Bronco and a 1973 Yamaha $175 \mathrm{~cm}^{3}$ DT2 "Enduro" motorcycle was used to produce soil compaction. The Bronco had 10-15LT (light truck) tires which were $19.7 \mathrm{~cm}$ wide and inflated to 2.6 bars. The vehicle and driver together weighed $2190 \mathrm{~kg}$. The motorcycle was fitted with a 3.25-18-4PR front tire and a 3.50/4.00-18-6PR knobby back tire which were 8.3 and $10.2 \mathrm{~cm}$ wide, respectively. The motorcycle and driver together weighed $188 \mathrm{~kg}$. 
Table 5.1 Track widths created by different numbers of 4-WD Ford "Bronco" and motorcycle transits (i.e., "Passes").

\begin{tabular}{ccc}
\hline Vehicle Transits & \multicolumn{2}{c}{ Width of Track in $(\mathrm{cm})$} \\
\hline & Bronco & Motorcycle \\
3 & 23 & 13 \\
5 & 30 & 15 \\
10 & 30 & 15 \\
20 & 40 & 20 \\
100 & 45 & 30 \\
\hline
\end{tabular}


The bronco and motorcycle were driven across the study plots at a steady speed of about $15 \mathrm{kmhr}^{-1}$ to produce sets of tracks which consisted of $1,3,5,10,20$ and 100 (the motorcycle only) vehicle transits. The multiple transits along the same track were made with as little lateral spread as possible. Typical track widths are shown in Table 1. A large part of this spread resulted from greater divergence of a small proportion of the transits used to make a track. Most vehicle passes and all subsequent penetrometer measurements (see below) were made close to the center of the tracks.

A total of 14 sets of tracks was established at site 1 beginning on August 19, 1977. The first tracks on August 19, 1977, were made two days after $1.28 \mathrm{~cm}$ of rain were measured about $10 \mathrm{~km}$ north of the study site. Eleven sets of tracks were established at site 2 beginning on October 28 , 1977. The last set of tracks at each site were made on April 20, 1978.

\section{Measurements of Soil Strength}

Soil strength was measured in the field from the surface to a depth of $60 \mathrm{~cm}$ with a hand-held recording penetrometer (Carter, 1967) using a 1.27 $\mathrm{cm}^{2}, 30^{\circ}$ cone tip. According to Taylor (1971, 1974) the mechancial resistance of soil to expanding roots is best characterized by penetrometer soil strength measurements. Measurements were made both near field capacity (in order to produce the most comparable mesurements) and after soils had become drier. Soil moisture was measured as mass wetness by drying samples for 24 hours at $105^{\circ} \mathrm{C}$. Values of soil mass wetness are given in Tables 5.2 to 5.5. Soils under shrub canopies were avoided when making penetrometer measurements, whether in tracked or untracked soils. The sandier soils under shrubs at sites 1 and 2 occupy much less total area than intershrub soils and have much lower values of soil strength when tracked or untracked than the corresponding controls or treatments between shrubs.

Soil strengths at depths of $5,10,15,20,25$, and $30 \mathrm{~cm}$ below the surface were analyzed statistically with the Student-Newman-Keuls Test (Sokal and Rohlf, 1969).

\section{Measurements of Annual Plant Response}

Annual plant density, cover, and biomass were measured with standard methods which are discussed in detail by Rowlands et al. in Chapter 6 .

\section{Results}

1. Increases in Soil Strength in Relation to Numbers of Vehicle Transits

The 4-WD Ford Bronco produced greater increases in soil strength than a Yamaha motorcyle when both were driven over wet soil at site 1 an equivalent number of times (Tables 5.2a and 5.3a). As expected, 4-WD tracks made on dry soil at site 1 created much smaller increases in soil strength compared to tracks made on wet soil (Table 5.4a). Tracks made by the 4-WD in wet soil at site 2 also showed significant increases with increasing numbers of transits (Table 5.5a). The increases were not as great as those produced by driving the same 4-WD on wet soil at site 1, possibly because the wet sand at site 2 may have compacted less readily than the wet loamy sand at site 1 . 
Table 5.2 Mean Soil strength (Bars) produced by different numbers of Ford Bronco transits on wet soil at site 1 measured on three successive dates when mass wetness values (M.W.) for the top $30 \mathrm{~cm}$ of soil in the control were $6.0 \%, 5.1 \%$ and $1.8 \%$ respectively. Means followed by the same letter are not significantly different at an experiment wide error rate $(\phi)$ of 0.01 according to the Student-Newman-Keuls procedure.

\begin{tabular}{cccccccc} 
A. August & 19,$1977 ; \mathrm{MW}=6.0 \%$ & \multicolumn{2}{c}{ Depth $(\mathrm{cm})$} \\
No. Passes & 5 & 10 & 15 & 20 & 25 & 30 \\
\cline { 2 - 7 } 0 & $4.3 \mathrm{Z}$ & $9.0 \mathrm{Z}$ & $7.7 \mathrm{Z}$ & $5.4 \mathrm{Z}$ & $6.7 \mathrm{Z}$ & $7.8 \mathrm{Z}$ \\
1 & $9.5 \mathrm{Y}$ & $10.1 \mathrm{Z}$ & $11.4 \mathrm{Z}$ & $9.5 \mathrm{Z}$ & $8.3 \mathrm{ZY}$ & $8.1 \mathrm{Z}$ \\
3 & $13.3 \mathrm{X}$ & $18.1 \mathrm{Y}$ & $17.5 \mathrm{Y}$ & $15.9 \mathrm{Y}$ & $11.1 \mathrm{YX}$ & $12.8 \mathrm{Z}$ \\
5 & $12.6 \mathrm{X}$ & $19.8 \mathrm{Y}$ & $21.5 \mathrm{Y}$ & $16.5 \mathrm{Y}$ & $13.0 \mathrm{X}$ & $15.4 \mathrm{Z}$ \\
10 & $15.9 \mathrm{X}$ & $25.6 \mathrm{X}$ & 22 & $\mathrm{Y}$ & $17.6 \mathrm{Y}$ & $12.6 \mathrm{X}$ & $12.3 \mathrm{Z}$ \\
20 & $19.4 \mathrm{~W}$ & $30.7 \mathrm{~W}$ & $29.8 \mathrm{X}$ & $22.9 \mathrm{X}$ & $18.5 \mathrm{~W}$ & $14.5 \mathrm{Z}$
\end{tabular}

B. August $26,1977 \mathrm{MW}=5.1 \% \quad$ Depth $(\mathrm{cm})$

No. Passes 10 15 20 25 30

$\begin{array}{rrrrrrrrr}0 & 2.2 \mathrm{Z} & 11.1 \mathrm{Z} & 13.1 \mathrm{Z} & 13.1 \mathrm{Z} & 9.0 \mathrm{Z} & 10.3 \mathrm{Z} \\ 1 & 6.2 \mathrm{Z} & 16.3 \mathrm{ZY} & 16.4 \mathrm{Z} & 15.3 \mathrm{ZY} & 13.2 \mathrm{Z} & 10.4 \mathrm{Z} \\ 3 & 4.8 \mathrm{Z} & 21.5 \mathrm{YX} & 26.6 \mathrm{Y} & 22.9 \mathrm{YX} & 17.8 \mathrm{ZY} & 12.3 \mathrm{Z} \\ 5 & 7.8 \mathrm{Z} & 25.8 \mathrm{X} & 25.9 \mathrm{Y} & 23.6 \mathrm{YX} & 15.2 \mathrm{ZY} & 13.7 \mathrm{Z} \\ 10 & 5.2 \mathrm{Z} & 38.4 \mathrm{~W} & 37.0 \mathrm{X} & 27.2 \mathrm{X} & 18.9 \mathrm{ZY} & 13.7 \mathrm{Z} \\ 20 & 8.0 \mathrm{Z} & 52.1 \mathrm{~V} & 45.9 \mathrm{~W} & 29.2 \mathrm{X} & 25.1 \mathrm{Y} & 14.6 \mathrm{Z}\end{array}$

C. September 6, 1977; MW $=1.8 \%$ Depth $(\mathrm{cm})$

No. Passes 10 15 20 25 30

0 $12.1 \mathrm{Z}$ $20.7 \mathrm{Z}$ $20.0 \mathrm{Z}$ $18.4 \mathrm{Z}$ $18.8 \mathrm{Z}$ $18.9 \mathrm{Z}$

1 $30.0 \mathrm{Y}$

$48.5 \mathrm{Y}$

$44.5 \mathrm{Y}$

$29.3 \mathrm{z}$

22.1 Z

$16.9 \mathrm{Z}$

3

$38.5 \mathrm{Y}$

$54.0 \mathrm{Y}$

$44.1 \mathrm{Y}$

$26.6 \mathrm{z}$

$17.9 \mathrm{Z}$

$12.5 \mathrm{Z}$

5

$43.2 \mathrm{Y}$

$53.8 \mathrm{Y}$

49.0 Y

$32.0 \mathrm{z}$

$18.8 \mathrm{Z}$

$15.3 \mathrm{Z}$
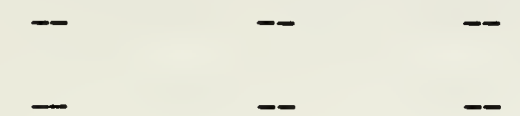
Mean soil strength (Bars) produced by different numbers of motorcycle transits on wet soil at site 1 measured on three successive dates when average soil mass wetness (M.W.) values for the top $30 \mathrm{~cm}$ of the control were $6.3 \%, 3.7 \%$ and $3.2 \%$ respectively. Means followed by the same letter(s) are not significantly different at an experiment-wide error rate $(\boldsymbol{\alpha})$ of 0.01 according to the Student-Newman-Keuls procedure.

A. January 24,$1978 ;$ M.W. $=6.3 \%$

\begin{tabular}{|c|c|c|c|c|c|c|}
\hline \multirow{3}{*}{$\begin{array}{c}\text { No. Passes } \\
0\end{array}$} & \multicolumn{5}{|c|}{ Depths (cm) } & \multirow[b]{2}{*}{30} \\
\hline & 5 & 10 & 15 & 20 & 25 & \\
\hline & 1.22 & $5.8 \mathrm{Z}$ & $8.5 \mathrm{ZY}$ & $6.8 \mathrm{ZY}$ & $6.4 \mathrm{ZY}$ & $7.3 \mathrm{z}$ \\
\hline 1 & $0.7 \mathrm{z}$ & $5.2 \mathrm{z}$ & $6.0 \mathrm{Z}$ & $5.7 \mathrm{Z}$ & $6.6 \mathrm{ZY}$ & $7.7 \mathrm{Z}$ \\
\hline 3 & $1.0 \mathrm{Z}$ & $8.4 \mathrm{Y}$ & $8.0 \mathrm{ZY}$ & $7.6 \mathrm{ZY}$ & $6.6 \mathrm{ZY}$ & $7.7 \mathrm{Z}$ \\
\hline 5 & $3.1 \mathrm{Z}$ & $10.1 Y X$ & $8.9 \mathrm{ZY}$ & $6.5 \mathrm{z}$ & $5.2 \mathrm{Z}$ & $7.3 \mathrm{z}$ \\
\hline 10 & $2.3 \mathrm{z}$ & $13.6 \mathrm{~W}$ & $9.1 \mathrm{ZY}$ & $10.1 \mathrm{YX}$ & $6.6 \mathrm{ZY}$ & $6.6 \mathrm{z}$ \\
\hline 20 & $3.2 \mathrm{z}$ & $11.5 \mathrm{XW}$ & $10.4 \mathrm{Y}$ & $7.8 \mathrm{ZY}$ & $6.8 \mathrm{ZY}$ & $6.7 \mathrm{z}$ \\
\hline 100 & $12.3 \mathrm{Y}$ & $21.3 \mathrm{~V}$ & $17.1 \times$ & $11.3 \mathrm{x}$ & $8.7 \mathrm{Y}$ & $9.3 \mathrm{Z}$ \\
\hline
\end{tabular}

B. April 20, 1978; M.W. $=3.7 \%$

\begin{tabular}{|c|c|c|c|c|c|c|c|}
\hline \multirow{2}{*}{$\begin{array}{c}\text { No. Passes } \\
0\end{array}$} & \multicolumn{7}{|c|}{ Depths (cm) } \\
\hline & $1.5 \mathrm{Z}$ & 10.12 & 9.8 & & $9.2 \mathrm{Z}$ & $8.3 \mathrm{z}$ & $11.1 \mathrm{Z}$ \\
\hline 1 & $1.2 \mathrm{Z}$ & $10.2 \mathrm{Z}$ & 9.0 & $\mathrm{Z}$ & $7.3 \mathrm{z}$ & $7.1 \mathrm{Z}$ & $10.1 \mathrm{Z}$ \\
\hline 3 & - & -- & - & & -- & - & - \\
\hline 5 & $3.5 \mathrm{z}$ & $12.0 \mathrm{Z}$ & 11.9 & $Z Y$ & $15.2 \mathrm{Z}$ & $11.0 \mathrm{Z}$ & $8.0 \mathrm{Z}$ \\
\hline 10 & $6.3 \mathrm{z}$ & $25.4 \mathrm{Y}$ & 17.2 & $Z Y$ & $11.2 \mathrm{Z}$ & $9.9 \mathrm{Z}$ & $10.3 \mathrm{z}$ \\
\hline 20 & $9.3 \mathrm{z}$ & $27.4 \mathrm{Y}$ & 19.1 & $Y$ & $14.1 \mathrm{Z}$ & $11.3 \mathrm{Z}$ & $12.3 \mathrm{Z}$ \\
\hline 100 & $38.4 \mathrm{Y}$ & $39.8 \times$ & 20.7 & $Y$ & $13.9 \mathrm{Z}$ & $13.6 \mathrm{z}$ & 9.32 \\
\hline
\end{tabular}

\begin{tabular}{cccccccc} 
No. Passes & \multicolumn{7}{c}{ Depths $(\mathrm{cm})$} \\
0 & $2.6 \mathrm{Z}$ & $14.4 \mathrm{Z}$ & $13.6 \mathrm{Z}$ & $12.6 \mathrm{Z}$ & $9.9 \mathrm{Z}$ & $16.4 \mathrm{Z}$ \\
\cline { 2 - 8 } 1 & $2.8 \mathrm{Z}$ & $18.8 \mathrm{ZY}$ & $16.8 \mathrm{Z}$ & $14.2 \mathrm{Z}$ & $11.6 \mathrm{Z}$ & $13.1 \mathrm{Z}$ \\
3 & $4.8 \mathrm{ZY}$ & $30.3 \mathrm{ZY}$ & $21.1 \mathrm{Z}$ & $12.2 \mathrm{Z}$ & $12.3 \mathrm{Z}$ & $17.3 \mathrm{Z}$ \\
5 & $3.7 \mathrm{ZY}$ & $34.5 \mathrm{Y}$ & $30.3 \mathrm{Z}$ & $20.9 \mathrm{Z}$ & $15.0 \mathrm{Z}$ & $15.7 \mathrm{Z}$ \\
10 & $7.0 \mathrm{ZY}$ & $27.6 \mathrm{ZY}$ & $21.7 \mathrm{Z}$ & $13.1 \mathrm{Z}$ & $7.4 \mathrm{Z}$ & $7.2 \mathrm{Z}$ \\
20 & $10.4 \mathrm{Y}$ & $34.3 \mathrm{Y}$ & $20.6 \mathrm{Z}$ & $20.3 \mathrm{Z}$ & $19.9 \mathrm{Z}$ & $14.5 \mathrm{Z}$
\end{tabular}


Table 5.4 Mean soil strength (Bars) produced by different numbers of Ford "Bronco" passes on dry soil at site 1 measured on three successive dates when average soil mass wetness (M.W.) values for the top $30 \mathrm{~cm}$ of the control were $6.3 \%, 3.7 \%$ and $3.2 \%$ respectively. Means followed by the same letter(s) are not significantly different at an experiment wide error rate $(\mathcal{O})$ of 0.01 according to the Student-Newman-Keuls procedure.

A. December 30,$1977 ;$ M.W. $=6.3 \%$

\begin{tabular}{cccccccc} 
& \multicolumn{7}{c}{ Depths $(\mathrm{cm})$} \\
0 & $2.5 \mathrm{ZY}$ & $5.2 \mathrm{Z}$ & $4.6 \mathrm{Z}$ & $5.6 \mathrm{Z}$ & $5.5 \mathrm{Z}$ & $6.6 \mathrm{Z}$ \\
\cline { 2 - 7 } 1 & $0.9 \mathrm{Z}$ & $3.8 \mathrm{Z}$ & $3.8 \mathrm{Z}$ & $2.9 \mathrm{Z}$ & $4.4 \mathrm{Z}$ & $5.5 \mathrm{Z}$ \\
3 & $1.4 \mathrm{Z}$ & $4.6 \mathrm{Z}$ & $4.7 \mathrm{Z}$ & $4.2 \mathrm{Z}$ & $4.3 \mathrm{Z}$ & $5.2 \mathrm{Z}$ \\
5 & $4.4 \mathrm{Y}$ & $6.0 \mathrm{Z}$ & $5.7 \mathrm{Z}$ & $5.4 \mathrm{Z}$ & $6.8 \mathrm{Z}$ & $5.6 \mathrm{Z}$ \\
10 & $7.2 \mathrm{X}$ & $6.7 \mathrm{Z}$ & $4.6 \mathrm{Z}$ & $4.7 \mathrm{Z}$ & $3.9 \mathrm{Z}$ & $6.5 \mathrm{Z}$ \\
20 & $10.5 \mathrm{~W}$ & $11.9 \mathrm{Y}$ & $8.5 \mathrm{Y}$ & $5.7 \mathrm{Z}$ & $5.3 \mathrm{Z}$ & $5.2 \mathrm{Z}$
\end{tabular}

B. April 20, 1978; M.W. $=3.7 \%$

Depths $(\mathrm{cm})$

No. Passes

$5 \quad 10$
15

0

1

$1.5 \mathrm{Z}$

$12.8 \mathrm{Z} \quad 12.8 \mathrm{Z}$

$9.6 \mathrm{Z}$

$8.9 \mathrm{Z}$

$8.8 \mathrm{Z}$

1

$2.5 \mathrm{Z}$

$10.2 \mathrm{Z}$

$9.2 \mathrm{Z}$

$7.5 \mathrm{Z}$

$7.3 \mathrm{Z}$

$7.3 \mathrm{Z}$

3

$4.9 \mathrm{Z}$

$13.9 \mathrm{Z}$

$11.7 \mathrm{Z}$

$8.8 \mathrm{Z}$

$8.1 \mathrm{Z}$

$9.5 \mathrm{Z}$

5

$16.5 \mathrm{Y}$

$20.9 \mathrm{Y}$

$12.0 \mathrm{Z}$

$10.2 \mathrm{Z}$

$8.6 \mathrm{Z}$

$9.6 \mathrm{Z}$

10

$10.6 \mathrm{ZY}$

$21.7 \mathrm{Y}$

$11.8 \quad \mathrm{Z}$

$7.7 \quad \mathrm{Z}$

$7.9 \mathrm{Z}$

$9.3 \mathrm{Z}$

20

$17.2 \mathrm{Y}$

$25.8 \mathrm{Y} \quad 14.0 \mathrm{Z}$

$8.1 \mathrm{Z}$

$6.6 \mathrm{Z}$

$7.4 \mathrm{Z}$

C. August 23, 1978; M.W. $=3.2 \%$

\begin{tabular}{cccccccc} 
& \multicolumn{7}{c}{ Depths $(\mathrm{cm})$} \\
0 & $3.9 \mathrm{ZY}$ & $14.2 \mathrm{Z}$ & $13.7 \mathrm{Z}$ & $11.9 \mathrm{ZY}$ & $9.7 \mathrm{ZY}$ & $14.6 \mathrm{Z}$ \\
\cline { 2 - 8 } 1 & $1.1 \mathrm{Z}$ & $14.4 \mathrm{Z}$ & $15.8 \mathrm{Z}$ & $10.8 \mathrm{Z}$ & $9.1 \mathrm{Z}$ & $13.5 \mathrm{Z}$ \\
3 & $4.7 \mathrm{ZY}$ & $23.7 \mathrm{Y}$ & $19.7 \mathrm{Z}$ & $16.1 \mathrm{ZY}$ & $13.8 \mathrm{ZYX}$ & $14.4 \mathrm{Z}$ \\
5 & $9.9 \mathrm{YX}$ & $29.1 \mathrm{Y}$ & $21.9 \mathrm{Z}$ & $17.8 \mathrm{ZY}$ & $16.8 \mathrm{YX}$ & $19.9 \mathrm{Z}$ \\
10 & $9.9 \mathrm{YX}$ & $51.2 \mathrm{X}$ & $35.1 \mathrm{Y}$ & $17.8 \mathrm{ZY}$ & $17.9 \mathrm{X}$ & $17.2 \mathrm{Z}$ \\
20 & $14.2 \mathrm{X}$ & $47.2 \mathrm{X}$ & $35.8 \mathrm{Y}$ & $20.1 \mathrm{Y}$ & $14.5 \mathrm{Y}$ & $12.2 \mathrm{Z}$ \\
\hline
\end{tabular}


Table 5.5 Mean soil strengths (Bars) produced by different numbers of Ford "Bronco" passes on wet soil at site 2 and measured on successive dates when average soil mass wetness values (M.W.) for the top $30 \mathrm{~cm}$ of control soil were $5.95 \%$ and $1.3 \%$ respectively. Average M.W. at the time of compaction (December 30, 1977 ) was $3.3 \%$. Means followed by the same letter(s) are not significantly different at an experiment wide error rate $(\alpha)$ of 0.01 according to the Student-Newman-Keuls procedure.

A. January 1,$1978 ;$ M.W. $=5.95 \%$

\begin{tabular}{cccccccc} 
& \multicolumn{7}{c}{ Depths $(\mathrm{cm})$} \\
0 & $1.3 \mathrm{Z}$ & $5.0 \mathrm{Z}$ & $6.4 \mathrm{Z}$ & $7.1 \mathrm{Z}$ & $8.5 \mathrm{Z}$ & $11.9 \mathrm{Z}$ \\
\cline { 2 - 8 } 1 & $1.8 \mathrm{Z}$ & $5.6 \mathrm{Z}$ & $7.4 \mathrm{Z}$ & $8.6 \mathrm{Z}$ & $9.5 \mathrm{Z}$ & $10.3 \mathrm{Z}$ \\
3 & $2.6 \mathrm{Z}$ & $8.7 \mathrm{Y}$ & $12.2 \mathrm{Y}$ & $12.2 \mathrm{Y}$ & $10.9 \mathrm{ZY}$ & $8.3 \mathrm{Z}$ \\
5 & $4.4 \mathrm{Z}$ & $11.9 \mathrm{X}$ & $15.2 \mathrm{X}$ & $15.6 \mathrm{YX}$ & $11.4 \mathrm{ZY}$ & $10.9 \mathrm{Z}$ \\
10 & $3.8 \mathrm{Z}$ & $12.4 \mathrm{X}$ & $17.0 \mathrm{X}$ & $18.0 \mathrm{X}$ & $14.5 \mathrm{Y}$ & $13.6 \mathrm{Z}$ \\
20 & $8.7 \mathrm{Y}$ & $17.3 \mathrm{~W}$ & $20.1 \mathrm{~W}$ & $15.9 \mathrm{YX}$ & $12.4 \mathrm{ZY}$ & $14.1 \mathrm{Z}$
\end{tabular}

B. April 20, 1978; M.W. = $1.30 \%$

\begin{tabular}{|c|c|c|c|c|c|c|}
\hline No. Passes & 5 & 10 & $\begin{array}{c}\text { Depths } \\
15 \\
\end{array}$ & 20 & 25 & 30 \\
\hline 0 & $4.0 \mathrm{Z}$ & $17.3 \mathrm{ZY}$ & $19.5 \mathrm{Z}$ & $15.4 \mathrm{Z}$ & $14.3 \mathrm{Z}$ & $15.3 \mathrm{Z}$ \\
\hline 1 & $8.5 \mathrm{ZY}$ & $14.0 \mathrm{Z}$ & $17.1 \mathrm{Z}$ & $16.2 \mathrm{z}$ & $13.8 \mathrm{Z}$ & $11.7 \mathrm{Z}$ \\
\hline 3 & $12.1 Y$ & $24.1 \mathrm{Y}$ & $26.6 \mathrm{z}$ & $20.2 \mathrm{z}$ & $13.9 \mathrm{z}$ & $11.4 \mathrm{Z}$ \\
\hline 5 & $24.6 x$ & $47.8 x$ & $48.6 \mathrm{Y}$ & $32.6 Y$ & $18.9 \mathrm{Z}$ & $15.9 \mathrm{Z}$ \\
\hline $10^{1}$ & -- & - & -- & - & - & -- \\
\hline $20^{1}$ & -- & -- & - & - & - & - \\
\hline
\end{tabular}

1 The soil could not be penetrated due to its extreme strength upon drying ( $>65$ bars). 
Bodman and Constantin (1965) reported that loamy sands are the soils most susceptible to density increases under loading. Wet soils at site 2 were also more greatly compacted by the 4-WD than by the motorcycle. As was also the case for site 1 , less compaction was created at site 2 by driving the $4-W D$ vehicle or motorcycle on soil that was dry than on soil that was wet.

\section{Increase in Soil Strength Compared to Soil Depth}

All statistically significant increases in soil strength occurred within the top $25 \mathrm{~cm}$. Driving the 4-WD on wet soil compacted the soil to a greater depth than driving either the 4-WD on dry soil or the motorcycle on wet soil.

Tracks produced by driving the 4-WD on wet soil at site 1 (Table 5.2a) showed signficant differences in soil strength with as little as 3 passes at a depth of $25 \mathrm{~cm}$. However, driving the 4-WD on dry soil at site 1 produced no significant differences below $15 \mathrm{~cm}$ (Table 5.4a). Significant differences in soil strength at a depth of $15 \mathrm{~cm}$ were produced only after 20 passes. Driving the motorcycle on wet soil at site 1 produced significant differences in soil strength between the control and 100 pass tracks (Table 5.3a) down to $20 \mathrm{~cm}$ but not below.

For smaller numbers of motorcycle transits, significant differences in soil strength between the control and treatments only occurred for three or more transits at a depth of (but not below) $10 \mathrm{~cm}$.

Tracks made with the 4-WD on the wet sand at site 2 caused significant increases in soil strength in comparison to the control as deep as $25 \mathrm{~cm}$ below the surface (Table 5.5a). Larger significant increases in compaction occurred at a depth of $25 \mathrm{~cm}$ in the wet soil at site 1 (Table 5.2a) than at site 2 .

In addition to possible differences in compactability of the sand compared to loamy sand the wetting front from previous rainfall had an average depth of about $25 \mathrm{~cm}$ when 4-WD tracks were made at site 2 (Table 5.4a) compared to an average depth of around $45 \mathrm{~cm}$ when 4 WD tracks were made at site 1 (Table 5.2a). The more shallow wetting depth at site 2 may have limited the depth of compaction. 


\section{Relationships Between Compaction and Soil Drying}

As the soils of both compacted and control (tracked and untracked) areas became drier with time the rate of increase in soil strength was much greater in the compacted zones (Tables 5.2 through 5.5).

Rates of increase in soil strength from August 19, 1977 (Table 5.2b) were much greater under tracks created by higher numbers of 4-WD transits, and therefore compacted to a greater degree initially, than under tracks created by smaller numbers of passes. By September 6, 1977 (Table 5.2c), 20 days after the heavy summer rain, even the area compacted by a single vehicle transit had a significantly higher soil strength than the control and strengths under the 10 and 20 pass treatments exceeded 65 bars (the operational ceiling of the penetrometer). The only exceptions to the increases in soil strength with time were measured at depths of $5 \mathrm{~cm}$ on August 26,1977 . This was probably due to light rainfall $(0.20 \mathrm{~cm}$ of rain was measured on August 23, 1977, about 10 kilometers north of the site).

The relationship between soil strength, soil depth, days after significant rainfall $(1.28 \mathrm{~cm}$ of rainfall measured about $10 \mathrm{~km}$ north of site 1 ), and number of transits in a vehicle track were analyzed for the 4-WD tracks made on wet soil at site 1 (Table 5.2 ) by multiple linear regression as $S=5.72-0.11(D)+0.86(R)+3.17(T) ; r=0.68$ where:

$$
\begin{aligned}
& \mathrm{S}=\text { Soil Strength (Bars) } \\
& \mathrm{D}=\text { Depth (cm) } \\
& \mathrm{R}=\text { Number of days after a rain } \\
& \mathrm{T}=\text { Number of Vehicle Transits }
\end{aligned}
$$

Some soil strength values under the 1,3 , and 5 pass tracks were over 65 bars on April 20,1977, and only measurable values were used in equation 1, so the equation probably represents an underestimate of increased strength with compaction and drying.

Large increase in soil strength of drying compacted areas compared to drying control areas also occurred in the sandy soils at site 2 (Table 5.5). Single pass tracks remained close in value to the control after drying (Table 5.5b). Tracks created by five vehicle transits had very large increases in strength compared to controls between January 12, 1978, and April 20, 1978. All values of soil strength in the 10 and 20 transit tracks exceeded 65 bars on April 20, 1978 .

Tracks made by the 4-WD vehicle when soil at site 1 was dry (Table 5.4) showed large increases in strength of compacted soil compared to untracked soil after subsequent wetting and drying. Single pass tracks of the motorcycle on wet soil and the 4-WD on dry soil in Tables 5.3 and 5.4 remained close in value to controls even under the driest conditions. Mean values for multiple pass tracks of the 4-WD on dry soil and the motorcycle on wet soil increased substantially in comparison to controls with drying. The 100 pass motorcycle tracks reached soil strengths in excess of 65 bars on August 23, 1978. 


\section{E. Discussion}

Soil strengths exceeding 20 bars, measured near field capacity with the same type of recording penetrometer, have been reported to greatly limit root extension of alfalfa (Medicago sativa L.), corn (Zea mays L.), and cotton (Gossypium hirsutum L.) (Grimes et. al., 1975; and Grimes et. al., 1978). Maximum mean values of soil strength within the top $30 \mathrm{~cm}$ of the soil profile reached values close to 20 bars in our experiment when measured near field capacity for five passes of the 4-WD and 100 passes of the motorcycle over wet soil at site 1 and 20 passes of the 4-WD over wet soil at site 2. Maximum mean values of soil strength at site 1 (measured at field capacity) were considerably below 20 bars after 20 passes of the 4-WD vehicle over dry soil.

Because desert annuals are more often subjected to substantial periods of drying than agricultural crops, the large increases in strength upon drying of compacted soil in comparison to uncompacted soil may cause a greater response of desert plants to slight or modest compaction than would be expected from penetrometer measurements made close to field capacity. Mirreh and Ketcheson (1972) reported that soil strength in laboratory tests increased at a greater rate with decreasing matric potential at higher bulk densities than at lower bulk densities. They stated that as soils dry beyond the tensionmeter range the decrease in cross-sectional area of interstitial water becomes so great that water bonds are lost and soil strength increases less rapidly with further decreases of matric potential. This may eventually result in no additional strength increase or even a decrease in strength with further drying of soil. In compacted soil the greater proportion of small pores causes larger amounts of interstitial water to be retained as matric potential decreases. The greater numbers of water bonds remaining in compacted soil during drying produce a larger increase in strength as matric potentials decrease. The much greater rate of soil strength increase in drying compacted soil than untracked soil shown in our experiments may be related to the same causes. There may be greater water content in drying compacted soil than drying untracked soil because of reduced plant growth and transpiration on the compacted soil. As an illustration, mass wetness of the top $15 \mathrm{~cm}$ of soil under the 20 pass track had an average value of 2.9 percent $\left(5.3 \mathrm{~cm}^{3} \mathrm{~cm}^{-3}\right.$ volume wetness) on September 6, 1977; whereas the top $15 \mathrm{~cm}$ of adjacent untracked soil had an average mass wetness of 1.1 percent $\left(1.8 \mathrm{~cm}^{3} \mathrm{~cm}^{-3}\right.$ volume wetness). The track had a large reduction in growth of annuals in the summer of 1977 (Rowlands et. al., in Chapter 6) which may have resulted in a larger water content. Higher values of water content compared to untracked soil undoubtedly also occurred in some of the tracks created by smaller numbers of transits (water content not measured) which also had significant reductions in density of annuals (Rowlands et. al., Chapter 6). 
Merrill and Rawlins (1979) grew sorghum plants (Sorghum bicolor (L.) Moench.) in lysimeters with three different irrigation frequencies. The least frequently irrigated treatment (water added when soil at depths of 25 and $40 \mathrm{~cm}$ reached -5 bars or - 10 bars, respectively) had 25 percent and 40 percent less shoot dry weight than the daily irrigated plants for the two times that the experiment was done. Root lengths at the ends of the two experiments were 21 percent and 28 percent less on the least frequently irrigated plants than on the daily irrigated plants. Greacen and $\mathrm{Oh}$ (1972) and Taylor and Ratliff (1969) showed that root extension rate was well correlated with penetrometer soil strength but only poorly or not at all with matric potential until matric potentials decreased below those used by Merrill and Rawlins for their least frequent irrigation treatment. For this reason and because significant differences in plant water potentials compared to the more frequently watered plants occurred only during one time interval in the $-5,-10$ bar treatment, Merrill and Rawlins concluded that differences in soil strength associated with the different irrigation treatments appeared to be the predominant factor controlling root distribution. Differences in frequencies of desert rains will also produce differences in soil strength which similarly should be expected to affect root growth of desert annuals, apart from plant stress effects produced by decreasing soil water potentials per se. Where the increases in soil strength with drying are intensified by compaction, the effects of drying may cause even greater reductions in plant growth than noted by Merrill and Rawlins.

Rowlands et. al. (Chapter 6 ) reported that significant reductions in annual cover compared to controls occurred at site 1 during April 1979 in tracks created by as few as one 4-WD pass on wet soils, 20 4-WD passes on dry soil, or five motorcycle passes on wet soil. All of these tracks had soil strengths (measured near field capacity) which were substantially less than 20 bars, a value which has been related to large decreases in root growth of agricultural plants by Grimes et. al. (1975) and Grimes et. al. (1978). The greater sensitivity of desert annuals probably resulted from greater periods of drying during the growing season which causes the large increases in soil strength of tracked soil compared to untracked soil.

Desert annual plant response to compaction varied with seasonal rainfall characteristics. The springs of 1978 and 1979 had very different rainfall patterns. Between December 1, 1978 and May 25, 1979, $9.70 \mathrm{~cm}$ of rainfall was measured in Stoddard Valley approximately $10 \mathrm{~km}$ north of site 1. During 1978 , a wetter year with more frequent rains totaling 19.63 $\mathrm{cm}$ between December 18, 1977 and May 1, 1978, soil strength would have remained closer to the minimum values (e.g., August 19, 1977 in Table 5.2A) of soil strength for a greater part of the time and plant growth on compacted soil had less reduction in growth compared to untracked soil than during the spring of 1979 (see Rowlands et. al., Chapter 6). 
Desert annual response also varied with species. Relatively large, taprooted, annual dicotyledons such as Chaenactis fremontii Gray and Erodium cicutarium (L.) L'Her had significant reductions in cover in all track treatments of Table 5.2 compared to controls in April, 1979. In contrast Schismus barbatis (L.) Thell, a grass with fibrous roots, had significantly higher cover in comparison to controls for the $1,3,10$, and 20 pass tracks of Table 5.2. The single cotyledon leaf and fibrous root system of the grass allow greater ease of germination and root growth, respectively, than is the case for the taprooted dicotyledons. Greater amounts of water available to the grass in compacted soil (because other non-grass species were reduced in density and size) may be another reason for increased growth of grasses in the track.

Because soil water was characterized by mass wetness rather than matric potential or soil water potential it is difficult to relate the soil water values to plant availability. At average mass wetness values at site 1 of 1.8 percent and 3.2 percent annual plants showed no evidence of water stress. Growth of roots to obtain additional water may be of considerable importance in the drying soil because movement of water to the roots will become very slow.

Soils which have been intensely used by off-road vehicles (e.g., on campsites, pit areas, or vehicle trails) generally had higher measured values of wet soil strength than maximum values under the tracks of our studies. Soil strengths measured in wet soils of campsites frequently ranged from about 35 to over 65 bars. Intensely used motorcycle trails had wet soil strengths which typically ranged from 20 to 60 bars. The areas of low to moderate compaction such as we have studied may cover a larger total area than the more highly compacted soils. The uncertainty about locations and total areas of low to moderate compaction, the variation in plant response with species, and the relationship between plant response and rainfall history during a growing season indicate the complexity of interpreting desert plant response to soil composition. 
VI. EXPERIMENTS ON THE EFFECTS OF SOIL COMPACTION ON ESTABLISHMENT, COVER, AND PATTERN OF WINTER AND SUMMER ANNUALS IN THE MOJAVE DESERT

BY

PETER G. ROWLANDS, JOHN A. ADAMS, HYRUM B. JOHNSON, AND ALBERT S. ENDO

\section{TABLE OF CONTENTS}

\section{$\underline{\text { Page }}$}

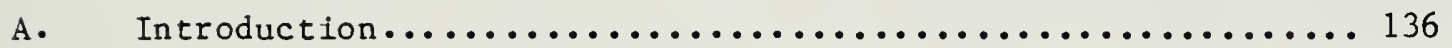

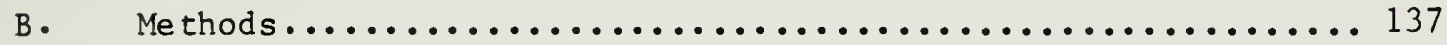

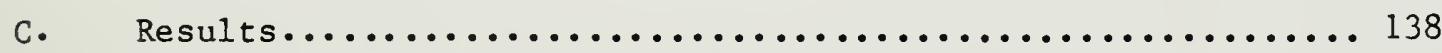

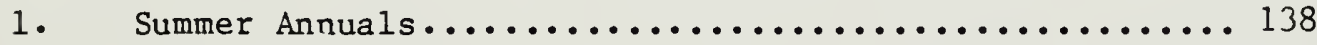

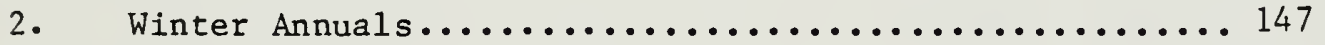

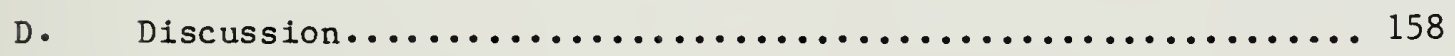



Off-road vehicles may affect soil plant relationships by excessively compacting the soil and altering the soil surface properties. As a result, changes are brought about in physical factors such as temperature and temperature fluctuations, aeration, infiltration, and soil strength, and some chemical properties may also be changed (Snyder et al, 1976; Lull, 1959; Wilshire et al, 1978a; Wilshire et al, 1978b; Webb and Wilshire, 1978; Davidson and Fox, 1974$)$. Significant amounts of soil compaction may reduce germination (Rosenberg, 1964; Davidson and Fox, 1974; Wilshire and Nakata, 1976). Seeds that lie in compacted zones may not receive a normal thermal incubation, sufficient water to wash off coated inhibitors, as much organic material, or proper plant nutrition (Luckenbach and Bury, 1978; Luckenbach, 1975; Parish, 1971; Went and Watergaard, 1949; Went, 1948).

Substantial reductions in soil moisture may occur as a result of reduced infiltration of water, due to structural changes in the soil as a result of compaction. Loss of plant canopy, changes in insulating characteristics of the soil by soil structure disruption, and changes in moisture content significantly extend the diurnal range of soil temperatures over a 24 -hour period by as much as $12^{\circ} \mathrm{C}$ in areas used by ORVs in comparison to unused areas. Such modifications affect all temperature sensitive processes in the soil (Webb et al, 1978; Wilshire et al, 1978; Nielsen and Humphries, 1966). In an area near San Francisco intensively used by ORVs, organic carbon was reduced $33 \%$ below adjacent unused areas. Soil moisture was reduced by an average of $43 \%$ to a depth of $30 \mathrm{~cm}$ and bulk density was increased by an average of $18 \%$ to a depth of $90 \mathrm{~cm}$ (Wilshire et al, 1978). Furthermore, according to these authors, the factor most limiting seedling germination and growth in compacted soils is water availability. This is a factor which is of particular importance in arid and semiarid areas, even in relatively uncompacted soils.

Most of what is known about the effects of compaction on plant physiology is derived from the agricultural literature. When other conditions for plant growth are not limiting, increases in soil strength due to compaction will reduce the rate of both emergence and root elongation (Taylor et al, 1966) and the proportion of seedlings that emerge or the proportion of roots which penetrate the impeding layer. Compacted layers will also reduce biomass of agricultural crops such as corn (Zea mays) if the layers cause the plant to undergo substantial additional stress for water or nutrients (Taylor et al, 1966, 1971; Carter et al, 1965; Carter and Tavernetti, 1968; Taylor et al, 1967). Limitation of plant root development results in an increased demand for irrigation, natural or otherwise, to meet evapotranspirational requirements (Grimes et al, 1975). If these demands are not met, the plant lapses into water stress. Leaf area and transpiration increase until constricted roots can no longer transmit enough water for transpiration. Plants wilt severely and soon die (Taylor and Klepper, 1978). Compaction of a sandy loam soil in the San Joaquin Valley in tractor 
traffic zones reduced root length density ( $\mathrm{cm}$ of root per $\mathrm{cm}^{3}$ of soil) of Alfalfa (Medicago sativa) by as much as $60 \%$ in a $15-30 \mathrm{~cm}$ depth zone. Concurrently, dry matter production fell from $532 \mathrm{~g} / \mathrm{m}^{2}$ in the control to $142 \mathrm{~g} / \mathrm{m}^{2}$ in trafficked zones (Grimes et al, 1978). In another study Grimes et al (1975) showed that soils whose resistances were greater than 250 psi $\left(18.3 \mathrm{~kg} / \mathrm{cm}^{2}\right)$ restricted growth of both cotton and corn seedlings growing in a sandy loam. Similar findings were published by Lowry et al (1970) for cotton (Gossypium sp.) growing in loamy sand, and by Phillips and Kirkham (1962) for corn growing in both clayey and sandy soils. According to Taylor and Burnett (1964), there seems to be generally small differences among crop species in their ability to penetrate soils with high strengths. Moreover plant growth is inversely correlated to both bulk density (Zimmerman and Kardos, 1961; Veihmeyer and Hendrickson, 1948) and soil strength but is limited critically by soil strength (Taylor and Gardner, 1963).

There seems to be some differences in the abilities of the shoots of monocots and dicots to penetrate soils with crusts or compacted soils. Many dicotyledonous plants must push or pull large cotyledons through the soil crust and must displace an area of crust much larger than the diameter of the stem exerting the growth force. On the other hand, the thrust that shoots of grasses and cereals exert on high-strength soil crusts is concentrated as a point load (Taylor, 1971). As a result, it is highly probable that monocots may be more successful in germinating on high-strength soils and soil crusts.

In an ORV monitored coastal dune system, Wood and Robertson (1976) found that seedlings of tree species in areas damaged by ORVs had low survival rates and that other species showed reduced flowering capability. As a result, species which reproduced vegetatively by rhizomes (i.e., dune grasses) were favored over plants which lacked such abilities. In a like manner, Luckenbach and Bury (1978) observed that disturbance of soils favors the establishment of weedy species such as Salsola spp. presumably because these "weeds" can penetrate compacted soils more easily than native species. Wells (1961) and Webb and Wilshire (1979) found that Stipa speciosa, a rhizomatous bunch grass, was one of the first invaders on the abandoned, but highly compacted streets and avenues of a Nevada ghost town. These data seem to indicate that species specific differences in the ability to penetrate compacted soils exist in non-agricultural, disturbed areas.

\section{B. Methods}

As part of the soil compaction study made by the BLM in Johnson and Stoddard Valleys, San Bernardino County, California, and described earlier in this report (Chapter 5) by Adams, et al., densities of both summer and winter annuals were monitored, beginning in summer of 1977 , and continuing to the spring of 1979 . At the beginning of the experiment, ten $0.1 \mathrm{~m}^{2}$ quadrats were placed in each of the tracks created by $1,2,3,5,7,10$ and 20 passes (figure 6.9a) of a Ford "Bronco" $4 \times 4$ vehicle, 100 passes of a 
motorcycle, and control areas. Subsequently, the size of the quadrats was reduced to .05 and then to $.025 \mathrm{~m}^{2}$ to increase both the speed and efficiency of counting. Unusually high winter precipitation in 1978 produced an immense crop of annuals. In addition, the experimental design was changed to one which established separate controls for each of the seven treatments. Biomass estimates were made for each plot by harvesting. In 1979, annual cover was measured by a point frame (Levy and Madden, 1933; Muller-Dombois and Ellenberg, 1974) within each of the treatment areas and a control. Since preliminary analysis of the data showed that neither cover nor density distributions were homoscedastic among treatments and did not approach normality, parametric procedures were not used. Instead, nonparametic methods including the Mann-Whitney U procedure, Friedman's Two Way Analysis of Variance and the Kruskal-Wallis procedure and its associated a posteriori significance tests (Zar, 1973; Sokal and Rholf, 1969; and Hollander and Wolfe, 1973) were used to analyze the data.

\section{Results}

Although three separate sites were studied in both Johnson and Stoddard Valley, only the results from one of Stoddard Valley sites, number 1 , will be presented in full since they are representative of the whole.

\section{Summer Annuals}

Density of summer annuals was measured in 1977 and 1978. The dominant annuals in both years were Pectis papposa (Asteraceae) and Bouteloua barbata (Poaceae) with appreciable amounts of Mollugo cerviana (Aizoaceae) and Euphorbia setiloba (Euphorbiaceae). Growth was initiated by the onset of summer storms or "Chubascos" caused by uncommon influxes of moist air from the Gulf. Summer rainfall (July-September) was 1.62 in. in 1977 and 0.49 in. in 1978 as measured in nearby $(\approx 24 \mathrm{~km})$ Barstow.

Only two species, Pectis papposa and Bouteloua barbata had densities and frequencies high enough to ensure a valid statistical treatment. In 1977, each species separately, and both species combined showed definite "dose-response" trends indicating negative effects of increasing numbers of vehicular passes on annual density (Figure 6.1). At the same time soil strength measured by mechanical impedance (Bars) increased substantially from the control to 20 passes (Figure 6.8). However, differences in plant density among treatments were significant only with regard to Pectis papposa and the total density for all species combined. There were no significant differences in the densities of Bouteloua barbata among treatments (Table 6.1). However, a trend of decreasing average densities with increased numbers of passes was evident. Pectis papposa dropped from 18 plants/0.1 $\mathrm{m}^{2}$ in the control to $1 / 0.1 \mathrm{~m}^{2}$ at 20 passes, Bouteloua barbatus from 22 to 8 , and all species combined from 76 to 10 . 


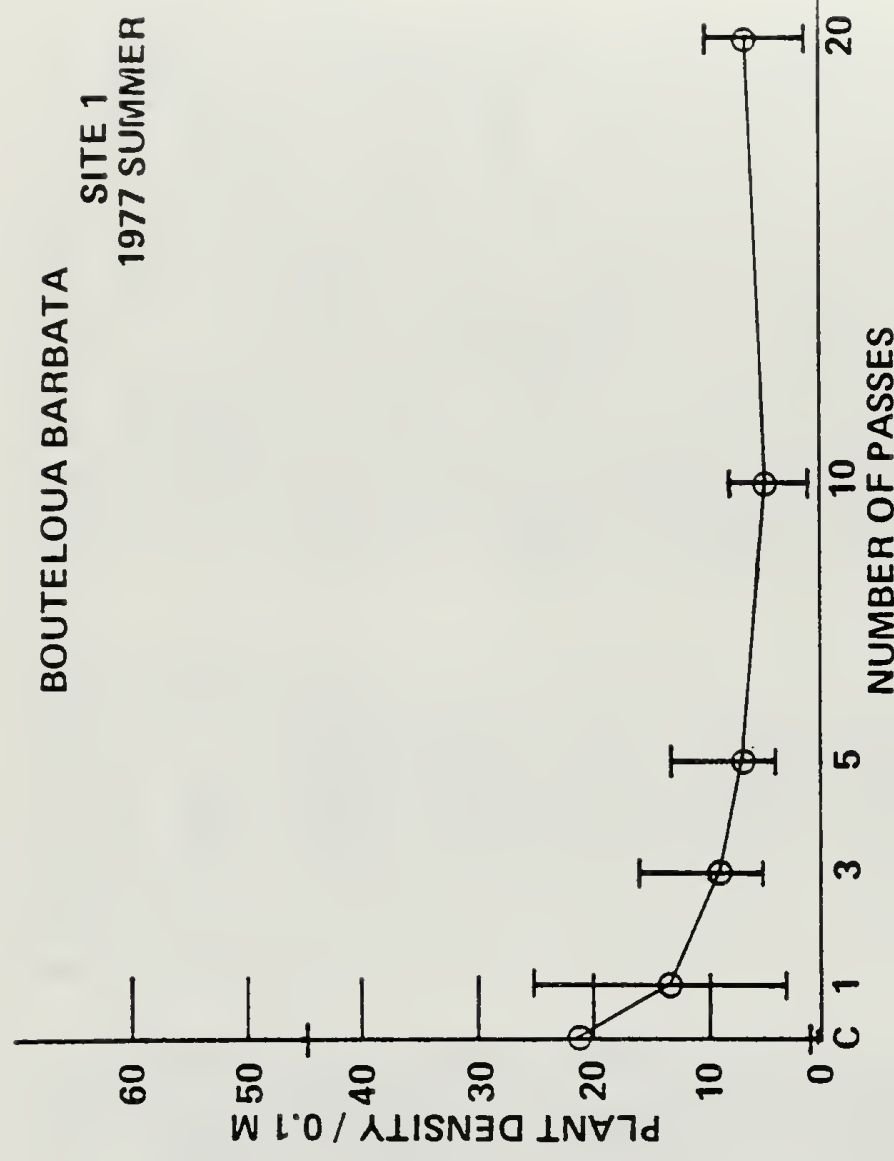

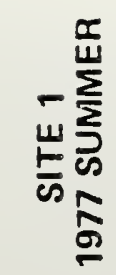
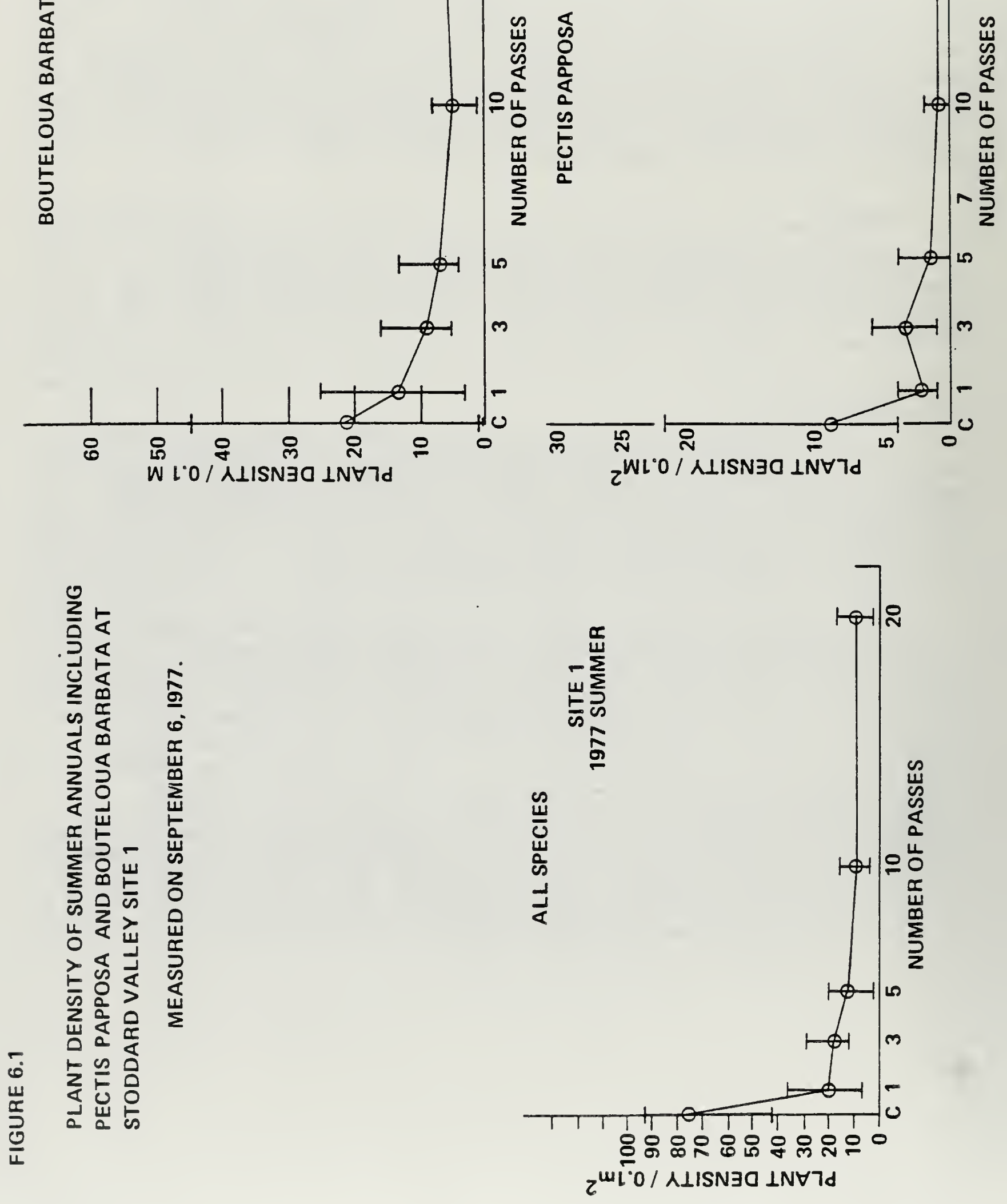
Table 6.1 Multiple Comparisons Tests for Differences in Densities of Summer Annuals Among Compaction Treatments Resulting From Variable Passes of a $4 \times 4$ Vehicle Over the Soil Surface. Five $0.1 \mathrm{~m}^{2}$ Replicates Were Made per Treatment. The Underlined Treatments Were Not Significantly Different From One Another at an Experimentwise Error Rate $(\alpha)$ of 0.05 .

\section{Species:}

Kruskal-Wallis Corrected

Rank Sums

Rank of Rank Sums

Treatment (No. Passes)

Ave. Density/0.1 $\mathrm{m}^{2}$

\section{: Pectis papposa}

$$
\mathrm{H}=14.343 ; 0.01<\mathrm{P}<.05
$$

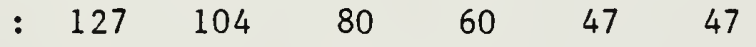

$\begin{array}{lllllll}: & 1 & 2 & 3 & 4 & 5 & 6\end{array}$

\begin{tabular}{lllllll} 
& $\mathrm{C}$ & $3 \mathrm{P}$ & $\mathrm{IP}$ & $5 \mathrm{P}$ & $\mathrm{IOP}$ & $2 \mathrm{PP}$ \\
\hline
\end{tabular}

$\begin{array}{lllllll}: & 8.8 & 5.4 & 2.0 & 1.4 & 0.8 & 0.25\end{array}$

Species

: Bouteloua barbata

Kruskal-Wallis Corrected $\mathrm{H}=6.377 ; 0.05<\mathrm{P}<0.1$

Rank Sums

$\begin{array}{lllllll}: & 111 & 91 & 82.5 & 66.5 & 66 & 48\end{array}$

Rank of Rank Sums

$\begin{array}{lllllll}: & 1 & 2 & 3 & 4 & 5 & 6\end{array}$

Treatment (No. Passes) :

\begin{tabular}{llllll}
$C$ & $1 P$ & $3 P$ & $5 P$ & $20 P$ & $10 P$ \\
\hline
\end{tabular}

Ave. Density/0.1 $\mathrm{m}^{2}$

: $\quad 21.4 \quad 11.6$

$\begin{array}{llll}8.8 & 7.2 & 6.6 & 5.0\end{array}$
Species

Kruskal-Wallis Corrected

Rank Sums

Rank of Rank Sums

Treatment (No. Passes)

Ave. Density/0.1 $\mathrm{m}^{2}$
: Combined $^{1}$

$H=17.558 ; \quad P<0.01$

$\begin{array}{llllll}: & 140 \quad 91 & 88.5 & 54 & 47.5 & 44\end{array}$

$\begin{array}{lllllll}: & 1 & 2 & 3 & 4 & 5 & 6\end{array}$

\begin{tabular}{llllllll}
$:$ & $\mathrm{C}$ & $1 \mathrm{P}$ & $3 \mathrm{P}$ & $5 \mathrm{P}$ & $10 \mathrm{P}$ & $20 \mathrm{P}$ \\
\hline
\end{tabular}

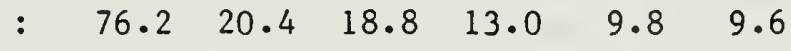

1 Combined species includes all individuals present including those belonging to species not singled out for analysis because of sporadic distribution within the various treatments. 
In 1978, the experimental design of the experiment was changed to include 10 pairwise treatment-control replicates per treatment and the sample area was reduced from 0.1 to $0.025 \mathrm{~m}^{2}$ to facilitate counting of annual plants. Part of the reasoning behind this change in design was the assumption that significant intrinsic heterogeneity existed among treatments, necessitating the inclusion of more than one control. Subsequent analysis of the data verified this assumption. Analysis of only plant density figures from control plots within site 1 showed a significant difference in distribution of density values for species, both summer and winter annuals, among the various controls (Table 6.2). Only when density values for all species were combined did the differences among the various controls become more significant (Table 6.2). Even so, the combined density for spring annuals, in spite of a nonsignificant value for Kruskal-Wallis $\mathrm{H}$ (distributed approximately as chi-squared) was found, subsequent to a posteriori examination to be heterogeneous. The set of control quadrats alongside the treatment consisting of 10 passes by a $4 \times 4$ vehicle was significantly different from the rest (Table 6.2). No apparent pattern associated with the rank of the rank sums associated with each control could be discerned among either winter or summer annuals except that more of ten than not Controls 3,5 , and 7 seemed to have higher rank sums (and, therefore on the whole, higher average densities) than the other controls. This is no doubt due to intrinsic site heterogeneity, a factor which should not be ignored in future studies of a similar nature and obviates the need for great care in establishing control plots.

The data derived from paired control-treatment studies from site 4 during the summer of 1978 gave rise to basically the same interpretations as did the 1977 studies as well as some additional insight. Although many of the comparisons were not significantly different, there was always a higher average density of Pectis papposa in the control plots than in the treatments. Conversely, for Bouteloua barbata, except for 20 passes, densities were higher in the treatments than in the controls (Table 6.3 , Figure 6.3).

In Adams et al., (Chapter 5) it was shown that the degree of soil compaction is significantly related to the proximity in time to preceding precipitation. Sites $1,1 \mathrm{~A}$ and $1 \mathrm{~B}$ in Stoddard Valley were impacted 3 , 10 , and 21 days after a summer rain respectively. As a result, one would expect a higher density of plants in corresponding treatments in site $1 B$ than in site $1 \mathrm{~A}$ which would, in turn have higher plant densities, on the whole, than site 1 . This is not the case (Figure 6.2, Table 6.4); no consistent trends in this direction could be found. Significant differences in densities of Bouteloua, Pectis, and total density were produced by varying the number of vehicular passes; site differences were significant only for Pectis papposa (Table 6.4). However, density values in treatments compacted 21 days after a rain (site 1B) were actually lower than the other two sites. Since many summer annuals were already above ground by 10 days after the rain, a large amount of plant material was directly destroyed by vehicular action. As a result, much lower densities were 
Stoddard Valley

September 1978 $\longrightarrow$ Compacted 3 days after Rain $\square$ Compacted 10 days after Rain $\triangle \sim$ Compacted 21 days after Rain
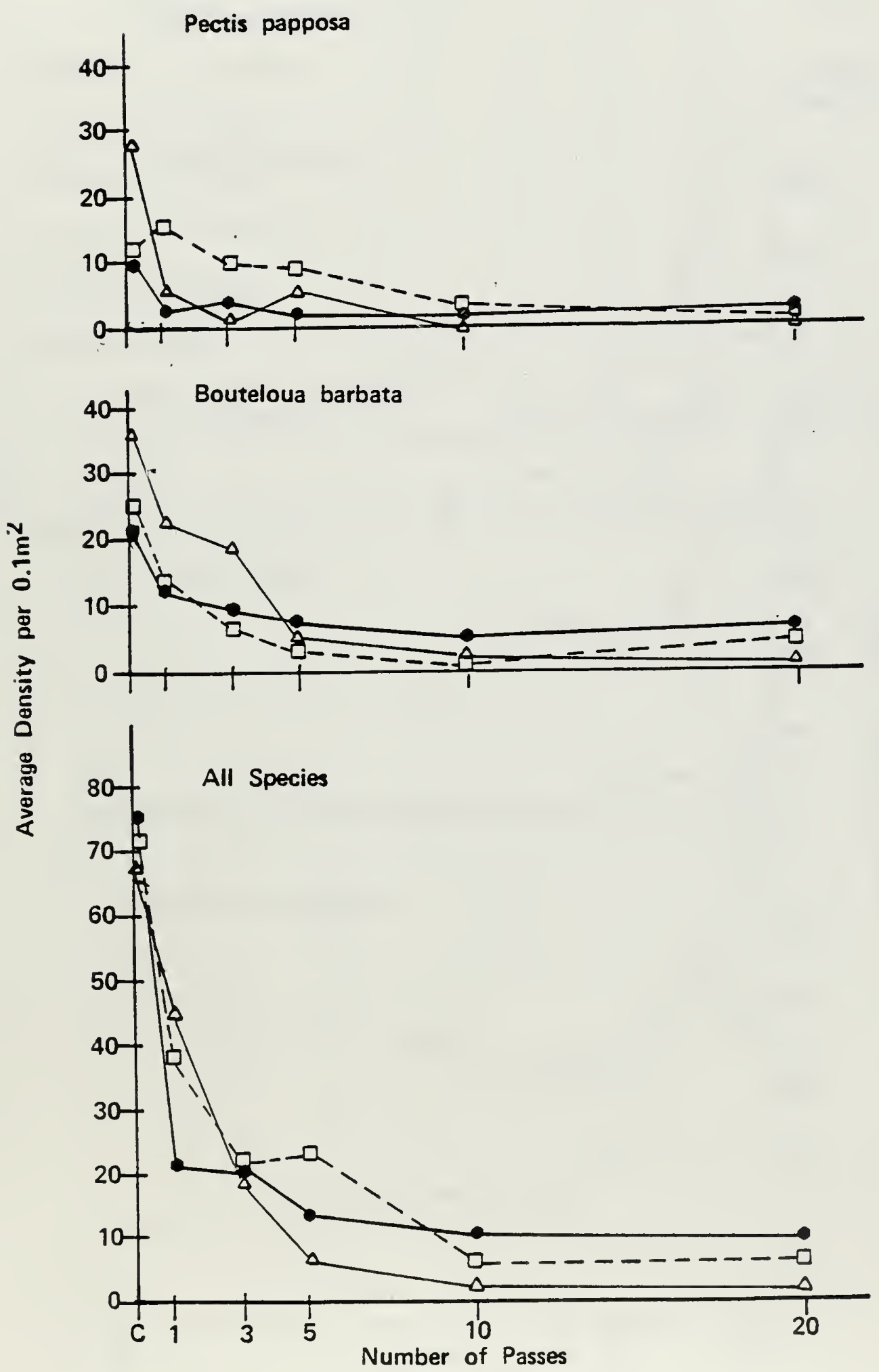


\section{SITE 1}

Stoddard Valiey

September 1978

\section{- Control}

- Treatment
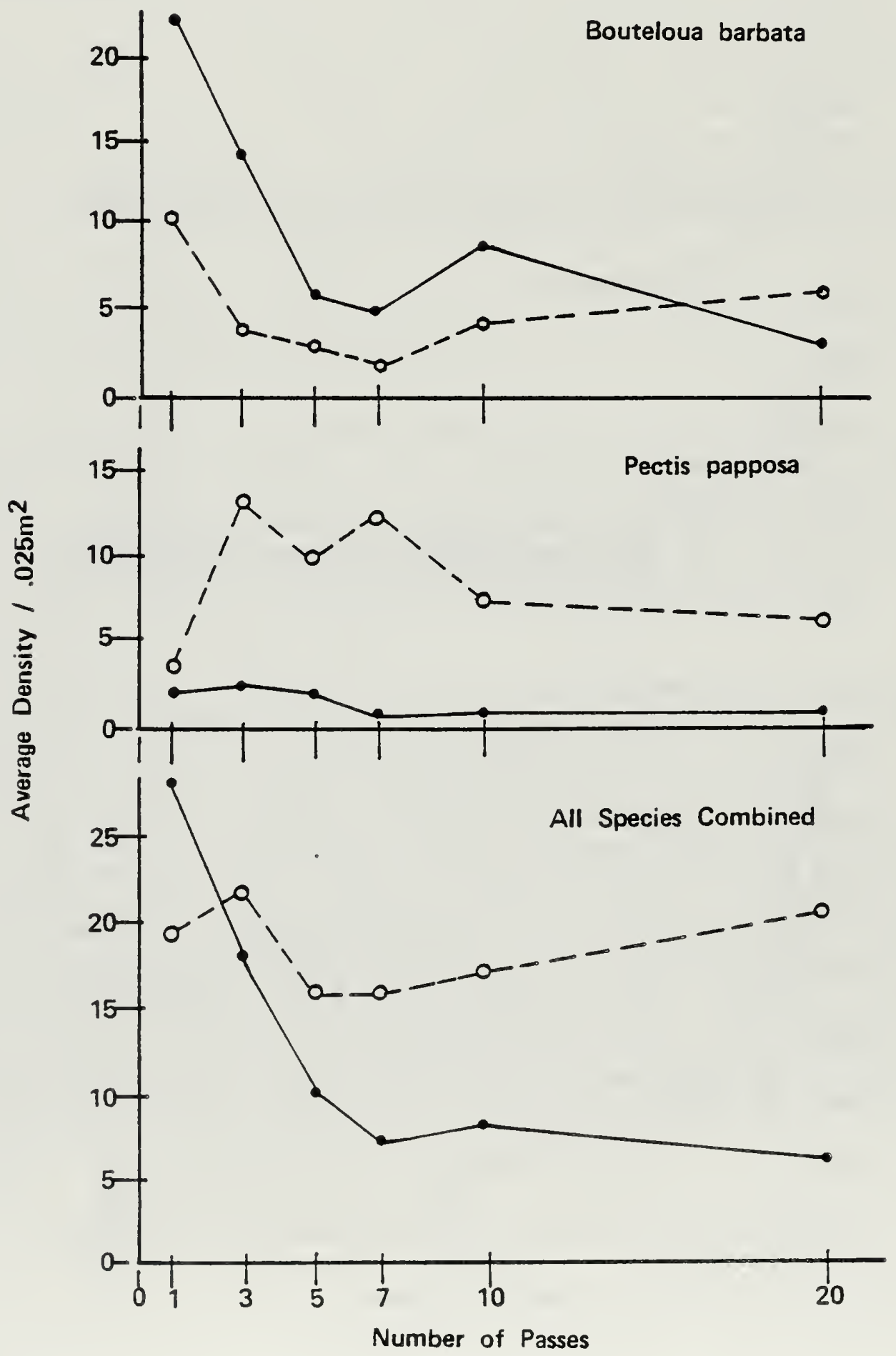
Table 6.2 Comparison of Plant Densities Among Controls at Stoddard Valley Site 1 for Both Winter and Summer Annuals. $C_{20}$ Refers to the 10 Control Plots Set Up Alongside the Track Produced by 20 Passes of A $4 \times 4$ Vehicle. Those Controls which Are Underlined Are Not Significantly Different. Experiment-wide Error Rate $(\alpha)=0.05$.

\begin{tabular}{|c|c|c|c|c|c|c|c|c|}
\hline \multirow[b]{2}{*}{ Date } & \multirow[b]{2}{*}{ Species } & \multirow{2}{*}{ ruskal-Wallis } & \multicolumn{6}{|c|}{ Rank of Rank Sums } \\
\hline & & & 1 & 2 & 3 & 4 & 5 & 6 \\
\hline \multirow[t]{4}{*}{$\mathrm{w} / \mathrm{sp} \cdot 78$} & Chaenactis fremontii & $17.22 * *$ & $\mathrm{C}_{20}$ & $\mathrm{C}_{7}$ & $\mathrm{C}_{5}$ & $c_{1}$ & $\mathrm{C}_{3}$ & $\mathrm{C}_{10}$ \\
\hline & Erodium cicutarium & $17.24 * *$ & $\mathrm{C}_{5}$ & $\mathrm{C}_{7}$ & $\mathrm{C}_{20}$ & $c_{1}$ & $\mathrm{C}_{10}$ & $\mathrm{C}_{3}$ \\
\hline & Schismus barbatus & $23.47 * *$ & $\mathrm{C}_{3}$ & $\mathrm{C}_{1}$ & $c_{10}$ & $\mathrm{C}_{7}$ & $\mathrm{C}_{5}$ & $\mathrm{C}_{20}$ \\
\hline & All Species Combined & $11.40^{\mathrm{ns}}$ & $\mathrm{C}_{7}$ & $\mathrm{C}_{3}$ & $\mathrm{C}_{20}$ & $c_{1}$ & $\mathrm{C}_{5}$ & $\mathrm{C}_{10}$ \\
\hline \multirow[t]{3}{*}{ Sum '78 } & Bouteloua barbata & $14.20 *$ & $c_{1}$ & $\mathrm{C}_{3}$ & $\mathrm{C}_{10}$ & $\mathrm{C}_{20}$ & $\mathrm{C}_{5}$ & $\mathrm{C}_{7}$ \\
\hline & Pectis papposa & $24.49 * *$ & $\mathrm{C}_{3}$ & $\mathrm{C}_{7}$ & $\mathrm{C}_{5}$ & $c_{1}$ & $\mathrm{C}_{20}$ & $\mathrm{c}_{10}$ \\
\hline & All Species Combined & $3.44^{\mathrm{ns}}$ & $\mathrm{C}_{3}$ & $c_{1}$ & $\mathrm{C}_{20}$ & $\mathrm{C}_{10}$ & $\mathrm{C}_{5}$ & $\mathrm{C}_{7}$ \\
\hline
\end{tabular}

$* \mathrm{P}<.05$

** $\mathrm{P}<.01$

ns Not Significant 


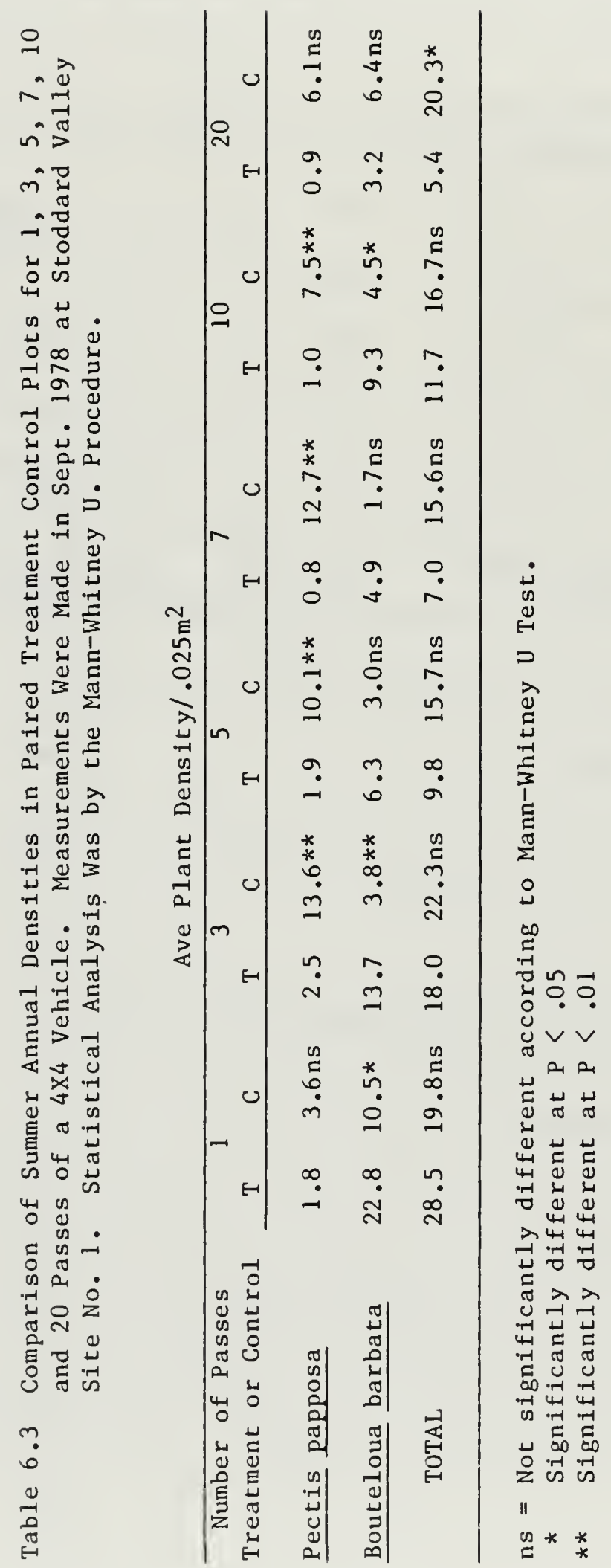


Table 6.4 Analysis of Differences in Total Density Among Treatments (No. of Passes of a $4 \times 4$ Vehicle) and Sites Which Had Been Compacted 3 (Site 1), 10 (Site 1A), and 21 (Site 1B) Days After a September 1977 Rainstorm in Stoddard Valley. Analysis Was Done Using Friedman's Method for Randomized Blocks (Nonparametric).

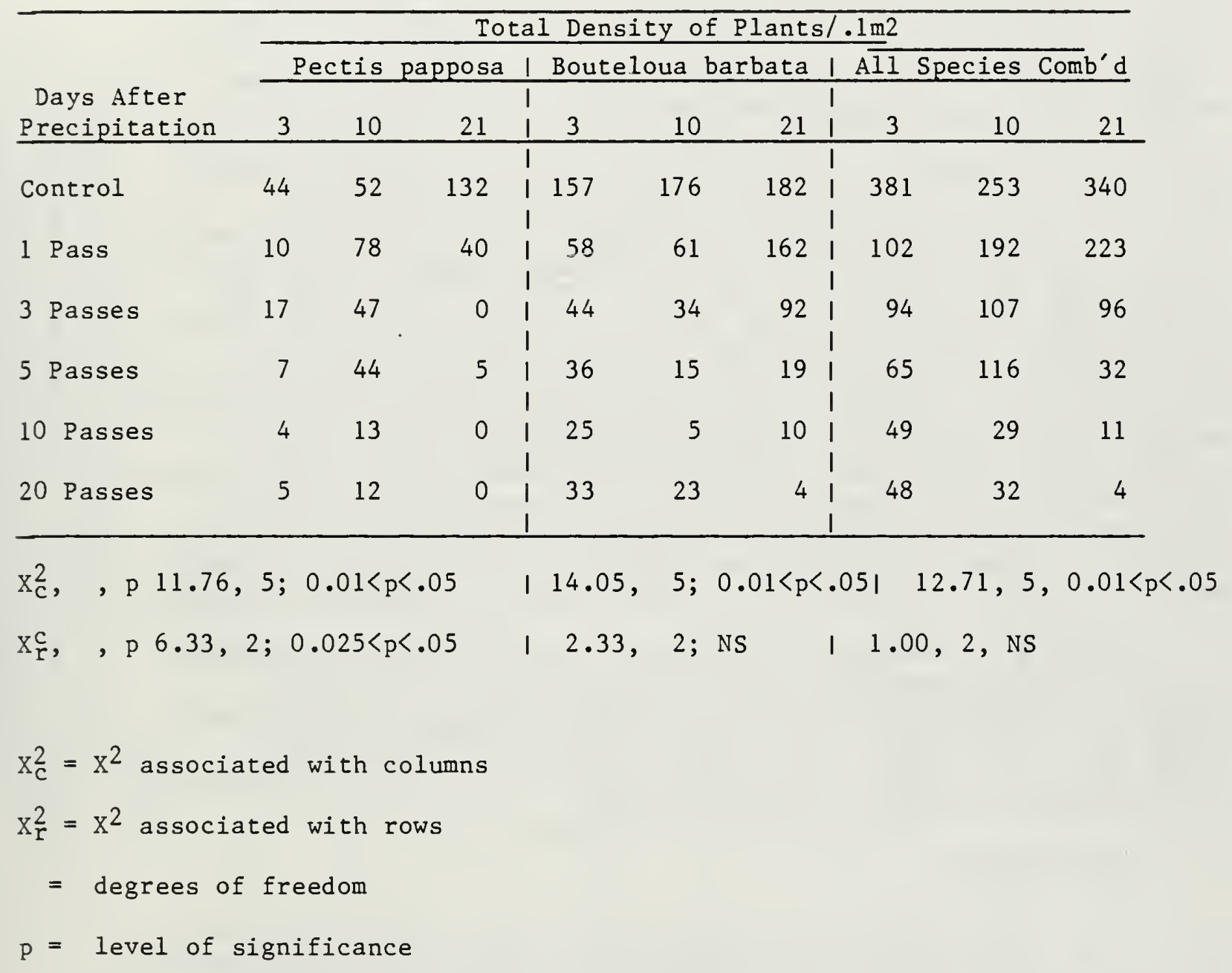


measured on sites $1 A$ and $1 B$. Unfortunately, the "hypothetical" pattern did not establish itself either in spring or in summer, 1978 where no direct damage was inflicted. We conclude that a considerable amount of heterogeneity exists among sites.

Average individual dry weights of Pectis papposa were higher $(.031 \mathrm{gm} /$ plant) in the control area than in the treatments; however, weights increased from about $.015 \mathrm{gm} / \mathrm{plant}$ in the track created by one pass of a vehicle to $.022 \mathrm{gm} / \mathrm{plant}$ in the 20 pass track. Except for a decline in average weights of plants within the 7 and 10 pass tracks, average weights of Bouteloua barbata rose from $.013 \mathrm{gm} / \mathrm{plant}$ in the control area to $.033 \mathrm{gm} / \mathrm{plant}$ in the 20 pass track. One pass of a large motorized vehicle is sufficient to reduce the standing crops of Pectis papposa by about $88 \%$, from $88.4 \mathrm{gm} / \mathrm{m}^{2}$ to $10.4 \mathrm{gm} / \mathrm{m}^{2}$. Thereafter there is 1ittle change in the standing crop of pectis from treatment to treatment. On the other hand, the standing crop of Bouteloua barbata increased dramatically from $79 \mathrm{gm} / \mathrm{m}^{2}$ in the control area to $173 \mathrm{gm} / \mathrm{m}^{2}$ in the track created by 1 pass of a $4 \times 4$ vehicle, and then dropped off (Table 6.5). This indicates a positive response to lower levels of compaction until some sort of threshold is reached, whereupon production falls off. This threshold is obviously higher for Bouteloua than for Pectis and may reflect the differences in seedling morphology that exist between monocots and dicots. That is, the fibrous rooted grass with its coleoptiles exerting a point force on the soil may more easily penetrate compacted soil than the tap-rooted Pectis with its two relatively large cotyledons. These data would seem to indicate the existence of species specific differences in growth and establishment in response to compaction.

Results from experiments involving tracks produced by motorcycles did not differ substantially from those created by $4 \times 4$ vehicles. Density of both Bouteloua barbata and Pectis papposa were significantly higher in control areas than in tracks created by 100 passes of a motorcycle (Figure 6.4). Total density of annual plants was reduced by $95 \%$ in tracks as compared to control areas.

\section{Winter Annuals}

Winter annuals (Table 6.6) were measured both in April 1978 and April 1979; both years received above average ppt. ( 8.3 in. (Oct-Apr) in 1977-1978 and 4.0 in 1978-1979 at Barstow) which apparently had a substantial ameliorating effect on the responses of winter annuals, as measured by density, to compaction. As a consequence, the results were not as clearcut as those for summer annuals. Nevertheless some interesting results were obtained (Table 6.7 , Figure 6.5 ).

Although in many cases (Table 6.7) differences between pairwise controls and treatments were significant, many were not and no evident patterns could be discerned. Only for Erodium cicutarium were plant densities in all control plots higher than in treatments, but only the controltreatment pairs for 3 and 20 passes were significantly different. 


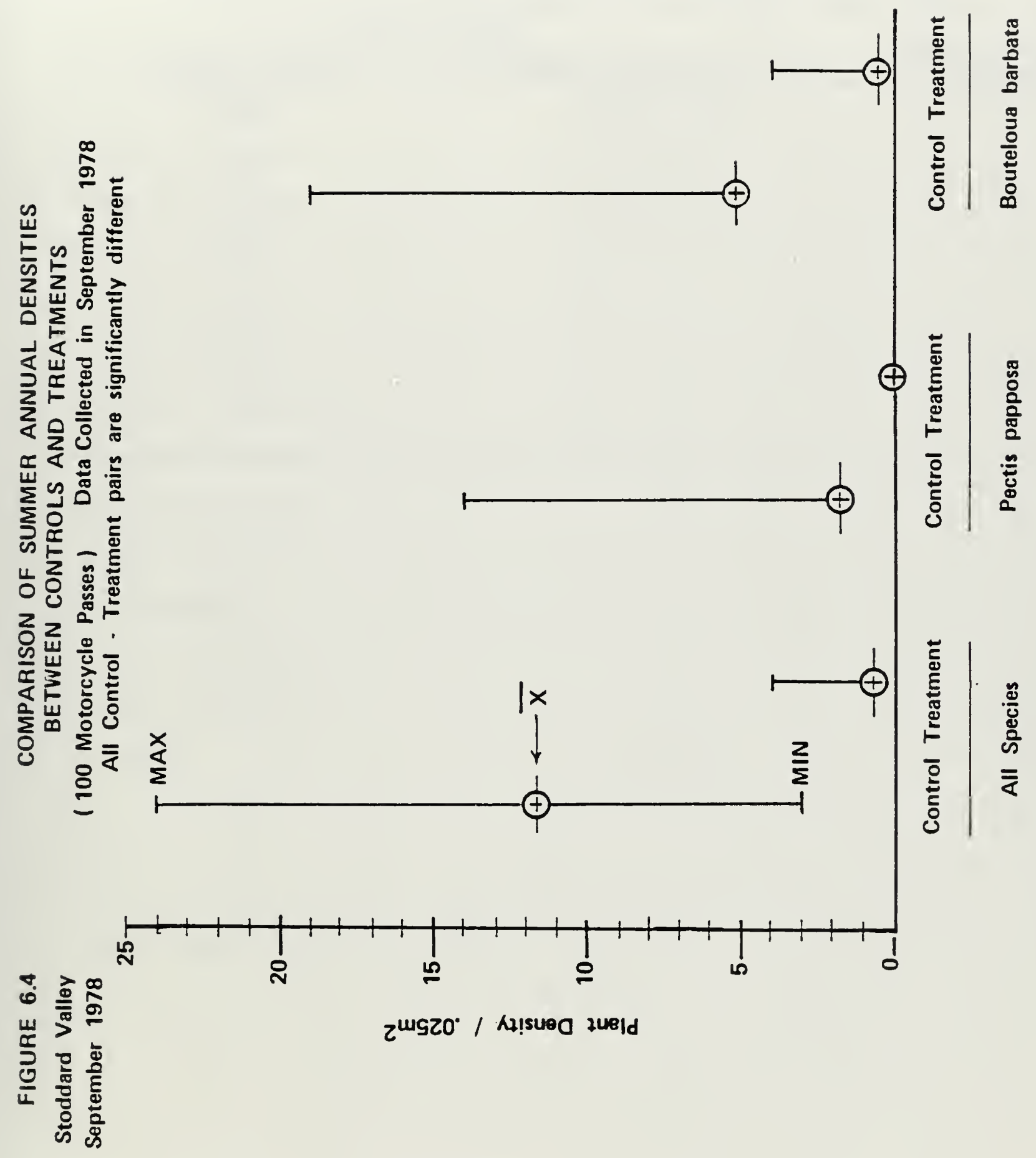


Table 6.5 Biomass of Summer Annuals Harvested in Stoddard Valley, Sept. 1978, Among Seven Treatment Classes

No. of Passes

Treatments

\section{C}

1

3

5

7

10

20
Biomass $\left(\mathrm{gm} / \mathrm{m}^{2}\right)$

Bouteloua barbata Pectis papposa

$$
79.0
$$

88.4

173.3

10.4

153.4

12.0

$78 \cdot 1$

13.7

37.2

4.2

96.7

6.8

42.2

7.6 
Table 6.6 Percent Cover of All Winter Annuals as Measured by Point Frequency (Levy and Madden, 1933) in a Control Transect at Stoddard Valley Site 1, April 1979. No Points Taken $=400$, All With Intershrub Spaces

\section{Species}

Erodium cicutarium

Chaenactis fremontii

Phacelia fremontii

Amsinckia tesselata

Lotus humistratus

Platystemon californicus

Eriogonum macculatum

Eriogonum nidularium

Eriophyllum wallacei

Gilia angelina

Mentzelia albicaulis

Schismus barbatus

TOTAL

\section{Percent Cover}

26.00

13.50

1.00

1.00

.25

$\mathrm{p}^{1}$

$\mathrm{P}$

P

P

$\mathrm{P}$

P

$42.00 \%$

$1 \quad P=$ present but not encountered 
Densities in treatments were not significantly different from any of the controls with respect to Schismus barbatus or to the combined densities of all winter annuals. Densities of Chaenactis fremontii were significantly different between the control and its adjacent 1 pass treatment. There were no significant differences thereafter and the general trend seemed to be an increase in density with increasing numbers of passes and therefore compaction (Table 6.7, Figure 6.5). Both Chaenactis and Erodium appeared visually not to be affected by the high soil strength in the tracks created by 20 passes of the Ford "Bronco" ( 30 bars) as observed in May 1978 (Figure 6.9a). Platystemon californicum, on the other hand were substantially reduced in size within the tracked area as compared to the control (Figure $6.9 \mathrm{a}, \mathrm{b}, \mathrm{c}$ ). However, two months earlier, both the roots and shoots of Erodium cicutarium appeared substantially larger in the control than in the tracked area created by 20 passes of the ORV (Figure $6.8 \mathrm{~b}$ ).

Two interesting observations were made by plotting the data in Figure 6.5. First: There was an abrupt increase in plant densities in the control plots for 3,5 , and 7 passes for all species. This was also indicated by analysis of densities of summer annuals as mentioned previously. Second: The controls appear to "track" the treatments; that is, there is a high degree of correspondence between the two. These data may indicate a high degree of environmental heterogeneity, possibly due to soil composition or other factors which can be responsible for abrupt changes in pattern of annual plant establishment. When abundant moisture is available as occurred in the winter and spring of 1977-78 to above average precipitation; remember compaction acts primarily in reducing soil water availability; the pattern of annual establishment may respond to other limiting factors and reduction in plant vigor which would otherwise occur during periods of normal rainfall in highly compacted desert soils is ameliorated.

Results from density measurements in 1979 did not differ substantially from those of 1978 and will not be discussed in the interests of space.

Plant cover was first measured in April 1979 by point frame and gave very clear and easily interpretable results. Cover of Chaenactis was reduced $86 \%$ by one pass of a $4 X 4$ vehicle. Cover subsequently rose to $53 \%$ of the control at 5 passes; however, this is probably an anomaly possibly caused by misplacements of the point frame or a natural change in soil structure. Cover of Erodium was reduced $40 \%$ by one pass. Total cover was reduced by $33 \%$. Schismus barbatus responded positively to the disturbance. No measurable quantities were encountered in the control transect and only $1 \%$ cover was recorded in the 5 pass treatment which did not differ significantly from the control (Table 6.8). The 1, 3, 10, and 20 passes did not differ significantly among themselves and cover ranged from 5.5 to $8 \%$. The control was significantly different from the treatments (which did not significantly differ among themselves) with regard to Chaenactis, Erodium and the total cover (Table 6.8, Figure 6.10). This is evidence that a "threshold" level of compaction exists for at least Chaenactis and Erodium which is surpassed by only one pass of a $4 \times 4$ vehicle and after which, substantial increases in compaction fail to cause a corresponding decrease in cover. 


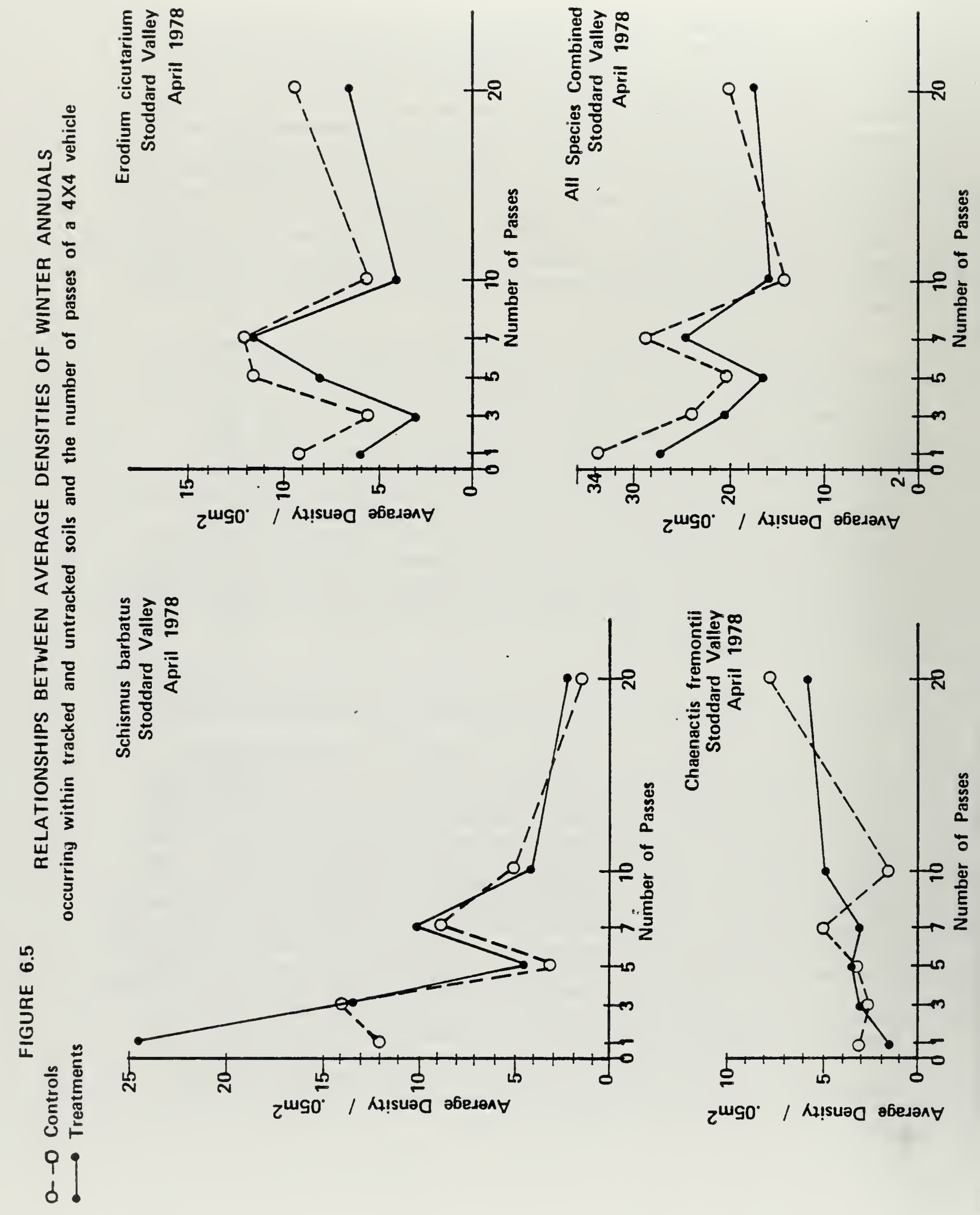


FIGURE 6.6

COMPARISON OF DENSITIES OF WINTER ANNUALS COLLECTED IN CONTROL AREAS AND WITHIN THE TRACK CREATED BY 100 PASSES OF A MOTORCYCLE.
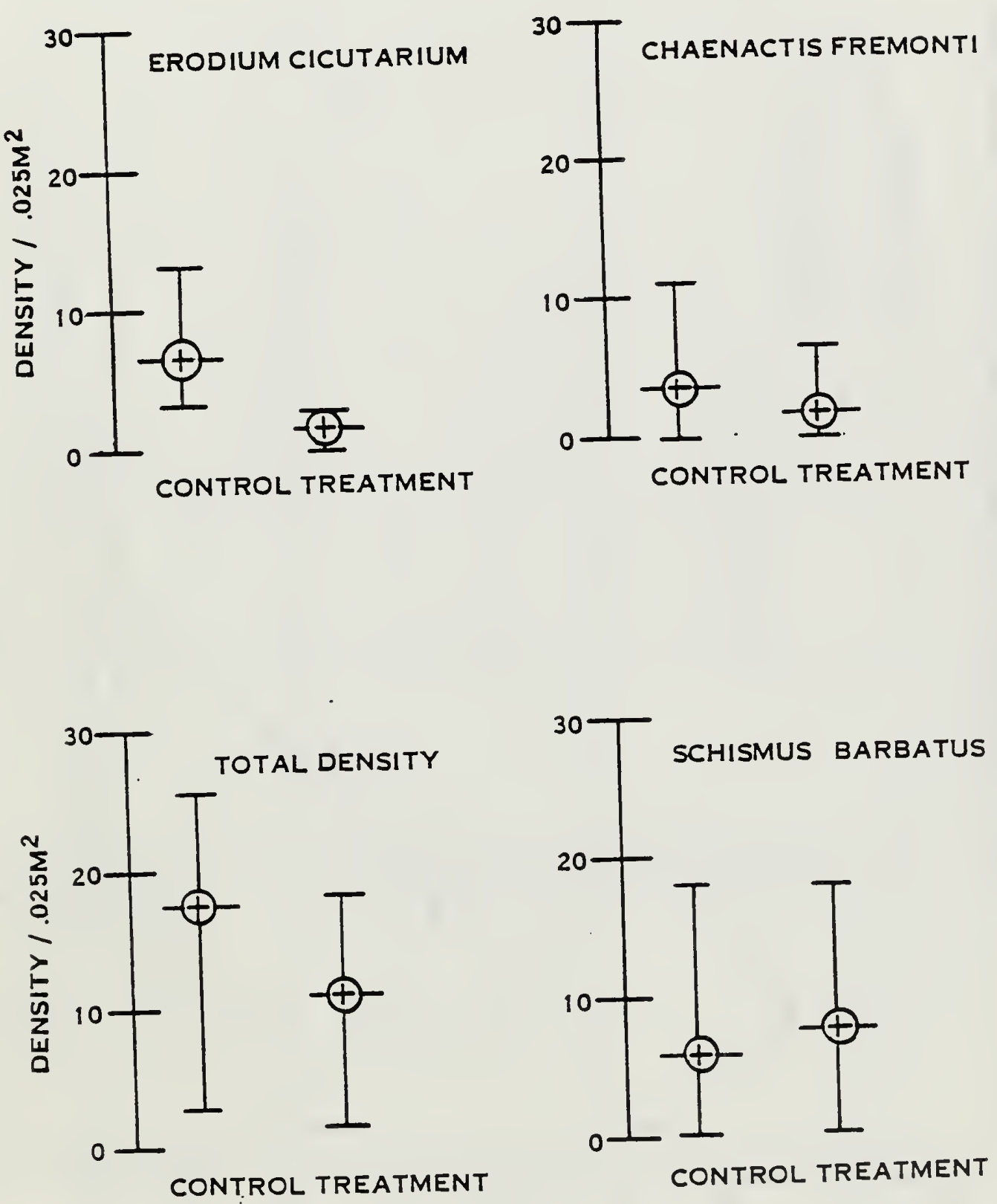


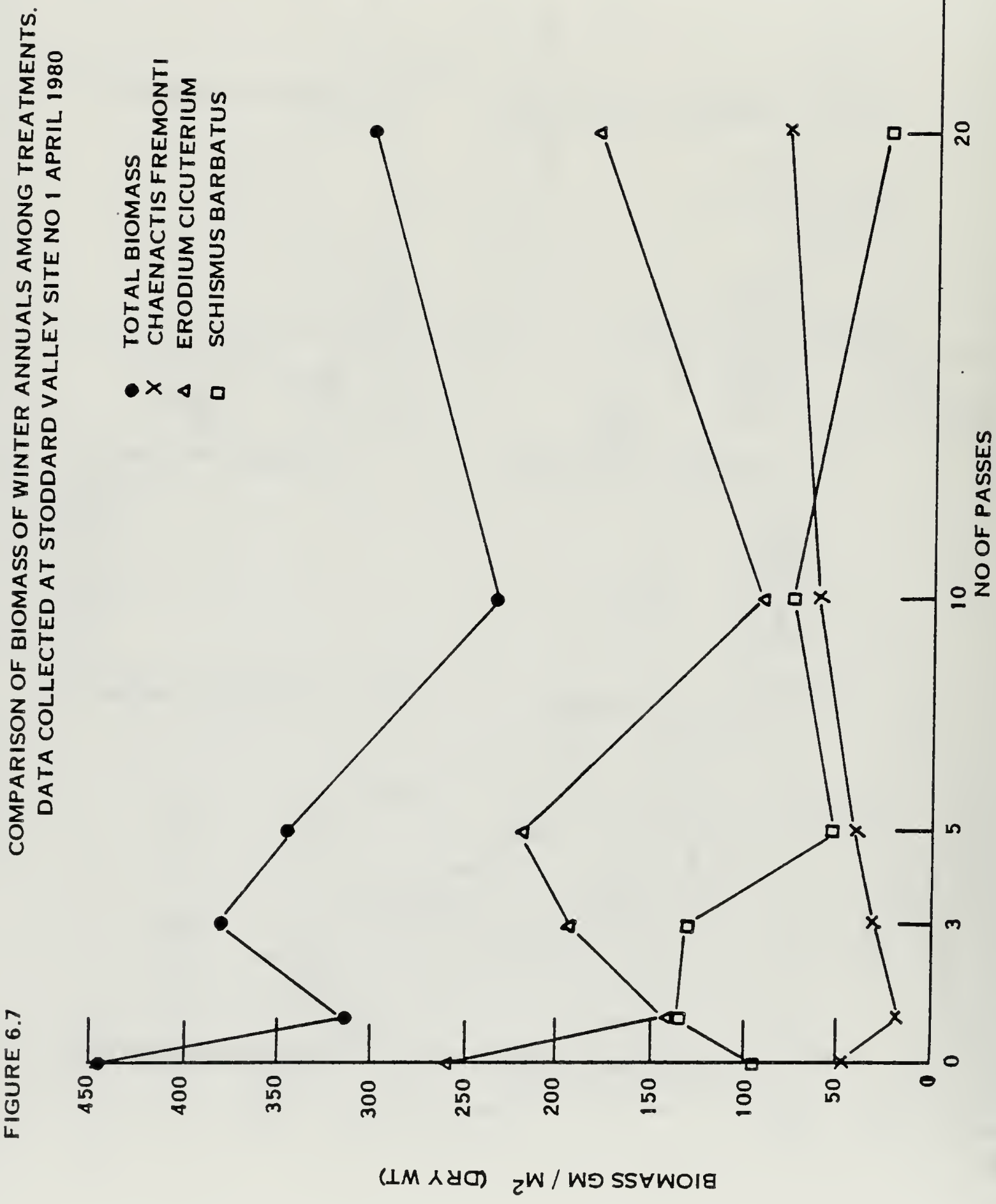




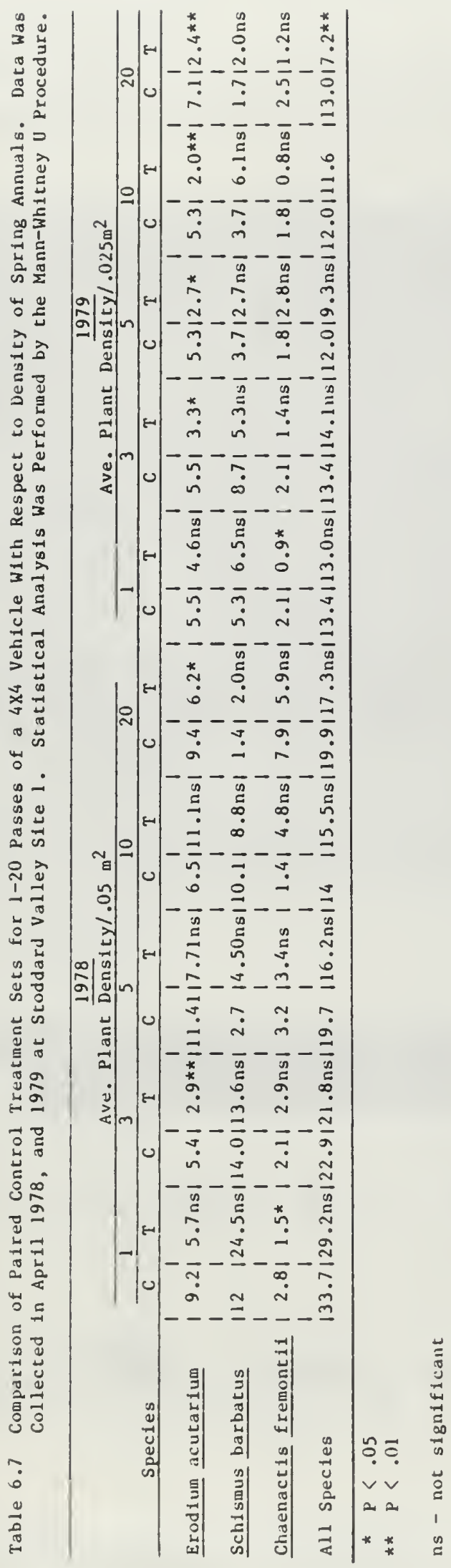


Figure 6.8 a. Tracks created by 20 passes of a Ford "Bronco" at site 1 in Stoddard Valley, CA., Aug. 19, 1977.

b. Ten individuals of Erodium cicutarium collected at random from inside these tracks (top row) and outside the tracks (bottom row) on Mar. $12,1978$.

\section{a}

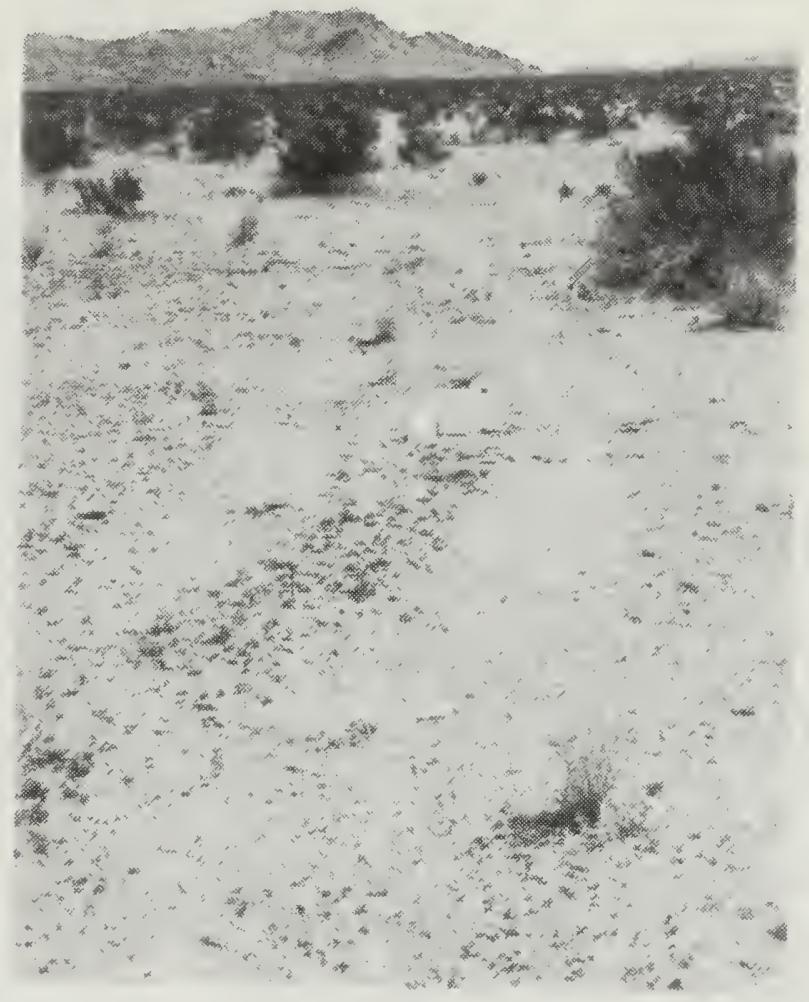

b

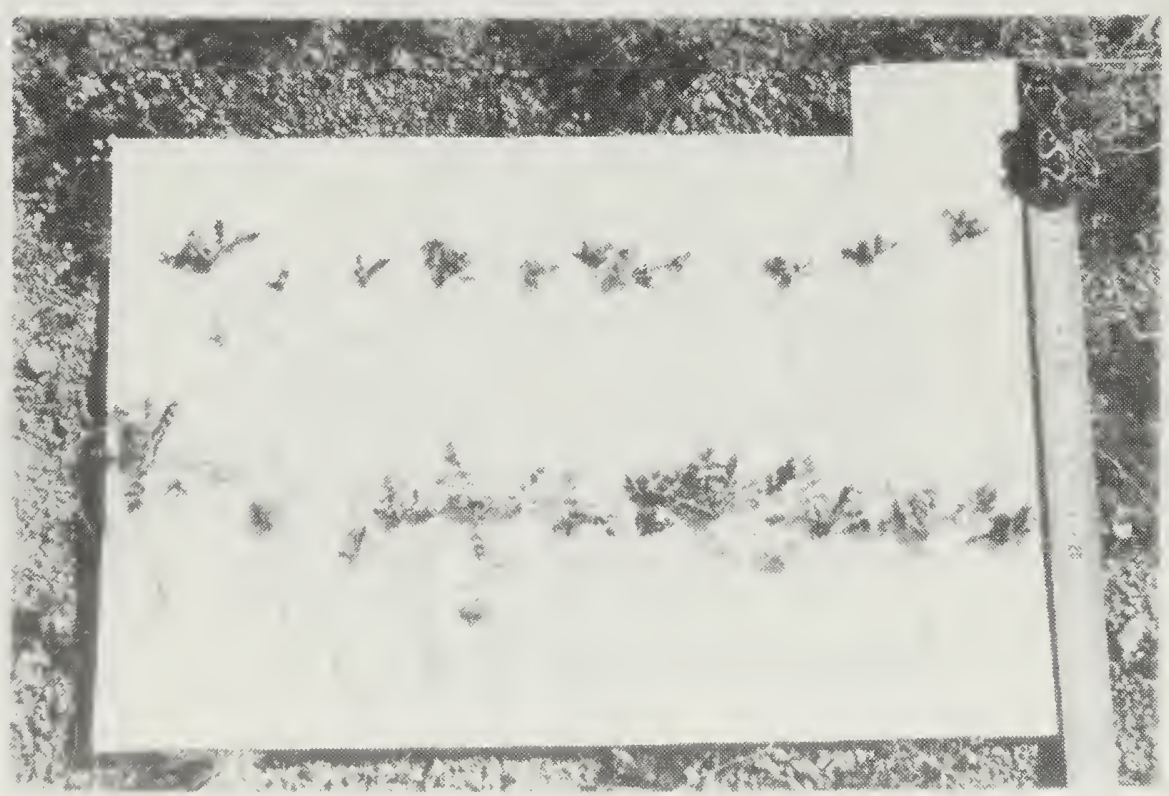


Figure 6.9 a. Comparison of annual plants on May 9, 1978 in the control (upper row) and in tracks (10wer row) created by 20 passes of a Ford "Bronco" at site 1 on Aug. 19, 1977. Chaenactis (1eft) and Erodium (center) were similar in size on control and tracked areas but Platystemon collected from within tracked areas (right) had large reductions in both root and shoot growth.

b. Closeup of Platystemon from the track created by 20 passes of the Bronco.

c. Closeup of Platystemon from adjacent control area.

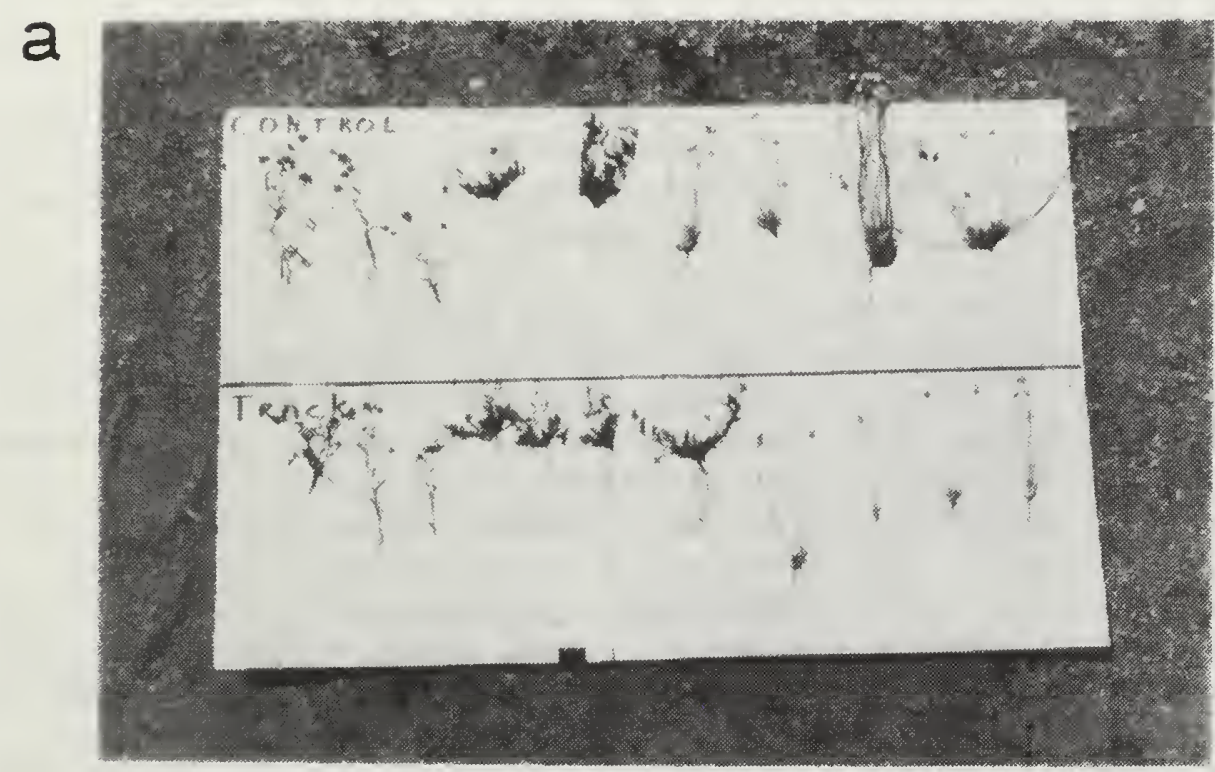

b

C

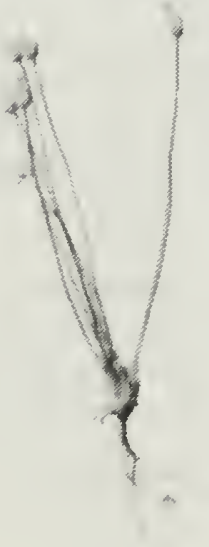


Significant decreases in cover of Erodium cicutarium ( $P<.01)$, Chaenactis fremontii $(P<.01)$ and in total cover $(P<.01)$ were observed in the track created by 100 motorcycle passes (Figure 6.11). There was no measurable cover of Schismus barbatus in the control and only a trace (1.5\%) in the track. Evidently, under these extremely compacted conditions the cover of Schismus though very low, was still greater than in und isturbed areas.

\section{Discussion}

The response of annual plants to soil compaction is a function of the intensity of soil compaction, the type of soil compacted, the time of compaction relative to changes in soil moisture levels, the amount and pattern of precipitation falling after compaction has occurred, the innate chemical and physical properties of the soil, the species of plant, and, just as important, the way one measures response.

Taylor and Burnett (1964) reported that there seemed to be no differences among crop species in their ability to penetrate soils of high strength. However, soil strengths in those experiments exceeded ( 18 bars), well above those under which significant differences in cover and density and substantial changes in biomass were observed in the Stoddard Valley plots. Soil strengths above 25 bars probably exceed the tolerance levels of most plant species, crops or otherwise. This certainly seems to be the case in the Stoddard Valley plots where 1 pass significantly reduced the cover of both Erodium cicutarium and Chaenactis fremontii. Even though Schismus barbatus responds positively at first to increases in compaction, neither it, nor any other species exhibits increases in cover, relative to their controls, at soil strengths beyond 18 bars. It therefore follows that the interval between 0 and around 18-20 bars may be the most critical in determining both the nature and extent of species specific responses to compaction for desert annual plants in situ. Biomass and density measurements, of both winter and summer annuals in 1978 and 1977 when analyzed, enabled similar interpretations to be derived, but with some modifications. These were due largely to the ameliorating effects of the above average winter and spring precipitation in 1977-78, and were manifested in a fluctuating, rather unstable relationship between compaction and both density and biomass of winter annuals. Summer annuals, measured in 1978 behaved predictably. Probably, in a dryer year, where precipitation is nearer or below average, or where much of the precipitation falls within a narrow period of time, the pattern of response of winter annuals to progressively increasing compaction would be similar to the response of summer annuals. Summer annuals receive intense doses of precipitation in the space of a few days, with often no more thereafter. As a result, a compacted soil would severely limit the ability of the plants to withdraw water after a short period of time. On the other hand, if winter precipitation occurs at normal or above normal levels and is spaced at regular intervals throughout the season, winter annuals may survive at near normal ratios and grow to normal size even though root development is restricted by the compacted soils, which under other conditions would severely limit withdrawal of soil water. Under normal conditions of precipitation, the compaction created by only one or two passes of a large vehicle or several passes of a motorcycle on wet soil along the same track will substantially reduce biomass, cover, and density of winter annuals. 
Table 6.8 Multiple Comparisons Test for Differences in Cover of Winter Annuals Among Compaction Treatments Resulting From A Variable Number Passes of $4 \times 4$ Vehicle Over the Soil Surface. Cover was Measured by a Point Frame Recording "Hits" on Annuals, up to 20 Per Replicate Times 10 Replicates Per Treatment. The Underscored Treatments Are Not Significantly Different. Data Collected in Stoddard Valley, California, April 1979.

Species :

Kruskal-Wallis Corrected

Rank Sums

Rank of Rank Sums

Treatment (No. Passes) :

Ave. Cover Per Treat. (\%)
: Chaenactis fremontii

$$
\mathrm{H}=22.782 ; \quad \mathrm{P}<.01
$$

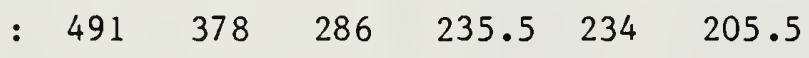$$
\begin{array}{lllllll}
: & 1 & 2 & 3 & 4 & 5 & 6
\end{array}
$$

\begin{tabular}{llllll}
$\mathrm{C}$ & $5 \mathrm{P}$ & $10 \mathrm{P}$ & $1 \mathrm{P}$ & $20 \mathrm{P}$ & $3 \mathrm{P}$ \\
\hline
\end{tabular}

$\begin{array}{llllll}17.5 & 8.0 & 4.0 & 2.5 & 2.5 & 1.5\end{array}$

Species

Kruskal-Wallis Corrected

Rank Sums

Rank of Rank Sums

Treatment (No. Passes)

Ave. Cover Per Treat.(\%) :
: Erodium cicutarium

$\mathrm{H}=12.332 ; \quad 0.02<\mathrm{P}<0.5$

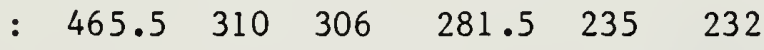

$\begin{array}{lllllll}: & 1 & 2 & 3 & 4 & 5 & 6\end{array}$

\begin{tabular}{llllll}
$\mathrm{C}$ & $1 \mathrm{P}$ & $3 \mathrm{P}$ & $5 \mathrm{P}$ & $20 \mathrm{P}$ & $10 \mathrm{P}$ \\
\hline
\end{tabular}

$\begin{array}{llllll}31.0 & 18.6 & 12.5 & 11.0 & 8.5 & 8.0\end{array}$

: Schismus barbatus

$$
\mathrm{H}=16.372 ; \mathrm{P}<.01
$$

$\begin{array}{llllll}\text { : } 402 \quad 377.5 \quad 345.5 \quad 310 & 220 & 175\end{array}$

$\begin{array}{lllllll}: & 1 & 2 & 3 & 4 & 5 & 6\end{array}$

\begin{tabular}{lllllll}
$10 P$ & $3 P$ & $1 P$ & $20 P$ & $5 P$ & $C$ \\
\hline
\end{tabular}

$\begin{array}{llllll}8.0 & 7.5 & 5.5 & 6.5 & 1.0 & t\end{array}$


Table 6.8 Continued.

Total Annual Cover

Kruskal-Wallis Corrected $\quad \mathrm{H}=18.764 ; \mathrm{P}<.01$

Rank Sums

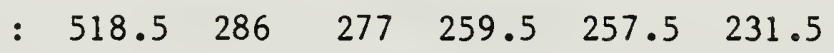

Rank of Rank Sums

$\begin{array}{lllllll}: & 1 & 2 & 3 & 4 & 5 & 6\end{array}$

Treatment (No. Passes) :

\begin{tabular}{llllll}
$\mathrm{C}$ & $3 \mathrm{P}$ & $1 \mathrm{P}$ & $5 \mathrm{P}$ & $10 \mathrm{P}$ & $20 \mathrm{P}$ \\
\hline
\end{tabular}

Ave. Cover Per Treat.(\%) : $\begin{array}{lllllll}53.5 & 22.5 & 22.0 & 21.0 & 21.0 & 19.0\end{array}$

$t=$ trace 
FIGURE 6.11

COMPARISON OF COVER OF SPRING ANNUALS

Growing within a Control Area and the

Track Created by 100 Passes of a Motorcycle

Soil moisture levels at the time of compaction are important in determining the intensity of compaction in most soils. Therefore, it seems reasonable to expect that this relationship should be reflected in differential establishment and growth responses of desert annuals; that is, one would expect relatively higher survival of plants in soils which were compacted while water content is low, than when it is high. This was not found to be the case. In summer 1977 the absence of the hypothetical pattern could be blamed on outright destruction of plants in those sites run over 10 and 21 days after a summer rain; young plants had germinated by this time; whereas in the treatment which was run over 3 days after the rainfall, no seeds had germinated. However, neither was the hypothetical pattern of annual establishment observed in the spring or the summer, 1978. We conclude under these circumstances that normally occurring substrate hetergeneity among sample areas at the same site which causes patchiness in the pattern of annual plant establishmdent may be more important than effects caused by the interaction of a compacting agent and soil moisture levels at the time of compaction.

The extent of environmental heterogeneity was shown by analysis of the controls for the spring 1978 experiments. The consequences for experimental design in similar experments are obvious. Because of the patchiness of annual pants which occur in the intershurb spaces, some sort of pattern analysis (Kershaw, 1973; Pielou, 1979) should be performed to identify areas of abrupt pattern change before establishing controls and treatments.

In general, density measurements are not as trustworthy as either biomass or cover in establishing degrees of trend in annual plant response to compaction or other potentially mutable environmental factors. Lathrop (1979) showed that density values alone can be deceiving in assessing the relative recovery rates of vegetation on tank trails. Cover data, presented by Lathrop (1979), when analyzed by us inferred a far slower rate of recovery, which would have been judged almost complete if only plant density values were taken into account (see Section IV). Cover and biomass integrate both establishment and growth, whereas density only reflects establishment. Obviously, from the data presented both in this report and in the literature, the response of both annual and perennial plant species is manifested in differences in the magnitude of cover, biomass, and density.

Although somewhat attenuated by above average rainfall, one pass of a $4 \times 4$ vehicle is sufficient to significantly depress both density and cover and substantially reduce the biomass of both winter and summer annuals in its tracks. As a result, even "haphazard" travel by these vehicles has the capability of significantly reducing the standing crop of annuals by as much as $33 \%$ in the impacted areas. If several or more vehicles are involved, large areas can suffer long term reductions of both wildlife and livestock forage. Motorcycles, although much 1 ighter than $4 \times 4$ vehicles, may actually cause more damage by the addition of shear to compaction forces. Damage caused by shear would be of a short-term nature. Because motorcycle tires are generally much narrower than those of a $4 \times 4$ and since there are less of them, the mass distribution per unit surface area impacting the ground (and therefore, compaction) is of the same order of magnitude, but distributed over a smaller area. As a result, several motorcycles have the potential for causing as much or more deterioration to native annual populations as a $4 X 4$ vehicle. Furthermore, much terrain which is inaccessible to $4 \mathrm{X} 4$ vehicles may be impacted by the more versatile motorcycles so that the cumulative impact of motorcycles on a regional landscape may far outstrip that of $4 \times 4$ vehicles. 
The amount of time required for recovery from compaction may be long term and varies with the region, compacting agent and depth of compation. Webb and Wilshire (1979), concluded that soils may take several centuries to fully recover from the effects of compaction, Lusby (1970) estimated soil recovery from compaction is three years after removal of cattle from salt-desert-shrub type vegetation in Colorado. Reynolds and Packer (1963), estimated a recovery period of 5-10 years following removal of heavy grazing. However, depths of compaction due to grazing seldom exceed $15 \mathrm{~cm}$ and compaction is usually restricted to the surface $5 \mathrm{~cm}$. After 40 years, Power (1974), reported that plant growth on compacted clay soils in Oregon was still depressed. These estimates of soil recovery time although interesting are highly speculative.

According to Heady (1975), freezing-thawing and wetting-drying together with the activities of animals begin to reduce soil compaction as soon as it occurs. Soil micro and macro fauna, especially ants, may be very effective in loosening up high-strength soils. Indeed, there appeared to be more ant nests built within the $4 \times 4$ tracks than within the control areas. Any prediction of recovery time must take into account the fact that micro and macro faunal distribution in soils may be patchy and that different areas of compacted soils may recover at different rates and that recovery time is inversely related to, among other factors, the density of soil fauna, and the intensity of their activities. Although investigations within this area are beyond the scope of this report, original research could provide much insight into this problem. Freezing-thawing and wettingdrying are probably of little importance in alleviating compaction of the soils of warm-dry deserts, but may be of more importance in Great Basin Desert (cold desert) sites and at higher elevations in arid regions. At any rate, in order to cut recovery time, soil ripping to depths of perhaps one foot may be necessary to enhance rehabilitation of compacted areas. 
VII. THE EFFECTS OF OFF-ROAD VEHICLES

ON SOILS, VEGETATION AND

COMMUNITY PROCESSES: A SUMMARY

BY

PETER G. ROWLANDS AND JOHN A. ADAMS

TABLE OF CONTENTS

$\underline{\text { Page }}$

A. The Problem . . . . . . . . . . . . . . . 166

B. Impacts on Soils. . . . . . . . . . . . . . . 168

1. Compaction ................... . . 168

2. Erosion. ................... . . 169

3. Dust . . . . . . . . . . . . . . 170

4. Valley Fever ..................... 170

5. Impacts on Surface Crusts

6. The Present and Future Extent of ORV Induced Impacts . . . . 171

C. Impacts on Plant Growth and Development ............ 171

D. Recovery, Revegetation, and Restoration of Desert Lands Damaged by off-Raod Vehicles............... . 174 


\section{A. The Problem}

The problem of off-road vehicle damage to, and management of, western rangelands and deserts is one which is rife with controversy. On the one hand are ORV users who have what they feel are legitimate sociological needs and personal rights to recreate on the public lands in any manner they see fit. On the other side are conservationist and preservationist groups, many desert residents, and competing users of the land such as cattlemen, who see ORV use as not only wasteful of and damaging to natural resources, but intrusive on their particular way of life in the desert. The arguments for and against the use of off-road vehicles are both emotional and noisy and border in some cases on the violent. In many cases, well trained desert scientists, seeing actual research areas or foreseeing potential research areas being damaged have entered the foray with the usual effect of "clouding the issues" with, in some ways scientific, but in many ways unscientific, basically emotional opinions. Scientists are human like anyone else and their reaction is understandable, though probably it is not in the best interests of science.

A recent editorial by Philip Handler, President of the National Academy of Sciences in Science, June 6, 1980 , puts this in perspective:

"The public image of science and scientists has been distorted by the participation of scientists in public policy formation. Beneath the surface, the environmental and consumer movements may be an expression of anomie, a cry of protest for the sense of powerlessness of the individual educated citizen - patently a serious sociopolitical circumstance. However, a frequent surrogate for that deep-seated complaint is an expression of concern about the safety of some product or technology, based always on an assertion of risk that was first brought forward by some member of the scientific community. The societal response has been attempts at examination of such matters by risk and cost/benefit analysis. Well, risk/benefit analysis can certainly inform the decision-maker. But his decision must necessarily still turn on a value judgment, conditioned by his social, economic, philosophic, and religious views. But that is the nature of the political process. The public acceptability of a given level of risk is a political, not a scientific, question.

Difficulty arises in the scientific community from confusion of the role of scientist qua scientist with that of scientist as citizen, confusion of the ethical code of the scientist with the obligation of the citizen, blurring the distinction between intrinsically scientific and intrinsically political questions. When scientists fail to recognize these boundaries, their own ideological beliefs, usually unspoken, easily becloud seemingly scientific debate. 
A decade ago it might have been desirable to flag potential hazards for public attention and proceed as if each were a clear and present danger. It is time to return to the ethics and norms of science so that the political process may go on with greater confidence. The public may wonder why we do not already know that which appears vital to decision - but science will retain its place in public esteem only if we steadfastly admit the magnitude of our uncertainties and then assert the need for further research. And we shall lose that place if we dissemble or if we argue as if all necessary information and understanding were in hand. Scientists best serve public policy by living within the ethics of science, not those of politics. If the scientific community will not unfrock the charlatans, the public will not discern the difference - and science and the nation will suffer."

In between the two factions lie the public agencies responsible for administering the public lands; the Forest Service and the Bureau of Land Management in particular who always seem to be in the position of "reacting" to user demands, rather than forming proactive management strategies based upon research and well constructed bases of data. For example: assumptions are often made about so called "sacrifice" or "kiss-off" areas; because these are so badly damaged, they are not worth saving. As we shall see, the present damage may have been exaggerated by all parties concerned but trends may be present which should be recognized and arrested now.

There are particularly bothersome misuses of definitions and terms being used by the parties involved. Reference is often made to "fragile" desert or "fragile soil crusts" or "the desert is a total ecosystem." Such terms are often found in public laws such as the Federal Land Policy and Management Act, and other documents without any apparent regard as to the implications of their use, the definitions involved, or the recognition that many well respected scientists and citizens may not agree that the definitions as stated are valid or in fact that such things can even be defined. The user groups claim that the desert is "tough." What does that mean? Just what is the ultimate significance of accelerated erosion? What does fragile mean? The desert is fragile relative to what - a tropical rain forest, the arctic tundra, a vacant lot undergoing secondary succession? The Bureau of Land Management Manual 6740 defines fragile as "sensitive to external stimuli which may disturb the existing balance of conditions and properties, especially in an irreversible direction." By this definition we put it to you that every ecosystem is fragile from the tropical rain forest to an old field. To say that the desert is fragile, therefore simply equates it to an old field. What about ecosystem? Is the desert really a total ecosystem? It might surprise some people to know that some respected desert scientists for example Professor Noy-Meir of the Hebrew University of Israel 1 has stated that since interaction between species is of little importance in desert communities, the understanding of desert communities involve simply the sum of autecological information about the component species. The ecosystem concept is of little value in such habitats. Charles Darwin, incidentally made the same point over 
one hundred years earlier. Even if we grant that these and similar such terms are clearly understood by certain specialists in the field and have some practical value, they are misunderstood by others and at best are superficial descriptions of places and situations. At worst, they are "buzz words" used in a manner akin to phlogiston in the 16 th century, obscuring the issues and leading to a mystical approach to the problems of disturbance induced changes in natural habitats. They are also cliche.

There is a great need to investigate this problem on a completely objective level, to present the data as they are found in the literature and as they have been derived from original research and to expose them to critical and objective scrutiny. Only then can these muddied waters be cleared and a comprehensive evaluation be made. Here the work of the scientist ends and that of the management specialist begins, but there is no "bottom line" the scientist and researcher cannot tell management exactly how many off road vehicles to put in a certain area in order to avoid impact. This is a benefit/risk decision which management has to make. The scientist has no more nor less right to make such decisions than the layman. The scientist/researcher is not a "tin god."

\section{B. Impacts on Soils}

Just how extensive is ORV damage to desert soils and vegetation?

\section{Compaction}

We have seen that most desert soils, including many sands are susceptible to intense compaction if driven across a sufficient number of times. Some cohesionless sands (i.e. dunes) are very resistant to compaction whether wet or dry and playa soils when dry will have considerable resistance to compaction. In other types of soil the principal factors influencing soil compaction are soil moisture content, the density of vehicular activity and characteristics of the vehicles themselves (i.e., weight, content, surface area of the tires, etc.). One pass of a four-wheel-drive vehicle (4WD) or motorcycle appears to cause only small amounts of additional compaction, however, multiple passes along the same track of motorcycles on wet soil or a $4 \mathrm{WD}$ on dry soil are required to produce significant increases in compaction in comparison to undisturbed areas. On "pit" areas severe compaction and denudation of vegetation has been measured over large areas but highly compacted trails on adjacent "free play" areas usually cover less than 10 percent of the surface. compaction can best be avoided by restricting ORV activity to dry soils.

${ }^{1}$ Quoted by P. D. Moore in Nature 275:691-692 
Compaction of soil effects both physical and chemical properties of the soil, greatly increasing soil strength, decreasing penetrability, and infiltration rates, and increasing the range of temperature fluctuations within the soil. Probably soil strength is the principal factor limiting plant growth, overshadowing the others by the intensity of its effects. Soil chemical properties show the greatest changes on hillsides where displacement of surface soils exposes subsurface soil which may have markedly different properties. However, at best, these changes are indirect effects. On gentle terrain changes in soil chemical properties are less. More important is the disruption and dispersal of chemical nutrients, which have accumulated under shrubs when these have been destroyed by ORVs, but again, not a direct result of compaction. The effects of compaction and other soil modifying factors on nitrogen - fixation is unclear. Probably the most drastic changes are in the pattern of occurrence of active sources of nitrogen fixation, rather than changes in magnitude.

\section{Erosion}

The modifications of the soil surface which are induced by the forces of compaction and shear leave soils susceptible to erosion by both water and wind leading to displacement of large volumes of surface material as sediment and fugitive dust.

Hillclimbs on slopes over 20 percent show large increases in water erosion as well as mechanical displacement of soil. Increased runoff and sediment production has not been shown to occur from single passes of a four-wheel-drive or motorcycle, but experiments with simulated heavy rainfall, such as might occur during a torrential downpour of a summer thunderstorn or a 100 year storm, shows increases in runoff and sediment movement from tracks made by multiple passes of ORVs, even on gentle slopes. On gentle slopes, there is little movement of material off site, but where highly compacted trails run for long distances down gentle slopes, as for example, those radiating northward from the Johnson Valley Pit area, significant erosion may occur even on relatively level terrain with slopes as low as 3 percent.

Desert soils, except perhaps for cohesionless sands and some playa soils are much more susceptible to wind erosion after disburbance by ORVs or similar agents loss of soil material to wind erosion is inversely proportional to the relative amounts of coarse material (greater than $1 \mathrm{~mm}$ dia.) present and directly proportional to the width of the continuous disturbed area (erosion fetch) and the wind velocity. Disjunct tracks with intervening undisturbed soils will be less susceptible to high rates of wind erosion than continuous areas of disturbance such as pit areas or dirt roads. 


\section{Dust}

Wind erosion of soils disturbed by vehicles produces fugitive dust. There is some evidence that vehicular activity can increase both the frequency and intensity of dust storms in arid lands and can exacerbate desertification in some areas. However, even though large amounts of particulate material may be displaced into the air by an ORV race $\left(10^{3}\right.$ metric tons) this is several orders of magnitude smaller than a well developed terrestrial dust storm where $10^{5}-10^{9}$ tons of material may be removed and carried aloft. Generation of dust by ORV events varies greatly with changes in distance from the event soil conditions, especially moisture, dispersive meteorology and vehicle participation but are typically well in excess (up to ten times the daily and 100 times the hourly standard) of applicable air quality standards in areas of participants and spectator congregation. Total suspended particulate levels drop to background with 24 to 48 hours after the event, but depending upon the meteorological conditions could impact sensitive areas from 2-15 km downwind. Fugitive dust can be mitigated by restricting events to soils lacking in fine particles, soils with high existing wind erosion rates in an undisturbed condition which will not have appreciable increases in wind erosion with disturbance, and soils with low existing wind erosion rates in an undisturbed condition which will retain these low rates in a disturbed condition. On unstabilized sand dunes, for example, dust planes from ORVs generally do not rise above a height of one meter behind the most active vehicle before settling clears the air within seconds. The soils of playa centers retain a low potential for wind erosion even after disturbance. It is best to avoid disturbance of soils with high concentrations of fine particles as these tend to omit more particulate matter upon movement unless the structure of the soil is highly resistant to breakage. Such soils to be avoided include but are not limited to: The silty soils often found on playa margins or those underlying desert pavement.

\section{Valley Fever}

One of the hazards of dust is that it of ten carries the spores of Valley Fever or Coccidioidomycosis caused by the fungus known as Coccidioides imitis. Out of 500 samples tested in ORV open areas throughout the CDCA only two positive results were found, both in Johnson Valley. Valley fever is probably not widespread through open areas, however, the distribution of the disease is so spotty that a larger number may be required to confirm or deny its presence. A legal precedent has been set which confirms liability of landholders to claims made by persons who contract the disease while present on real estate owned or administered by such landholders. 


\section{Impacts on Surface Crusts}

Off-road and other types of mechanized vehicles destroy surface crusts both by shear and compaction stresses. Once crusts are destroyed wind erosion may be greatly increased. But, in general, the effects of human activities on cryptogamic surface crusts in arid areas is poorly understood. In a strict botanical sense, the presence of soil crust may not be advantageous as they are detrimental to seed germination and seedling emergence; they reduce infiltration, increase runoff and water erosion and reduce plant water-use efficiency. On the other hand on small watersheds crust formation could be encouraged to gain additional water on adjacent areas or simply to increase surface water supplies. A high vegetation cover retards crust formation, low cover encourages it. Soil crusts are destroyed by, but reform after rains.

There has been no definitive research linking crustal disruption to deleterious effects on soil-nitrogen-fixing processes contrary to the "conventional wisdom" of some authors. Very probably effects will be manifested not in declines of magnitude of nitrogen fixation (which actually could increase in ORV tracks because water would "pool" possibly creating favorable microhabitats for soil cryptogams) but in the pattern of activity. There is no known research relating ORV impacts on desert soils to effects on soil microfloral abundance, species composition or species diversity.

Because of this general lack of knowledge the statements of several authors regarding the catastrophic effects of the destruction of "fragile" desert soil crusts are premature and unwarranted. Hypotheses, even likely ones are meant to be tested, not flouted. We do not mean to diminish the possible deleterious effects of off-road vehicles on desert biogeocoenoses. However, with respect to soil crusts, a good case seems only to have been made for increases in the wind erosion which will ensue upon their destruction.

\section{The Present and Future Extent of ORV Induced Impacts}

One of the most important questions to answer concerns the amount of soil and associated vegetation which will receive impacts in the next 20 years. At the present time, ORV and ORV-related impacts desert-wide include 1229 acres in pit areas and campsites, 5943 acres of hillclimbs and 40,765 acres of highly compacted trails. Pit areas and campsites are for the most part highly compacted throughout whereas hillclimbs and areas of highly compacted trails are compacted in some areas, but not throughout. Areas with highly compacted trails, for example, usually have between five and ten percent of their surfaces compacted by such trails. Since the Bureau of Land Management administers about 12,000,000 acres of land in the CDCA, pit areas and campsites, hillclimbs and areas of highly compacted trails constitute 0.01 percent, 0.05 percent, and 0.34 percent of this area respectively. These impacts have occurred over approximately a twentyyear period. 
These data are not flawless. Interpreting the tables on extent of ORV use by Adams and Endo in the first chapter is complicated. Large areas outside the acreages shown are also impacted albeit at a lower level, by ORVs. The estimates presented are also low because some of the aerial photographs used are not recent, but date from 1973-1974. Although we are confident that the majority of highly impacted areas of the desert have been located, a few may have been missed. Furthermore, areas of light to moderate compaction, which may also show significant reductions in the growth of some plant species have not been delimited; these latter areas, however, are generally adjacent to those exhibiting more highly compacted soils. The error in estimation of extent of ORV estimates is therefore on the side of underestimation, however, this error is certainly no more than 20 percent and is probably less than 10 percent. Assuming the full error rate of 20 percent, then a possible 0.48 percent of the CDCA or about 60,000 acres have been impacted by ORVs in some form or another. If the sport grows at the same rate as it has over the past 20 years, then by the year 2000 about 1 percent of the CDCA could be impacted which would amount to approximately 120,000 acres. This is most unlikely since 1) the existing areas would probably receive additional use, 2 ) constraints imposed by the California Desert Plan would prevent extensive expansion into new areas and. 3) because of fuel constraints associated with energy availability and costs, the sport is as likely to decline as increase.

In light of the above considerations and data, such statements as those made by representatives of the U. S. Geological Survey ${ }^{2}$ that under the protection alternative of the Draft California Desert Plan "fifty-four percent of the CDCA is under this alternative, exposed to this [ORV] hazard for as long as seven years and 39 percent indefinitely" are quite misleading. In our opinion, rather than viewing the $\mathrm{ORV}$ problem as a significant impact to desert soils as a whole, soil disturbances should be considered through their impacts on biological or scenic resources.

\section{Impacts on Plant Growth and Development}

Experiments have shown that one pass of a 4 WD vehicle on wet soil creates soil compaction sufficient to significantly reduce the cover and density of several species of annual plant species in the Mojave Desert. Some species such as Shismus barbatus and Bouteloua barbaba at first respond positively to the compaction created by up to three passes of a $4 \mathrm{WD}$ vehicle on wet soil. Even these species declined as mechanical impedence of the wet soil exceeded 18 bars, a value which also appears to be a threshold value for agricultural crops. Soil strength values above 25 bars probably exceed the tolerance level of most plant species, native, introduced, cultivated or otherwise.

2 Response of the U.S. Geological Survey to the Draft California Desert Plan and Environmental Impact Statement, George H. Davis for H. William Menard, June 16, 1980. 
Heavier than normal rainfall in the desert tended to ameliorate the effects of soil compaction on plant growth but under normal conditions of precipitation the compaction created by only one or two passes of a motorcycle along the same track on wet soil substantially reduces the combined biomass cover, and density of all winter or summer annual plants within the tracked area. However, normally occurring substrate heterogeneity among sample areas at the same site causes patchiness in the pattern of annual plant establishment which may in some cases be more important a factor in controlling plant response than the effects created by the interaction of a compacting agent and soil moisture levels at the time of compaction.

In general, the response of annual plants to soil compaction is a function of 1) the type of soil compacted, 2) the intensity of compaction, 3) the time of compaction relative to changes in soil moisture levels, 4) the amount and pattern of precipitation falling after compaction has occurred, 5) the innate chemical and physical properties of the soil at different sites, 6) the species of plant, 7) innate on-site substrate heterogeneity, and 8 ) the way response is measured by the investigator. There is no reason to assume why the newly germinated seedlings of perennial species should not behave similarly to annual plants in their response to compacted soils.

Severe water erosion in areas with shallow soil underlain by material impervious to roots, as on many hillclimb areas, may greatly reduce potential for plant growth. Water erosion on deeper soils or those whose parent material can be penetrated by roots will not be as detrimental to plant growth. Accelerated water or wind erosion may disperse nutrient elements which have been accumulating underneath shrubs and thus reduce the number of sites which are favorable to plant growth. Accelerated wind erosion may also decrease soil productivity by removing surface soil which of ten has higher concentrations of nutrient elements essential to plant growth.

Surface shearing, which uproots and disrupts root systems, and crushing of foliage root systems and seedlings are the direct impacts on vegetation from off-road vehicles. These impacts can cause changes in patterns and composition of vegetation as reflected in changes in plant density, cover, and species diversity within a site. Changes may be more or less intense depending upon the intensity and rate of use by ORVs, regional and local climates, topography, and soil type, among other factors. Densities of perennial plants in heavily used desert areas have been reported to have declined by 38-100 percent as compared with adjacent relatively unused areas. Likewise, plant cover may decline $35-85$ percent and species diversity 24-82 percent depending upon the intensity of use. 
Random driving of vehicles is generally far less destructive, on an area-wide basis than organized and repeated driving on established courses. There is significant correlation between the regularity (intensity) of driving and the degree of damage to a shrub. Very slight disturbances may cause no measureable differences in plant response or actually cause positive responses by causing (usually through induction of resprouting by minor breakage of plant parts) increases in cover. Water harvesting effects through concentration of runoff from compacted areas may increase vegetational growth in an "edge-effect." However, on an area-wide basis such "positive effects" are negligible and the overall effect of ORVs on vegetation is highly negative and deleterious.

The only practical mitigations for ameliorating vegetation destruction are reduction and strict management of use intensity, which should be kept as low as is feasible, discouragement of concentrated use, whether in race courses or "fellowship" areas, avoidance of steep slopes, and if possible, avoidance of wet-season use.

D. Recovery, Revegetation, Rehabilitation and Restoration of Desert Lands Damaged by off-Road Vehicles

Revegetation is the natural or artifical process of replacing the plant cover of denuded areas. It is not necessarily synonomous with "succession" which as defined for more mesic ecosystems probably does not occur in arid areas. Desert vegetation upon destruction, replaces itself directly by new seedlings of the same species. Characteristically, in deserts, species of the original vegetation continue to occupy disturbed sites with population increases in some species (i.e., pioneer species) and declines in others. But, floristically distinct assemblages, or seral stages between pioneer and climax communities which in humid regions occur in orderly and predictable sequence, are not present. Revegetation differs from rehabilitation which merely attempts to restore the levels of productivity to predisturbance levels and reclamation which only attempts to return a site to a condition conducive to growth and establishment of the original species inhabitants of the area. Restoration requires reconditioning and total recovery of the disturbed area such that predisturbance conditions including species composition are precisely replicated. On a practical level, restoration of disturbed land occurs only through the process of natural revegetation and "recovery" which may take centuries to millenia due to the great environmental stresses, particularly water availability. which severely limits the rates of metabolic processes, in arid environments. The desert is not "tough" as some off-road enthusiasts have so glibly put it and restoration as a management objective is for all practical purposes unattainable.

Because there are no known examples in the plant world of a growth strategy which enables plant species to withstand both the rigors of a stressful environment and the vicissitudes of continued disturbance, and because revegetation (whether natural or anthropogenically induced) is such a slow process, the idea of rest and rehabilitation of heavily used ORV areas is not worthy of consideration even if unlimited funds are available. 
It is important in this regard to remember that irrespective of "claims" to the contrary, no study or attempt at artificial rehabilitation and revegetation of desert disturbance has been an unqualified or even a qualified success. Rest and reuse should only be considered in areas impacted by highly dispersed off-road vehicle use, for example: occasional races. However, it must be ensured that such areas are closed after the event and monitored until recovery is deemed to be complete. 


\section{REFERENCES}

Adams, S., B. R. Strain, and M. S. Adams. 1969. Water-repellent soils and annual plant cover in a desert scrub community of southeastern California. In DeBano, L. F. and J. Letey (eds.) Proc. Symp. Water-repellent Soils, University of California,. Riverside. pp. 289-296.

Arizona State University. 1976. Evaluation of highway dust hazards along interstate route 10 in the Casa Grande-Eloy region. Final report prepared for Arizona Department of Transportation, Highways Division. $123 \mathrm{pp}$.

Babcock and Sons, and Gallaher and Bovey, Geotechnical Consultants. 1973. A study of California desert soils subjected to recreational vehicle use for the Bureau of Land Management.

Bagnold, R. A. 1941. The physics of blown sand and desert dunes. Methuen, London. $265 \mathrm{pp}$.

Bassett, A. M., and D. H. Kupfer. 1964. A geologic reconnaissance in the southeastern Mojave Desert. California Division of Mines and Geology. Special Report 83, 43 pp.

Badaracco, R. and S. Branson. 1976. Bureau of Land Management Memorandum, Riverside, California.

Baver, L. D., W. H. Gardner, and W. R. Gardner. 1972. Soil physics. Wiley, New York. 498 pp.

Beals, E. 1960. Forest bird communities of the Apostle Islands, Wisconsin Willson Bull. $72: 156-181$.

Beatley, J. C. 1969. Biomass of desert winter annual plant populations in southern Nevada. Oikos. 20:261-273.

1974. Effects of rainfall and temperature on the distribution and behavior of Larrea tridentata (creosote bush) in the Mojave Desert of Nevada. Ecology 55(2):245-261.

1976. Vascular Plants of the Nevada Test Site and central southern Nevada: Ecologic and Geographic Distributions. Nat. Tech. Info. Serv., ERDA, Springfield, VA. Tl0-26881/DAS 316 pp.

Bisal, F., and W. Ferguson. 1970. Effect of nonerodible aggregates and wheat stubble on initiation of soil drifting. Can. J. Soil Sci. $50: 31-34$.

Bodman, G. B., and G. K. Constantin. 1965. Influence of particle size distribution in soil compaction. Hilgardia 36:567-591.

Bray, J. R. and J. T. Curtis. 1957. An ordination of the upland forest communities of Southern Wisconsin Ecol. Monogr. 27:325-349.

Brodhead, J. M., and P. J. Godfrey. 1977. Off-road vehicle impact in Cape Cod National Seashore: Disruption and Recovery of Dune Vegetation. Int. Journal Biometeor. 21(3) pp. 299-306. 
Brum, G. D., 1979. Cool water - Kramer $220 \mathrm{KV}$ transmission line revegetation study. Semi-annual progress report II. Southern California Edison Co. 43 pp.

Bureau of Land Management. 1972. Evaluation and recommendations El Cajon Valley Motorcycle Club's unauthorized race. Special Report USDI, BLM, Riverside District Office.

Bureau of Land Management. 1975. Evaluation report: 1974 Barstow Las Vegas motorcycle race. USDI, BLM, Riverside District Office. $130 \mathrm{pp}$.

Bureau of Land Management. 1979. Unpublished study of values, issues, and concerns identified by residents of the California Desert.

1979. Analysis, review and recommendations of off-road vehicles on public lands, Council on Environmental Quality. BLM position paper. 20 pp.

Bury, R. B., R. A. Lukenbach, and S. D. Busak. 1977. Effects of offroad vehicles on vertebrates in the California desert. USDI, Fish and Wildlife Service, Wildlife Research Report 8, Wash, DC. 23 pp.

Cameron, R. E. 1958. Fixation of nitrogen by algae and associated organisms in semi-arid soils: identification and characterization of soil organisms. M. S. Thesis, University of Arizona, Tucson. 129 pp.

1964a. Algae of southern Arizona, Part II. Algal flora (exclusive of blue green algae) Revue Algologique. 7:151-177.

1964b. Terrestrial algae of southern Arizona. Trans. of the American Microscopical Soc. 83:212-218.

1966. Soil sampling parameters for extraterrestrial life detection. J. Ariz. Acad. Sci. 4:3-27.

Cameron, R. E., and G. B. Blank. 1966. Desert algae: soil crusts and diaphanous substrata as algal habitats. Jet Propulsion Laboratory Tech. Rep. No. 32-971. California Institute of Technology, Pasadena. 41 pp.

Carter, L. M. 1967. Portable recording penetrometer measures soil strength profiles. Agric. Eng. 48:348-349.

Carter, L. M., J. R. Stockton, J. R. Tavernetti, and R. F. Colwick. 1965. Precision tillage for cotton production. Trans. of the ASAE 8:177-179.

Carter, L. M., and J. R. Tavernetti. 1968. Influence of precision tillage and soil composition on cotton yields. Trans. of the ASAE 11:65-67, 73 .

Chepil, W. S. 1951. Properties of soil which influence wind erosion - 4. State and stability of dry soil structure. Proc. Soil Sci. Soc. Am. $16,113-117$.

Chepil, W. S., and R. A. Milne. 1941. Wind erosion of soils in relation to size and nature of the exposed area. Scientific Agriculture 
Chepil, W. S., and N. Woodruff. 1963. The physics of wind erosion and its control. Advances in Agronomy 15. A. G. Norman (ed.). Academic Press, New York.

Chepil, W. S., W. C. Moldenhauer, J. A. Hobbs, N. L. Nossaman and H. M. Taylor. 1962. Deep plowing of sandy soil. USDA Prod. Res. Rpt. No. 64.

Chew, R. M., and A. E. Chew. 1965. The primary productivity of a desert shrub (Larrea tridentata) community. Ecol. Monogr. 35:355-375.

Clark County District Health Department, Air Pollution Control Division. 1971. Impact of "Mint 400" on Air Quality in the Las Vegas Valley. Unpublished report.

Clements, F. E. 1916. Plant succession: an analysis of the development of vegetation. Carnegie Inst. Wash. Publ. 242.

Clements, T., J. F. Mann, Jr., R. O. Stone, and J. L. Eymann. 1963. A study of windborne sand and dust in desert areas. U. S. Army Natick Laboratories, Natick, Mass. Technical Report ES-8, 69 pp.

Cline, M. G. 1977. Historical highlights in soil genesis, morphology, and classification. Soil Science Society of America Journal $41(2): 250-254$.

Cottam, G., and J. T. Curtis. 1956. The use of distance measurements in phytosociological sampling. Ecology 37:451-460.

Cowherd, C., Jr., K. Axetell, Jr., C. M. Guenther, and G. A. Jutze. 1974 . Development of emission factors for fugitive dust sources. U. S. Environmental Protection Agency report No. 450/3-74-037.

Cox, G. W. 1976. Laboratory manual of general ecology. Wm. C. Brown, Dubuque. 232 pp.

Curtis, J. T. 1959. The vegetation of Wisconsin. University Wis. Press, Madison. 657 pp.

Daniel, H. A. 1936. Physical changes in soils of the southern high plains due to cropping and wind erosion. Jour. Amer. Soc. Agron. 28:570-580.

Daniel, H. A. and W. H. Langham. 1936. The effect of wind erosion and civilization on the total nitrogen and organic matter content of soils in the southern high plains. Jour. Amer. Soc. Agron. 28:587-596.

Daubenmire, R. F. 1968. Plant communities: a textbook of plant synecology. Harper and Row, New York. 300 pp.

Davis, E. L., and S. Winslow. 1966. Giant ground figures of prehistoric deserts. Proc. Amer. Philosophic Soc. 109:8-21.

Davidson, E., and M. Fox. 1974. Effects of off-road motorcycle activity on Mojave Desert vegetation. In Preliminary studies of off-road vehicles on the Northwestern Mojave Desert: A collection of papers, K. Berry (ed.). p. 19-44. 
Davidson, Eric. 1973. Effects of off-road motorcycle activity on Mojave Desert vegetation. In preliminary studies of off-road vehicles on the Northwestern Mojave Desert: a collection of papers, K. Berry (Ed.). p. 19-44.

Davidson, E., and M. Fox. 1974. Effects of off-road motorcycle activity on Mojave Desert vegetation and soil: Madrono 22(8):381-412.

Davidson, E. L., and S. Winslow. 1966. Giant ground figures of the prehistoric deserts. Proceedings of American Philosophical Society. $109: 8-21$.

DeBano, L. F., and J. Letey. 1969. Water repellent soils. Proc. Symp. On Water-Repellent Soils. University of California, Riverside. 354 pp.

Drouet, F. 1937. The Brazilian myxophycae. Am. J. Bot. 24:598-606.

Drouet, F. 1943. Myxophycae of eastern California and western Nevada. Field Museum of Natural History, Botanical Series 20:145-176.

Duck, T. A. 1978. The effects of off-road vehicles on desert flora: In Abstracts, So. Calif. Acad. Scis., Annual Meet., Santa Barbara, Calif., p. 44 .

Durrel1, L. W. 1956. Microgreenhouses. The Green Thumb. July, p. 17 .

1962. Algae of Death Valley. Transactions of the American Microscopical Soc. $81: 267-273$.

Eckert, R. E., F. F. Peterson, M. K. Wood, and W. H. Blackburn. 1977. Properties, Occurrence and Management of Soils with Vesicular Surface Horizons. Special Study by USDI, BLM and Nevada Agricultural Experiment Station. Contract No. 52500-CT5(N).

Egler, F. E. 1979. Vegetation change - changed. Review of J. Miles, Vegetation Dynamics, Wiley Publications, New York, 1970, 80 p., Ecology 60:1077.

Elwell, M. M., J. W. Slosser, and H. A. Daniel. 1938. Revegetation and gully control experiments in the Red Plains region. Soil Conservation $5: 17-20$.

Eskew, D. L. and I. P. Ting. 1978. Nitrogen fixation by legumes and bluegreen algae-lichen crusts in a Colorado Desert environment. Ameri. J. Bot. $65: 850-856$.

Fletcher, J. E., and W. P. Martin. 1948. Some effects of algae and molds in the rain crusts of desert soils. Ecology 29:95-100.

Fox, M. 1973. Compaction of soil by off-road vehicles at three sites in the Mojave Desert, in Berry, K. H. (ed), Preliminary studies of the effects of off-road vehicles on the northwestern Mojave Desert: A collection of papers, Ridgecrest, California, privately published, pp $1-13$.

Geological Society of America, Committee on Environment and Public Policy. 1977. Impacts and management of off-road vehicles, Boulder, Colo., Geol. Soc. Amer. 8 pp. 
Gill, W. R. and G. E. Vandenberg. 1967. Soil dynamics in tillage and traction. USDA Agr. Res. Ser. Agriculture Handbook No. 316.

Gillette, D. A. 1977. Fine particle emissions due to wind erosion. Trans ASAE 20:891-897.

Gillette, Dale. 1978. A wind tunnel simulation of the erosion of soil: effect of soil texture, sandblasting, wind speed, and soil consolidation on dust production. Atmospheric Environment 12:1735-1743.

Gillette, D. A., J. Adams, A. S. Endo, and D. Smith. 1979. Threshold friction velocities on typical Mohave Desert soils, undisturbed and disturbed by off-road vehicles. Proc. of the 1979 Powder and Bulk Solids Conference, Annual Fine Particle Soc. Meeting, May 15-17. Philadelphia (In press.).

Gillette, D. A., and T. R. Walker. 1977. Characteristics of airborne particles produced by wind erosion of sandy soil, high plains of West Texas. Soil Sci., 123:97-110.

Giroux, Hans. 1979. Fugitive Dust Impacts During Off-Road Vehicle (ORV) Events in the California Desert. Unpublished BLM Report.

Goudie, A. S. 1978. Dust storms and their geomorphological implications. Journal of Arid Environments 1:291-310.

Graves, W. L. 1976. Revegetation of disturbed sites with native shrub species in the western Mojave Desert. In Kay, B. L. Test of seeds of Mohave Desert shrubs. BLM Contract No. 53500-CT4-2(N), Document Obligation No. 6809 FY 1976, pp 11-35.

Graves, W., B. L. Kay, and W. A. Williams. 1974. Seed-treatment studies of seven Mohave Desert shrub species. In Kay, B. L. Test of seeds of Mohave Desert shrubs. BLM Contract No. 53500-CT4-2(N), Document Obligation No. 6809 FY 1974.

1978. Revegetation of disturbed sites in the Mojave Desert with native shrubs. Calif. Agric. 32:4-5.

Greacon, E. L., and J. S. Oh. 1972. Physics of root growth. Nature New Biol. Sci.25:1169-1180.

Greely, R., D. Iverson, J. B. Pollack, N. Udovich, and B. White. 1973. Wind tunnel studies of Martian aeolian processes. NASA Technical Memorandum 62, p. 297.

Greig-Smith, P. 1964. Quantitative plant ecology, 2nd Ed. Butterworths, Lond on. $256 \mathrm{pp}$.

Grime, J. P. 1979. Plant strategies and vegetation processes. John Wiley and Sons, New York. 222 pp.

Grimes, D. W., R. J. Miller, and P. L. Wiley. 1975. Cotton and corn root development in two field soils of different strength characteristics. Agron. J. 67:519-523. 
Grimes, D W., W. R. Sheesley, and P. L. Wiley. 1978. Alfalfa root development and shoot regrowth in compact soil of wheel traffic patterns. Agron. J. 70(6):955-958.

Hanes, T. L. 1971. Succession after fire in the chapparal of southern California. Ecol. Monogr. 41:27-52.

Harrison, P. 1976. Environmental effects of off-road vehicles. U. S. Dept. Agric., Engr. Tech. Inform. Sep. Field Notes 8:4-8.

Heady, R. F. 1975. Rangeland management. McGraw-Hill, New York. 460 pp. Henrikson, E. and B. Simu. 1971. Nitrogen fixation by lichens. Okios 22:119-121.

Hitch, C. J. B. and W. D. P. Stewart 1973. Nitrogen fixation by lichens in Scotland. New Phytol. 72:509-524.

Hollander, M., and D. A. Wolfe. 1973. Nonparametric statistical methods. John Wiley and Sons. New York. 403 pp.

Holmgren, R. C. and S. S. Hutchings. 1972. Salt desert shrub response to grazing use. In wildland shrubs, their biology and utilization. Proc. Int. Syrup. Utah State University, Logan. pp. 153-165.

Hosier, P. E. and T. E. Eaton. 1980. The impact of vehicles on dune and grassland vegetation on a southeastern North Carolina barrier beach. Journal of Applied Ecology 17: 173-182.

Hovland, H. J., and J. K. Mitchell. 1972. Model studies of the failure mechanism associated with a sphere rolling down a soil slope. Jour. Terramechanics 9(1), p. 37-50.

Hunt, C. B., and D. R. Mabey. 1966. Stratigraphy and structure. Death Valley, California, U. S. Geological Survey Professional Paper 494A, p. Al-Al 162 .

Hunt, C. B., and L. W. Durrell. 1966. Plant ecology of Death Valley. Geolog. Surv. Prof. Pap. 509, 68 pp.

Hunt, C. B., T. W. Robinson, W. A. Bowles, and A. L. Washburn. 1966. Hydrologic basin, Death Valley, California. U. S. Geological Survey Professional Paper 494B, P. Bl-B138.

Hunter, R. B., A. Wallace, and E. M. Romney. 1976. Nitrogen transformations in Rock Valley and adjacent areas of the Mojave Desert. U. S./IBP Desert Biome Res. Memo 76-78. Utah State University, Logan.

Huppert, M. 1968. Recent developments in coccidioidomycosis. Rev. Med. Vt. Mycol. $6: 279-294$.

Ishihara, T., and Y. Iwagaki. 1952. On the effect of a sandstorm in controllilng the mouth of the Kiku River. Disaster Prevention Research Institute, Kyoto University Bulletin No. 2. 
Iverson, R. M. 1979. Processes of accelerated erosion on desert hillslopes modified by vehicular traffic. Submitted to Earth Surface Processes.

Johnson, H. B., F. C. Vasek, and T. Yonkers. 1975. Productivity, diversity, and stability relationships in Mojave Desert roadside vegetation. Bull. Torrey Botanical Club 102(3):106-115.

Kay, B. L. 1974. Test of seeds of Mohave Desert shrubs. BLM Contract No. 53500-CT4-2(N) Document Obligation No. 6809 FY 1974, 34 pp.

1975. Test of seeds of Mohave Desert shrubs. BLM Contract No. 53500-CT4-2(N) Document Obligation No. 6809 FY 1975, 24 pp.

1976. Test of seeds of Mohave Desert shrubs. BLM Contract No. 53500-CT4-2(N) Document Obligation No. 6809 FY 1976, 48 pp.

1979. Summary of revegetation attempts on the second Los Angeles Aqueduct. Mojave Revegetation Notes 22: 1-23.

Keefe, J., and K. Berry. 1973. Effects of off-road vehicles on desert shrubs at Dove Springs Canyon. In Preliminary studies of off-road vehicles on the Northwestern Mojave Desert: A collection of papers. K. Berry (ed.), p. 45-57.

Kemper, W. D., and D. E. Miller. 1975. Management of crusting soils: some practical possibilities. In Cary, J. W., and D. D. Evans (eds.), Soil Crusts, Univ. Ariz. Agric. Exp. Sta. Tech. Bul. No. 214, pp $1-6$.

Kershaw, K. A. 1973. Quantitative and dynamic plant ecology, 2nd Ed. American Elsevier Publishing Co., Inc., New York. 308 pp.

Klock, Brian T. 1976. Rehabilitating the effects of the off-road vehicle in the Mojave Desert. Master's Thesis, Dept. of Natural Resources Mgmt., Calif. Polytechnic State University, San Luis Obispo.

Knott, J. M. 1978. Asseessment of erosion and sedimentation in the Hungry Valley Area, Los Angeles and Ventura Counties, California. U. S. Geol. Survey Open-file Rept., in press.

Kolla, A., and P. E. Biscaye. 1977. Distribution and origin of quartz in the sediments of the Indian Ocean. J. of Sedimentary Petrology, $47: 642-649$.

Kuhn, Michael. 1974. Environmental effects of the off-the-road vehicles on the Kelso Dunes. Paper presented at the annual meeting of the California Council for Geographic Education, Bakersfield, CA, May 5, 1974.

Lacy, G. H. 1971. Soil ecology of Coccidioides immitis at archaeological sites. M.S. Thesis, California State College, Long Beach. 
Lathrop, Earl W. 1978. Final report: "Plant response parameters to recreational vehicles in the California Desert Conservation Area." BLM Contract No. CA-060-CT7-2824.

1979. Plant response studies to utility construction in the Mohave Desert, California. BLM Contract No. CA-060-CT8-53, 305 pp.

Leathers, Chester R. 1977. Plant components of desert dust in Arizona (unpublished abstract).

1979. Report of Soil Analyses. Report to the Bureau of Land Management. BLM Contract No. CA-060-CT7-2683, 5 pp.

Levy, E. B., and E. A. Madden. 1933. The point method of pasture analysis. New Zealand J. of Agric. 46:267-279.

Lewontin, R. C. 1969. The Meaning of stability, pp. 13-24. In Diversity and stability of ecological systems. Brookhaven Symposia in Biology No. 22,264 pp.

Liddle, M. J. and P. Grieg-Smith. 1975. A survey of tracks and paths in a sand dune ecosystem. 1. Soils. Journal of Applied Ecology 12: 893-908.

Lisitzin, A. P. 1972. Sedimentation in the world oceans. Soc. Economic Paleontologists and Mineralogists, Special Publication No. 17, 218 pp.

Llano, G. 1962. The terrestrial life of the Antarctic. Scientific American $207: 213-230$.

Lloyd, M., and R. J. Ghelardi. 1964. A Table for calculating the "equitability" component of species diversity. Journal of Animal Ecology $23: 217-225$.

Lowry, F. E., H. M. Taylor, and M. G. Huck. 1970. Growth rate of yield of cotton as influenced by depth and bulk density of soils pans. Soil Sci. Soc. Amer. Proc. 34:306-309.

Luckenbach, R.A. 1975. What ORVs are doing to the desert. Fremontia (Journal of the California Native Plant Society 2(4):3-11.

Luckenbach, R. A., and R. B. Bury. 1978. Off-road vehicle impact on desert vertebrates: a review In Berry, K. H. (ed.) The physical, biological, and social impacts of off-road vehicles on the California Desert. So. Calif. Acad. Sci. Special Publ. (In Press)

Ludwig, J., A. M. Oritz, and J. C. Owens. 1979. An evaluation of the plotless wandering quarter method for estimating the density of aggregated organisms (Abstract). Bul. of the Ecol. Soc. of Am. $60: 138$.

Lull, H. W. 1959. Soil compaction on forest and rangelands. U.S. Dept . Agric. For. Serv. Misc. Publ. No. 768, 33 pp.

Lusby, G. C. 1970. Hydrologic and biotic effects of grazing vs non-grazing near Grand Junction, Colorado. J. Range Management 23:256-260. Lynn, R. I and R. E. Cameron. 1973. The role of glgae in crust formaMemo. 74-41. 
Macgregor, A. N., and D. E. Johnson. 1971. Capacity of desert algal crusts to fix atmospheric nitrogen. Soil Sci. Soc. Amer. Proc. 35: 843-844.

Maddy, K. T. 1965. Observations on Coccidioides immitis found growing naturally in soil. Ariz. Med. 22:191-298.

Major, J. 1977. California climate in relation to vegetation. In Barbour, M. G., and J. Major (Eds.) Terrestrial vegetation of California. Wiley, New York, pp 11-74.

Margalef; R. 1968. Perspectives in Ecological Theory. Univ. of Chicago Press, Chicago, Illinois, 111 pp.

Mayland, H. F., T. H. McIntosh, and W. H. Fuller. 1966. Fixation of isotopic nitrogen on a semiarid soil by algal crust organisms. Soil Sci. Soc. Amer. Proc. 30:56-60.

McGinnies, W. G., B. J. Goldman, and P. Paylore. 1977. Deserts of the world: an appraisal of research into their physical and biological environments. University of Arizona Press, Tucson, 788 pp.

Meeuwig, R. C. 1971. Infiltration and water repellency in granitic soils. USDA, Forest Service Research Paper Int-III, 20 pp.

Merrill, S. D. and S. L. Rawlins. 1979. Distribution and growth of sorghum roots in response to irrigation frequency. Agronomy $\mathrm{J}$. $71: 738-745$.

Miles, J. 1979. Vegetation dynamics. Methuen, New York. 80 pp.

Miller, D. E., and R. O. Gifford. 1975. Modification of soil crusts for plant growth. In Cary, J. W., and D. D. Evans (eds.), Soil Crusts, Univ. Ariz. Agric. Exp. Sta. Tech. Bul. No. 214, pp. 7-16.

Mirreh, H. F. and J. F. Ketcheson. 1972. Influence of soil bulk density and matric pressure on soil resistance to penetration. Can. J. Soil Sci. 52:477-483.

Mispagel, M. E., and R.Zembal. 1978. Effects of military maneuvers on Mojave Desert vegetation: In Abstracts, So. Calif. Acad. Scis., Ann. Meet., Santa Barbara, Calif., p. 44.

Moewus, L. 1953. About the occurrence of freshwater algae in the semidesert around Broken Hill (N.S.W., Austrailia). Botanika Notiser 4:399-416.

Mooney, H. A., J. Ehleringer, and J. A. Berry. 1976. High photosynthetic capacity of a winter annual in Death Valley. Science 194:322-324.

Motorcycle Industry Council, Inc. 1977. Motorcycle Statistical Annual. Newport Beach, California.

Moss, H. C. 1935. Some field and laboratory studies of soil drifting in Saskatchewan. Sci. Agr. 15:665-675. 
Mueller-Dombois, D., and H. Ellenberg. 1974. Aims and methods of vegetation Ecology. John Wiley and Sons, 547 pp.

Muller, C. H. 1940. Plant succession in the Larrea - Flourensia climax. Ecology $21: 206-212$.

Nakata, J. K., H. G. Wilshire, and G. G. Barnes. 1976. Origin of Mojave Desert dust plumes photographed from space. Geology 4(11):644-648.

Nash, T.H., S. White, and J. M. Nash. 1974. Composition and biomass contribution of lichen and moss communities in the hot desert ecosystems. IBP Desert Biome RM 74-19.

Nielsen, K. F., and E. C. Humphries. 1966. Effects of root temperature on plant growth. Soils and Fertilizers. 29:1-7.

Odum, E. P. 1963. Ecology. Holt, Rinehart and Winston, 152 pp.

1971. Fundamentals of ecology. W. B. Saunders Co., Philadelphia, 574 pp.

Oliver, F. W. 1945. Dust storms in Egypt and their relation to the war period in Maryut 1939-45. Geograph J., 160 (1,2):26-49. Supplement same, $108: 222-226$.

Parish, D. H. 1971. Soil conditions as they affect plant establishment, root development, and yield: effects of compaction on nutrient supply to plants In Barnes, K. K. et al (eds.) Compaction of agricultural soils. Amer. Soc. of Agric. Egrs., St. Joseph, Michigan, pp. 277-291.

Pedco-Environmental Specialists, Incorporated (Cincinnati, Ohio). 1973. Investigation of fugitive dust - sources, emissions, and control. U. S. Environmental Protection Agency Report No. APTD-1582.

Phillips, R. E., and D. Kirkham. 1962. Mechanical impedance and corn seedling root growth. Soil Sci. Soc. Amer. Proc. 26:319-322.

Pianka, E. R. 1974. Evolutionary ecology. Harper and Row, New York, $365 \mathrm{pp}$.

Pickett, S. T. A. 1976. Succession: an evolutionary interpretation. Amer. Nat. 110:107-119.

Pielou, E. C. 1966. Shannon's Formula as a Measure of Species Diversity: Its Use and Misuse. American Naturalist 100:463-465.

Plunkett, 0. A., and F. E. Swatek. 1957. Ecological studies of Coccidioides immitis. In Proc. Symposium on Coccidioides immitis. P.H.S. Pub. No. 575. Communicable Disease Center, Atlanta, Georgia, p. $158-160$.

Power, F. W. 1974. Effects and observatims of soil compaction in the Salem District (Oregon), BLM Tech. Note, 12 pp.

Preston, F. W. 1969. Diversity and stability in the biological word, p. 1-12. In Diversity and stability of ecological systems. Brookhaven Symposia in Biology No. 22, 264 pp. 
Priestly, C. H. B. 1959. Turbulent transfer in the lower atmosphere, University of Chicago Press, Chicago, Ill., 130 pp.

Quesenberry, S. P. 1978. General soils map, soil association descriptions, U.S.L.E. factors, and wind erodibility groups for use in defining sensitivity to ORV impacts. For USDI, Geological Survey, in cooperation with Coachella Valley Resource Conservation District, unpublished.

Rauth, R. P. 1973. The Bureau of Land Management and its California Desert Policy: A Case study of the environmental effects of off-theroad vehicles on the Kelso Sand Dunes. Environmental Studies 199. U.C. Santa Barbara - Environmental Studies Dept.

Reynolds, H. G. and P. E. Packer. 1963. Effects of trampling on soils and vegetation. U. S. Dept. Agr. Misc. Publ. 940.116-122.

Rice, C. M. 1970. Individual report on aqueduct problems and solutions. BLM Memo $2870(\mathrm{P}-350)$. Portland Service Center, Portland, Oregon, 12 pp.

1971. Vegetation Study: L. A. Aqueduct, Bakersfield

District, BLM Report, Bakersfield Office, 9 pp.

Rice, C. M., and L. Walgren. 1972. Rehabilitation of disturbed arid areas with native desert species. BLM Report, BLM, Bakersfield, CA, 12 pp.

Rice, E. L. 1967. A Statistical method of determining quadrat size and adequacy of sampling. Ecology 48:1047-1049.

Roseburg, N. J. 1964. Response of plants to the physical effects of soil compaction. Advan. Agron. 16:181-196.

Reicosky, D. C., W. B. Voorhees, and J. K. Radke. 1975. Unsaturated water flow through a similated wheel track. Abstract of talk presented at 1979 annual meetings of American Society of Agronomy at Fort Collins, Co.

Rychert, R. C. and J. Skujins. 1974. Nitrogen fixation by blue-green algae-lichen crusts in the Great Basin desert. Soil Sci. Amer. Proc. $38: 768-771$.

Rychert, R., J. Skujins, D. Sorenson, and D. Porcella. 1978. Nitrogen fixation by lichens and free-hiring microorganisms in deserts In West, N. E. and J. J. Skujins (eds.). Nitrogen in desert ecosystems. Dowden, Hutchinson and Ross. Stroudsberg, PA. pp. 20-30.

Schwabe, G. H. 1963. Blaualgen der phototrophen grenzschict (Blaualgon and Lebenstraum VII). Pedobiologia 2:132-152.

Sharp, R. P. 1972. Geology field guide to southern California. Wm. C. Brown Co. Publishers, $181 \mathrm{pp}$.

Sheridan, D. 1979. Off-road Vehicles on Public Land. Council on Environmental Quality, Washington, D. C., 84 pp.

Shields, L. M., C. Mitchell, and F. Drouet. 1957. Alga - and lichen stabilized surface crusts as soil nitrogen sources. Am. J. Botany $44: 489-498$.

Sherve, F. 1942. The desert vegetation of North America. Bot. Rev. $8: 195-246$. 
Sherve, F. and A. L. Hinckley. 1937. Thirty years of change in desert vegetation. Ecology 18:463-478.

Skujins, J.J. 1975. Nitrogen dynamics in stands dominated by some major cool desert shrubs. IV. Inhibition by plant litter and limiting factors of several processes. US/IBP Desert Biome Res. Memo 75-33. USU Logan, $38 \mathrm{pp}$.

Skujins, J. J., and N. E. West. 1974. Nitrogen dynamics in stands dominated by some major cool desert shrubs. US/IBP Desert Biome Res. Memo. 74-42. Utah State Univ., Logan, 56 pp.

Skujins, J., W. G. Knight, Schijf, and P. A. Thompson. 1979. Use impact on arid soil biology and cryptogamic crusts. BLM Contract CA-060CT8-73, $62 \mathrm{pp}$.

Smith, R. L. 1974. Ecology and Field Biology, 2nd Ed. Harper and Row, Publishers, $850 \mathrm{pp}$.

Snyder, C. T., D. G. Frickel, R. F. Hadley, and R. F. Miller. 1976. Effects of off-road vehicle use on the hydrology and landscape of arid environments in central and southern California. USGS, Water Resources Investigations 76-99, 45 pp.

Soil Conservation Service. 1979. Guide for rating soil limitations for off-road vehicle trails. Section 403.6 (b) of National Soils Handbook, part 2 .

Sokal, R. R., and F. J. Rohlf. 1969. Biometry, Freeman, San Francisco, $775 \mathrm{pp}$.

Sorensen, D. L. and D. B. Porcella. 1974. Nitrogen erosion and fixation in cool desert soil-algal crusts in northern Utah. US/IBP Desert Biome. Res. Memo 74-37. USU Logan, UT. 18 pp.

Sparrow, S. D., F. J. Wooding, and E. H. Whiting. 1978. Effects of off-road Vehicle Traffic on Soils and Vegetation in the Denali Highway Region of Alaska. Journal of Soil and Water Conservation, pp. 20-28.

Stebbins, R. C. 1974. Off-road vehicles and the fragile desert. Amer. Biol. Teacher, 36(4):203-208 (part I), 36(4):294-304 (part II).

Stebbins, R. C. 1980. Off-road vehicle impacts on desert plants and animals and BLM management prescriptions In Letting, J. (ed.) The California Desert an introduction to natural resources and Man's impact. California Native Plant Society Special Publ. No. 5. Berkeley, CA.

Sternberg, L. 0. 1976. Growth forms of Larrea tridentata Madrono $23: 408-417$.

Sulenski, R. J. 1972. The natural revegetation of mine sites in the Las Vegas Valley and the feasibility of allowing the free use collection of cacti and other desert plants. BLM Report 7383-3042-5380 $(\mathrm{N}-053)$, BLM, Las Vegas, NV, $41 \mathrm{pp}$. 
Swatek, F. E., and 0. A. Plunkett. 1967. Coccidioides immitis in California. In Proc. of Second Coccidioidomycosis Symposium. Univ. of Arizona Press, Tucson, Arizona, pp. 255-264.

Taylor, H. M. 1971. Effects of soil strength on seedling emergence, root growth, and crop yield, pp. 292-305. In compaction of agricultural soils. Am. Soc. Agric. Eng. Monograph.

1974. Root behavior as affected by soil structure and strength. pp. 271-29l. In E. W. Carson (ed.). The plant root and its environment. Univ. Press of Virginia, Charlottesville, VA.

Taylor, H. M., and E. Burnett. 1964. Influence of soil strength on the root growth habits of plants. Soil Sci. 98:174-180.

Taylor, H. M., and H. R. Gardner. 1963. Penetration of cotton seedling taproots as influenced by bulk densicy, moisture content, and strength of soil. Soil Sci. 96:153-156.

Taylor, H. M., and B. Klepper. 1978. The role of rooting characteristics in the supply of water to plants. In Advances in Agronomy (In Press).

Taylor, H. M., G. M. Roberson, and J. J. Parker, Jr. 1966. Soil strength root penetration relations for medium - to coarse-textured soil materials. Soil Sci. 102:18-22.

1967. Cotton seedling taproot elongation as effected by soil strength changes induced by slurrying and water extraction. Soil Sci. Soc. Amer. Proc. 31:700-704.

Taylor, H. M. and L. F. Ratliffe. 1969. Root elongation rates of cotton and peanuts as a function of soil strength and soil water content. Soil Sci. 108:113-119.

Trew, M. J. 1973. The effects and management of trampling on coastal sand dunes. Journal of Environmental Planning and Polution Control: 38-49.

Uehara, G., and R. C. Jones. 1975. Bonding mechanisms for soil crusts: Part I. Particle surfaces and commenting agents. In Cary, J. W., and D. D. Evans (eds.) Soil crusts. Univ. Ariz. Agric. Exp. Sta. Tech. Bul. No. 214 pp 17-28.

University of California, Irvine. 1974. Desert land use and management in California: its ecological and sociological consequences. Irvine, Calif., Final Rept., NSF Grant GY-11425, 268 pp.

U. S. Dept. Commerce, Weather Bureau. 1964. Climatography of the United States No. 86. Decennial Census of United States Climate Climatic summary of the United States, supplement for 1951-1960.

Vasek, F. C., H. B. Johnson, and D. H. Eslinger. 1975a. Effects of pipeline construction on Cresote Bush Scrub vegetation of the Mojave Desert. Madrono 23: 1-64.

Vasek, F. C., H. B. Johnson, and G. D. Brum. 1975b. Effects of power transmission lines on vegetation of the Mojave Desert. Madrono $23(3): 114-130$. 
Vasek, F. C. 1979a. Plant succession in the Mojave Desert. Proc. Symposium on Southern California Desert Communities (In Press).

1979b. Age, cloning and longevity of creosote bush. Accepted for publication in the American Journal of Botany.

Vasek, F. C. and M. G. Barbour. 1977. Mojave Desert shrub vegetation, In M. G. Barbour and J. Major (eds.), Terrestrial vegetation of California. Wiley, New York, pp. 835-867.

Veihmeyer, F. J., and A. E. Hendrickson. 1948. Soil density and root penetration. Soil Sci. 65:487-493.

Vog1, R. J. 1976. A primer of ecological principles. Pyro Unlimited. Cypress, California, 177 pp.

Vollmer, A. T., B. G. Maza, P. A. Medica, F. B. Turner, and S. A. Bamberg. 1976. The impact of off-road vehicles on a desert ecosystem. Environmental management 1(2):115-129. Springer-Verlag, New York, Inc.

Wallace, A., R. M. Romney, and R. B. Hunter. 1978. Nitrogen cycle in the Northern Mojave Desert: Implications and Predictions. In N. E. West and J. J. Skujins (eds.), Nitrogen in Desert Ecosystems, pp. 207-218.

Warkentin, B. P. 1971. Effects of compaction on content and transmission of water in soils, pp. 126-153. In compaction of agricultural soils. Am. Soc. Agric. Eng. Monograph.

Watt, K. E. F. 1972. Man's efficient rush toward deadly dullness. Nat. Hist. $81(2): 74-82$.

Weaver, J. E., and F. E. Clements. 1938. Plant Ecology. McGraw-Hill, New York, 601 pp.

Webb, R. H. 1978. The effects of off-road vehicles on desert soil in the Dove Springs Canyon, in Berry, K. H. (ed.). The physical, biological, and social impacts of off-road vehicles on the California Desert: So. Calif. Acad. Scis. Spec. Publ., in press.

Webb, R. H., H. C. Ragland, and W. H. Godwin. 1977. Soil erodibility and erosion control recommendations. Final report on Hollister Hills State Vehicular Recreation Area. Unpublished report to the Resources Division, Calif. Dept. of Parks and Recreation, 17 pp.

Webb, R. H., H. C. Ragland, W. H. Godwin, and D. Jenkins. 1978. Environmental effects of soil property changes with off-road vehicle use: Environ. Manage. 2(3):219-233.

Webb, R. H., and H. G. Wilshire. 1978. An annotated bibliography of the effects of off-road vehicles on the environment. USGS Open-File Report 78-149, 2 pp.

1980. Recovery of soils and vegetation in a Mojave Desert ghost town. Journal of Arid Environments: In Press.

Wells, P. V. 1961. Succession in desert vegetation on streets of a Nevada ghost town. Science 34:670-671. 
Went, Fritz W. 1948. Ecology of desert plants. I. Observations on germination in the Joshua Tree National Monument, California. Ecology 29 (3) 242-253.

Went, F. W., and M. Westergaard. 1949. The ecology of desert plants III. Development of plants in the Death Valley National Monument, California. Ecology 30:26-38.

Whittaker, R. H. 1975. Communities and ecosystems, 2 nd edition. MacMillan Publishing Co., Inc., New York, 385 pp.

Williams, W. A., O. D. Cook, and B. L. Kay. 1974. Germination of native desert shrubs. California Agriculture 26:13.

Willis, W. O., and W. A. Raney. 1971. Effects of compaction on content and transmission of heat in soils, pp. 165-177. In compaction of agricultural soils. Am. Soc. Agric. Eng. Monograph.

Wilshire, H. G. 1977. Study results of nine sites used by off-road vehicles that illustrate land modifications. USGS Open-File Report $77-601,19 \mathrm{pp}$.

1979. Letter to Mr. Charles Warren, Chairman, Council on Environmental Quality.

Wilshire, H. G. and J. K. Nakata. 1976. Off-road vehicle effects on California's Mojave Desert. California Geol. 29 (6): 123-132.

Wilshire, H. G., J. K. Nakata, J. K. Shipley and K. Prestegaard. 1978a. Impact of vehicles on natural terrain at seven sites in the San Francisco Bay Area. Environmental Geology 2(5): 295-319.

Wilshire, H.G., Shipley, S., and Nakata, J. K. 1978b. Impacts of off-road vehicles on vegetation. Tran. 43 rd North American Wildlife and Nat. Resources Conf., pp. 131-139.

Wilshire, H. G. and J. K. Nakata. 1978. Erosion of off-road vehicle sites in southern California, in Berry, K. H. (ed.). The physical, biological, and social impacts of off-road vehicles on the California Desert. So. Calif. Acad. Science Spec. Publ., in press.

Wischmeir, W. H. 1976. Use and misuse of the universal soil loss equation. J. Soil and Water Conserv. 31(1): 5-9.

Wood, J. P. and R. W. Robertson. 1976. Off-road vehicles: Some policy planning and management considerations. Proceedings of the National Symposium of off-road vehicles in Australia. Australin Institute of Parks and Recreation.

Zar, G. H. 1974. Biostatistical analysis. Prentice Hall, Englewood Cliffs, NJ. 620 pp.

Zimmerman, R. P. and L. T. Kardos. 1961. Effects of bulk density on root growth. Soil science. 91: 280-288. 


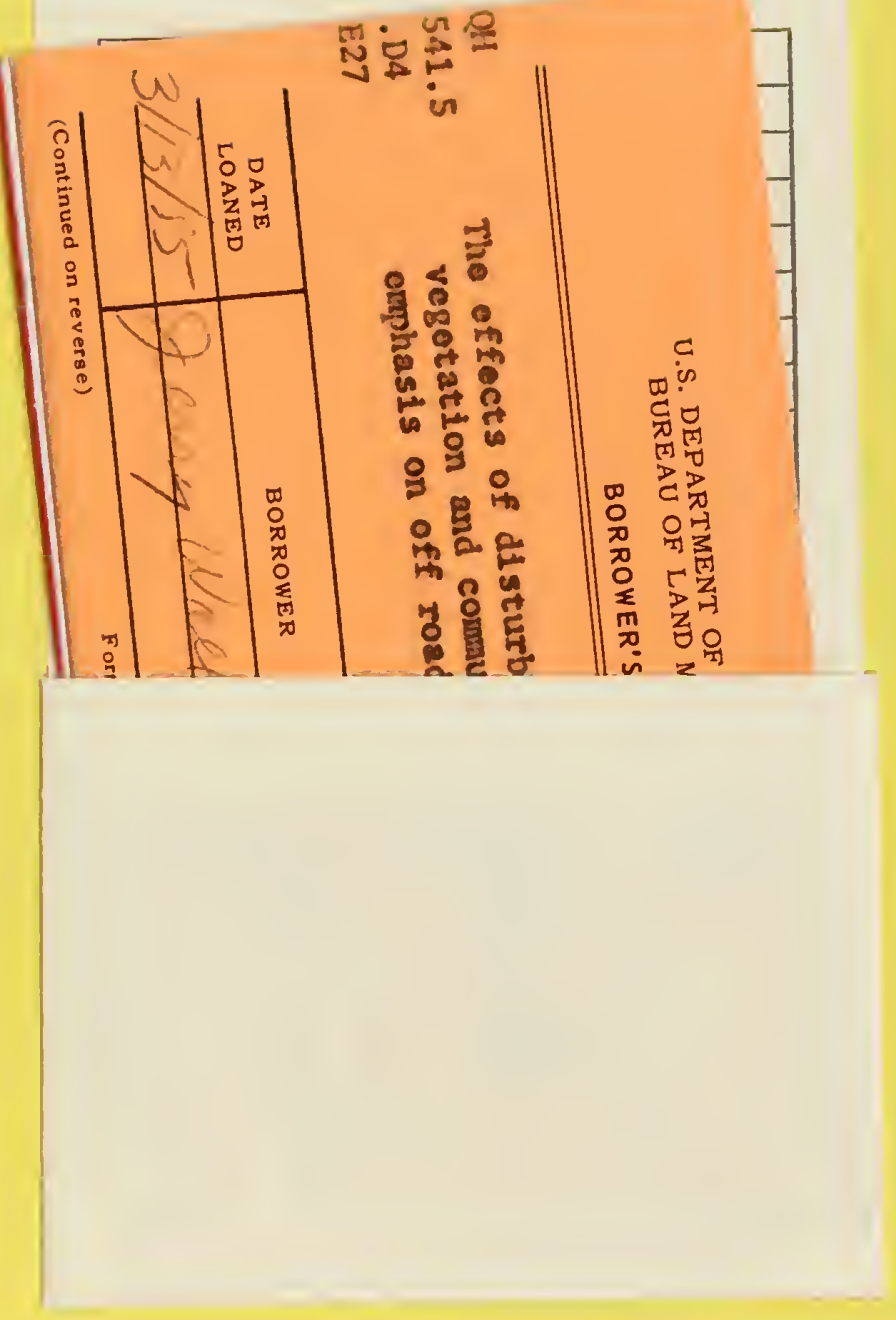


